\title{
A review of operational, regional-scale, chemical weather forecasting models in Europe
}

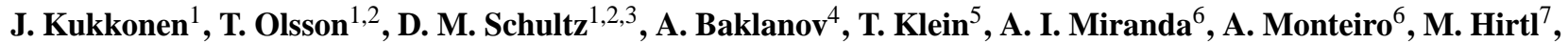 \\ V. Tarvainen ${ }^{1}$, M. Boy ${ }^{2}$, V.-H. Peuch ${ }^{8,9}$, A. Poupkou ${ }^{10}$, I. Kioutsioukis ${ }^{10}$, S. Finardi ${ }^{11}$, M. Sofiev ${ }^{1}$, R. Sokhi ${ }^{12}$, \\ K. E. J. Lehtinen ${ }^{13,14}$, K. Karatzas ${ }^{15}$, R. San José ${ }^{16}$, M. Astitha ${ }^{16}$, G. Kallos ${ }^{18}$, M. Schaap ${ }^{19}$, E. Reimer $^{20}$, H. Jakobs $^{21}$, \\ and K. Eben 22 \\ ${ }^{1}$ Finnish Meteorological Institute, Helsinki, Finland \\ ${ }^{2}$ Division of Atmospheric Sciences, Department of Physics, University of Helsinki, Finland \\ ${ }^{3}$ Centre for Atmospheric Science, School of Earth, Atmospheric and Environmental Sciences, \\ University of Manchester, Manchester, UK \\ ${ }^{4}$ Danish Meteorological Institute, Copenhagen, Denmark \\ ${ }^{5}$ Swedish Meteorological and Hydrological Institute, Norrköping, Sweden \\ ${ }^{6}$ CESAM \& Department of Environment and Planning, University of Aveiro, Aveiro, Portugal \\ ${ }^{7}$ Section of Environmental Meteorology, Central Institute for Meteorology and Geodynamics, Vienna, Austria \\ ${ }^{8}$ Meteo-France, Toulouse Cedex, France \\ ${ }^{9}$ ECMWF, Reading, UK \\ ${ }^{10}$ Laboratory of Atmospheric Physics, Physics Department, Aristotle University of Thessaloniki, Thessaloniki, Greece \\ ${ }^{11}$ ARIANET s.r.l., Milano, Italy \\ ${ }^{12}$ University of Hertfordshire, Hatfield, UK \\ ${ }^{13}$ Finnish Meteorological Institute, Kuopio, Finland \\ ${ }^{14}$ Dept. Applied Physics, University of Eastern Finland, Kuopio, Finland \\ ${ }^{15}$ Department of Mechanical Engineering, Aristotle University of Thessaloniki, Thessaloniki, Greece \\ ${ }^{16}$ Technical University of Madrid, Madrid, Spain \\ ${ }^{17}$ Energy, Environment and Water Research Center (EEWRC), The Cyprus Institute, Cyprus \\ ${ }^{18}$ Faculty of Physics, University of Athens, Athens, Greece \\ ${ }^{19}$ TNO Built Environment and Geosciences, Utrecht, The Netherlands \\ ${ }^{20}$ Freie Universität Berlin, Berlin, Germany \\ ${ }^{21}$ University of Cologne, Cologne, Germany \\ ${ }^{22}$ Institute of Computer Science, Academy of Sciences of the Czech Republic, Prague, Czech Republic
}

Correspondence to: J. Kukkonen (jaakko.kukkonen@ fmi.fi)

Received: 17 January 2011 - Published in Atmos. Chem. Phys. Discuss.: 21 February 2011

Revised: 15 November 2011 - Accepted: 7 December 2011 - Published: 2 January 2012

\begin{abstract}
Numerical models that combine weather forecasting and atmospheric chemistry are here referred to as chemical weather forecasting models. Eighteen operational chemical weather forecasting models on regional and continental scales in Europe are described and compared in this article. Topics discussed in this article include how weather forecasting and atmospheric chemistry models are integrated into chemical weather forecasting systems, how physical processes are incorporated into the models through parameterization schemes, how the model architecture affects the pre-
\end{abstract}

dicted variables, and how air chemistry and aerosol processes are formulated. In addition, we discuss sensitivity analysis and evaluation of the models, user operational requirements, such as model availability and documentation, and output availability and dissemination. In this manner, this article allows for the evaluation of the relative strengths and weaknesses of the various modelling systems and modelling approaches. Finally, this article highlights the most prominent gaps of knowledge for chemical weather forecasting models and suggests potential priorities for future research 
directions, for the following selected focus areas: emission inventories, the integration of numerical weather prediction and atmospheric chemical transport models, boundary conditions and nesting of models, data assimilation of the various chemical species, improved understanding and parameterization of physical processes, better evaluation of models against data and the construction of model ensembles.

\section{Introduction}

Chemical weather is defined here as the short-term (less than two weeks) variability of the atmospheric chemical composition. This definition is complementary to the traditional meteorological definition of weather, which is commonly characterized only by physical variables (e.g. temperature, wind, mass, radiation, humidity). Methods that include a combination of weather forecasting and atmospheric chemistry simulations are here referred to as chemical weather forecasting (CWF). CWF can therefore be seen as a specific category of air-quality forecasting, where air-quality forecasting models using numerical weather prediction (NWP) models are CWF models, but air-quality forecasting models using statistical methods are not (Kukkonen et al., 2009c). Similarly, for accuracy and consistency in replacing the traditional term air-quality forecasting and information system, we introduce a new term chemical weather forecasting and information system (CWFIS) to represent the integrated system responsible for the prediction and dissemination of chemical weather forecasts.

In the literature, numerous other terms are also used to refer to chemical weather and air-quality forecasting systems, such as, for instance, "chemical weather and air-quality forecasting models", "regional, continental or global air-quality models", "dispersion models", "atmospheric chemistry models", "chemical transport models", "air-chemistry models" and "atmospheric chemistry transport models". In this article, we also use some of these terms; however, "chemical transport models" is used specifically to refer to the atmospheric chemistry simulations.

Sometimes the term biological weather forecasting is used to refer to forecasting of biological constituents in the air, such as various pollen species and airborne allergens. This paper does not specifically address biological weather forecasting, although some of the considered models include treatments for airborne pollen species.

All the acronyms used in this article have been listed at the end of this article.

Lawrence et al. (2005) have previously reviewed the then-current state of CWF and emerging research challenges. Baklanov et al. (2008a, 2010b) and Schluenzen and Sokhi (2008) summarized existing mesoscale modelling systems and capabilities as an initial step to formulate recommendations for a unified integrated framework for mod- elling systems, although they did not compare the mathematical architecture of the various modelling systems. Baklanov (2010) also presented some gaps in our current understanding and recommended directions of future research for integrated CWF systems, although a valuable addition would be a more comprehensive set of recommendations summarizing the most urgent gaps of knowledge and research needs.

There are currently tens, possibly more than a hundred, CWFISs on a local, regional and continental scale in Europe and worldwide. Although abundant literature exists on the properties of individual models, scientific articles presenting compilations or synthesis of this information are scarce. Furthermore, the scientific evaluation of models against data defined to include also the detailed analysis and evaluation of the mathematical structure of such models or modelling systems in terms of the underlying physics and chemistry - are more limited. No scientific evaluations have been presented of a larger number of CWF models, although the Air-Quality Model Evaluation International Initiative (AQMEII) model intercomparison study is expected to be able to provide such information (Rao et al., 2011).

Despite a plethora of modelling options, it is far from obvious, which are the optimal ones in most cases. Thus, a systematic review of these options could substantially assist in evaluating the strengths and weaknesses of the various methods, and thus contribute to the development of better and more robust modelling methods in the future. Consequently, this present article aims to bring the field up to date with a comprehensive summary and assessment of the state of CWF in Europe.

\subsection{European-wide projects on chemical weather modelling and forecasting}

This study is part of the European Cooperation in Science and Technology (COST) ES0602 action, which provides a forum for benchmarking approaches and practices in data exchange and multi-model capabilities for CWF and near real-time information services in Europe (http: //www.chemicalweather.eu). The action was initiated by the Network of European Meteorological services (EUMETNET, http://www.eumetnet.eu) and the European Environment Agency (EEA). The content of this COST action, its main objectives and organisation have been reviewed by Kukkonen et al. (2009a, b), and the main results by Kukkonen et al. (2009c). The COST action includes participants from 20 countries, and its duration is from 2007 to 2011.

The COST ES0602 action has constructed a European open-access CWF portal (ECWFP) that includes access to a substantial number (more than 20) of available chemical weather forecasting systems (CWFS) and their numerical forecasts; these cover in total 31 areas in Europe (Balk et al., 2011; http://www.chemicalweather.eu/Domains). This portal can be used to find out, which CWF services are available for a specific domain, for specific source categories or 
for specific pollutants. Such a single point of reference for European CWF information has not previously been available. The Action has also investigated and reviewed existing chemical weather information systems and services (e.g. Karatzas and Kukkonen, 2009). This study has also been part of the EU-funded projects MEGAPOLI (Megacities: emissions, urban, regional and Global Atmospheric POLlution and climate effects, and Integrated tools for assessment and mitigation, http://www.megapoli.info; Baklanov et al., 2010a) and TRANSPHORM (Transport-related Air Pollution and Health impacts - Integrated Methodologies for Assessing Particulate Matter, http://www.transphorm. $\mathrm{eu} /$ ).

There are several other prominent ongoing European projects that address CWF. Some of the most important operational CWF programs lie within the EU-ESA (European Space Agency) programme GMES (Global Monitoring for Environment and Security, http://www.gmes.info), viz. the GEMS (Global and regional Earth-system (Atmosphere) Monitoring using Satellite and in-situ data, http: //gems.ecmwf.int) and PROMOTE (PROtocol MOniToring for the GMES Service Element, http://www.gse-promote. org; Poupkou et al., 2006) projects. The GMES Atmospheric Services focus on pre-operational monitoring and forecasting of atmospheric composition, dynamics and thermodynamics through advanced exploitation of satellite and in-situ data, on a European, national and local level. We define an operational modelling system as an automated one, which has a fall-back procedure in case the forecast fails. The latter is commonly a human part of the operational cycle. A preoperational modelling system could be defined as an automated system with a fall-back procedure that is not comprehensive.

There are also other related EU-funded projects, such as CITYZEN (megaCITY - Zoom for the Environment, https: //wiki.met.no/cityzen/start), EUCAARI (The European Integrated project on Aerosol Cloud Climate and Air-Quality Interactions, http://www.atm.helsinki.fi/eucaari) and EUSAAR (European Supersites for Atmospheric Aerosol Research, http://www.eusaar.net). Within the GEMS project, analyses and 72 -h forecasts have been presented using 12 state-of-theart regional chemical weather models on a pre-operational daily basis (http://gems.ecmwf.int). The models rely on the operational meteorological forecasts of the European Centre for Medium-Range Weather Forecasts (ECMWF), as well as on GEMS global chemical weather data. They all consider the same high-resolution (5-km horizontal grid spacing) anthropogenic and biogenic emissions inventories.

An example of a small-scale network of a few operational chemical weather services has been constructed within the first and second stages of the PROMOTE project. Although GEMS and PROMOTE CWF services have constituted major advances in this field - and are evidently valuable for a range of stakeholders - a limitation is that these projects have had a closed membership and have been fairly ori- ented around development. There is a need to involve additional stake-holders in a more comprehensive way, such as the national environmental agencies. This is also the task of the continuation projects of GEMS and PROMOTE, the MACC (Monitoring Atmospheric Composition and Climate) and PASODOBLE (Promote Air-Quality Services integrating Observations - Development Of Basic Localised Information for Europe) projects.

Another relevant program is Global Earth Observation and Monitoring (GEOmon, www.geomon.eu), the goal of which is to build an integrated European ground-based observational network of atmospheric composition to complement satellite observations. It lays the foundation for a European contribution to GEOSS (Global Earth Observation System of Systems, http://www.epa.gov/geoss) and optimizes the European strategy of monitoring atmospheric composition measurements (Tørseth and Fahre Vik, 2009).

\subsection{Aims and scope of this study}

Given the large variety of existing modelling systems and options, we must limit the scope of this article. Specifically, we select 18 operational CWF models on regional and continental scales (distance scales of approximately $10-6000 \mathrm{~km}$ ) in Europe for more detailed analysis. These models are among the most widely used in Western European countries, as well as in Eastern and Central-Eastern European countries. However, this collection of models is by no means exhaustive. Moreover, some of these models have been mainly developed elsewhere, especially in the United States.

This paper has three main aims. The first aim is to gather information on the selected operational CWF models in a systematic and harmonized format. The second aim is to provide and synthesize information that makes it possible for the readers to evaluate the relative strengths and limitations of the various models, and the components of the modelling systems. However, it is not the goal of this study to rank the models, or advocate one model over another. The third aim is to highlight the most prominent gaps of knowledge in CWF and to suggest priorities for future research directions.

We do not address purely diagnostic models, which do not include forecasting capabilities. The emergency preparedness models (such as those developed in case of nuclear and chemical accidents) are also outside the scope of this study. Because this article focuses on regional-scale models, we do not address modelling on global or urban scales. This study also addresses only operational CWF models. In comparison with genuine research models, and versions of operational models that are used only for research purposes, such operational models can include simplifications, such as a reduced resolution, smaller domains, and less sophisticated physics and chemistry modules. However, the discussion of the detailed operational characteristics of the modelling systems is outside the scope of this study; these have been addressed by Balk et al. (2011). This article also does not contain any 
new numerical intercomparisons of model predictions, or any novel evaluation of model predictions with data.

\subsection{Organization of this article}

This article is organized in the following manner. Section 2 introduces the 18 different CWF modelling systems and gives an overview of some of the relevant physical processes. Section 3 discusses the numerical weather prediction components of the models. Section 4 discusses the processes in the atmospheric dispersion and chemistry modelling components. Section 5 discusses the evaluation of the models. Section 6 discusses user operations of the model, including availability, computer requirements, documentation, user interfaces, sensitivity analyses, and dissemination. Section 7 looks forward to discuss emerging issues in the CWF community, including the identification of major gaps of knowledge and future research needs. Finally, Sect. 8 concludes this article.

The main characteristics of the selected $18 \mathrm{CWF}$ models considered in this study have been summarised and intercompared in several tables. Overviews of the main properties of the CWF and NWP models are first presented in Tables 1 and 2. The atmospheric dispersion, chemistry and aerosol modelling, and deposition components are reviewed in Tables 3-7. The natural emissions, and the grid spacings and coordinate systems are presented in Tables 8 and 9. The evaluation of each CWF model, and the availability, user communities, documentation, and presentation of forecasts in the internet are presented in Tables 10-12. Finally, in relation to future research needs, adjoint (inverse) dispersion modelling is reviewed in Table 13.

\section{Introduction to operational chemical weather forecasting models}

This section addresses some key concepts and introduces the main physical and chemical processes that are relevant for CWF. We have selected 18 operational, regional and continental scale CWF modelling systems for a more detailed examination.

First, we explain how the models were selected and how the key information was derived (Sect. 2.1). Second, we address how numerical weather prediction models can be integrated with CWF models (Sect. 2.2). For readability, this section also contains an introduction on the selected main properties of those models (Sect. 2.3), before we present a more detailed analysis and inter-comparison of model treatments for specific processes.

\subsection{Criteria for the selection of the models and the use of information sources}

A fairly large number of models were first suggested by the participants of the COST ES0602 action for a more detailed examination; participants from more than 20 European countries (listed in Kukkonen et al., 2009c) were encouraged to volunteer for this activity. Finally, 18 models were selected for inclusion in this article.

The main criteria for the selection of the 18 models were (i) the prominence and wide usage of the models, and (ii) the sufficient availability of scientific literature and Web-based documentation on the relevant model properties. Most of the models addressed in this study are also contained in the Model Documentation System (MDS) of EEA, accessible at http://air-climate.eionet.europa.eu/databases/MDS/index html, and in the joint COST 728 and COST 732 Model Inventory (C728/732MI), accessible at http://www.cost728.org (Schluenzen and Sokhi, 2008). We also aimed to present a balanced geographical representation across Europe.

Clearly, there are some prominent CWF systems that are not included in this article, such as CALIOPE (http://www. gmes-masters.com/service-application/caliope-system) and GEM-AQ (http://ecoforecast.eu/). Baldasano et al. (2008) and Pay et al. (2010) describe the Spanish CWF system CALIOPE and discuss modelling results over Europe and Spain. The CALIOPE model is operational and provides airquality forecasts over Europe on a horizontal resolution of $12 \times 12 \mathrm{~km}$ and over Spain on $4 \times 4 \mathrm{~km}$ (http://www.bsc.es/ caliope). The CALIOPE system also accounts for the mineral dust transport from North Africa to Europe and Spain by means of the BSC-DREAM8b model (Nickovic et al., 2001 and Perez et al., 2006), and gas-phase and aerosol pollutants by means of the CMAQ model.

To obtain the most credible and up-to-date information, model properties were derived primarily from published literature and from the developers or users of each model. We also used secondary information sources from the Web, such as the MDS, C728/732MI and the various web pages of individual modelling systems. In some cases, we received conflicting information from these sources. When that has happened, we extracted the information from the published literature whenever available, and then contacted the model developers for confirmation.

\subsection{The integration and coupling of numerical weather prediction and chemical transport models}

How NWP models couple with CWF models can be realized in one of two principal ways. Grell et al. (2005) and Baklanov et al. (2008a) suggested the following definitions.

Off-line modelling systems (also called one-way interactive models) contain a separate chemical transport model (CTM) driven by meteorological input data from meteorological pre-processors, measurements or diagnostic models, is driven by analysed or forecasted meteorological data from NWP archives or datasets, or reads output files from operational NWP models or specific meteorological models at limited time intervals (e.g. 1, 3, 6h). 

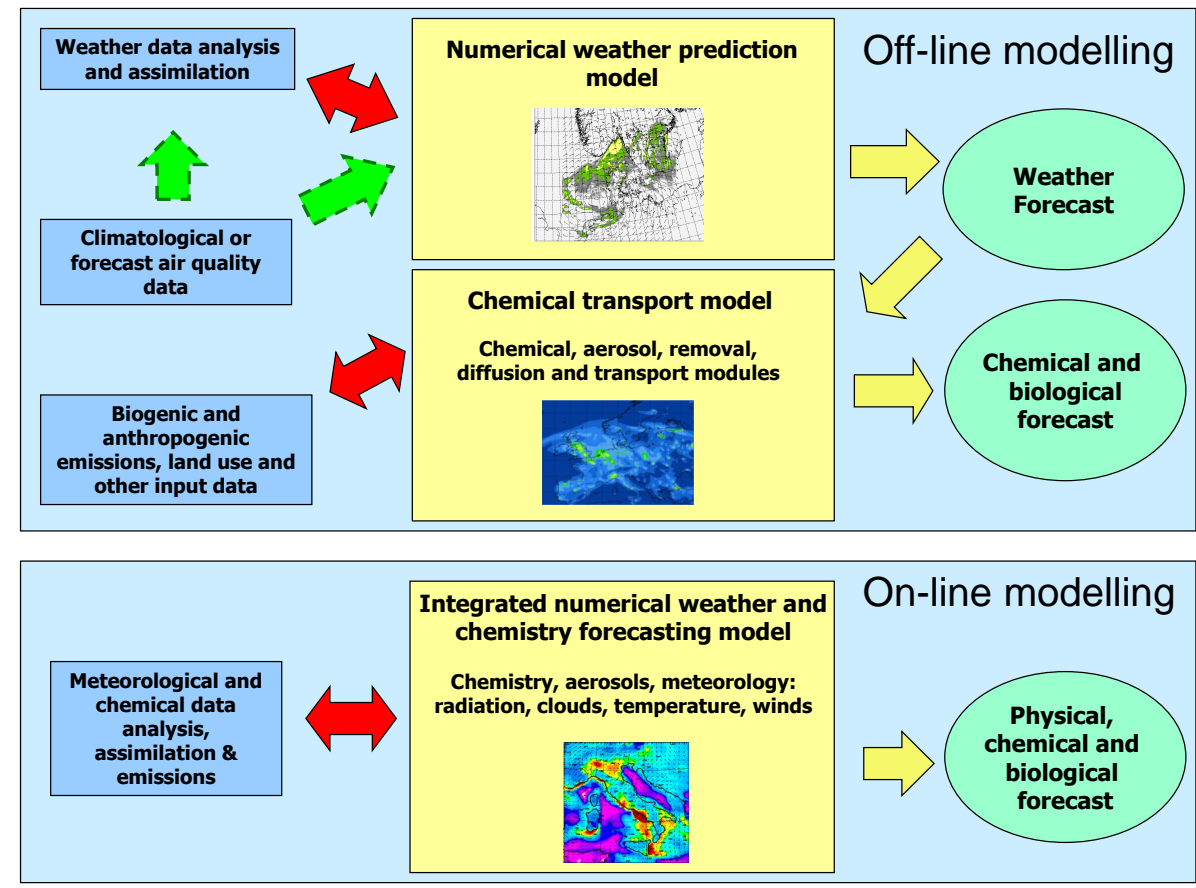

Fig. 1. Schematic diagram of the off-line and on-line coupled NWP and CTM modelling approaches for CWF.

On-line modelling systems (also called integrated or twoway interactive models) can be on-line access models, when meteorological data are available at each time-step (possibly via a model interface), or on-line integration of a CTM into a NWP model, where two-way feedbacks may be considered. We will use this latter definition for on-line coupled modelling.

The structure of on-line and off-line modelling systems has been schematically illustrated in Fig. 1.

The on-line integration of NWP or other meteorological models, with atmospheric aerosol and CTM allows all meteorological three-dimensional fields in CTMs at each time step to be used. It also facilitates the consideration of airpollution feedbacks (e.g. those due to aerosols or greenhouse gases) on meteorological processes and climate forcing, and further on the chemical composition. Within the 18 CWF models considered here, only three models (EnviroHIRLAM (Sect. 2.3.3), WRF-Chem (Sect. 2.3.18) and SKIRON/Dust (Sect. 2.3.16) in its new edition called ICLAMSIntegrated Community Limited Area Modeling System, Solomos et. al., 2011) are realised as on-line integrated models with two-way interactions. Previously, Zhang (2008) has reviewed the history and current status of the development and application of on-line coupled meteorology and chemistry models, with a focus on five representative models developed in the US including GATOR-GCMOM (Gas, Aerosol, Transport, Radiation, General Circulation, Mesocale, and Ocean Model), WRF-Chem, CAM3 (Community Atmosphere Model v.3), MIRAGE (Model for Integrated Re- search on Atmospheric Global Exhanges), and Caltech unified general circulation model. An overview and description of existing on-line coupled chemistry-meteorology models in Europe was done by Baklanov et al. (2010b).

There are potential problems communicating between offline coupled meteorological and CWF models. The advection schemes used in CWF models have to be improved for atmospheric chemistry transport models, as well as for NWP model, and it should be a high-priority task (e.g. Byun, 1999a, b; Baklanov et al., 2010b). For integrated atmospheric chemistry transport models, the requirements for advection schemes are even higher than for NWP models. They should be harmonised for all the scalars to maintain mass conservation and consistency. Thus, to achieve mass conservation, but at the same time maintain large time steps for the solution of dynamical equations, the models often include several advection schemes (such as semi-Lagrangian, Bott, SISL), which can be chosen in different combinations depending on the specific problem. The optimal way for online forecasting systems is to use the same conservative scheme for all the variables (e.g. for velocities, temperature, concentrations of chemicals, cloud water, humidity).

For offline atmospheric chemistry transport models, the choice of formulations and advection schemes is an independent and even more critically important problem (Byun, 1999a, b). Additionally, if NWP input data is used with non-conservative and unharmonized schemes (due to different schemes, grids, time steps in NWP and atmospheric chemistry transport models), the chemical part of offline 
Table 1. Selected main characteristics of the 18 chemical weather forecasting (CWF) models considered in this study.

\begin{tabular}{|c|c|c|c|c|c|c|}
\hline Model name & Coupling & $\begin{array}{l}\text { Country and institution } \\
\text { using it }\end{array}$ & CTM & NWP model & Type & Basic reference \\
\hline $\begin{array}{l}\text { ALADIN- } \\
\text { CAMx }\end{array}$ & Off-line & $\begin{array}{l}\text { ZAMG, } \\
\text { Austria, } \\
\text { Marcus Hirtl }\end{array}$ & CAMx & $\begin{array}{l}\text { ALADIN- } \\
\text { Austria }\end{array}$ & 3-D Eulerian & $\begin{array}{l}\text { http://www.cnrm.meteo.fr/aladin; } \\
\text { http://www.camx.com }\end{array}$ \\
\hline $\begin{array}{l}\text { CAMx- } \\
\text { AMWFG }\end{array}$ & Off-line & $\begin{array}{l}\text { National and Kapodistrian } \\
\text { University of Athens, } \\
\text { Greece, } \\
\text { George Kallos, } \\
\text { Marina Astitha }\end{array}$ & CAMx & SKIRON/Dust & 3-D Eulerian & $\begin{array}{l}\text { http://forecast.uoa.gr/index.php; } \\
\text { http://www.camx.com }\end{array}$ \\
\hline $\begin{array}{l}\text { ENVIRO- } \\
\text { HIRLAM }\end{array}$ & On-line & $\begin{array}{l}\text { DMI, } \\
\text { Denmark, } \\
\text { International HIRLAM team, } \\
\text { Alexander Baklanov }\end{array}$ & Enviro & HIRLAM & 3-D Eulerian & $\begin{array}{l}\text { http://hirlam.org; } \\
\text { www.hirlam.org/chemical }\end{array}$ \\
\hline EURAD-RIU & Off-line & $\begin{array}{l}\text { RIU, Cologne, Germany } \\
\text { Hermann Jakobs, } \\
\text { Hendrik Elbern, } \\
\text { Michael Memmesheimer }\end{array}$ & EURAD & MM5 & 3-D Eulerian & http://www.eurad.uni-koeln.de \\
\hline FARM & Off-line & $\begin{array}{l}\text { ARIANET s.r.1. } \\
\text { Italy, } \\
\text { Giuseppe Calori, } \\
\text { Camillo Silibello }\end{array}$ & FARM & RAMS & 3-D Eulerian & $\begin{array}{l}\text { http://www.aria-net.it/index_eng.php; } \\
\text { http://www.minni.org/htm_farm2/Introduzione.htm }\end{array}$ \\
\hline $\begin{array}{l}\text { LOTOS- } \\
\text { EUROS }\end{array}$ & Off-line & $\begin{array}{l}\text { TNO/RIVM/PBL/KN, } \\
\text { The Netherlands, } \\
\text { P. J. H. Builtjes, M. Schaap, } \\
\text { R. M. A. Timmermans }\end{array}$ & $\begin{array}{l}\text { LOTOS- } \\
\text { EUROS }\end{array}$ & ECMWF & 3-D Eulerian & http://www.lotos-euros.nl/ \\
\hline MATCH & Off-line & $\begin{array}{l}\text { SMHI, } \\
\text { Sweden, } \\
\text { Lennart Robertson, } \\
\text { Thomas Klein }\end{array}$ & MATCH & $\begin{array}{l}\text { ECMWF, } \\
\text { HIRLAM }\end{array}$ & 3-D Eulerian & $\begin{array}{l}\text { http://www.smhi.se/sgn0106/if/meteorologi/match. } \\
\text { htm; } \\
\text { Robertson et al. (1999), } \\
\text { Langner et al. (2005) }\end{array}$ \\
\hline MM5-CAMx & Off-line & $\begin{array}{l}\text { National and Kapodistrian } \\
\text { University of Athens Aristotle } \\
\text { University of Thessaloniki, } \\
\text { Greece } \\
\text { Zerefos Christos, } \\
\text { Melas Dimitrios }\end{array}$ & CAMx & MM5 & 3-D Eulerian & $\begin{array}{l}\text { http://www.mmm.ucar.edu/mm5; } \\
\text { http://www.camx.com; } \\
\text { http://lap.phys.auth.gr/gems.asp }\end{array}$ \\
\hline $\begin{array}{l}\text { MM5- } \\
\text { CHIMERE }\end{array}$ & Off-line & $\begin{array}{l}\text { Mesoscale Prediction Group } \\
\text { in the Mesoscale and } \\
\text { Microscale Meteorology } \\
\text { Division, NCAR, Greece, } \\
\text { Lia Fragkou (Model user) }\end{array}$ & CHIMERE & MM5 & 3-D Eulerian & $\begin{array}{l}\text { http://www.mmm.ucar.edu/mm5; } \\
\text { http://www.lmd.polytechnique.fr/chimere }\end{array}$ \\
\hline $\begin{array}{l}\text { MM5/WRF- } \\
\text { CMAQ }\end{array}$ & Off-line & $\begin{array}{l}\text { MM5-PSU/NCAR, Run } \\
\text { operationally by the ESMG } \\
\text { at Computer Science School } \\
\text { of the Technical University of } \\
\text { Madrid (UPM), Spain, } \\
\text { Roberto San José WRF-NCAR/ } \\
\text { NCEP run routinely at the } \\
\text { Centre for Atmospheric and } \\
\text { Instrumentation Research } \\
\text { (CAIR), University of } \\
\text { Hertfordshire, UK, } \\
\text { Ranjeet Sokhi }\end{array}$ & CMAQ & MM5/WRF & 3-D Eulerian & $\begin{array}{l}\text { http://www.mmm.ucar.edu/mm5; } \\
\text { http://www.mmm.ucar.edu/wrf/users/; } \\
\text { http://www.cmaq-model.org }\end{array}$ \\
\hline MOCAGE & Off-line & $\begin{array}{l}\text { Météo-France, Direction de } \\
\text { la Production and Centre } \\
\text { National de Recherches } \\
\text { Météorologiques, France, } \\
\text { Vincent-Henri Peuch } \\
\text { (project leader) }\end{array}$ & MOCAGE & $\begin{array}{l}\text { ARPEGE, } \\
\text { ALADIN, } \\
\text { ECMWF }\end{array}$ & 3-D Eulerian & $\begin{array}{l}\text { Dufour et al. (2004); } \\
\text { http://www.prevair.org }\end{array}$ \\
\hline NAME & Off-line & $\begin{array}{l}\text { Atmospheric Dispersion } \\
\text { Group, UK } \\
\text { Paul Agnew }\end{array}$ & NAME & $\begin{array}{l}\text { Met Office } \\
\text { Unified Model }\end{array}$ & $\begin{array}{l}3-\mathrm{D} \\
\text { Lagrangian }\end{array}$ & $\begin{array}{l}\text { http://www.metoffice.gov.uk/research/ } \\
\text { modelling-systems/dispersion-model }\end{array}$ \\
\hline
\end{tabular}


Table 1. Continued.

\begin{tabular}{|c|c|c|c|c|c|c|}
\hline Model name & Coupling & $\begin{array}{l}\text { Country and institution } \\
\text { using it }\end{array}$ & CTM & $\begin{array}{l}\text { NWP } \\
\text { model }\end{array}$ & Type & Basic reference \\
\hline OPANA & Off-line & $\begin{array}{l}\text { Environmental Software and } \\
\text { Modelling Group, Computer } \\
\text { Science School, Technical } \\
\text { University of Madrid, } \\
\text { LHTEE, AUT, NCAR/Pen, } \\
\text { Spain, } \\
\text { Roberto San José }\end{array}$ & OPANA & MEMO & 3-D Eulerian & $\begin{array}{l}\text { http://atmosfera.lma.fi.upm.es/equal/equal/ } \\
\text { show_long.htm } \\
\text { http://artico.lma.fi.upm.es }\end{array}$ \\
\hline RCG & Off-line & $\begin{array}{l}\text { FU-Berlin, Institute for } \\
\text { Meteorology Germany, } \\
\text { Rainer Stern, Eberhard Reimer, } \\
\text { Andreas Kerschbaumer }\end{array}$ & $\begin{array}{l}\text { REM- } \\
\text { CALGRID }\end{array}$ & GME & 3-D Eulerian & $\begin{array}{l}\text { http://www.trumf.de; } \\
\text { Stern (2003) }\end{array}$ \\
\hline SILAM & Off-line & $\begin{array}{l}\text { Finnish Meteorological Institute, } \\
\text { Finland, } \\
\text { Mikhail Sofiev }\end{array}$ & SILAM & $\begin{array}{l}\text { ECMWF, } \\
\text { HIRLAM, } \\
\text { WRF, } \\
\text { AROME, } \\
\ldots\end{array}$ & $\begin{array}{l}\text { 3-D } \\
\text { Lagrangian, } \\
\text { 3-D Eulerian }\end{array}$ & http://silam.fmi.fi \\
\hline SKIRON/Dust & On-line & $\begin{array}{l}\text { National and Kapodistrian } \\
\text { University of Athens, } \\
\text { Greece, } \\
\text { George Kallos }\end{array}$ & SKIRON & Eta & 3-D Eulerian & $\begin{array}{l}\text { http://forecast.uoa.gr/dustinfo.php, } \\
\text { Kallos et al. (2006), } \\
\text { Spyrou et al. (2010) }\end{array}$ \\
\hline THOR & Off-line & $\begin{array}{l}\text { National Environmental } \\
\text { Research Institute, } \\
\text { Denmark, } \\
\text { Jørgen Brandt }\end{array}$ & $\begin{array}{l}\text { DEHM (UPM, } \\
\text { OSPM) }\end{array}$ & Eta & $\begin{array}{l}\text { 3-D Eulerian } \\
\text { (DEHM) } \\
\text { 3-D } \\
\text { Lagrangian } \\
\text { (UPM) }\end{array}$ & $\begin{array}{l}\text { http://thor.dmu.dk; } \\
\text { http://www2.dmu.dk/atmosphericenvironment/ } \\
\text { thor/index.htm }\end{array}$ \\
\hline WRF-Chem & On-line & $\begin{array}{l}\text { NOAA 2008, Currently under } \\
\text { research application in the } \\
\text { ESMG-Computer Science } \\
\text { School - Technical University } \\
\text { of Madrid (UPM), } \\
\text { Spain, } \\
\text { Roberto San José }\end{array}$ & CHEM & WRF & 3-D Eulerian & $\begin{array}{l}\text { http://cprm.acd.ucar.edu/Models/WRF-Chem; } \\
\text { http://ruc.noaa.gov/wrf/WG11/; }\end{array}$ \\
\hline
\end{tabular}
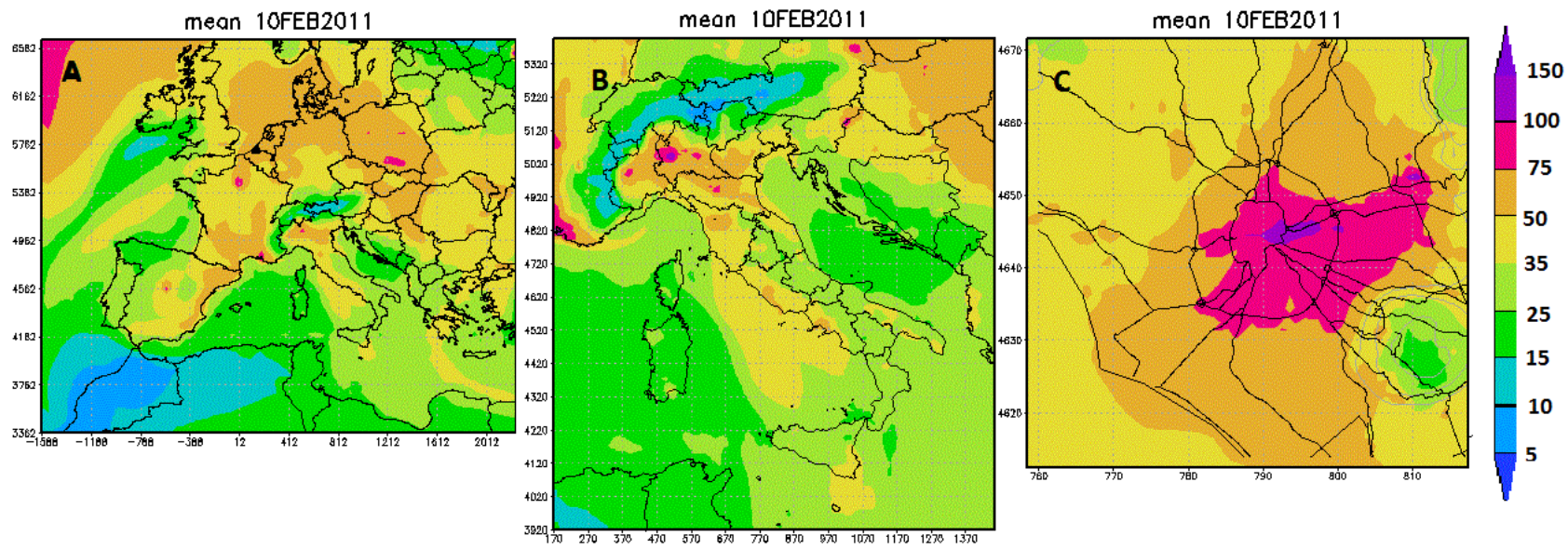

Fig. 2. The forecasted daily average concentrations of $P_{10}$ near the ground level on 10 February 2011 , provided by the FARM model in (a) Europe, (b) Italy and (c) the urban area of Rome. The horizontal grid spacing in the forecasts of these three simulations are 48, 12 and $1 \mathrm{~km}$, respectively. The scales on all the axes are in $\mathrm{km}$, and the concentrations are in $\mu \mathrm{g} \mathrm{m}^{-3}$ 
Table 2. Selected main characteristics of the numerical weather prediction models considered.

\begin{tabular}{|c|c|c|c|c|c|c|c|}
\hline $\begin{array}{l}\text { Model } \\
\text { name }\end{array}$ & $\begin{array}{l}\text { Hydrostatic/ } \\
\text { nonhydrostatic }\end{array}$ & $\begin{array}{l}\text { Vertical } \\
\text { coordinate }\end{array}$ & Reference & $\begin{array}{l}\text { Cloud } \\
\text { microphysics }\end{array}$ & $\begin{array}{l}\text { Convective } \\
\text { parameterization } \\
\text { scheme }\end{array}$ & PBL scheme & $\begin{array}{l}\text { Global or } \\
\text { Limited-area } \\
\text { model }\end{array}$ \\
\hline ALADIN & Hydrostatic & $\begin{array}{l}\text { Pressure or } \\
\text { Sigma- } \\
\text { pressure } \\
\text { hybrid }\end{array}$ & http://www.cnrm.meteo.fr/aladin/ & Kessler (1969) & Bougeault (1985) & $\begin{array}{l}\text { First order } \\
\text { turbulence } \\
\text { closure (Louis, } \\
\text { 1979; Louis } \\
\text { et al., 1982) }\end{array}$ & Limited-area \\
\hline ECMWFIFS & Nonhydrostatic & Hybrid & $\begin{array}{l}\text { http://www.ecmwf.int/research/ } \\
\text { ifsdocs/ }\end{array}$ & Tiedke (1993) & $\begin{array}{l}\text { Modified Tiedke } \\
\text { (1989) scheme } \\
\text { (Nordeng, 1994) }\end{array}$ & $\begin{array}{l}\text { Modified Louis } \\
\text { et al. (1982) } \\
K \text {-theory scheme } \\
\text { (Beljaars and } \\
\text { Viterbo 1999) }\end{array}$ & Global \\
\hline Eta & Nonhydrostatic & Eta & $\begin{array}{l}\text { Mesinger et al. (1988), } \\
\text { Janjić (1990, 1994) }\end{array}$ & Ferrier et al. (2002) & $\begin{array}{l}\text { Betts-Miller-Janjić and } \\
\text { Kain-Fritsch }\end{array}$ & $\begin{array}{l}\text { Mellor-Yamada } \\
2.5 \text {-order }\end{array}$ & Limited-area \\
\hline GME & Hydrostatic & $\begin{array}{l}\text { Sigma- } \\
\text { pressure } \\
\text { hybrid }\end{array}$ & Majewski et al. (2002) & $\begin{array}{l}\text { Kessler-type } \\
\text { scheme (Doms } \\
\text { and Schättler, } \\
\text { 1997) }\end{array}$ & Tiedtke (1989) & $\begin{array}{l}\text { 2nd order, } \\
\text { Mellor and } \\
\text { Yamada (1974) }\end{array}$ & Global \\
\hline HIRLAM & $\begin{array}{l}\text { Hydrostatic/ } \\
\text { nonhydrostatic }\end{array}$ & $\begin{array}{l}\text { Sigma- } \\
\text { pressure } \\
\text { hybrid }\end{array}$ & http://hirlam.org & $\begin{array}{l}\text { STRACO } \\
\text { (Soft Transition } \\
\text { Condensation) }\end{array}$ & $\begin{array}{l}\text { STRACO (modified } \\
\text { Kuo scheme), } \\
\text { Rasch and } \\
\text { Kristjánsson (1998), } \\
\text { Kain-Fritsch }\end{array}$ & $\begin{array}{l}\text { Cuxart Bougeault } \\
\text { Lacarrere, } \\
\text { order } 1.5 \mathrm{TKE} \\
\text { scheme }\end{array}$ & Limited-area \\
\hline MEMO & Nonhydrostatic & Sigma & $\begin{array}{l}\text { Kunz and Moussiopoulos (1995), } \\
\text { Moussiopoulos et al. (1997) }\end{array}$ & $\begin{array}{l}\text { No moist } \\
\text { processes }\end{array}$ & $\begin{array}{l}\text { No moist } \\
\text { processes }\end{array}$ & $K$-theory & Limited-area \\
\hline MM5 & Nonhydrostatic & Sigma & Dudhia (1993), Grell et al. (1995) & $\begin{array}{l}\text { Various } \\
\text { possible } \\
\text { schemes }\end{array}$ & $\begin{array}{l}\text { Various } \\
\text { possible } \\
\text { schemes }\end{array}$ & $\begin{array}{l}\text { Various } \\
\text { possible } \\
\text { schemes }\end{array}$ & Limited-area \\
\hline Unified Model & Nonhydrostatic & Height & $\begin{array}{l}\text { Cullen et al. (1997), } \\
\text { Davies et al. (2005) }\end{array}$ & $\begin{array}{l}\text { Wilson and } \\
\text { Ballard } \\
\text { extended by } \\
\text { Forbes }\end{array}$ & $\begin{array}{l}\text { Gregory and } \\
\text { Rowntree (1990) }\end{array}$ & Lock et al. (2000) & $\begin{array}{l}\text { Limited-area or } \\
\text { global }\end{array}$ \\
\hline WRF & Nonhydrostatic & $\begin{array}{l}\text { Sigma or } \\
\text { sigma- } \\
\text { pressure } \\
\text { hybrid }\end{array}$ & $\begin{array}{l}\text { Janic et al. (2001), Janic (2003), } \\
\text { Skamarock et al. (2005) }\end{array}$ & $\begin{array}{l}\text { Various } \\
\text { possible } \\
\text { schemes }\end{array}$ & $\begin{array}{l}\text { Various } \\
\text { possible } \\
\text { schemes }\end{array}$ & $\begin{array}{l}\text { Level } 2.5 \text { Mellor } \\
\text { and Yamada } \\
\text { Janic, or non } \\
\text { local YSU } \\
\text { scheme }\end{array}$ & Limited-area \\
\hline RAMS & Nonhydrostatic & $\begin{array}{l}\text { Height, } \\
\text { sigma or } \\
\text { eta }\end{array}$ & $\begin{array}{l}\text { Pielke et al. (1992), } \\
\text { Cotton et al. (2003) }\end{array}$ & $\begin{array}{l}\text { Various } \\
\text { possible } \\
\text { schemes }\end{array}$ & $\begin{array}{l}\text { Various } \\
\text { possible } \\
\text { schemes }\end{array}$ & $\begin{array}{l}\text { Various } \\
\text { possible } \\
\text { schemes }\end{array}$ & $\begin{array}{l}\text { Limited-area or } \\
\text { global }\end{array}$ \\
\hline
\end{tabular}

atmospheric chemistry transport models can produce unrealistic forecasts. For online coupling, it is not a problem if one uses the same mass-conservative scheme for chemistry, cloud water and humidity. The wide variety of existing modelling systems has led to a number of approaches and methods implemented in interface modules. Tasks performed by interfaces are minimised in some coupled systems (as online models do not need interfaces per se); these rely on surface fluxes, and turbulence and dispersion parameters (such as eddy viscosity) that are provided by the meteorological drivers.

Other modelling systems use interface modules that implement surface and boundary-layer parameterisations to estimate dispersion parameters. In some cases, interfaces are used to enhance the resolution of local physiographic data, and possibly introduce advanced parameterisations (e.g. those for urbanisation). Moreover, interface modules can include the evaluation of emissions of species that can be strongly influenced by meteorology, such as biogenic
Volatile Organic Compounds (VOC), windblown dust, sea salt, and pollen.

\subsection{Overview of the CWF modelling systems}

The 18 models discussed in this article are now briefly introduced, presented in alphabetical order by their acronyms. A summary of selected main characteristics of these models appear in Table 1. The aim of this section is to give a quick overview of the models, before a more detailed and systematic examination of their properties. The European countries of the model users are listed in the titles. In some cases, these countries may differ from the countries where these models were originally developed.

Selected examples on operational forecast products have been illustrated in Fig. 2a-c. The European- and Italian-scale forecasts were computed using the same two-way nested simulations, whereas forecasts for Rome were performed independently using the Italian-scale simulation results as 
Table 3. Brief characterizations of the main physical and chemical components of the CWF models.

\begin{tabular}{|c|c|c|c|c|c|c|}
\hline Model name & $\begin{array}{l}\text { Advection and } \\
\text { convection }\end{array}$ & Diffusion & Dry deposition & Wet deposition & Chemistry package & Aerosol package \\
\hline $\begin{array}{l}\text { ALADIN- } \\
\text { CAMx }\end{array}$ & $\begin{array}{l}\text { Eulerian continuity } \\
\text { equation closed by } \\
K \text {-theory equations } \\
\text { in flux form. The ad- } \\
\text { vection scheme of Bott } \\
\text { (1989) is used }\end{array}$ & $\begin{array}{l}\text { Horizontal diffusion: } \\
\text { Smagorinsky } \\
\text { approach. Vertical } \\
\text { diffusion: Louis (1979) } \\
\text { approach (uses the } \\
\text { Richardson number } \\
\text { and the mixing length) }\end{array}$ & $\begin{array}{l}\text { Physical: separate } \\
\text { resistance models for } \\
\text { gases and aerosols. } \\
\text { Numerical: deposition } \\
\text { velocity as surface } \\
\text { boundary condition for } \\
\text { vertical diffusion }\end{array}$ & $\begin{array}{l}\text { Physical: seperate scavenging } \\
\text { models for gases and aerosols. } \\
\text { Numerical: uptake as a function } \\
\text { of rainfall rate, cloud water } \\
\text { content, gas solubility and } \\
\text { diffusivity, PM size }\end{array}$ & $\begin{array}{l}\text { SAPRC-99: } 114 \text { species, } \\
217 \text { reactions }\end{array}$ & $\begin{array}{l}\text { The CW scheme is used for } \\
\text { aerosol chemitry. It divides } \\
\text { the size distribution into } \\
\text { two static modes (coarse } \\
\text { and fine). Primary species } \\
\text { are modeled as fine and/or } \\
\text { coarse particles, while all } \\
\text { secondary species are } \\
\text { modeled as fine particles } \\
\text { only }\end{array}$ \\
\hline $\begin{array}{l}\text { CAMx- } \\
\text { AMWFG }\end{array}$ & $\begin{array}{l}\text { Eulerian continuity } \\
\text { equation closed by } \\
K \text {-theory. } \\
\text { The advection } \\
\text { solver used is The } \\
\text { Area Preserving } \\
\text { Flux-Form } \\
\text { advection solver of } \\
\text { Bott (1989) }\end{array}$ & $\begin{array}{l}\text { Horizontal diffusion } \\
\text { based on } \\
\text { Smagorinsky } \\
\text { approach. Vertical } \\
\text { diffusion coefficients } \\
\text { supplied via input file } \\
\text { (from the meteoro- } \\
\text { logical model) }\end{array}$ & $\begin{array}{l}\text { Separate resistance } \\
\text { models for gases and } \\
\text { aerosols. Numerical: } \\
\text { deposition velocity } \\
\text { as surface boundary } \\
\text { condition for vertical } \\
\text { diffusion }\end{array}$ & $\begin{array}{l}\text { Separate scavenging models for } \\
\text { gases and aerosols. Numerical: } \\
\text { uptake as a function of rainfall } \\
\text { rate, cloud water content, gas } \\
\text { solubility and diffusivity, PM size }\end{array}$ & Carbon Bond (CB-IV) & $\begin{array}{l}\text { RADM aqueous chemistry scheme, } \\
\text { ISORROPIA gas/aerosol } \\
\text { partitioning scheme, SOAP } \\
\text { scheme for SOA formation, } \\
\text { both Coarse/Fine scheme and } \\
\text { Multi sectional approach. } \\
\text { Options for two variable } \\
\text { (coarse/fine) bulk scheme and } \\
\text { fixed sectional scheme (sections by } \\
\text { user choice) with all microphysics. } \\
16 \text { aersosol chemical species. } \\
\text { (Sulfate, Nitrate, Ammonium, } \\
\text { Water, Anthropogenic SOA, } \\
\text { Biogenic SOA, Polymerized } \\
\text { anthropogenic SOA, Polymerized } \\
\text { biogenic SOA, Sodium, Chloride, } \\
\text { Primary Organic Aerosol, Primary } \\
\text { Elemental Carbon, Fine Other } \\
\text { Primary, Fine Crustal, Coarse } \\
\text { Other Primary, Coarse Crustal) }\end{array}$ \\
\hline $\begin{array}{l}\text { Enviro- } \\
\text { HIRLAM }\end{array}$ & $\begin{array}{l}\text { Several possibili- } \\
\text { ties: globally and } \\
\text { locally-conserva- } \\
\text { tive schemes for } \\
\text { advection (Bott, } \\
1989 ; \text { Kaas, 2008). } \\
\text { STRACO convec- } \\
\text { tion and Tiedtke } \\
\text { mass-flux schemes } \\
\text { to convect aerosols } \\
\text { and gases. } \\
\text { Eulerian continuity } \\
\text { equation closed } \\
\text { by } K \text {-theory }\end{array}$ & $\begin{array}{l}\text { Vertical diffusion by } \\
\text { native TKE-1 scheme } \\
\text { (Cuxart, 2000). } \\
\text { Horizontal diffusion by } \\
\text { the native extra scalar } \\
\text { system. Improved } \\
\text { parameterisation for } \\
\text { urban boundary layer } \\
\text { and mixing height }\end{array}$ & $\begin{array}{l}\text { Separate resistance } \\
\text { models for gases } \\
\text { and aerosols. Three } \\
\text { regimes gravitaton } \\
\text { settling parameterisa- } \\
\text { tions for different size } \\
\text { aerosols }\end{array}$ & $\begin{array}{l}\text { Separate 3-D scavenging } \\
\text { models for gases and } \\
\text { aerosols, and for rain-out and } \\
\text { wash-out with particle size- } \\
\text { dependent parameterisations } \\
\text { (Baklanov and Sørensen, 2001) }\end{array}$ & $\begin{array}{l}\text { Four mechanisms for } \\
\text { gas-phase chemistry can } \\
\text { be used: NWP-Chem } \\
\text { (default scheme), } \\
\text { RADM2, RACM and } \\
\text { an extended version } \\
\text { (includes isoprene and } \\
\text { DMS chemistry) } \\
\text { of CBMZ }\end{array}$ & $\begin{array}{l}\text { Aerosol module comprises } \\
\text { thermodynamic equilibrium model } \\
\text { NWP-Chem-Liquid and an aerosol } \\
\text { dynamics model (Korsholm et al., } \\
\text { 2008). } 4 \text { aerosol modules: } \\
\text { modal CAC (default, Gross and } \\
\text { Baklanov, 2004) and MADE } \\
\text { (Ackermann et al., 1998), and } \\
\text { sectional MOSAIC (Zaveri et al., } \\
\text { 2007) and SALSA (on test phase, } \\
\text { Kokkola et al., 2008) }\end{array}$ \\
\hline EURAD-RIU & $\begin{array}{l}\text { fourth order Bott } \\
\text { scheme } \\
\text { (Bott, 1989) }\end{array}$ & $\begin{array}{l}\text { Vertical mixing based } \\
\text { on scaling regimes } \\
\text { (Holtslag et al., 1990) }\end{array}$ & $\begin{array}{l}\text { Deposition velocity } \\
\text { based on landuse } \\
\text { type and season. } \\
\text { Revised parameteri- } \\
\text { zation by Zhang } \\
\text { et al. (2003) }\end{array}$ & $\begin{array}{l}\text { Gas-phase: Henrys law } \\
\text { equilibria for all prognostic } \\
\text { species. Aerosol phase } \\
\text { (Binkovski, 1999): the } \\
\text { accumulation mode particles } \\
\text { form cloud condensation nuclei } \\
\text { and are } 100 \% \text { absorbed into the } \\
\text { cloud water. The Aitken mode } \\
\text { forms interstitual aerosol which } \\
\text { is scavenged by cloud droplets. } \\
\text { The wet removal of aerosol is } \\
\text { proportional to the wet removal } \\
\text { of sulfate }\end{array}$ & $\begin{array}{l}\text { RADM2 (Stockwell et al., } \\
\text { 1990), RACM (Stockwell } \\
\text { et al., 1997), Euro-RADM } \\
\text { (Stockwell and Kley, } \\
\text { 1994) - The Euro-RADM } \\
\text { chemical mechanism was } \\
\text { developed to model } \\
\text { European atmospheric } \\
\text { chemistry. It is based } \\
\text { upon the Regional Acid } \\
\text { Deposition Model } \\
\text { mechanism, version } 2 \\
\text { (RADM2) }\end{array}$ & $\begin{array}{l}\text { The aerosol dynamics model } \\
\text { MADE (Ackermann et al., 1998), } \\
\text { SORGAM (Schell et al., 2001) }\end{array}$ \\
\hline FARM & $\begin{array}{l}\text { Horizontal: } \\
\text { Blackman cubic } \\
\text { polynomials } \\
\text { (Yamartino, 1993). } \\
\text { Vertical: hybrid } \\
\text { semi-implicit Crank- } \\
\text { Nicolson/fully implicit } \\
\text { scheme (Yamartino } \\
\text { et al., 1992) }\end{array}$ & $\begin{array}{l}\text { Horizontal diffusion } \\
\text { based on } \\
\text { Smagorinsky } \\
\text { approach or stability } \\
\text { dependent paramet- } \\
\text { erizations. Different } \\
\text { vertical diffusion } \\
\text { parameterizations } \\
\text { based on PBL-scaling. } \\
K_{h} \text { and } K_{z} \\
\text { evaluated by } \\
\text { SURFPRO } \\
\text { pre-processor }\end{array}$ & $\begin{array}{l}\text { Deposition velocity } \\
\text { (from SURFPRO } \\
\text { pre-processor) } \\
\text { depending on land } \\
\text { type, season, surface } \\
\text { meteorology, surface } \\
\text { wetness, by means of } \\
\text { a big leaf resistance } \\
\text { model after Walcek } \\
\text { et al. (1986) and } \\
\text { Wesely (1989) }\end{array}$ & $\begin{array}{l}\text { Precipitation scavenging based } \\
\text { on EMEP (2003) }\end{array}$ & $\begin{array}{l}\text { Two mechanisms } \\
\text { implemented through } \\
\text { KPP chemical pre- } \\
\text { processor (Sandu et al., } \\
\text { 1995): an updated } \\
\text { version of the chemical } \\
\text { mechanism implemented } \\
\text { in the EMEP Lagrangian } \\
\text { Acid Deposition Model } \\
\text { (Hov et al., 1988) } \\
\text { including the treatment } \\
\text { of Persistent Organic } \\
\text { Polluttants (POPs) and } \\
\text { mercury and SAPRC-99 } \\
\text { (Carter, 2000). Photolysis } \\
\text { reaction rates estimated } \\
\text { either using simple } \\
\text { look-up tables or an } \\
\text { on-line version of the } \\
\text { Tropospheric Ultraviolet- } \\
\text { Visible Model (TUV, } \\
\text { Madronich, 1987). Cloud } \\
\text { effects on actinic flux } \\
\text { considered }\end{array}$ & $\begin{array}{l}\text { CMAQ aero3 module to } \\
\text { includes aerosol processes: modal } \\
\text { scheme with three modes and } \\
\text { all microphysics. ISORROPIA } \\
\text { and SORGAM models to include } \\
\text { aerosol thermodynamics/ } \\
\text { partitioning respectiverly for } \\
\text { inorganic and organic species }\end{array}$ \\
\hline
\end{tabular}


Table 3. Continued.

\begin{tabular}{|c|c|c|c|c|c|c|}
\hline Model name & $\begin{array}{l}\text { Advection and } \\
\text { convection }\end{array}$ & Diffusion & Dry deposition & Wet deposition & Chemistry package & Aerosol package \\
\hline $\begin{array}{l}\text { LOTOS- } \\
\text { EUROS }\end{array}$ & $\begin{array}{l}\text { Advection following } \\
\text { Walcek (2000). No } \\
\text { explicit convection, } \\
\text { vertical grid follows } \\
\text { pbl from } \\
\text { meteorology }\end{array}$ & $\begin{array}{l}\text { Vertical turbulent } \\
\text { mixing formulation } \\
\text { uses } K \text {-diffusion }\end{array}$ & Resistance approach & $\begin{array}{l}\text { Scavenging rates depending on } \\
\text { Henry's law constants for gases } \\
\text { and following Scott (1978) for } \\
\text { particles }\end{array}$ & $\begin{array}{l}\text { Updated CBM-4 with } \\
\text { Carter's 1-product } \\
\text { isoprene scheme: homo- } \\
\text { and heterogenous } \\
\text { conversion of } \mathrm{NO}_{2} \text { to } \\
\mathrm{HNO}_{3} .28 \text { species and } \\
66 \text { reactions, including } \\
12 \text { photolytic reactions }\end{array}$ & $\begin{array}{l}\text { Bulk scheme with possibility for } \\
\text { several size ranges. ISORROPIA, } \\
\text { MARS or EQSAM options for } \\
\text { calcluating equilibrium between } \\
\text { gas and particle phase sulfate, } \\
\text { nitrate, ammonium, water }\end{array}$ \\
\hline MATCH & $\begin{array}{l}\text { Modeled using } \\
\text { a Bott-type } \\
\text { advection scheme } \\
\text { (Bott, 1989). Up to } \\
\text { forth order schems } \\
\text { are implemented in } \\
\text { the horozontal and } \\
\text { up to second order } \\
\text { in the vertical }\end{array}$ & $\begin{array}{l}\text { Parameterized using } \\
\text { three primary } \\
\text { parameters: the } \\
\text { surface friction } \\
\text { velocity, the surface } \\
\text { sensible heat flux and } \\
\text { the boundary layer } \\
\text { height }\end{array}$ & $\begin{array}{l}\text { Modelled using } \\
\text { a resistance } \\
\text { approach. Deposition } \\
\text { schemes with different } \\
\text { degrees of } \\
\text { sophistication are } \\
\text { available }\end{array}$ & $\begin{array}{l}\text { Assumed to be proportional to } \\
\text { the precipitation intensity using } \\
\text { species-specific scavenging } \\
\text { coefficients. For particles, } \\
\text { several different schemes } \\
\text { are avalable }\end{array}$ & $\begin{array}{l}\text { Extended EMEP MSC-W } \\
\text { model chemistry } \\
\text { (Simpson et al., 1993). } \\
\text { Aqueous-phase oxidation } \\
\text { is implemented following } \\
\text { Berge (1993). The } \\
\text { formation of ammonium } \\
\text { sulfate and -nitrate is } \\
\text { modelled following Hov } \\
\text { et al. (1994). } 110 \\
\text { thermal, } 28 \text { photo- } \\
\text { chemical, } 2 \text { aqueous- } \\
\text { phase, } 5 \text { aerosol } \\
\text { reactions and } 4 \text { gas- } \\
\text { phase aqueous-phase } \\
\text { and aerosol equlibria } \\
\text { between } 60 \text { chemical } \\
\text { components }\end{array}$ & $\begin{array}{l}\text { Bulk scheme with several } \\
\text { non-interacting size ranges. } \\
\text { Equilibrium between particle } \\
\text { and gas phase }\end{array}$ \\
\hline MM5-CAMx & $\begin{array}{l}\text { MM5: vertical } \\
\text { advection of } \\
\text { moisture and } \\
\text { temperature are } \\
\text { resolved by } \\
\text { applying linear } \\
\text { interpolation } \\
\text { methods. } \\
\text { Convection in } \\
\text { cumulus clouds } \\
\text { is parameterized } \\
\text { with the } \\
\text { Kain-Fritsch } 2 \\
\text { parameterization. } \\
\text { CAMx: Eulerian } \\
\text { continuity equation } \\
\text { closed by } K \text {-theory }\end{array}$ & $\begin{array}{l}\text { MM5: MRF Planetary } \\
\text { Boundary-Layer (PBL) } \\
\text { scheme. } \\
\text { CAMx: horizontal } \\
\text { diffusion based on } \\
\text { Smagorinsky } \\
\text { approach. Vertical } \\
\text { diffusion coefficients } \\
\text { supplied via input file } \\
\text { (from the meteor- } \\
\text { ological model) }\end{array}$ & $\begin{array}{l}\text { CAMx: physical: } \\
\text { separate resistance } \\
\text { models for gases and } \\
\text { aerosols. Numerical: } \\
\text { deposition velocity } \\
\text { as surface boundary } \\
\text { condition for vertical } \\
\text { diffusion }\end{array}$ & $\begin{array}{l}\text { Separate scavenging models for } \\
\text { gases and aerosols. Numerical: } \\
\text { uptake as a function of rainfall } \\
\text { rate, cloud water content, gas } \\
\text { solubility and diffusivity, PM size }\end{array}$ & $\begin{array}{l}\text { CAMx: Carbon Bond } \\
\text { (CB-IV) }\end{array}$ & $\begin{array}{l}\text { RADM aqueous chemistry } \\
\text { algorithm, ISORROPIA } \\
\text { inorganic aerosol } \\
\text { thermodynamics/partitioning, } \\
\text { SOAP scheme for SOA } \\
\text { formation. Options for two } \\
\text { variable (coarse/fine) bulk scheme } \\
\text { and fixed sectional scheme } \\
\text { (sections by user choice) with } \\
\text { all microphysics. } 16 \text { aersosol } \\
\text { chemical species (sulfate, nitrate, } \\
\text { ammonium, water, anthropogenic } \\
\text { SOA, biogenic SOA, polymerized } \\
\text { anthropogenic SOA, polymerized } \\
\text { biogenic SOA, sodium, chloride, } \\
\text { primary organic aerosol, primary } \\
\text { elemental carbon, fine other } \\
\text { primary, fine crustal, coarse } \\
\text { other primary, coarse crustal) }\end{array}$ \\
\hline $\begin{array}{l}\text { MM5- } \\
\text { CHIMERE }\end{array}$ & $\begin{array}{l}\text { MM5: based on } \\
\text { a finite difference } \\
\text { formulation of the } \\
\text { time-dependent Navier- } \\
\text { Stokes equations. } \\
\text { CHIMERE: } \\
3 \text { advection } \\
\text { schemes: the } \\
\text { Parabolic } \\
\text { Piecewise Method, } \\
\text { the Godunov } \\
\text { scheme and the } \\
\text { simple upwind } \\
\text { first-order scheme }\end{array}$ & $\begin{array}{l}\text { MM5: bulk PBL, high } \\
\text { resolution Blackadar } \\
\text { PBL, Burk. Thompson } \\
\text { PBL, Eta PBL, MRF } \\
\text { PBL, Gayno-Seaman } \\
\text { PBL, Pleim-Chang } \\
\text { PBL. CHIMERE: } \\
\text { vertical turbulent } \\
\text { mixing takes place } \\
\text { only in the boundary- } \\
\text { layer. The formulation } \\
\text { uses } K \text {-diffusion, } \\
\text { without counter- } \\
\text { gradient term }\end{array}$ & $\begin{array}{l}\text { CHIMERE: } \\
\text { considered for model } \\
\text { gas species and is } \\
\text { parameterized as } \\
\text { a downward flux out } \\
\text { of the lowest model } \\
\text { layer. The deposition } \\
\text { velocity is described } \\
\text { through a resistance } \\
\text { analogy (Wesely } \\
\text { 1989) }\end{array}$ & $\begin{array}{l}\text { MM5: nonconvective } \\
\text { precipitation scheme, warm } \\
\text { rain, simple ice, mixed-phase, } \\
\text { Goddard microphysics, Reisner } \\
\text { graupel, Schultz microphysics. } \\
\text { CHIMERE: follows the scheme } \\
\text { proposed bu Loosmore (2004) }\end{array}$ & $\begin{array}{l}\text { CHIMERE: offers the } \\
\text { option to include } \\
\text { different gas phase } \\
\text { chemical mechanisms. } \\
\text { MELCHIOR1 (Lattuati, } \\
\text { 1997): more than } 300 \\
\text { reactions of } 80 \text { gaseous } \\
\text { species. The hydro- } \\
\text { carbon degradation is } \\
\text { fairly similar to the EMEP } \\
\text { gas phase mechanism. } \\
\text { MELCHIOR2: } 44 \text { species } \\
\text { and about } 120 \text { reactions } \\
\text { is derived from } \\
\text { MELCHIOR (Derognat, } \\
\text { 2003), following the } \\
\text { concept of chemical } \\
\text { operators (Carter, 1990) }\end{array}$ & $\begin{array}{l}\text { Sectional with } 6 \text { size bins } \\
\text { (each bin internally mixed). All } \\
\text { microphysical processes included. } \\
7 \text { species (primary particle } \\
\text { material, nitrate, sulfate, } \\
\text { ammonium, biogenic secondary } \\
\text { organic aerosol (SOA), } \\
\text { anthropogenic SOA and water) }\end{array}$ \\
\hline $\begin{array}{l}\text { MM5/WRF- } \\
\text { CMAQ }\end{array}$ & $\begin{array}{l}\text { Several } \\
\text { possibilities. } \\
\text { Normally Global- } \\
\text { mass conserving } \\
\text { scheme. Vertical } \\
\text { difussion is mainly } \\
\text { done with the } \\
\text { Asymmetric } \\
\text { Convective model } \\
\text { (ACM2) for MM5 } \\
\text { and the Yonsei } \\
\text { University (YSU) } \\
\text { PBL parameteriza- } \\
\text { tion for WRF }\end{array}$ & $\begin{array}{l}\text { PBL scheme and } \\
\text { diffussion (MRF PBL); } \\
\text { surface scheme: Noah } \\
\text { Land Surface Scheme } \\
\text { and Monin Obukhov } \\
\text { surface layer scheme }\end{array}$ & $\begin{array}{l}\text { Physical: separate } \\
\text { resistance models for } \\
\text { gases and aerosols. } \\
\text { Numerical: } \\
\text { deposition velocity as } \\
\text { surface boundary } \\
\text { condition for vertical } \\
\text { diffusion }\end{array}$ & $\begin{array}{l}\text { Physical: seperate scavenging } \\
\text { models for gases and aerosols. } \\
\text { Numerical: uptake as a function } \\
\text { of rainfall rate, cloud water } \\
\text { content, gas solubility and } \\
\text { diffusivity, PM size }\end{array}$ & $\begin{array}{l}\text { CB04 and CB05; Also } \\
\text { RADM chemistry. It } \\
\text { includes cloud and } \\
\text { aerosol chemistry }\end{array}$ & $\begin{array}{l}\text { Modal scheme with three modes } \\
\text { and all microphysics. Aerosol } \\
\text { species: elemental and organic } \\
\text { carbon, dust, and other species } \\
\text { not further specified. Secondary } \\
\text { species considered are sulfate, } \\
\text { nitrate, ammonium, water, and } \\
\text { secondary organics from } \\
\text { precursors of anthropogenic and } \\
\text { biogenic origin. Possibilities to run } \\
\text { the aerosol MADRID scheme }\end{array}$ \\
\hline
\end{tabular}


Table 3. Continued.

\begin{tabular}{|c|c|c|c|c|c|c|}
\hline Model name & $\begin{array}{l}\text { Advection and } \\
\text { convection }\end{array}$ & Diffusion & Dry deposition & Wet deposition & Chemistry package & Aerosol package \\
\hline MOCAGE & $\begin{array}{l}\text { Advection is based } \\
\text { upon the semi- } \\
\text { lagrangian scheme } \\
\text { of (Williamson and } \\
\text { Rasch, 1989) with } \\
\text { global mass } \\
\text { conversation } \\
\text { imposed, while } \\
\text { convection is } \\
\text { parameterised } \\
\text { using (Bechtold } \\
\text { et al., 2001). See } \\
\text { details and } \\
\text { evaluation in } \\
\text { (Josse et al., } \\
\text { 2004) }\end{array}$ & $\begin{array}{l}K \text {-diffusion approach, } \\
\text { based upon } \\
\text { (Louis, 1979) }\end{array}$ & $\begin{array}{l}\text { Resistance approach: } \\
\text { for gases, it is based } \\
\text { upon (Wesely, 1989) } \\
\text { with refinements for } \\
\text { stomatal resistance } \\
\text { (Michou et al., 2004); } \\
\text { for aerosol, the } \\
\text { approach is described } \\
\text { in (Nho-Kim et al., } \\
\text { 2004) }\end{array}$ & $\begin{array}{l}\text { For scavenging by large-scale } \\
\text { precipitation and below } \\
\text { convective cloud, the } \\
\text { parameterisation is based upon } \\
\text { (Giorgi and Chameides, 1986), } \\
\text { with a special treatment for snow } \\
\text { flakes. For scavenging within } \\
\text { convective clouds, it is done } \\
\text { within the convective } \\
\text { paramaterisation as described } \\
\text { in (Mari et al., 2000) }\end{array}$ & $\begin{array}{l}\text { Several options are } \\
\text { available. In the } \\
\text { operationnal version, } \\
\text { the scheme is a merge } \\
\text { from the schemes RACM } \\
\text { (Stockwell et al., 1997) } \\
\text { and REPROBUS (Lefevre } \\
\text { et al., 1994), thus } \\
\text { offering a comprehensive } \\
\text { representation of both } \\
\text { tropospheric and } \\
\text { stratospheric chemistry. } \\
\text { The scheme comprises } \\
118 \text { species for a total of } \\
\text { over } 300 \text { homogeneous } \\
\text { and heterogeneous } \\
\text { chemistry reactions }\end{array}$ & $\begin{array}{l}\text { Aerosol is described using a bulk } \\
\text { approach with size bins (typically } \\
5 \text { to } 20 \text { bins per species). } \\
\text { Evaluation is currently available } \\
\text { for black carbon } \\
\text { (Nho-Kim et al., 2005), } \\
\text { dust (Martet et al., 2009) and } \\
\text { sulfate (Ménégoz et al., 2009) }\end{array}$ \\
\hline NAME & $\begin{array}{l}\text { NAME does not } \\
\text { have its own } \\
\text { convection scheme. } \\
\text { It obtains advection } \\
\text { fields from the } \\
\text { UK Met. Office's } \\
\text { numerical weather } \\
\text { prediction model, } \\
\text { the Unified Model } \\
\text { (Cullen, 1993) }\end{array}$ & $\begin{array}{l}\text { Modelled using } \\
\text { random walk } \\
\text { techniques. } \\
\text { Parameterised profiles } \\
\text { of turbulence param- } \\
\text { eters such as velocity } \\
\text { variances and } \\
\text { Lagrangian time } \\
\text { scales are employed. } \\
\text { Normally a Gaussian } \\
\text { scheme is used. } \\
\text { However for } \\
\text { convective conditions } \\
\text { a skewed turbulence } \\
\text { scheme is available }\end{array}$ & $\begin{array}{l}\text { Uses a resistance } \\
\text { analogy approach } \\
\text { and sedimentation of } \\
\text { heavy particles is also } \\
\text { included }\end{array}$ & $\begin{array}{l}\text { Based on parameterised } \\
\text { scavenging coefficients and } \\
\text { differs according to precipitation } \\
\text { type (convective, dynamic) }\end{array}$ & $\begin{array}{l}\text { Based on the scheme for } \\
\text { the STOCHEM model. } \\
40 \text { advected tracers }+18 \\
\text { non-advected } \\
140 \text { reactions }+23 \\
\text { photolytic reactions } \\
16 \text { emitted species }\end{array}$ & $\begin{array}{l}\text { A mass based scheme } \\
\text { incorporating sulphate, nitrate, } \\
\text { ammonium, and secondary } \\
\text { organic aerosols. Additional } \\
\text { scheme exist for sea salt ( } 2 \text { size } \\
\text { bias) and mineral dust ( } 6 \text { size bias) }\end{array}$ \\
\hline OPANA & $\begin{array}{l}\text { Piecewise parabolic } \\
\text { method (PPM) which } \\
\text { is a monotonic } \\
\text { scheme with } \\
\text { geometric non- } \\
\text { linear adjustments } \\
\text { to the parabolic } \\
\text { concentration distribu- } \\
\text { tions }\end{array}$ & $\begin{array}{l}\text { Two convective } \\
\text { boundary-layer } \\
\text { schemes: Blackadar } \\
\text { and ACM. Local } \\
\text { diffusion, vertically } \\
\text { continuous } \\
\text { integration, smooth } \\
\text { transition from stable } \\
\text { to convective and } \\
\text { faster matrix solver. } \\
\text { Updated eddy } \\
\text { diffusion scheme }\end{array}$ & $\begin{array}{l}\text { Chemical gases: } \\
\text { Wesely (1989). } \\
\text { Aerosol chemistry: } \\
\text { Binkowski and } \\
\text { Shankar (1995) } \\
\text { approach. These } \\
\text { schemes are based } \\
\text { on the resistance } \\
\text { approach which } \\
\text { assumes a canopy, } \\
\text { aerodynamical and } \\
\text { bulk resistance }\end{array}$ & $\begin{array}{l}\text { Physical: seperate scavenging } \\
\text { models for gases and aerosols. } \\
\text { Numerical: uptake as a function } \\
\text { of rainfall rate, cloud water } \\
\text { content, gas solubility and } \\
\text { diffusivity, PM size }\end{array}$ & $\begin{array}{l}\text { The CBM-IV chemical } \\
\text { mechanism in short and } \\
\text { long modes are included } \\
\text { in the system. The RADM } \\
\text { model and the SAPRC-99 } \\
\text { chemical scheme are also } \\
\text { included. These schemes } \\
\text { simulate the chemical } \\
\text { reactions in the atmosfere } \\
\text { for organic and also } \\
\text { inorganic reactions }\end{array}$ & $\begin{array}{l}\text { Modal scheme with three modes } \\
\text { and all microphysics. Aerosol } \\
\text { species: elemental and organic } \\
\text { carbon, dust, and other species } \\
\text { not further specified. Secondary } \\
\text { species considered are sulfate, } \\
\text { nitrate, ammonium, water, and } \\
\text { secondary organics from } \\
\text { precursors of anthropogenic and } \\
\text { biogenic origin. Possibilitirs to run } \\
\text { the aerosol MADRID scheme }\end{array}$ \\
\hline RCG & $\begin{array}{l}\text { Walcek (2000). } \\
\text { The number of } \\
\text { steps within the } \\
\text { advection scheme } \\
\text { is chosen such that } \\
\text { the courant } \\
\text { restriction } \\
\text { is fulfilled }\end{array}$ & $\begin{array}{l}\text { Vertical turbulent } \\
\text { mixing formulation } \\
\text { uses } K \text {-diffusion. } \\
\text { Stable and convective } \\
\text { boundary-layer } \\
\text { diffusion coefficients } \\
\text { based on PBL scaling } \\
\text { regimes. In addition: } \\
\text { mixing by use of time } \\
\text { and space dependent } \\
\text { coordinate based on } \\
\text { mixing height }\end{array}$ & $\begin{array}{l}\text { Resistance approach } \\
\text { (Erisman et al., 1994). } \\
\text { Gases: function of } \\
\text { species dependent } \\
\text { Henry constant and } \\
\text { precipitation rate. } \\
\text { Particles: below-cloud } \\
\text { simplescavenging } \\
\text { coefficient approach } \\
\text { with identical } \\
\text { coefficients for all } \\
\text { particles }\end{array}$ & $\begin{array}{l}\text { Gases: function of species } \\
\text { dependent Henry constant and } \\
\text { precipitation rate. Particles: } \\
\text { below-cloud simplescavenging } \\
\text { coefficient approach with } \\
\text { identical coefficients for all } \\
\text { particles }\end{array}$ & $\begin{array}{l}\text { Gas phase: updated } \\
\mathrm{CBM}-4 \text { with Carter's } \\
\text { 1-product isophere } \\
\text { scheme: homo- and } \\
\text { heterogenous conversion } \\
\text { of } \mathrm{NO}_{2} \text { to } \mathrm{HNO}_{3} \text {, } \\
\text { aqueous phase } \\
\text { conversion of } \mathrm{SO}_{2} \text { to } \\
\mathrm{H}_{2} \mathrm{SO}_{4} \text { through oxidation } \\
\text { by } \mathrm{H}_{2} \mathrm{O}_{2} \text { and } \mathrm{O}_{3} \text {, } \\
\text { equilibrium concentration } \\
\text { fot } \mathrm{SO}_{2}, \mathrm{H}_{2} \mathrm{O}_{2} \text { and } \mathrm{O}_{3} \\
\text { from } \mathrm{Henry} \text { constants }\end{array}$ & $\begin{array}{l}\text { ISORROPIA. Bulk equilibrium } \\
\text { scheme. species: mineral coarse } \\
\text { between } 2.5 \mu \mathrm{m} \text { and } 10 \mu \mathrm{m} \text {, } \\
\text { primary aerosol smaller than } \\
2.5 \mu \mathrm{m} \text {, primary elemental carbon, } \\
\text { primary organic carbon, secondary } \\
\text { organic aerosols, sulfate, nitrate, } \\
\text { ammonium, sea-salt }\end{array}$ \\
\hline SILAM & $\begin{array}{l}\text { Lagrangian kernel } \\
\text { uses the iterative } \\
\text { advection of Eerola } \\
\text { (1990). Eulerian } \\
\text { kernel is built } \\
\text { on the basis of } \\
\text { Galperin (2000) }\end{array}$ & $\begin{array}{l}\text { Lagrangian: assumes } \\
\text { the well-mixed PBL } \\
\text { and fixed random- } \\
\text { walk parameters in } \\
\text { the free troposphere. } \\
\text { Exchange between } \\
\text { the PBL and tropo- } \\
\text { sphere takes place } \\
\text { due to variation of } \\
\text { the PBL height. } \\
\text { Eulerian: follows } \\
\text { the } K \text {-closure with } \\
\text { approach of } \\
\text { Gernikhovich } \\
\text { et al. (2004) and } \\
\text { Sofiev et al. (2010a) } \\
\text { for } K_{z} \text { evaluation }\end{array}$ & $\begin{array}{l}\text { Varies for different } \\
\text { chemical schemes } \\
\text { but generally is based } \\
\text { on resistive analogy } \\
\text { with certain simplifi- } \\
\text { cations or extensions. } \\
\text { Aerosols: both gravi- } \\
\text { tational and diffusional } \\
\text { paths are considered } \\
\text { with the sedimentation } \\
\text { treated via Stokes } \\
\text { terminal velocity }\end{array}$ & $\begin{array}{l}\text { Follows the scavenging coeffi- } \\
\text { cient approach, distinguishing } \\
\text { between the in- and sub-cloud, } \\
\text { as well as rain-, snow-types of } \\
\text { scavenging }\end{array}$ & $\begin{array}{l}\text { 1. Acid basic transfor- } \\
\text { mations } 2 \text {. CB-4 } 3 \text {. Sox } \\
\text { module } 4 \text {. Radioactive } \\
\text { decay of up to } \sim 500 \\
\text { nuclides } 5 \text {. Toxic species } \\
6 \text {. Aerosols } 7 \text {. Natural } \\
\text { birch pollen } 8 \text {. Sea salt } \\
\text { 9. Passive tracer }\end{array}$ & $\begin{array}{l}\text { Two schemes: bulk and ADB } \\
\text { (Aerosol Dynamics Basic - } \\
\text { research mode only). Both } \\
\text { schemes use the user-defined } \\
\text { set of bins. Bulk scheme allows } \\
\text { treatment of any chemically inert } \\
\text { aerosol. ADB scheme distin- } \\
\text { guishes between SIA, sea salt, } \\
\text { dust, primary PM - in soluble and } \\
\text { insoluble phases }\end{array}$ \\
\hline SKIRON/Dust & $\begin{array}{l}\text { Horizontal: the } \\
\text { Eta/NCEP model } \\
\text { scheme for advec- } \\
\text { tion of a passive } \\
\text { substance (Janjić, } \\
\text { 1997). Vertical: } \\
\text { the scheme of } \\
\text { Van Leer (1977) }\end{array}$ & $\begin{array}{l}\text { A 2nd order diffusion } \\
\text { scheme is used } \\
\text { for lateral diffusion } \\
\text { by utilizing the } \\
\text { Smagorinsky-type } \\
\text { horizontal diffusion } \\
\text { coefficient modified by } \\
\text { the presence of the } \\
\text { model turbulent kinetic } \\
\text { energy term (Janjić, } \\
\text { 1990) }\end{array}$ & $\begin{array}{l}\text { Surface deposition of } \\
\text { particles occurs via } \\
\text { diffusion, impaction, } \\
\text { and/or gravitational } \\
\text { settling using the } \\
\text { resistance approach } \\
\text { of Slinn and Slinn } \\
\text { (1980) }\end{array}$ & $\begin{array}{l}\text { Wet deposition of particles occur } \\
\text { above and below the clouds as } \\
\text { described by Seinfield and } \\
\text { Pandis (1998) }\end{array}$ & No chemistry & Bulk scheme for dust \\
\hline
\end{tabular}


Table 3. Continued.

\begin{tabular}{|c|c|c|c|c|c|c|}
\hline Model name & $\begin{array}{l}\text { Advection and } \\
\text { convection }\end{array}$ & Diffusion & Dry deposition & Wet deposition & Chemistry package & Aerosol package \\
\hline THOR & $\begin{array}{l}\text { Time integration } \\
\text { for the advection } \\
\text { term is performed } \\
\text { with a predictor- } \\
\text { corrector scheme } \\
\text { with several } \\
\text { correctors (Zlatev, } \\
\text { 1995) }\end{array}$ & $\begin{array}{l}K \text {-theory, constant } \\
K \text { in horizontal, and } \\
\text { vertical } K_{z} \text { based } \\
\text { on Monin-Obukhov } \\
\text { similarity theory for } \\
\text { the surface layer, } \\
\text { extended to the whole } \\
\text { mixing layer }\end{array}$ & $\begin{array}{l}\text { DEHM: velocities of } \\
\text { the species are based } \\
\text { on the resistance } \\
\text { method }\end{array}$ & $\begin{array}{l}\text { DEHM: parameterised by } \\
\text { a simple scavenging ratio } \\
\text { formulation with different } \\
\text { in-cloud and below-cloud } \\
\text { scavenging }\end{array}$ & $\begin{array}{l}\text { A chemical scheme } \\
\text { similar to the EMEP } \\
\text { scheme with } 60 \text { species } \\
\text { and } 120 \text { chemical } \\
\text { reactions is included } \\
\text { in the model }\end{array}$ & $\begin{array}{l}\text { DEHM: Bulk scheme. Three of } \\
\text { the species are primary particu- } \\
\text { lates }\left(\mathrm{PM}_{25}, \mathrm{PM}_{10} \text {, TSP). Further- }\right. \\
\text { more sea salt is implemented in the } \\
\text { model }\end{array}$ \\
\hline WRF-Chem & $\begin{array}{l}\text { Several possibil- } \\
\text { ities. Normally } \\
\text { Global-mass con- } \\
\text { serving scheme. } \\
\text { Vertical difussion } \\
\text { is mainly done } \\
\text { with the Yonsei } \\
\text { University PBL } \\
\text { parameterization }\end{array}$ & $\begin{array}{l}\text { PBL scheme with the } \\
\text { Yonsei University } \\
\text { parameterization }\end{array}$ & $\begin{array}{l}\text { Physical: separate } \\
\text { resistance models for } \\
\text { gases and aerosols. } \\
\text { Numerical: deposition } \\
\text { velocity as surface } \\
\text { boundary condition for } \\
\text { vertical diffusion }\end{array}$ & $\begin{array}{l}\text { Physical: separate scavenging } \\
\text { models for gases and aerosols. } \\
\text { Numerical: uptake as a function } \\
\text { of rainfall rate, cloud water } \\
\text { content, gas solubility and } \\
\text { diffusivity, PM size }\end{array}$ & $\begin{array}{l}\text { CB05, CBMZ and RADM } \\
\text { chemical schemes }\end{array}$ & $\begin{array}{l}\text { Option for sectional (MOSAIC, } \\
8 \text { bins) and modal (MADE) } \\
\text { aerosol models }\end{array}$ \\
\hline
\end{tabular}

boundary conditions. The date of the forecasts (10 February 2011) corresponds to a severe air-quality episode, during which concentrations of $\mathrm{PM}_{10}$ (Particulate Matter $<10 \mu \mathrm{m}$ ) in the European, and Italian and Roman domains were substantial.

\subsubsection{ALADIN-CAMx (Austria)}

The chemical weather model for Austria, AQA (Air-Quality model for Austria), consists of the meteorological model ALADIN-Austria (Sect. 3.2.5) and the chemical transport model CAMx (Comprehensive Air-Quality Model with extensions; http://www.camx.com). The two models are coupled off-line. The modelling system ALADIN-CAMx was implemented for the first time in Baumann-Stanzer et al. (2005). The forecasts, which are done in cooperation with the University of Natural Resources and Applied Life Sciences in Vienna (BOKU), are supported by the regional governments in Austria.

The SAPRC99 (Statewide Air Pollution Research Center in Riverside, California, Sect. 4.3.7) gas-phase photochemistry module (Carter, 2000) used in the operational AQA forecasts considers 76 different species and 217 reactions. The model system generally uses European Monitoring and Evaluation Programme (EMEP; http://www.emep.int) emissions for Europe. For the countries Austria, Czech Republic, Slovakia and Hungary, the original $50 \times 50 \mathrm{~km}$ data are downscaled to $5 \times 5 \mathrm{~km}$ based on an inventory from 1995 . The EMEP data for 2005 (Vestreng et al., 2006) was used during summer 2007. In addition, a new highly resolved emission inventory for the City of Vienna (Orthofer et al., 2005 ) is used. Before 2008, terpene and isoprene emissions were calculated according to Guenther et al. (1993), and biogenic $\mathrm{NO}$ and $\mathrm{NO}_{2}$ emissions were calculated according to Williams et al. (1987) and Stohl et al. (1996). For the operational chemical weather forecasts in 2009, these methods were replaced by the BEIS3 (Biogenic Emission Inventory System) mechanism, which is implemented in the emission model SMOKE (Sparse Matrix Operator Kernel Emissions model).

Monthly average (1991-2001) concentrations of the different species are used as boundary conditions for the coarse grid. The concentrations were obtained from model calculations (Krüger et al., 2008), which were conducted for the EU-project CECILIA (Central and Eastern Europe Climate Change Impact and Vulnerability Assessment, http: //www.cecilia-eu.org). Forecasts of total column ozone are provided by the ECMWF IFS (Integrated Forecast System) model (Sect. 3.2.1).

\subsubsection{CAMx-AMWFG (Greece)}

The AM\&WFG (Atmospheric Modelling and Weather Forecasting Group, National and Kapodistrian University of Athens, Greece) developed the chemical weather forecasting system CAMx-AMWFG, which is based on the CAMx photochemical model. The system utilizes the SKIRON/Dust modelling system (Sect. 2.3.16) meteorological fields in order to prepare long-range transport of gases and particulate matter for Europe and the Mediterranean Region. The CAMx model was developed for regional-scale modelling of ozone and other pollutants (ENVIRON, 1997, 2006). Products from this model are 48-h operational forecasts of $\mathrm{O}_{3}, \mathrm{NO}_{2}$, $\mathrm{SO}_{2}$, and particulate sulfate $\left(\mathrm{PSO}_{4}\right)$ fields for the Mediterranean region and Europe every hour produced once per day (http://forecast.uoa.gr/camxindx.php). Additionally, CAMxAMWFG can provide the concentration and deposition for sodium and chloride (from sea-salt production), sulfate produced on dust $\left(\mathrm{DSO}_{4}\right)$, and nitrate produced on dust $\left(\mathrm{DNO}_{3}\right)$.

\subsubsection{Enviro-HIRLAM (Denmark and others)}

Enviro-HIRLAM (Environment - HIgh Resolution Limited Area Model) is an on-line coupled NWP (Sect. 3.2.4) and CTM model for research and forecasting of both meteorological and chemical weather. The modelling system was developed by DMI (Danish Meteorological Institute) with 
other collaborators (Chenevez et al., 2004; Baklanov et al., 2008b; Korsholm et al., 2008) and included by the European HIRLAM consortium as the baseline system in the HIRLAM Chemical Branch (www.hirlam.org/chemical).

To make the model suitable for CWF in urban areas, the meteorological part is improved by implementation of urban sublayer modules and parameterisations. The aerosol module in Enviro-HIRLAM has two parts: (i) a thermodynamic equilibrium model (NWP-Chem-Liquid) and (ii) the aerosol dynamics model CAC (tropospheric Chemistry Aerosol Cloud model). Parameterisations of aerosol feedback mechanisms in the Enviro-HIRLAM model are described in Korsholm et al. (2008) and Korsholm (2009).

Users have the option to choose one of several chemical mechanisms: RADM2 (Sect. 4.3.6), RACM (Sect. 4.3.6) or the newly developed, economical NWP-Chem. On-line Enviro-HIRLAM is used at DMI for operational pollen forecasting. The DMI operational system also includes the offline version (the so-called CAC system), which is used operationally for CWF (e.g. in GEMS) and the Lagrangian model DERMA (Danish Emergency Response Model of the Atmosphere; Sørensen et al., 2007) for emergency preparedness modelling.

\subsubsection{EURAD-RIU (Germany)}

The EURAD model (European Air Pollution and Dispersion model) is an chemical weather forecast model system for research and assessment. The model system was developed at the Rhenish Institute for Environmental Research (RIU) at the University of Cologne, Germany. The EURAD Air Quality Forecast System consists of three major components: MM5 (Sect. 3.2.8) to predict the needed meteorological variables, the EURAD Emission Module (EEM) to calculate the temporal and spatial distribution of the emission rates of the major pollutants, and the EURAD Chemistry Transport Model (EURAD-CTM) to predict the concentrations and deposition of the main atmospheric pollutants.

For the initial and boundary conditions, the NCEP GFS (National Centers for Environmental Prediction, Global Forecast System) is interpolated onto the grids of the nested MM5 domains. The nesting enables consistent modelling from local to continental scales. Geographical information (e.g. orography, land-use type) is taken from the United Sates Geological Survey (USGS) database.

EURAD uses the RADM2 and its successor RACM for computing the chemical processes and MADE (Modal Aerosol-Dynamics model for EURAD) for computing aerosol processes. RADM2 contains 63 reactive species treated in 158 chemical reactions. There is an option to run the code with the more sophisticated RACM chemistry. Detailed aqueous-phase chemistry is incorporated, as well. The horizontal and vertical transport is performed by the fourth-order Bott advection scheme, and vertical mixing of the species is treated by an implicit vertical diffusion scheme.
The sink at the lower boundary of the model is treated by wet and dry deposition parameterization. The major driver for wet deposition is the predicted precipitation. The dry deposition is calculated via the deposition velocity for each species, which depends upon the properties of the particle, the meteorological conditions and the land-use type.

The daily output of meteorological and atmospheric constituents covers Europe, Central Europe and the German States of North Rhine-Westfalia, Lower Saxony and Bavaria. These products are published on the EURAD website (http: //www.riu.uni-koeln.de).

\subsubsection{FARM (Italy)}

FARM (Flexible Air-quality Regional Model) was originally derived from STEM-II (Sulfur Transport and dEposition Model; Carmichael et al., 1998) and was later developed as an independent project by ARIANET s.r.l. (http://www.aria-net.it). The model development is presently supported by ENEA (Ente per le Nuove tecnologie, l'Energia e l'Ambiente; www.enea.it) within the national project MINNI (Modello Integrato Nazionale a supporto della Negoziazione Internazionale sui temi dell'inquinamento atmosferico; www.minni.org) funded by the Italian Ministry of Environment. A short model presentation is available at http://www.aria-net.it/front/ENG/codes/files/10.pdf, a more detailed on-line description (in Italian) can be found at http: //www.minni.org/sistema/sistema-modellistico-atmosferico/ modulo-chimico, and a comprehensive user's guide is provided on request. Recent applications are documented in Gariazzo et al. (2007), Silibello et al. (2008) and Calori et al. (2008).

SAPRC-99 (Carter, 2000) and an updated version of the chemical mechanism implemented in the EMEP Lagrangian Acid Deposition Model (Hov et al., 1988), including the treatment of Persistent Organic Pollutants (POPs) and mercury, and gas-phase chemical mechanisms have been implemented into the model using KPP chemical pre-processor (KPP, Kinetic Pre-Processor: Damian et al., 2002; Sandu et al., 2003; Daescu et al., 2003). The integration of the chemical reactions is performed by means of the the following methods included in KPP: Rosenbrock (Sandu et al., 2003) and LSODE (the Livermore Solver for Differential Equations; Radhakrishnan and Hindmarsh, 1993). Photolysis reaction rates appearing in the mechanism can be estimated either using simple look-up tables or an on-line version of the Tropospheric Ultraviolet-Visible Model (TUV, Madronich, 1987). SAPRC99 is coupled with the CMAQ (Community Multiscale Air-Quality model) aero3 (3rd generation aerosol) module to include aerosol processes. In the presence of a cloud layer, a simplified aqueous-phase mechanism includes sulfate production in clouds.

FARM runs operationally at ARIANET coupled with the meteorological model RAMS (Regional Atmospheric Model System; Cotton et al., 2003, Sect. 3.2.10) to 
produce national-scale chemical weather forecasts (http:// www.aria-net.eu/QualeAria). The model is run by some Italian Regional Environmental Protection Agencies (ARPA) to produce chemical weather analyses and forecasts. In particular, ARPA Lazio runs the model driven by RAMS to produce urban chemical weather forecasts for Rome (Finardi et al., 2009) available at http://www.arpalazio. net/main/aria/sci/previsioni/pm10.php; ARPA Piemonte together with Novara and Torino Provinces use the model driven by COSMO I7 (Italian implementation of the LM model, formerly known as LAMI, Limited Area Model Italy, http://www.arpa.emr.it/sim/?mappe_numeriche) to forecast air quality over Torino City (Finardi et al., 2008) and Novara Province (Pittini et al., 2007), with results browsable at http://www.provincia.torino.it/ambiente/ inquinamento/aria/qualita/ipqa/index and at http://www. provincia.novara.it/arianova/WEB/index.html; and ARPA Lombardia uses FARM and a meteorological analysis using the ECMWF as a background field to compute near-realtime chemical weather analyses (http://ita.arpalombardia.it/ ITA/qaria/doc_DistribSpazialeCalcolata.asp).

\subsubsection{LOTOS-EUROS (The Netherlands)}

Several models have been developed in The Netherlands. Netherlands Organisation for Applied Scientific Research (TNO) developed LOTOS (Builtjes, 1992; Schaap et al., 2004) and the National Institute for Public Health and the Environment (RIVM) developed EUROS (de Leeuw and van Rheineck Leyssius, 1990; Matthijsen et al., 2002). During 2004, the two models were unified, resulting in the LOTOSEUROS model version 1.0 (LOng Term Ozone Simulation - EURopean Operational Smog model, Schaap et al., 2008; http://www.lotos-euros.nl). The model can be used to model the fate of pollutants such as photo-oxidants, aerosols, heavy metals and POPs over Europe.

The model is used operationally to forecast air pollution over Europe and the Netherlands, driven by the meteorology from ECMWF IFS (Sect. 3.2.1). The model is used to perform 72-h European forecasts (twice daily) at 30- and 15$\mathrm{km}$ horizontal grid spacing and a smaller domain over the Netherlands at a $15-\mathrm{km}$ horizontal grid spacing, including data assimilation of ozone measurements (van Loon et al., 2004). $\mathrm{PM}_{10}$ forecasts are produced including a bias correction (Manders et al., 2009).

\subsubsection{MATCH (Sweden)}

The Multi-scale Atmospheric Transport and Chemistry (MATCH) model is a three-dimensional, Eulerian model developed at SMHI (Swedish Meteorological and Hydrological Institute). It is used in a range of applications from urban-scale studies with grid spacings on the order of a $\mathrm{km}$ or smaller (e.g. Gidhagen et al., 2005) to regional and continental-scale studies on eutrophic deposition and photo- chemistry (e.g. Langner et al., 2005; Engardt et al., 2005; Andersson et al., 2007). MATCH is used for air-quality assessment in Sweden and the Baltic Sea region and for forecasts of radioactivity in case of nuclear emergencies in Europe (Langner et al., 1998).

MATCH includes modules describing emissions, advection, turbulent mixing and dry and wet deposition. Depending on the application, specific modules describing chemistry or aerosol dynamics can be added to the basic transport model. The MATCH design has flexible horizontal and vertical resolution and allows for an arbitrary number of chemical compounds. The advection scheme (Bott, 1989) is fourth-order in the horizontal and secondorder in the vertical. A complete description of the transport model can be found in Robertson et al. (1999) and in the on-line documentation (http://www.smhi.se/sgn0106/if/ meteorologi/match.htm). Details on the photochemistry version of MATCH can be found in Andersson et al. (2007) and van Loon et al. (2007). Emissions used for the runs are based on EMEP2003.

The current MATCH operational system for CWF consists of two components, driven by HIRLAM and ECMWF meteorology, respectively. The MATCH-HIRLAM component uses meteorological data provided by the HIRLAM NWP model (Sect. 3.2.4) that is operational at SMHI. MATCHHIRLAM is primarily targeted to ozone and is run once a day. A run consists of a hindcast of the previous day and forecasts for the present day and the next day. The model grid comprises nearly all of Europe with a horizontal grid spacing of $44 \mathrm{~km}$ (http://www.airviro.smhi.se/MAQS). MATCHECMWF is a part of the GEMS/MACC regional cluster and uses ECMWF IFS (Sect. 3.2.1) meteorology. It is currently operated with horizontal grid spacing of 0.5 and $0.2^{\circ}$ (since 2011) and provides 72-h forecasts of such quantities as $\mathrm{O}_{3}$, $\mathrm{NO}, \mathrm{NO}_{2}, \mathrm{CO}, \mathrm{SO}_{2}, \mathrm{PM}_{2.5}, \mathrm{PM}_{10}$, visibility and aerosol optical depth (AOD) (http://gems.ecmwf.int/).

\subsubsection{MM5-CAMx (Greece)}

MM5-CAMx is the combination of the limited-area, nonhydrostatic, terrain following and sigma-coordinate meteorological model MM5 (Sect. 3.2.8) coupled off-line with the three-dimensional Eulerian photochemical transport model CAMx. The forecast system performs a 72-h forecast of daily mean and daily maximum $\mathrm{O}_{3}, \mathrm{NO}, \mathrm{NO}_{2}, \mathrm{CO}, \mathrm{SO}_{2}$, and $\mathrm{PM}_{10}$ concentrations on three domains: two on the regional scale (Europe, Balkan Peninsula) and one on an urban scale (Athens) (http://lap.phys.auth.gr/gems.asp).

\subsubsection{MM5-CHIMERE (France and Portugal)}

MM5-CHIMERE consists of two models: the PSU/NCAR (National Center for Atmospheric Research) Mesoscale Model MM5 (Sect. 3.2.8) which is used to compute the meteorological variables that are needed to drive the 
chemistry-transport model, and the MM5-CHIMERE model (http://www.lmd.polytechnique.fr/chimere/), developed by IPSL (Laboratoire de Météorologie Dynamique), which is used to predict the concentrations and deposition of several tropospheric species. MM5-CHIMERE has been primarily designed to produce daily forecasts of ozone, aerosols and other pollutants and to make long-term simulations for emission control scenarios. MM5-CHIMERE is executed over a range of spatial scales from a global and regional scale (domains of several thousands of kilometers) to an urban scale (100-200 km) with horizontal grid spacings of $1-100 \mathrm{~km}$. Products are daily 72 -h forecasts for $\mathrm{O}_{3}, \mathrm{NO}_{2}, \mathrm{PM}_{2.5}, \mathrm{PM}_{10}$ and desert dust (http://prevair.org).

\subsubsection{MM5/WRF-CMAQ (Spain, UK)}

The CMAQ (United States Environmental Protection Agency, Community Multiscale Air Quality) model includes a suite of chemical as well as transport and dynamic schemes (Byun and Schere, 2006). It includes dynamical and chemical interactions between atmospheric pollutants on multiple scales in a modular framework. CMAQ has been designed for assessing the impact of multiple pollutants including tropospheric $\mathrm{O}_{3}$ and other oxidants, speciated particulate matter, and acid-deposition species on time scales from an hour to years.

CMAQ is a widely used chemistry transport model which has been linked to a number of meteorological models including MM5, Eta and WRF (Sects. 3.2.8, 3.2.6, and 3.2.9, respectively). Although WRF has superseded MM5, the MM5-CMAQ is used for example to provide 72-h forecasts for hourly, daily maxima and daily average information related to $\mathrm{O}_{3}, \mathrm{NO}_{2}, \mathrm{CO}, \mathrm{SO}_{2}, \mathrm{PM}_{10}, \mathrm{PM}_{2.5}$ and $\mathrm{NH}_{3}$ (http://verde.lma.fi.upm.es/cmaq_eu/).

Examples of CWF model forecasts can be found in Eder et al. (2006, 2009); they examine the performance of the model for forecasting 8-h ozone concentrations over the USA. CMAQ is also used operationally in the UK to predict footprints of industrial power plants for pollutants such as $\mathrm{SO}_{2}$ and $\mathrm{PM}_{10}$ (e.g. Yu et al., 2008). CMAQ is supported and distributed by the Community Modelling and the Analysis System center (CMAS, http://www.cmascenter.org/).

\subsubsection{MOCAGE (France, Spain, Romania)}

The MOCAGE (Modèle de Chimie Atmosphérique à Grande Echelle, Model of Atmospheric Composition at Large Scales) three-dimensional multi-scale CTM has been designed at Météo-France for both research and operational applications. MOCAGE is applicable to CWF, tracking and back-tracking of accidental point-source releases, trans-boundary pollution assessment, assimilation of remotesensing measurements of atmospheric composition, and studies on the impact of anthropogenic emissions of pollutants on climate change, with more than 40 references in the international peer-reviewed literature (e.g. Dufour et al., 2004; Bousserez et al., 2007).

MOCAGE has the flexibility to be run in different configurations with different parameterizations depending upon its application. The model considers the troposphere and stratosphere on the planetary scale and over limited-area subdomains at higher horizontal resolution. The model provides (by default) its own time-dependent chemical boundary conditions.

MOCAGE has been run daily since 2001. In 2004, MétéoFrance joined the partnership consortium and operational platform "Prév'Air" (http://www.prevair.org; Rouil et al., 2009) in charge of the pollution monitoring and forecasting for the French Ministry of Environment. Within this platform, 72-h forecasts are delivered daily to Prév'Air users, including ozone, precursors and aerosol over the globe (horizontal grid spacing of $\left.2^{\circ}\right)$, Europe $\left(0.5^{\circ}\right)$ and France $\left(0.1^{\circ}\right)$.

MOCAGE is also run daily in the context of GMES atmosphere projects (GEMS and now MACC, http://www. gmes-atmosphere.eu/services/raq), participating in the preoperational ensemble forecasting system. The configuration used in this context has two domains and covers the globe at $2^{\circ}$ horizontal grid spacing and Europe $\left(15^{\circ} \mathrm{W}-35^{\circ} \mathrm{E}\right.$ and $35^{\circ} \mathrm{N}-70^{\circ} \mathrm{N}$ ) at $0.2^{\circ}$ grid spacing. MOCAGE is also run by the Spanish and Romanian national meteorological services for their research and operations. MOCAGE is coupled to the computational fluid dynamics software PALM (http://www.cerfacs.fr $/ \sim$ palm) and can assimilate using variational methods (3DVAR, 3DFGAT or 4DVAR) profiles, columns or surface measurements of key atmospheric pollutants (e.g. El Amraoui et al., 2010).

\subsubsection{NAME (UK)}

NAME (Numerical Atmospheric dispersion Modelling Environment) is an off-line Lagrangian chemical transport model developed by the UK Met Office (Jones et al., 2007). It provides a flexible modelling environment able to predict dispersion over distances ranging from kilometres to the whole globe and for time periods from minutes upwards. This flexibility allows the model to be used in a variety of applications, including emergency response (e.g. Webster et al., 2007) and routine chemical weather forecasting.

NAME uses meteorology from the Met Office Unified Model (UM, Sect. 3.2.3) in either global or limited area configuration. Chemical modelling within NAME employs the scheme originally derived for the STOCHEM model (UK Meteorological Office Chemistry-transport Model, Collins et al., 1997). This scheme models gaseous and aqueous phase chemistry and has 40 advected and 18 non-advected tracers, 140 reactions and 23 photolytic reactions; 16 species are emitted. The dry deposition scheme used is based on a resistance network analogy for deposition velocity modelling. Particles can also be removed from the model atmosphere by fall out due to gravity, impaction with the surface, washout 
by falling precipitation, and rainout, where the pollutant is absorbed directly into cloud droplets as they form.

Emissions are pre-processed using three datasets: (i) the UK National Atmospheric Emission Inventory at 1-km grid spacing; (ii) a 5-km grid-spacing inventory for shipping emissions around the UK; (iii) the EMEP 50-km grid spacing inventory outside the UK. The UK routine chemical weather forecast configuration of NAME employs a nested configuration, with an outer domain covering Western Europe and an inner domain covering the UK. The effective model grid for the inner domain corresponds to a grid spacing of around $8 \mathrm{~km}$. The model provides forecasts out to 5 days and routine output parameters include atmospheric concentrations of ozone, $\mathrm{CO}, \mathrm{NO}_{2}, \mathrm{SO}_{2}, \mathrm{PM}_{10}$ and secondary aerosol species.

\subsubsection{OPANA (Spain and others)}

OPANA is an Operational version of the ANA model (Atmospheric mesoscale Numerical pollution model for urban and regional Areas). OPANA is composed of several constituent models, including a nonhydrostatic mesoscale meteorological model (REMEST, based on MEMO and MM5, Sects. 3.2.7 and 3.2.8, respectively), a chemical model, emission model, and deposition model (San José et al., 2002). OPANA is designed to operate routinely to forecast air quality for 5-7 days. OPANA produces daily chemical weather forecasts in Leicester City Council (UK), Madrid Municipality (Spain) and Las Palmas de Gran Canaria (Spain). It is also used as an impact assessment system for industrial installations. Numerical products include daily 72-h forecasts for $\mathrm{O}_{3}, \mathrm{NO}_{2}, \mathrm{CO}, \mathrm{SO}_{2}$, and $\mathrm{PM}_{10}$ (http://artico.lma.fi.upm.es/).

\subsubsection{RCG (Germany)}

The urban-scale photochemical model CALGRID (California Grid Model; Yamartino et al., 1992) and the regionalscale model REM3 (Regional Eulerian Model; Stern, 1994) were used as the starting point for the urban/regional-scale model, REM-CALGRID (RCG, Stern, 2003). The RCG model has been designed to fulfill the requirements of the ambient air-quality framework directive 96/62/EC of the European Commission (Stern et al., 2008). RCG is run in offline mode. For long-term diagnostic applications, the meteorological driver is prepared by the analysis system TRAMPER (Tropospheric Realtime Applied Meteorological Procedures for Environmental Research, Reimer and Scherer, 1992).

For operational forecasting, the meteorology derives from the GME model (Global Model, Sect. 3.2.2). The model is part of a model system development including statistical and fuzzy models (Reimer and Dlabka, 2000) and Eulerian model RCG (Flemming and Reimer, 2000) to forecast especially surface ozone concentrations. The full system is documented in Reimer et al. (2000). After transformation of GME data to RCG coordinates, the boundary layer parameters are determined anew by the TRAMPER boundary-layer module.

The forecast system was developed for local abatement strategies for German authorities to apply the so-called German ozone law in the 1990s. With the introduction of EU directives, the diagnostic tests on emission scenarios became much more important than real-time forecasts. The RCG model has been operational for more than $10 \mathrm{yr}$, running every day at 12:00 UTC and producing a 72-h forecast over Central Europe (http://www.trumf.de/).

\subsubsection{SILAM (Finland, Estonia, Russia, Lithuania and Spain)}

The SILAM modelling system (Air-Quality and Emergency Modelling System) includes both Eulerian and Lagrangian dynamic kernels (e.g. Sofiev et al., 2006a, b; Saarikoski et al., 2007; Siljamo et al., 2008; Sofiev et al., 2009; Saarnio et al., 2010; http://silam.fmi.fi). The model applications range from global to meso-beta scale (grid spacing down to $1 \mathrm{~km}$ ). The SILAM model is an open-access system, and the source code is publicly available on the web. The model is the official chemical weather forecasting tool on regional and larger scales in Finland and Lithuania. The model is also used for research purposes in Estonia, Russia, Lithuania and Spain.

The model has been used operationally in the EU-funded GEMS and MACC (http://www.gmes-atmosphere.eu) and EU-funded PROMOTE (http://www.gse-promote.org) and PASODOBLE projects. The predicted species include the concentrations of $\mathrm{O}_{3}, \mathrm{NO}_{\mathrm{x}}, \mathrm{SO}_{\mathrm{x}}, \mathrm{NH}_{\mathrm{x}}, \mathrm{VOCs}$, sea salt, anthropogenic $\mathrm{PM}_{2.5}$ and $\mathrm{PM}_{10}$, as well as pollution from wildland fires (e.g. Saarikoski et al., 2007; Sofiev et al., 2009, 2011b; Saarnio et al., 2010; and for selected biogenic aerosols, such as allergenic pollen (e.g. Sofiev et al., 2006b, 2011; Siljamo et al., 2008; Veriankaitë et al., 2010). The model is capable of four-dimensional variational data assimilation (Sofiev and Atlaskin, 2004). The model has recently been applied to evaluate the dispersion of primary $\mathrm{PM}_{2.5}$ emissions across Europe and in more detail over Finland, and to assess the resulting adverse health impacts (Tainio et al., 2009, 2010; Karvosenoja et al., 2010).

The meteorological information is extracted most commonly from the Finnish Meteorological Institute (FMI) variant of the weather forecasting model HIRLAM (Sect. 3.2.4), which is used as a downscaling tool for ECMWF Integrated Forecast System forecasts (which are also used without modifications), and from the regional AROME (Applications of Research to Operations at Mesoscale, Sect. 3.2.5) model simulations for Southern Finland and the Baltic States. The products are 54- and 72-h forecasts for Finland, the Baltic States, and Europe (http://silam.fmi.fi). The structure of the SILAM modelling system has been schematically illustrated in Fig. 3. 


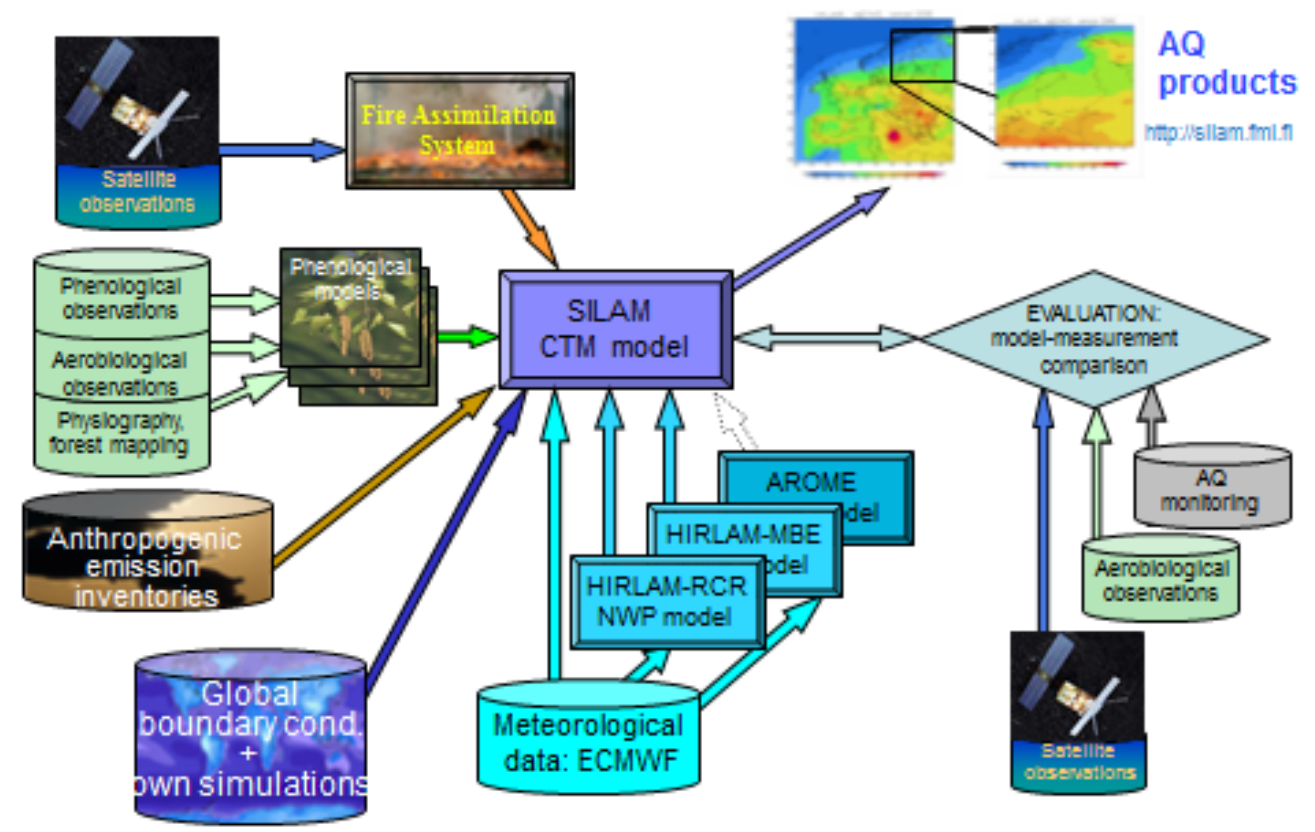

Fig. 3. The components, input and output data, and model evaluation of a regional chemical weather assessment and forecasting model SILAM.

\subsubsection{SKIRON/Dust (Greece)}

SKIRON/Dust is a modelling system that couples the National Oceanic and Atmospheric Administration (NOAA) Eta NWP model (Sect. 3.2.6) on-line with a dust transport model. As of this writing, SKIRON's NWP component runs at $5-\mathrm{km}$ horizontal grid spacing, using the nonhydrostatic version with the Betts-Miller-Janjić convective parameterization scheme. Other modifications to the Eta model in SKIRON include a different radiative transfer scheme, differences in the soil properties in the surface parameterization, more soil and vegetation categories, and the incorporation of sloped surfaces in the surface energy balance.

The dust module of the system is based on the work of Nickovic et al. (2001) and Spyrou et al. (2010). The dust transport submodel includes eight size bins of dust particles (Marticorena and Bergametti, 1995; Zender et al., 2003; Pérez et al., 2006), the calculation of AOD, and the correction of radiative transfer through look-up tables (Kaufman et al., 2002). Dry and wet deposition schemes have been improved, and in-cloud scavenging has been included (Kumar et al., 1995; Seinfeld and Pandis, 1998; http://forecast.uoa. gr/dustindx.php).

\subsubsection{THOR (Denmark)}

THOR is an integrated air-pollution forecast and scenario management system (Brandt et. al., 2001b; http://thor.dmu. $\mathrm{dk}$ ), consisting of an off-line coupled three-dimensional NWP model Eta (Sect. 3.2.6) and several air-pollution models (e.g. Danish Eulerian Hemispheric Model DEHM, Ur- ban Background Model UBM, point source model OML, Operational Street Pollution Model OSPM, accidental release model Danish Rimpuff and Eulerian Accidental release Model DREAM). The model covers most of the Northern Hemisphere with a two-way coupled nest over Europe. The system is capable of 72-h forecasts of weather and air pollution from regional scale over an urban area down to individual street canyons in cities. DREAM can be used for any accidental release such as from power plants, industrial sites, and natural and human made fires (http://www2.dmu.dk/1_Viden/2_miljoe-tilstand/3_luft/ 4_spredningsmodeller/5_Thor/default_en.asp).

THOR can inform and warn the public in case of high air-pollution levels and for policy management (e.g. by emission-reduction or traffic scenarios) of many different chemical compounds. THOR is executed up to four times every day. The products are 72-h forecast and daily maximum of $\mathrm{O}_{3}, \mathrm{NO}, \mathrm{NO}_{2}, \mathrm{SO}_{2}$, and $\mathrm{SO}_{4}$ for Denmark and Europe (http://www2.dmu.dk/1_Viden/2_Miljoe-tilstand/3_luft/ 4_udsigt/Default.asp).

\subsubsection{WRF-Chem (Spain and others)}

When the WRF (http://www.wrf-model.org/; Sect. 3.2.9) model is coupled with an atmospheric chemistry module to produce WRF-Chem (Grell et al., 2005) simulations of chemistry and aerosols from cloud scales to regional scales can be performed. WRF-Chem was developed by NCAR and NOAA with contributions from Pacific Northwest National Laboratory (PNNL), US Environmental Protection Agency 
(EPA), and university scientists (http://www.acd.ucar.edu/ wrf-chem/).

The version of WRF-Chem running in Spain is an online model; it solves the chemistry every $10 \mathrm{~min}$ and the meteorological time step is 5 min. The EMIssion MOdel (EMIMO) (Computer Science School - Technical University of Madrid, UPM) provides emission data for every grid cell, per hour and per primary pollutant, based on TNO European emissions. Products are daily 72-h $\mathrm{O}_{3}, \mathrm{NO}_{2}, \mathrm{SO}_{2}, \mathrm{CO}$, $\mathrm{PM}_{10}, \mathrm{PM}_{2.5}$ and $\mathrm{NH}_{3}$ forecasts for Europe (http://verde.lma. fi.upm.es/wrfchem_eu/).

\section{Numerical weather prediction models}

Nearly all operational air-quality models have two components, a numerical weather prediction component and an airpollution chemistry and physics component. The purpose of this section is twofold. First, we discuss the characteristics of NWP models that affect the ability of the coupled model to produce accurate forecasts of air quality (Sect. 3.1). Second, we provide a brief overview of the different NWP models in operational air-quality models in Europe (Sect. 3.2). Tribbia and Anthes (1987) provide a review of the scientific basis for numerical weather prediction, and Stensrud (2007) reviews physical parameterization schemes.

\subsection{Selected characteristics of NWP models}

In this section, the model architectures and physical processes in the NWP models are discussed.

\subsubsection{Formulation of NWP models}

NWP models can be divided into hydrostatic and nonhydrostatic models. Hydrostatic models assume that the accelerations of vertical velocity are small relative to that of gravity. Nonhydrostatic models, on the other hand, are capable of modelling vertical accelerations exceeding that of gravity, such as are found in deep, moist convection. Most models with horizontal grid spacings less than $10 \mathrm{~km}$ are run using nonhydrostatic models.

Another aspect is the vertical coordinate used in the formulation of the governing equations. Some models use pressure as their vertical coordinate, whereas others use a terrainfollowing $\sigma$ coordinate, where $\sigma=\left(p-p_{\mathrm{s}}\right) \div\left(p-p_{\mathrm{t}}\right), p$ is pressure, $p_{\mathrm{s}}$ is surface pressure, and $p_{\mathrm{t}}$ is pressure at the top of the model (usually fixed at 100,50 , or $10 \mathrm{hPa}$ ). Others are hybrid systems that blend $\sigma$ coordinates near the surface and pressure coordinates aloft, obtaining the benefits of both coordinate systems (simpler formulation of governing equations in pressure coordinates and better representation of near-surface flows along $\sigma$ surfaces).

\subsubsection{Cloud microphysical parameterizations}

Accurate forecasting of the size distributions and number concentrations of cloud and precipitation water particles is important for deposition, photochemistry and aerosol-cloudradiation interaction in CWF models. On the grid scale, cloud and precipitation processes are handled by cloud microphysical parameterizations. When grid-cell-sized regions of the model atmosphere become saturated, model clouds begin to form. Because these processes act on scales smaller than the grid-scale, cloud microphysical parameterizations handle the distributions and the conversions of condensed water substance between cloud water, rain water, cloud ice, snow, graupel, and hail. Schemes range in sophistication from (i) those that neglect ice processes to (ii) one-moment schemes (predicting only mixing ratios of each hydrometeor species) and to (iii) two-moment schemes (predicting number concentrations and mixing ratios). Because of the relative lack of knowledge about microphysical processes, highermoment schemes and more sophisticated parameterizations do not necessarily lead to better predictions of clouds and precipitation. Straka (2009) presents a recent review of cloud microphysical parameterizations and principles.

\subsubsection{Convective parameterization schemes}

The choice of convective parameterization scheme in numerical weather prediction models is important for two reasons. As Baldwin et al. (2002) lament: "All convective parameterizations contain arbitrary parameter settings and have characteristic behaviors that are sometimes inconsistent with reality." First, the morphology and evolution of the convective systems that form in the model may depend on the convective scheme. For example, Bukovsky et al. (2006) showed that curved convective lines often formed in an operational model with the Betts-Miller-Janjić scheme, but did not initiate in the right place and time, whereas convective systems formed with the Kain-Fritsch scheme did not form bowing segments as frequently, but did initiate in the right place and time.

Second, how the convective parameterization changes the model atmosphere may not resemble what happens in reality. For example, Baldwin et al. (2002) showed that the BettsMiller-Janjić scheme does not produce cold pools comparable to those observed in the wake of convective systems and may eliminate convective inhibition more quickly than in reality.

Models with horizontal grid spacings less than $5 \mathrm{~km}$ are often considered to be convection-permitting models, meaning that convective parameterizations can be omitted (at least partly for large-scale convection storms), allowing convective instabilities to be handled on the grid scale. In these models, the cloud microphysical parameterizations must do all the work of relieving instability. At least one study, however, has shown that improved handling of deep convection in 
models in convection-permitting models can be achieved by running a convective parameterization (Yu and Lee, 2010). Another limitation of convective parameterization schemes is that only heat and moisture are redistributed. Momentum is generally not, partly because methods to handle such redistribution have not been developed.

A common assumption is that convective parameterization schemes exist to parameterize convective precipitation on the sub-grid scale. In fact, convective parameterization schemes exist to relieve the model of gravitational or buoyant instability in the vertical. Any precipitation created by the adjustment of the atmosphere back to stability because of the convective parameterization scheme (called convective precipitation or subgrid-scale precipitation) is merely a byproduct of the readjustment. Models usually have two schemes for releasing moist gravitational instability, one for deep convection such as thunderstorms, and one for shallow convection such as the stratocumulus clouds that cap the planetary boundary layer in the subtropics. Currently, of the models considered in this article, two convective schemes are implemented in the ECMWF IFS (Sect. 3.2.1) and EnviroHIRLAM (Sect. 2.3.3).

There are two general classes of convective schemes. Because many convective parameterization schemes are developed from research on tropical convection, most of these schemes release the conditional instability almost as quickly as it is formed, maintaining convective neutrality. These are called statistical-equilibrium schemes, following the terminology in Emanuel (1994, Sects. 11.2 and 12.3) and Mapes (1997). Such schemes include the Kuo $(1965,1974)$, Arakawa-Schubert (1974), Betts-Miller (1986) and the BettsMiller-Janjić (Janjić, 1994), and Tiedke (1989) schemes.

Convection in the mid and high latitudes, however, often does not behave in this manner. Instability may build up over hours or days, kept from being released by a lowertropospheric stable layer or inversion called a cap or lid, measured by an energy barrier called the convective inhibition. Convection is released by some mechanism to lift unstable parcels past the layer of convective inhibition to release the instability. Such schemes are called activated or triggered schemes (Sects. 11.2 and 12.3 in Emanuel, 1994; Mapes, 1997). Such schemes include the Kain-Fritsch (Kain and Fritsch, 1990, 1993; Kain, 2004) scheme and its derivatives (e.g. Bechtold et al., 2001).

\subsubsection{Boundary layer parameterization schemes for NWP models}

Similar to convective parameterizations that redistribute heat and moisture when the atmosphere becomes unstable to moist processes, boundary-layer parameterizations serve a similar purpose for the near-surface layer of air. Some way is needed for models to distribute the heat, moisture, and momentum as the free atmosphere joins with the surface through the unresolved scales of turbulence present in the planetary boundary layer. The stability of the planetary boundary layer affects how this redistribution occurs, so some schemes work better for stably stratified situations (i.e. surface inversions), others work better for unstably stratified situations (i.e. convective boundary layers), and yet others work better for neutrally stratified situations (i.e. well-mixed boundary layers).

Despite their sophistication, the schemes used in NWP models have limitations, and these limitations can be critical for CWF applications. For example, CWF models may need greater vertical resolution within the boundary layer or improved surface sublayer parameterizations, especially for urban-scale air-pollution modelling where low-level emissions within the surface layer are occurring (from traffic, for example). Mixing height is a quantity needed for boundarylayer parameterizations, and it may be quite variable, especially over different land categories in urban areas or due to internal boundary layers, blending heights, etc. Furthermore, in some situations, the mixing height may even be poorly defined. Therefore, the boundary-layer parameterisations in NWP models used for CWF should be further improved, as discussed in the overview in Baklanov and Grisogono (2007) and Sokhi et al. (2010).

\subsubsection{Initial and lateral boundary conditions}

Initial conditions come from the observations collected worldwide and transmitted through the Global Telecommunications System. In addition, local sources of data such as Doppler radars, satellites, mesoscale observations, and buoys may also be included. The process by which observations are ingested into the model, interpolated onto the model grid, and balanced to produce a dynamically consistent set of initial conditions is called data assimilation. Some data assimilation systems are three-dimensional variational assimilation approaches (3DVAR), whereas others also include assimilating data in time (4DVAR). Some of the newest dataassimilation approaches involve ensemble Kalman filtering (EnKF), an approach that recognizes that the initial conditions are not (and can never be) perfectly known.

NWP models can cover a global domain or be limitedarea models, with a regional domain. Limited-area models have to accommodate lateral boundary conditions from some larger-scale (usually global) model (the so-called noninteractive approach discussed by Staniforth, 1997). Because output from global models is infrequent (usually only stored every 3 or $6 \mathrm{~h}$ ) and the limited-area models need input at their domain boundaries every model time step (usually tens of seconds), the data along the lateral boundaries is usually interpolated linearly in time. For situations where the flow may be changing or new features are moving into the limited-area domain through the boundaries, large errors may be introduced (Nutter et al., 2004; Elmore et al., 2006b).

To accommodate for boundary issues, noise, model spinup, and other specious features entering the domain, an adjustment region is required upstream of the relevant 
meteorological region. Staniforth (1997, p. 19) offers a simple practical test that limited-area models should meet: "the solution obtained over a limited area should well match that of an equivalent-resolution model integrated over a muchlarger domain." Alternatively, an interactive approach could be employed either through two-way nesting or variable resolution (Staniforth, 1997).

\subsection{NWP models used in European CWF modelling systems}

In this section, we discuss the different NWP models that commonly are used to provide meteorological data to the operational chemical weather models. The characteristics of each model are summarized in Table 2. Rather than in alphabetical order, the models are discussed in two groups: hydrostatic models then nonhydrostatic models.

\subsubsection{ECMWF IFS}

Widely regarded as the most accurate NWP model in the world, the ECMWF was developed from a European COST action to provide global medium-range weather forecasts (Woods, 2006). At the time of this writing (August 2011), the nonhydrostatic ECMWF model known as the Integrated Forecast System (IFS) is T1279, an equivalent grid spacing of about $16 \mathrm{~km}$, with 91 vertical hybrid-coordinate levels and a model top at $0.01 \mathrm{hPa}$. The model is run twice a day at 00:00 and 12:00 UTC. The nonhydrostatic dynamical core comes from the ALADIN model (Sect. 3.2.5). The convective scheme is a modified Tiedke (1989) scheme (Nordeng, 1994), testing for shallow, deep, and midlevel convection (e.g. above a frontal zone or inversion). The surface scheme is Tiled ECMWF Scheme for Surface Exchanges over Land (TESSEL) and has been revised to include surface hydrology and the choice of a global soil texture (Balsamo et al., 2009). Access to the model and its output is proprietary for 18 European member states and 10 states with co-operation agreements.

\subsubsection{GME}

GME (global model) from German Weather Service (DWD) is a hydrostatic model and is designed for the routine forecast of complex weather development on synoptic scales (Majewski et al., 2002). The vertical domain extends up to the stratosphere. For regional weather forecasts, the nonhydrostatic limited-area models COSMO-EU and COSMODe (Consortium for Small-Scale Modelling) are used with boundary conditions from GME (www.dwd.de). The global model GME is defined on an icosahedral grid with about 60$\mathrm{km}$ horizontal grid spacing. Within the postprocessing, all fields are transformed to a latitude-longitude geographical grid.

\subsubsection{Unified model}

The Unified Model (UM; Cullen, 1993) was developed by the UK Met Office and introduced in 1990. The Unified Model can serve as a hydrostatic global model or a nonhydrostatic limited-area model (Davies et al., 2005). The model vertical coordinate is height, and the convective parameterization is based on Gregory and Rowntree (1990). The boundary-layer scheme is described by Brown et al. (2008). The Unified Model is a proprietary model and has limited access to those outside the UK Met Office.

\subsubsection{HIRLAM}

The High-Resolution Limited Area Model (HIRLAM; Undén et al., 2002; http://hirlam.org) derives from a consortium of European meteorological institutes (Denmark, Estonia, Finland, Iceland, Ireland, Norway, The Netherlands, Spain, and Sweden, with France as a research partner). HIRLAM is run at a variety of grid spacings from 50 to $1.5 \mathrm{~km}$, depending on country, with the reference version being run at FMI. HIRLAM is a hydrostatic model, although a nonhydrostatic version also exists. Three convective parameterization schemes are available: STRACO (Soft TRAnsition COnvection), which is a modified Kuo scheme that aims to produce a smooth transition between convective clouds and large-scale condensation, Rasch and Kristjánsson (1998), and Kain and Fritsch (1990, 1993). HIRLAM is available to member states, but access can be granted for other users by a special agreement.

\subsubsection{ALADIN, ARPEGE, and AROME}

ALADIN (Aire Limitée Adaptation Dynamique INitialisation) is a limited-area version of the French global model ARPEGE (Action de Recherche Petite Echelle Grande Echelle, which was the basis for the ECMWF IFS), growing out of a French-led consortium. ALADIN uses a modified version of the Bougeault (1985) convective scheme and a terrain-following-pressure hybrid vertical coordinate. The ALADIN and HIRLAM consortia joined together starting in 2004 to form the HARMONIE consortium (Hirlam Aladin Research on Meso-scale Operational NWP in Euromed) in which a new model has been developed (AROME; Seity et al., 2010).

\subsubsection{Eta}

The Eta model was the operational limited-area hydrostatic model from June 1993 to June 2006 in the United States. The model uses a unique step-coordinate vertical coordinate called the eta (hence the name of the model), a modified version of the $\sigma$ coordinate (Mesinger et al., 1988; Janjić, 1990, 1994). The Eta model uses a version of the Betts-Miller convective scheme (Betts and Miller, 1986; Janjić, 1994; Baldwin et al., 2002). Research versions of the Eta included 
a sigma-coordinate version, a nonhydrostatic version, and a version with the Kain-Fritsch convective parameterization scheme (Baldwin et al., 2002; Kain et al., 2003). One problem with the Eta model is that it fails to reproduce strong surface winds associated with downslope windstorms, partly as a result of the way that the mountain waves are handled in the eta coordinate system (Gallus, 2000; Gallus and Klemp, 2000).

\subsubsection{MEMO}

MEMO (MEsoscale MOdel) is a nonhydrostatic mesoscale model for simulating wind flow. MEMO was developed by the Aristotle University of Thessaloniki and the University of Karlsruhe. MEMO has been used to study the wind fields around urban areas (e.g. Kunz and Moussiopoulos, 1995). The model uses a terrain-following coordinate and has two physical parameterizations of importance - radiative transfer (Moussiopoulos, 1987) and $K$-theory for the planetary boundary layer - but neglects moist processes by assuming the atmosphere is unsaturated. MEMO is coupled with the photochemical chemical transport model MARS (Model for the Atmospheric Dispersion of Reactive Species) to produce the European Zooming Model (EZM; Moussiopoulos, 1995). Because MEMO does not contain moist atmospheric processes, its applicability when clouds and precipitation are present is limited.

\subsubsection{MM5}

The fifth-generation Pennsylvania State University/National Center for Atmospheric Research Mesoscale Model (MM5) is a nonhydrostatic limited-area model that has been one of the most popular open-source mesoscale models in the world (Dudhia, 1993; Grell et al., 1994; http://www.mmm. ucar.edu/mm5). MM5 is a terrain-following $\sigma$-coordinate model with a large degree of flexibility in choosing domains, nestings, grid spacings, and model physics. For example, as of the writing of this article, users of the MM5 can choose from six convective parameterizations, seven resolvable-scale cloud microphysics parameterizations, six planetary boundary-layer parameterizations, seven surface parameterizations, and four atmospheric radiation schemes, although many of these schemes are outdated, overly simple, or inappropriate for some weather situations. As such, care is needed when configuring the model to ensure optimal performance.

\subsubsection{WRF}

The successor to the MM5 is the open-source Weather Research and Forecasting model (WRF; Skamarock and Klemp, 2008; Wang et al., 2009). The goal of WRF is to produce a common architecture for both research and operations to build upon (http://wrf-model.org). WRF has two nonhydrostatic dynamic cores, the ARW (Advanced Research WRF), developed primarily by the National Center for Atmospheric Research, and the NMM (Nonhydrostatic Mesoscale Model; Janjić et al., 2001; Janjić, 2003), developed primarily by the NOAA/National Centers for Environmental Prediction. The WRF-ARW uses a $\sigma$ vertical coordinate in either a limitedarea or global domain, whereas the WRF-NMM uses a hybrid $\sigma$-pressure vertical coordinate. One of the recent additions to WRF is the positive-definite advection scheme, which improves the conservation of advected quantities and prevents negative quantities such as mixing ratio and chemical concentrations (Skamarock, 2006; Skamarock and Weisman, 2009).

\subsubsection{RAMS}

The Regional Atmospheric Modeling System (RAMS; Pielke et al., 1992; Cotton et al., 2003) is a nonhydrostatic limited-area model developed by Colorado State University. Like MM5, RAMS is a terrain-following $\sigma$-coordinate model with the flexibility to choose the domains, grid spacings, and model physics packages.

\section{Chemical transport models: architectures and physical processes}

The chemical transport models (CTM) simulate processes controlling the distribution of chemical species in space and time. To calculate atmospheric concentrations of pollutant species, the modelling framework needs to incorporate several key processes: advection (Sect. 4.1), turbulent diffusion (Sect. 4.2), chemical transformation (Sect. 4.3), aerosol processes and microphysics (Sect. 4.4), deposition of pollutants (Sect. 4.5), temporal allocation and distribution of anthropogenic and natural emissions (the latter in Sect. 4.6), and horizontal and vertical grid spacing (Sect. 4.7). Although there are a large number of three-dimensional CWF models available, most of these are based on similar frameworks for linking these interactions, and they all solve the continuity equations for mass conservation of the pollutants in the atmosphere. Anthropogenic emission inventories have not been addressed in detail in this study, although some challenges in their development are discussed in Sect. 7.1.

Transport of pollutant species involves both advection and diffusion. Advection refers to the movement of pollutant species by the mean wind fields, whereas diffusion involves sub-grid-scale turbulent mixing of pollutants. By definition, advection transports the pollutants without a significant change in the concentration in the considered volume, whereas diffusion involves dilution and hence leads to lowering of pollutant concentrations. In an Eulerian frame of reference, the computational domain of a CWF model consists of a matrix of contiguous grid cells forming a finite three-dimensional volume (also called a box). As this box 
is a subset of the entire atmospheric globe, lateral boundary conditions define the advection into the modelling grid.

Horizontal advection is typically considered dominant, and no exchange at the top boundary of the domain is assumed. However, a realistic representation of stratospheric intrusions into the troposphere is possible only by adjusting the boundary conditions at the top. The model also has to include at least the lower stratosphere to allow for these usually small-scale features. Consequently, stratospheric intrusions are not properly addressed by the currently available operational models.

One of the key problems in atmospheric composition modelling is knowing the accuracy and reliability of the numerical schemes applied. A less appreciated, but also an important, issue is to ensure the compatibility between the schemes applied in different modules of the modelling system. Usually, the model construction employs operator splitting (e.g. Seinfield and Pandis, 2006), thus distinguishing the advection scheme, diffusion algorithm, chemical transformation module, dry, and wet deposition, data assimilation control module, and a set of supplementary modules including meteorological pre-processor. Of these, advection and diffusion are usually closely linked. The order of evaluating the terms can influence the results. Therefore, the half-step mirroring is used sometimes. In other words, all terms are evaluated twice during each model time step - first in direct and then in reverse order. This approach may also increase the order of approximation (Marchuk, 1986).

The main physical and chemical components of the selected 18 models have been summarized in Table 3 .

\subsection{Advection}

Existing advection schemes can be categorized by one of four approaches: finite-difference, flux, semi-Lagrangian, and spectral. The basic principles of these schemes were formulated several decades ago and, with certain modifications, are still applied.

The diversity of advection routines developed during the last $50 \mathrm{yr}$ and still under construction is explained by a long list of requirements to such schemes. The most important ones are positive definiteness to the scheme, minimal numerical viscosity, limited non-monotonicity, sufficiently high stability, absence of phase error, local and global mass conservation, and sufficiently high numerical efficiency. Unfortunately, meeting all requirements simultaneously is not possible. For example, more numerical viscosity smoothes the result, thus improving monotonicity.

The most important criteria when selecting a scheme seems to be the positive definiteness of the algorithm (i.e. a guarantee that mass will remain positive after the advection step) and monotonicity (i.e. minimizing highfrequency fluctuations of the field). These two criteria can be optimised to some extent at a cost of substantial numerical viscosity, which is a common problem for most of the Eule- rian advection schemes. Only the scheme of Galperin (1999, 2000) has exactly zero numerical viscosity, but at a somewhat increased non-monotonicity of instant concentration fields and additional memory requirements.

Other criteria, sometimes mentioned but rarely given the highest priority, are minimization of phase error (i.e. correct representation of the transport velocity), the scheme transportivity (i.e. shift of the centre of mass of a puff from the analytical solution), and additivity (i.e. correct treatment of superimposed puffs). Two other features are also important: the conservation of mass and costs of the computations. The mass-conservation problem is usually considered as the highest priority in the chemistry-transport models, so that schemes that significantly violate this requirement are excluded from consideration. Finally, the efficiencies of the advection schemes (both in terms of the computational time and memory) are potentially important, but rarely considered more important than positive definiteness or mass conservation.

Interestingly, these two features are not the most important aspects to be considered for NWP models. Although the conservation of mass is desirable in NWP models, this criterion is usually compromised, if an algorithm that is not exactly conservative has a better performance or monotonicity.

The finite-difference schemes involve direct discretization of the dispersion equation and involve various types of interpolation functions to evaluate derivatives of the concentration fields, as reviewed by Richtmyer (1962), Leith (1965), and Roach (1976). Examples of specific developments are van Leer $(1974,1977)$ and Russel and Lerner (1981). These once-popular schemes usually suffer from substantial numerical viscosity and limited stability, which sets very stringent limitations to the Courant number (the ratio of the maximum distance passed during the model time step to the model grid cell size). Consequently, interest has largely shifted towards flux and semi-Lagrangian schemes for practical applications.

Flux-type schemes are based on an evaluation of the admixture fluxes at the borders of the grid cells using some interpolation procedure for determining the concentrations and wind speed (e.g. Odman, 1998). Probably the most widely used flux-type scheme is Bott $(1989,1992,1993)$ and its derivatives (e.g. Syrakov, 1996; Syrakov and Galperin, 1997, 2000) involving different approximation functions (i.e. Bessel functions instead of Lagrangian polynomials). Although these schemes suffer from both stability and viscosity problems, they are superior to finite-difference approaches. Flux-type schemes also require special efforts to maintain mass conservation.

Semi-Lagrangian schemes (e.g. Crowley, 1967, 1968; Egan and Mahoney, 1972; Pedersen and Prahm, 1974; Smolarkiewicz, 1982; Prather, 1986; Williamson and Rasch, 1989; Staniforth and Côté, 1991, and references therein; Galperin, 1999, 2000; Sofiev, 2000b) represent the concentrations as a set of masses distributed according to certain rules inside the grid cell and advect like Lagrangian particles, 
although some properties are conserved. A sub-class of these schemes include purely Lagrangian schemes (Eliassen, 1978; Eerola, 1990; Stohl et al., 2005) where the masses are essentially independent and transported individually with the follow-up reprojection to the computational grid. These schemes have better numerical viscosity, which can be made exactly zero (Galperin, 2000), and stability (i.e. their working range of Courant number is probably the widest out of all types of the advection schemes). However, many semi-Lagrangian schemes exhibit large non-monotonicity and other distortions of the transported field, which require substantial efforts and computational resources to be kept under control.

By comparison, Lagrangian schemes are rarely used for chemistry composition computations, mainly due to the unbearable overhead of meeting the requirements posed by nonlinear chemical transformation mechanisms. Nevertheless, such schemes are theoretically possible. Such schemes naturally resolve the numerical diffusion problem, which plagues the performance of almost all Eulerian schemes. Although the diffusion problem is seemingly inevitable in Eulerian schemes, Lagrangian advection schemes do not suffer this problem because they lack explicit discretization of horizontal movement, which is performed in continuous space rather than in predefined grid meshes. As a result, numerical viscosity of purely Lagrangian schemes is always zero. Such a result comes at a price of $100 \%$ non-monotonicity of the concentration fields, which originates from limited spatial representativeness of a single Lagrangian particle.

Spectral models (e.g. Kreiss and Oliger, 1972; Prahm and Christensen, 1977; Zlatev and Berkowicz, 1988) use Fourier transformation to convert the differential equations into algebraic ones, which are then solved analytically. Such schemes are more commonly used in NWP models than chemical transport models.

One new line of development, often based on semiLagrangian schemes, is adaptive-grid advection algorithms (e.g. Staniforth and Cote, 1991 and references therein; Lagzi et al., 2004; Jablonowski, 2004 and references therein; Jablonowski et al., 2006). These schemes are geared at solving the problems with sharp gradients in the computed variables and with a wide range of spatial and temporal scales of input forcing. The advantage of more accurate computations in the sub-domains that require high resolution outweighs the extra errors introduced by repeated reprojection of the main fields, as well as the extra computational time needed for the grid transformation.

Within the 18 models considered in this review, only a few use the same type of advection scheme. There is, however, a general lack of detail regarding the descriptions of the advection mechanisms in the publications for each of the models, which suggests that the schemes are implemented with minor, if any, deviations from the original source. Examples of the schemes used by the selected models are: Bott (1989) (CAMx, Enviro-HIRLAM,
MATCH), Piecewise Parabolic Method (PPM) of Colela and Woodward (1984) (CAMx, CMAQ and CHIMERE), Walcek (2000) (RCG, LOTOS-EUROS), Yamartino (1993) and Wicker and Skamarock (2002) (CMAQ, WRF-Chem and FARM), Williamson and Rasch (1989) (semi-Lagrangian scheme of MOCAGE), Eerola (1990) (Lagrangian SILAM kernel), Galperin (1999, 2000) (Eulerian SILAM kernel), Janjić (1997) (SKIRON/Dust), Zlatev (1995) (THOR), and Cullen (1993) (NAME).

Some models have more than one advection algorithm. In particular, CAMx allows the user to choose between Bott and PPM, as well as an optional Plume-in-Grid formulation for representing the large point sources in the lower-resolution grid. Enviro-HIRLAM has options for semi-Lagrangian schemes, in particular the CISL (Kaas, 2008). SILAM has two dynamic kernels: Lagrangian and Eulerian; either can be selected for a particular run via a switch in the model control file.

\subsection{Horizontal and vertical turbulent diffusion}

Turbulent mixing representation is substantially different for meteorological and chemical transport parts of the operational chemical weather models. For meteorological modules, the role of turbulence is more important, as it is the turbulent friction that connects the model to the surface, ensures exchange of momentum in the vertical and, in the end, leads to formation of the planetary boundary layer. In the chemical transport models, the role of turbulence is limited to an additional term of the tracer transport, which is usually important only along the vertical axis.

The basics of the so-called turbulent closure for the atmospheric dynamics models was laid down by Boussinesq (1877), who introduced the term of eddy viscosity as a means of description of the momentum flux due to presence sub-grid-scale (unresolved) turbulent eddies and grid-scale (resolved) gradient of wind speed. The approach was further generalised to the transport of any scalar quantity by introducing the eddy diffusivity connecting the grid-scale scalar flux and its gradient. Smagorinski (1963) suggested a useful formula for eddy viscosity in numerical models, which is based on local derivatives of the wind speed and the model resolution. It is still used by many atmospheric dynamics models.

Some of the complexities of implementing diffusion are the limited applicability of the first-order Boussinesq closure in both strongly stable and convective stratifications, problems in adequate description of the turbulent length scale in the free troposphere (i.e. where the distance to the surface is no longer an adequate scale), and a "competition" with the numerical viscosity of the advection schemes. Strong stratification leads to the appearance of significant anisotropy of turbulence and correlation between the orthogonal directions. Some extreme cases, such as deep convection, can be 
taken out of the diffusion module and parameterised separately (Sect. 3.1.3).

The horizontal diffusion is based on the Smagorinsky approach (1963) within ALADIN-CAMx, SKIRON/Dust, FARM, CAMx-AMWFG and MM5-CAMx. MM5CHIMERE and MM5-CAMx use the Medium-Range Forecast Planetary Boundary Layer (MRF PBL) scheme. Horizontal diffusion in the CMAQ model is based on a grid-sizedependent algorithm that combines Smagorinsky's approach with a term to minimize numerical diffusion (Byun and Schere, 2006). MM5 uses several PBL schemes: bulk, highresolution Blackadar, Burk-Thompson, Eta, Gayno-Seaman and Pleim-Chang. SILAM involves two approaches, depending on the kernel. The solution with the Lagrangian kernel uses prescribed horizontal diffusion via random particle relocation at each model time step (Eerola, 1990). In contrast, the Eulerian one includes an embedded algorithm that reflects the main features of the $K$-closure model; the horizontal eddy diffusivity is dependent on the wind speed.

For the vertical diffusion, the $K$-diffusion scheme is widely used, but otherwise, there are not many similarities between different models. In ALADIN-CAMx and MOCAGE, the vertical diffusion is calculated according to the Louis (1979) approach, which uses the Richardson number and the mixing length. Two convective boundary-layer schemes are implemented in OPANA: Blackadar and the Asymmetric Convective Model (ACM, Pleim and Chang, 1992). OPANA also includes local diffusion, vertically continuous integration, smooth transition from stable to convective with a faster matrix solver, and an updated eddy diffusion scheme.

RCG's vertical turbulent mixing formulation uses $K$ diffusion in combination with mixing height, which is treated as one layer above a 50-m surface layer. Its stable and convective boundary-layer diffusion coefficients are based on PBL scaling regimes. Therefore, vertical mixing is dominated by the time-dependent evolution of the mixed layer.

FARM also uses $K$-diffusion; eddy viscosities can be produced by the meteorological driver or by the preprocessor SURFPRO (SURrface atmosphere interFace PROcessor), which can choose among different parameterisations, based on PBL scaling. In MM5-CHIMERE, the vertical turbulent mixing takes place only in the boundary layer. The formulation uses $K$-diffusion, without the counter-gradient term. The vertical diffusion is mainly modelled with the ACM2 (Pleim, 2007a, b) in MM5-CMAQ; WRF-Chem uses the PBL parameterization by the Yonsei University (YSU).

The Eulerian kernel in SILAM is modelled according to the $K$-closure, with the approach of Genikhovich et al. (2004) used for the evaluation of $K_{z}$. The Lagrangian kernel within SILAM assumes a well-mixed PBL and fixed random-walk parameters in the free troposphere. Exchange between the PBL and the troposphere in the Lagrangian version takes place due to variation of the PBL height. In $\mathrm{MATCH}$, the turbulence is parameterized using three primary parameters: the surface friction velocity, the surface sensible heat flux and the boundary-layer height.

The main limitation of the Lagrangian system of SILAM is the assumption of a well-mixed PBL. For the Eulerian SILAM variant, the $K$-closure is used for diffusion in the vertical direction and also for horizontal diffusion. The eddy diffusivity of the vertical profile is evaluated at every time step by Sofiev et al. (2010). The limitations on the large scale originate partly from the simplified free-troposphere diffusion. The Lagrangian kernel assumes fixed mixing coefficient, whereas the Eulerian one assumes $10 \%$ of the PBL maximum $K_{z}$ value. In LOTOS-EUROS, the mixing layer is treated as one layer, and the ground level output is generated by assuming a vertical profile near the ground based on the deposition velocities.

\subsection{Chemistry}

Presently the main air-pollution issues in Europe are the human health impacts of exposure to particulate matter and ozone, and to a lesser extent nitrogen dioxide, sulphur dioxide, carbon monoxide, lead and benzene (EEA, 2007). Ozone is formed in the atmosphere in photochemical reaction cycles, which brings the ozone precursors (i.e. $\mathrm{NO}_{\mathrm{x}}$, VOCs) and their gas-phase atmospheric chemistry to the focus of CWF. All state-of-the-art chemical modules in most of the modelling systems in this review include these reaction cycles.

The choice of a chemical scheme for a CWF model is always a compromise between its complexity, the requirements and restrictions of the modelling system, how it is applied, and the available computational resources. Basic gas-phase inorganic chemistry is usually included in all models, and the schemes are often quite similar because inorganic atmospheric chemistry is well established.

A photochemical oxidation mechanism of VOCs is necessary in any CWF model aiming to predict the ozone concentrations - here the models may differ considerably, with different levels of detail and different parameterisations. In addition to the anthropogenic VOCs, the oxidation of biogenic VOCs should be included, especially if the model domain covers regions with dense forests or agricultural lands. If the modelling system is to be used for acid deposition or acidification/eutrophication studies, representation of aqueousphase sulphur chemistry is required, and, to predict the concentrations of atmospheric particulate matter, a representation of inorganic gas-particle partitioning is needed. Several approaches have been developed, which typically involve the simplification of more comprehensive chemical schemes to include only the key chemical constituents and processes. In the following, concise descriptions of some viable approaches are given.

The most commonly used chemical sub-model types among the chemical weather prediction models discussed in this review are (in alphabetical order): CBM-IV, RADM and 
Table 4. Selected main characteristics of the chemical submodels that are included in the CWF models. NC $=$ not considered.

\begin{tabular}{|c|c|c|c|c|c|}
\hline $\begin{array}{l}\text { Chemical } \\
\text { sub-model }\end{array}$ & Dispersion models & Chemical species & Photolysis rates & Aqueous-phase & References \\
\hline Acid-Basic & SILAM & $\begin{array}{l}29 \text { species } \\
(18 \text { advected })\end{array}$ & 12 reactions & $\begin{array}{l}\text { Oxidation of } \mathrm{SO}_{2} \text { to } \\
\text { sulphates, } \\
\text { parallel to gas-phase } \\
\text { reaction }\end{array}$ & $\begin{array}{l}\text { Galperin and Sofiev (1998); } \\
\text { Sofiev (2000) }\end{array}$ \\
\hline $\begin{array}{l}\text { CBM-IV (CB- } \\
\text { IV) }\end{array}$ & $\begin{array}{l}\text { CAMx } \\
\text { CMAQ } \\
\text { LOTOS-EUROS } \\
\text { OPANA } \\
\text { RCG }\end{array}$ & $\begin{array}{l}33 \text { compounds } \\
81 \text { reactions }\end{array}$ & $\begin{array}{l}12 \text { reactions. For most of the species } \\
\text { the clear sky photolysis rates are } \\
\text { calculated according to the Roeths } \\
\text { flux algorithm }\end{array}$ & $\mathrm{NC}$ & Gery et al. (1989) \\
\hline ISORROPIA & $\begin{array}{l}\text { CAMx } \\
\text { CHIMERE } \\
\text { CMAQ } \\
\text { LOTOS-EUROS } \\
\text { RCG }\end{array}$ & $\begin{array}{l}22 \text { species } \\
17 \text { equilibrium reactions }\end{array}$ & $\mathrm{NC}$ & $\mathrm{NC}$ & $\begin{array}{l}\text { Nenes et al. (1998a,b) } \\
\text { New version: } \\
\text { http://nenes.eas.gatech.edu/ } \\
\text { ISORROPIA/ } \\
\text { Fountoukis and Nenes (2007) }\end{array}$ \\
\hline MELCHIOR & CHIMERE & $\begin{array}{l}\text { Extended mechanism: } \\
80 \text { compounds } \\
320 \text { reactions } \\
\text { ( } 26 \text { inorganic) } \\
\text { Reduced mechanism: } \\
44 \text { compounds } \\
133 \text { reactions } \\
(26 \text { inorganic) }\end{array}$ & $\begin{array}{l}22 \text { photolysis reactions } \\
\text { Photolysis rates calculated under clear } \\
\text { sky conditions as a function of height } \\
\text { and attenuated by cloudiness }\end{array}$ & $\begin{array}{l}\text { Aqueous oxidation } \\
\text { of } \mathrm{SO}_{2} \text { by } \mathrm{O}_{3} \text {, } \\
\mathrm{H}_{2} \mathrm{O}_{2}, \mathrm{NO}_{2} \text { and } \mathrm{O}_{2} \\
\text { catalyzed by metal } \\
\text { ions }\end{array}$ & $\begin{array}{l}\text { http://www.lmd.polytechnique.fr/ } \\
\text { chimere } \\
\text { Schmidt et al. (2001) }\end{array}$ \\
\hline NWP-Chem & Enviro-HIRLAM & $\begin{array}{l}17(28) \text { advected species } \\
27(32) \text { gas-phase } \\
\text { reactions }\end{array}$ & 4 photolysis reactions & $\begin{array}{l}\text { Simplified liquid- } \\
\text { phase equilibrium } \\
\text { mechanism NWP- } \\
\text { Chem-Liquid with } \\
13 \text { reactions }\end{array}$ & $\begin{array}{l}\text { Korsholm et al. (2008) } \\
\text { Korsholm et al. (2009) }\end{array}$ \\
\hline $\mathrm{RACM}$ & $\begin{array}{l}\text { Enviro-HIRLAM } \\
\text { EURAD } \\
\text { MOCAGE }\end{array}$ & $\begin{array}{l}77 \text { compounds } \\
214 \text { reactions }\end{array}$ & $\begin{array}{l}23 \text { photolysis reactions, } \\
\text { procedure the same as in RADM2 }\end{array}$ & $\mathrm{NC}$ & Stockwell et al. (1997) \\
\hline $\begin{array}{l}\text { RADM2 } \\
\text { (RADM) }\end{array}$ & $\begin{array}{l}\text { CAMx } \\
\text { CHEM } \\
\text { CMAQ } \\
\text { Enviro-HIRLAM } \\
\text { EURAD } \\
\text { OPANA } \\
\text { WRF-Chem }\end{array}$ & $\begin{array}{l}63 \text { compounds } \\
156 \text { reactions } \\
\text { (38 inorganic) }\end{array}$ & $\begin{array}{l}21 \text { photolysis reactions } \\
\text { The photolysis module uses a radiative } \\
\text { transfer model. This module calculates } \\
\text { photolysis frequencies that considers } \\
\text { changes in the radiation with height } \\
\text { and changes in air composition such } \\
\text { as } \mathrm{O}_{3} ; \text { aerosols and water vapor }\end{array}$ & & Stockwell et al. (1990) \\
\hline SAPRC-99 & $\begin{array}{l}\text { Aladin-CAMx } \\
\text { CMAQ } \\
\text { FARM } \\
\text { OPANA }\end{array}$ & $\begin{array}{l}80 \text { compounds } \\
214 \text { reactions } \\
\text { (48 inorganic) } \\
16 \text { radicals }\end{array}$ & $\begin{array}{l}24 \text { photolysis reactions } \\
\text { Rate constants must be calculated } \\
\text { from their corresponding absorption } \\
\text { cross sections and quantum yields } \\
\text { given the spectrum and intensity of } \\
\text { the sunlight or other light source in } \\
\text { the simulation }\end{array}$ & $\mathrm{NC}$ & $\begin{array}{l}\text { SAPRC-99: } \\
\text { http://www.engr.ucr.edu/ carter/ } \\
\text { SAPRC99.htm } \\
\text { SAPRC-07: } \\
\text { http://www.engr.ucr.edu/ carter/ } \\
\text { SAPRC }\end{array}$ \\
\hline UNI-OZONE & $\begin{array}{l}\text { EMEP } \\
\text { MATCH(EMEP- } \\
\text { MSC-W) }\end{array}$ & $\begin{array}{l}71 \text { compounds } \\
123 \text { reactions } \\
\text { ( } 22 \text { inorganic) } \\
24 \text { radicals } \\
\text { (Ozone concentrations } \\
\text { from two-dimensional } \\
\text { global model } \\
\text { scaled by observed total } \\
\text { ozone colums) }\end{array}$ & $\begin{array}{l}22 \text { photolysis reactions } \\
J \text {-values calculated over clear sky } \\
\text { conditions and for two predefined } \\
\text { clouds }\end{array}$ & $\begin{array}{l}\text { Aqueous oxidation } \\
\text { of } \mathrm{SO}_{2} \text { by } \mathrm{O}_{3}, \mathrm{H}_{2} \mathrm{O}_{2} \\
\text { and } \mathrm{O}_{2} \text { catalyzed } \\
\text { by metal ions }\end{array}$ & $\begin{array}{l}\text { http://www.emep.int/OpenSource/ } \\
\text { index.html } \\
\text { Simpson et al. (2003) }\end{array}$ \\
\hline
\end{tabular}

RACM, SAPRC-99, and UNI-OZONE. In addition, three other chemical schemes, each implemented in only one of the discussed CWF systems, are considered: MELCHIOR, NWP-Chem, and SILAM acid basic. Some characteristics of these chemical sub-models are compared in Table 4.

Carter's (1996) one-product isoprene oxidation scheme is adopted for biogenic compounds in several models, and the ISORROPIA thermodynamic equilibrium scheme (http: //nenes.eas.gatech.edu/ISORROPIA/, Nenes et al., 1998a, b) is used to determine the physical state and composition of inorganic aerosols in many modelling systems. ISORROPIA does not consider aerosol size distributions or aerosol microphysical processes, which is why it is included in this section with other purely chemical schemes, instead of in Sect. 4.4.

The implementation of the chemical mechanisms in the chemical weather prediction systems often involves adaptations, updates or other modifications of the original scheme. These changes are not always well documented or 
Table 5. Comparison studies of the various chemical sub-models.

\begin{tabular}{|c|c|c|c|c|c|c|c|}
\hline References & $\begin{array}{l}\text { CBM-IV } \\
\text { (CB-IV) }\end{array}$ & ISORROPIA & MELCHIOR & $\begin{array}{l}\text { RADM2 } \\
\text { (RADM) }\end{array}$ & $\begin{array}{l}\text { SAPRC- } \\
\quad 99\end{array}$ & $\begin{array}{c}\text { UNI- } \\
\text { OZONE } \\
\text { (EMEP) }\end{array}$ & $\begin{array}{l}\text { Other not discussed } \\
\text { chemical submodules }\end{array}$ \\
\hline Anderson-Sköld and Simpson (1999) & & & & & & $\mathrm{X}$ & $\mathrm{X}$ \\
\hline Ansari and Pandis (1999a, b) & & $\mathrm{X}$ & & & & & $\mathrm{X}$ \\
\hline Cuvelier et al. (2007) & $\mathrm{X}$ & $\mathrm{X}$ & $\mathrm{X}$ & & $\mathrm{X}$ & $\mathrm{X}$ & $\mathrm{X}$ \\
\hline Dodge (2000) & $\mathrm{X}$ & & & $\mathrm{X}$ & $\mathrm{X}$ & & $\mathrm{X}$ \\
\hline Faraji et al. (2008) & $\mathrm{X}$ & & & & $\mathrm{X}$ & & \\
\hline Gross and Stockwell (2003) & & & & $\mathrm{x}$ & & $\mathrm{x}$ & $\mathrm{x}$ \\
\hline Jimenez et al. (2003) & $\mathrm{X}$ & & & $\mathrm{X}$ & $\mathrm{X}$ & $\mathrm{X}$ & $\mathrm{X}$ \\
\hline Kuhn et al. (1998) & $\mathrm{X}$ & & & $\mathrm{X}$ & & $\mathrm{X}$ & $\mathrm{X}$ \\
\hline Luecken et al. (2008) & $\mathrm{X}$ & & & & $\mathrm{X}$ & & $\mathrm{X}$ \\
\hline Sarwar et al. (2008) & $\mathrm{X}$ & & & & & & $\mathrm{X}$ \\
\hline Tilmes et al. (2002) & $\mathrm{X}$ & & & $\mathrm{X}$ & & $(\mathrm{X})$ & $\mathrm{X}$ \\
\hline van Loon et al. (2007) & $\mathrm{X}$ & $\mathrm{X}$ & $\mathrm{x}$ & & & $\mathrm{X}$ & $\mathrm{X}$ \\
\hline Vautard et al. (2007) & $\mathrm{X}$ & $\mathrm{X}$ & $\mathrm{X}$ & & $\mathrm{X}$ & $\mathrm{X}$ & $\mathrm{X}$ \\
\hline Yu et al. (2005) & & $\mathrm{X}$ & & & & & $\mathrm{X}$ \\
\hline
\end{tabular}

N.B. In some studies EMEP refers to older versions of the EMEP model chemistry.

transparent. Therefore, only the general features of the original chemical schemes are discussed below. In the following, the models using the different chemical modules are listed in brackets in the titles. More information about the details of the implementation of any chemical submodule in a particular CWF system can be found at the web sites of the prediction systems. A list of references on the comparisons of various chemical submodules is presented in Table 5.

\subsubsection{Acid basic (SILAM)}

The scheme is a further development of the DMAT model (dispersion model for atmospheric transport) algorithm (Pressman et al., 1991; Galperin and Sofiev, 1998; Sofiev, 2000) and it treats the production processes of secondary inorganic aerosols, such as sulphates, nitrates and ammonia. It includes 29 species, 12 photochemical, 27 inorganic and 12 methane and ethane reactions. Most of reactions take place in the gas phase and constitute the oxidation of $\mathrm{SO}_{2}, \mathrm{NO}_{\mathrm{x}}$, and $\mathrm{NH}_{3}$.

The ozone cycle is considered via the photostationary equilibrium shifted in the presence of organic species. This approach does not lead to accurate ozone estimates, but is sufficient for partitioning $\mathrm{NO}_{\mathrm{x}}$ into $\mathrm{NO}$ and $\mathrm{NO}_{2}$. Aqueous-phase and heterogeneous reactions are responsible for within-droplet $\mathrm{SO}_{2}$ oxidation, $\mathrm{N}_{2} \mathrm{O}_{5}$ hydrolysis and three-component equilibrium between ammonium, ammonium nitrate, and nitric acid, the description of which generally follows Finlayson-Pitts and Pitts (1998).

The previous version of the scheme has been evaluated within the scope of the EMEP programme (Sofiev et al., 1994), and a multi-annual evaluation was made by Sofiev (2000). The current version of the scheme is used in the MACC project with daily operational evaluation (http: //www.gmes-atmosphere.eu). A comparison with $\mathrm{NO}_{2}$ total column observed by Ozone Monitoring Instrument (OMI) onboard of Aura NASA (National Aeronautics and Space Administration) spacecraft has been performed by Huijnen et al. (2010).

\subsubsection{CBM-IV (CAMx, CMAQ, ENVIRO-HIRLAM, LOTOS-EUROS, OPANA, RCG, SILAM)}

The Carbon bond mechanism IV (CBM-IV, also called CBIV; Gery et al., 1989) is a lumped-structure condensed mechanism. The carbon bond approach is used to lump organic species. The code treats the reactions of four different types of species: inorganic species, explicit organic species, organic species represented by carbon surrogates and organic species that are represented by molecular surrogates. Inorganic chemistry is represented explicitly with no lumping. Organics represented explicitly are formaldehyde, ethene and isoprene. Carbon bond surrogates describe the chemistry of different types of carbon bonds commonly found as parts of lager molecules. CBM-IV is widely used in research and regulatory chemical weather models, such as Models-3/CMAQ (Byun and Ching, 1999). Recently, an updated version of the Carbon Bond mechanism (CBM05) has become available, and has been implemented in the most current versions of the CMAQ model (Yarwood et al., 2005; Sarwar et al., 2008; Luecken et al., 2008). Among other changes, this version of the mechanism contains 156 reactions involving 52 chemical species, updated rate constants, an extended inorganic reaction set for urban to remote tropospheric conditions, and $\mathrm{NO}_{\mathrm{x}}$ recycling reactions to represent the fate of $\mathrm{NO}_{\mathrm{x}}$ over multiple days. 


\subsubsection{ISORROPIA (CAMx, CHIMERE, CMAQ, ENVIRO-HIRLAM, LOTOS-EUROS, RCG, FARM)}

ISORROPIA ("equilibrium" in Greek) is a thermodynamic equilibrium aerosol module designed for the calculation of equilibrium concentrations of semi-volatile inorganic species (Nenes et al., 1998a, b; Fountoukis and Nenes, 2007). The aerosol system consists of sulphate, nitrate, ammonium, sodium, chloride and water, partitioned between gas, liquid and solid phases. Aerosol particles are assumed to be internally mixed (i.e. all particles of the same size have the same composition), and the model also determines the water content of the particles. In ISORROPIA, four distinct chemical species are possible in the gas phase, twelve in the liquid phase and nine in the solid phase. The number of species and equilibrium reactions solved in the calculation is determined by the relative abundance of each aerosol precursor $\left(\mathrm{NH}_{3}\right.$, $\mathrm{Na}, \mathrm{HNO}_{3}, \mathrm{HCl}, \mathrm{H}_{2} \mathrm{SO}_{4}$ ) and the ambient relative humidity and temperature.

ISORROPIA has been optimized for speed and robustness for application in urban, regional and global chemical weather models. The performance of ISORROPIA has been evaluated against several in-situ datasets (e.g. Nowak et al., 2006) and compared to other thermodynamic equilibrium schemes (e.g. Nenes et al., 1998b; Ansari and Pandis, 1999a, b; Yu et al., 2005). A new version of the ISORROPIA module that includes the treatment of the crustal species $(\mathrm{Ca}$, $\mathrm{K}, \mathrm{Mg}$ ) is called ISORROPIA II (not used at the moment in any of the discussed CWF models), and it is available online at http://nenes.eas.gatech.edu/ISORROPIA/.

\subsubsection{MELCHIOR (CHIMERE)}

The MELCHIOR (Modele Lagrangien de Chimie de l'Ozone a l'échelle Régionale; http://www.lmd.polytechnique.fr/ chimere/; Schmidt et al., 2001) chemical mechanism was originally developed from an earlier version of the EMEP chemistry model (Simpson, 1992; Vautard et al., 2001), with special attention to low $\mathrm{NO}_{\mathrm{x}}$ conditions and nighttime $\left(\mathrm{NO}_{3}\right)$ chemistry. The original extended version of the mechanism includes more than 300 chemical reactions of 80 gaseous species, whereas the reduced version (MELCHIOR2) treats 44 species and about 130 reactions. MELCHIOR2 has explicit oxidation schemes for methane, ethane, $n$-butane, ethene, propene and $o$-xylene. Biogenic compounds are represented by isoprene, $\alpha$ - and $\beta$-pinene, and lumped terpene, humulene and ocimene classes. Eight chemical operators (Carter, 1990; Aumont et al., 1996) are introduced in the reduced mechanism as surrogates for groups of reactive intermediates. In addition to the MELCHIOR2 gas-phase chemical mechanism, the CHIMERE modelling system also incorporates a sectional aerosol module with primary and secondary particles, multiphase sulphur and nitrogen chemistry, and the thermodynamic equilibrium scheme ISORROPIA (Nenes et al., 1998a, b).

The model has been applied e.g. to the simulation of airpollution episodes at regional and urban scales and ozonetrend analyses (Beekmann and Vautard, 2009, and references therein). The CHIMERE/MELCHIOR modelling system has also been used in operational forecasting of pollutant levels over Western Europe for several years, and it has been extensively compared to observations (http://www.prevair.org; Honoré et al., 2008).

\subsubsection{NWP-Chem (Enviro-HIRLAM)}

The NWP-Chem scheme is an economical scheme designed at DMI for operational forecasting (Korsholm et al., 2008). It consists of the NWP-Chem-Gas gas-phase chemistry scheme and thermodynamic equilibrium model NWP-Chem-Liquid. The scheme includes 27 main reactions and describes the basic chemistry of the photo-oxidation of VOC to peroxy radicals, the most important $\mathrm{NO}_{\mathrm{x}}$ reactions, the most important ozone formation reactions, sulphur (DMS = dimethyl sulfide is included) and isoprene chemistry (biogenic emissions of isoprene and other terpenes affects gas-phase chemistry such as ozone - as well as aerosol formation). In the present version of NWP-Chem-Gas, the ordinary differential equations are solved using the quasi-steady-state approximation (Hesstvedt et al., 1978).

\subsubsection{RADM2 (CAMX, CHEM, CMAQ, Enviro- HIRLAM, EURAD, OPANA, WRF-Chem) and RACM (Enviro-HIRLAM, EURAD, MOCAGE)}

The second-generation Regional Acid Deposition Model (RADM2) gas-phase chemical mechanism (Stockwell et al., 1990) was developed from the earlier RADM mechanism (Stockwell, 1986). The emissions were aggregated into model species based on similarities in chemical reactivity, organic functional groups and the reactivity of the organic compounds with $\mathrm{OH}$. The aggregation factors, rate parameters and product yields for the organic reactions were derived from the organic emissions aggregated into each model species (Middleton et al., 1990).

An evolution of RADM2-RADM, RACM (Regional Atmospheric Chemistry Mechanism), was proposed in (Stockwell et al., 1997). The reaction rate constants and product yields, as well as the cross sections and quantum yields for the photolysis were updated, and new condensed reaction mechanism was introduced for biogenic compounds. The mechanism was evaluated against data obtained from the University of California, Riverside, environmental chamber database (Carter et al., 1995). 


\subsubsection{SAPRC-99 (ALADIN-CAMx, CMAQ, FARM, OPANA)}

The chemical mechanism developed at the Statewide Air Pollution Research Center in Riverside, California (SAPRC99) is a detailed mechanism for the gas-phase atmospheric reactions of VOCs and oxides of nitrogen $\left(\mathrm{NO}_{\mathrm{x}}\right)$ in urban and regional atmospheres (http://www.engr.ucr.edu/ carter/ SAPRC99/). The scheme can be used in airshed models to determine absolute and relative ozone reactivities of many types of VOCs that can be emitted into the atmosphere, and for other control strategy and research applications. This mechanism represents a complete update of the Carter (1990) SAPRC-90 mechanism and incorporates recent reactivity data from a wide variety of VOCs. The mechanism has assignments for about 400 types of VOCs and can be used to estimate reactivities for about $550 \mathrm{VOC}$ categories.

A condensed version of SAPRC-99 was developed for use in regional models. A unique feature of this mechanism is a computational system to estimate and generate complete reaction schemes for most non-aromatic hydrocarbons and oxygenates in the presence of $\mathrm{NO}_{\mathrm{x}}$, from which condensed mechanisms for the model can be derived. The mechanism was evaluated against the results of approximately 1700 environmental chamber experiments carried out at the University of California, Riverside, including experiments to test ozone reactivity predictions for over 80 types of VOCs. The mechanism was used to update the various ozone reactivity scales developed by Carter (1994), including the widely used Maximum Incremental Reactivity (MIR) scale. However, the reactivity estimates for many VOC classes are uncertain, which must be taken into account when using these data for regulatory applications. For this reason, uncertainty classifications have been assigned to all VOCs, and upper limit MIRs for VOCs with uncertain mechanisms are presented.

A new version of the SAPRC chemical mechanism called SAPRC-07 (not used at the moment in any of the discussed CWF models) is available online at http://www.engr.ucr.edu/ $\sim$ carter/SAPRC, including references to detailed description about improvements and new compounds in the new version.

\subsubsection{UNI-OZONE (EMEP model, MATCH (EMEP-MSC-W))}

The chemical scheme of the Unified EMEP Model (UNIOZONE, http://www.emep.int/OpenSource/index.html; Simpson et al., 2003) contains full oxidant chemistry, gas and aqueous oxidation of $\mathrm{SO}_{2}$ to sulphate, ammonium chemistry, nighttime production of $\mathrm{HNO}_{3}$ and nitrate, coarse nitrate particle formation, as well as the advection of primary particles. Therefore, the scheme provides comprehensive chemistry for both photo-oxidant and acidification studies. The VOC scheme is lumped, with explicit oxidation mechanisms for methane, ethane, ethanol, $n$-butane, ethene, propene, $o$-xylene and isoprene. Since version 2.0, the module EQSAM (Metzger et al., 2002; Metzger, 2000) has been used in the Unified EMEP model to calculate the partitioning between gas and aerosol phase of $\mathrm{HNO}_{3}$ and $\mathrm{NO}_{3}^{-}$aerosol and $\mathrm{NH}_{3}$ and $\mathrm{NH}_{4}^{+}$aerosol (Tarrasón et al., 2004).

The EMEP model is revised by the Executive Body for the Convention on Long-range Transboundary Air Pollution (LRTAP). In the 1990s, the EMEP models also became the reference atmospheric chemical transport model for use in the Integrated Assessment Models supporting the development of air-quality polices under the EU Commission. The chemical schemes of the EMEP model have been extensively intercompared with other atmospheric chemistry models (e.g. Kuhn et al., 1998; Andersson-Sköld and Simpson, 1999; Gross and Stockwell, 2003; Jimenez et al., 2003; $\mathrm{Cu}-$ velier et al., 2007; Vautard et al., 2007).

\subsubsection{Synthesis and recommendations}

All chemical sub-models discussed in this section are implemented at least in one CWF model. Several comparisons of the chemical schemes and also the modelling systems have been carried out and are documented in the literature. However, no one study covers all the schemes or sub-models discussed here, and both the objectives and the implementation of the intercomparisons differ greatly. Thus, it is not possible to rank the performance of the sub-models in relation to each other, based on the existing literature.

Table 5 provides a comprehensive overview of the intercomparisons between different chemical schemes, including some that were not part of this study. A common conclusion in several of the documented intercomparisons appears to be that most models are able to reproduce or predict the ozone concentrations fairly well, whereas they do not perform as well in simulating other compounds, such as $\mathrm{NO}_{\mathrm{x}}$ and their reaction products (e.g. Kuhn et al., 1998; Gross and Stockwell, 2003; Jimenez et al., 2003; Vautard et al., 2007; Luecken et al., 2008). The skill of the models in simulating $\mathrm{PM}_{10}$ concentrations has also been poor or moderate (e.g. Vautard et al., 2007). A better understanding of the VOC oxidation mechanisms, especially because of their importance to secondary organic aerosol (SOA) formation (e.g. Kanakidou et al., 2005; Tunved et al., 2006) and the implementation of these processes in the CWF modelling systems also presents a formidable future challenge for chemical schemes.

The relative importance of the different components of chemical schemes (e.g. inorganic, organic, and aqueous phase chemistry) depends on the scientific aim and the applications of the CWF modelling system. Clearly, besides the structure of the chemical sub-module, the amount of available computer resources is another limiting factor for the accuracy of the concentration predictions. Available computer power may set an upper limit for the complexity of the chemical schemes that can be incorporated in the CWF modelling 
Table 6. The treatments for aerosol particles in the CWF models: size distribution, chemical composition and aerosol microphysics.

\begin{tabular}{|c|c|c|c|c|c|c|c|c|c|c|c|c|c|c|c|c|c|}
\hline \multirow[t]{2}{*}{ Model } & \multicolumn{3}{|c|}{ Size distribution representation } & \multicolumn{10}{|c|}{ Chemical components in particle phase } & \multicolumn{4}{|c|}{ Aerosol microphysics } \\
\hline & Bulk & Modal & Sectional & $\begin{array}{l}\text { Sea } \\
\text { salt }\end{array}$ & Dust & Elem. C & Org. C & Sulfate & Nitrate & Ammonium & Water & $\begin{array}{l}\text { Biog. } \\
\text { SOA }\end{array}$ & $\begin{array}{l}\text { Anthr. } \\
\text { SOA }\end{array}$ & Nucl. & Cond. & Coag. & Dep. \\
\hline $\begin{array}{l}\text { ALADIN } \\
\text {-CAMx }\end{array}$ & $\mathrm{X}$ & & $\mathrm{X}$ & $\mathrm{X}$ & $\mathrm{X}$ & $\mathrm{X}$ & $\mathrm{X}$ & $\mathrm{X}$ & $\mathrm{X}$ & $\mathrm{X}$ & $\mathrm{X}$ & $\mathrm{X}$ & $\mathrm{x}$ & $\mathrm{X}$ & $\mathrm{X}$ & $\mathrm{X}$ & $\mathrm{X}$ \\
\hline $\begin{array}{l}\text { CAMx } \\
\text {-AMWFG }\end{array}$ & $\mathrm{x}$ & & $\mathrm{x}$ & $\mathrm{X}$ & $\mathrm{x}$ & $\mathrm{X}$ & $\mathrm{x}$ & $\mathrm{X}$ & $\mathrm{x}$ & $\mathrm{x}$ & $\mathrm{x}$ & $\mathrm{x}$ & $\mathrm{x}$ & $\mathrm{X}$ & $\mathrm{x}$ & $\mathrm{X}$ & $\mathrm{X}$ \\
\hline $\begin{array}{l}\text { Enviro } \\
\text {-HIRLAM }\end{array}$ & & $\mathrm{X}$ & & $\mathrm{X}$ & $\mathrm{X}$ & & & $\mathrm{x}$ & & & & & & $\mathrm{X}$ & $\mathrm{x}$ & $\mathrm{X}$ & $\mathrm{X}$ \\
\hline FARM & & $\mathrm{X}$ & & $\mathrm{X}$ & $\mathrm{X}$ & $\mathrm{X}$ & $\mathrm{X}$ & $\mathrm{X}$ & $\mathrm{X}$ & $\mathrm{X}$ & $\mathrm{X}$ & $\mathrm{X}$ & $\mathrm{X}$ & $\mathrm{X}$ & $\mathrm{X}$ & $\mathrm{X}$ & $\mathrm{X}$ \\
\hline $\begin{array}{l}\text { LOTOS } \\
\text {-EUROS }\end{array}$ & $\mathrm{X}$ & & & $\mathrm{X}$ & $\mathrm{X}$ & $\mathrm{X}$ & $\mathrm{X}$ & $\mathrm{X}$ & $\mathrm{X}$ & $\mathrm{X}$ & $\mathrm{X}$ & $\mathrm{X}$ & & & & & $\mathrm{X}$ \\
\hline MATCH & $\mathrm{X}$ & & & $\mathrm{X}$ & $\mathrm{X}$ & $\mathrm{X}$ & $\mathrm{X}$ & $\mathrm{X}$ & $\mathrm{X}$ & $\mathrm{X}$ & $\mathrm{X}$ & & & & & & $\mathrm{X}$ \\
\hline $\begin{array}{l}\text { MM5 } \\
\text {-CAMx }\end{array}$ & $\mathrm{X}$ & & $\mathrm{X}$ & $\mathrm{X}$ & $\mathrm{X}$ & $\mathrm{X}$ & $\mathrm{X}$ & $\mathrm{X}$ & $\mathrm{X}$ & $\mathrm{X}$ & $\mathrm{X}$ & $\mathrm{X}$ & $\mathrm{x}$ & $\mathrm{X}$ & $\mathrm{X}$ & $\mathrm{X}$ & $\mathrm{X}$ \\
\hline $\begin{array}{l}\text { MM5 } \\
\text {-CHIMERE }\end{array}$ & & & $\mathrm{X}$ & $\mathrm{X}$ & $\mathrm{X}$ & $\mathrm{X}$ & $\mathrm{X}$ & $\mathrm{X}$ & $\mathrm{X}$ & $\mathrm{X}$ & $\mathrm{X}$ & $\mathrm{X}$ & $\mathrm{X}$ & $\mathrm{X}$ & $\mathrm{X}$ & $\mathrm{X}$ & $\mathrm{X}$ \\
\hline $\begin{array}{l}\text { MM5 } \\
\text {-CMAQ }\end{array}$ & & $\mathrm{X}$ & & $\mathrm{X}$ & $\mathrm{X}$ & $\mathrm{X}$ & $\mathrm{X}$ & $\mathrm{X}$ & $\mathrm{X}$ & $\mathrm{X}$ & $\mathrm{X}$ & $\mathrm{X}$ & $\mathrm{X}$ & $\mathrm{X}$ & $\mathrm{X}$ & $\mathrm{X}$ & $\mathrm{X}$ \\
\hline NAME & $\mathrm{X}$ & & & $\mathrm{X}$ & $\mathrm{X}$ & $\mathrm{X}$ & $\mathrm{X}$ & $\mathrm{X}$ & $\mathrm{X}$ & $\mathrm{X}$ & $\mathrm{X}$ & $\mathrm{X}$ & $\mathrm{X}$ & & & & $\mathrm{X}$ \\
\hline OPANA & & $\mathrm{X}$ & & $\mathrm{X}$ & $\mathrm{X}$ & $\mathrm{X}$ & $\mathrm{X}$ & $\mathrm{X}$ & $\mathrm{X}$ & $\mathrm{X}$ & $\mathrm{X}$ & $\mathrm{X}$ & $\mathrm{X}$ & $\mathrm{X}$ & $\mathrm{X}$ & $\mathrm{X}$ & $\mathrm{X}$ \\
\hline RCG & $\mathrm{X}$ & & & $\mathrm{X}$ & $\mathrm{X}$ & $\mathrm{X}$ & $\mathrm{X}$ & $\mathrm{X}$ & $\mathrm{X}$ & $\mathrm{X}$ & $\mathrm{X}$ & $\mathrm{X}$ & $\mathrm{X}$ & & & & $\mathrm{X}$ \\
\hline SILAM & $\mathrm{X}$ & & $\mathrm{X}$ & $\mathrm{X}$ & $\mathrm{X}$ & $\mathrm{X}$ & $\mathrm{X}$ & $\mathrm{X}$ & $\mathrm{X}$ & $\mathrm{X}$ & $\mathrm{X}$ & & & $\mathrm{X}$ & $\mathrm{X}$ & $\mathrm{X}$ & $\mathrm{X}$ \\
\hline $\begin{array}{l}\text { SKIRON/ } \\
\text { Dust }\end{array}$ & $\mathrm{X}$ & & & & $\mathrm{X}$ & & & & & & & & & & & & $X$ \\
\hline THOR & $\mathrm{X}$ & & & $\mathrm{X}$ & & & & & & & & & & & & & $\mathrm{X}$ \\
\hline $\begin{array}{l}\text { WRF } \\
\text {-Chem }\end{array}$ & & X(MADE) & X(MOSAIC) & $\mathrm{X}$ & $\mathrm{X}$ & $\mathrm{X}$ & $\mathrm{X}$ & $\mathrm{X}$ & $\mathrm{X}$ & $\mathrm{X}$ & $\mathrm{X}$ & $\mathrm{X}$ & $\mathrm{X}$ & $\mathrm{X}$ & $\mathrm{X}$ & $\mathrm{X}$ & $\mathrm{X}$ \\
\hline
\end{tabular}

systems. The aim for any CWF model is therefore to find the chemical sub-model with the best balance between scientific accuracy and computational efficiency.

\subsection{Aerosol processes and microphysics}

The demands for more accurate and detailed aerosol-size distribution, microphysics and chemistry description capability in atmospheric models have increased dramatically during recent years. On the one hand, this is because aerosols represent the largest uncertainty in global climate models when predicting radiative forcing (e.g. Solomon et al., 2007). On the other hand, and more relevantly to this review, particle size, composition and morphology are crucial to estimate lung penetration of aerosols and their health effects. This important motivation has resulted in a development and refinement of aerosol modules that are used in CWF models.

Atmospheric particulates have numerous sources, ranging from primary emissions (such as dust or pollen) to complicated aerosol formation processes involving gas-phase, liquid-phase and surface reactions (Seinfeld and Pandis, 1998). This presents several challenges to CWF models, especially as only a limited number of aerosol process submodels are generally available, and the state-of-the-art has not yet been established. As in the case of chemistry modules, there is no generally recognised single model that would be widely used by most of the CWF models.

The species covered by the various models include sea salt, dust, elemental carbon, organic carbon, sulfate, ni- trate, ammonium, biogenic SOA and anthropogenic SOA (Table 6). Chemical weather models also commonly include only a fraction of the particulate matter components, leading to an underprediction of PM mass values. For example, in most cases, natural pollen is missing, suspended dust may be missing or not accurately evaluated, sea salt and emissions from wild-land fires may be missing, and secondary organic compounds are in many cases poorly represented. Due to the extreme complexity of this issue, easy-to-use semi-empirical methods have also been proposed for evaluating the longrange transported fraction of $\mathrm{PM}_{2.5}$ (e.g. Kukkonen et al., 2008).

The different aerosol description options can be classified by (a) how the size distribution is represented and (b) what kind of aerosol microphysics is included in the modelling system. We classify the aerosol process methods according to the way they represent the size distribution. These can be grouped in three different categories: bulk schemes, modal schemes and sectional schemes. Some models have only one choice for the aerosol size distribution description, whereas others have several options.

One limitation to using detailed aerosol size distribution and composition descriptions arises from the lack of sizeand composition-segregated emission data. The emission inventories are typically based on total mass only, and using a modal or sectional scheme requires assumptions about the emission size and chemical composition distributions.

The state-of-art at present consists of a size-resolved sectional representation for the aerosol size distribution with 
equilibrium chemistry partitioning packages for both inorganics and organics. In addition, all major microphysical processes (nucleation, coagulation, condensation, wet and dry deposition) are included, as well as schemes for biogenic and anthropogenic SOA formation. Table 6 lists different characteristics of each of the various aerosol modules.

\subsubsection{Bulk schemes}

In bulk schemes, typically the total mass of suspended particles (TSP) or the mass in a certain size interval, or several non-interacting intervals, is modelled. The intervals are typically one or some combination of $\mathrm{PM}_{1}, \mathrm{PM}_{2.5}, \mathrm{PM}_{10}$ and TSP. Such an approach is computationally efficient, but naturally has severe limitations when size-dependent processes are important.

To estimate the health effects of the respirable particles better, the focus of both measurements and modelling has gradually moved from $\mathrm{PM}_{10}$ and TSP to $\mathrm{PM}_{2.5}$ and $\mathrm{PM}_{1}$. Since the lung penetration function and the health effects are dependent in a complicated manner on both the size and chemical composition, bulk schemes will likely be replaced gradually by the more resolved (but computationally more expensive) modal and sectional schemes (Zhang et al., 1999).

\subsubsection{Modal schemes}

In modal schemes (Whitby and McMurry, 1997), the aerosol size distribution is represented by a small number of modes (size categories), the properties of which are modelled as functions of time and location. This typically involves a predescribed assumption (e.g. log-normal) of the functional form of the modes. This approach is computationally more expensive than bulk methods, but less resource-consuming than sectional methods. For this reason, such schemes have been quite common in regional and global models. The performance of modal schemes is limited when new-particle formation is important. One additional challenge in modal schemes is due to pre-assumed size- and composition ranges of the modes, resulting in a need for redistributions of the particles between modes (e.g. Vignati et al., 2004).

\subsubsection{Sectional schemes}

In sectional schemes (Jacobson, 2005), the continuous size distribution is replaced by a large number of discrete bins (i.e. the size distribution is approximated by a histogram). The model has equations for the particle concentration (number or mass) and chemical composition that are solved for each bin. The sectional scheme is the most flexible and accurate one, but it is computationally the most expensive. With increasing computing power and memory, more CWF models are adopting sectional schemes as their choice for aerosol size distribution representation. A major challenge for CWFs using sectional aerosol representations is improving the quality and level of detail of the emission inventories to match the sophistication of the rest of the model, which is a concern regarding both size and chemical-composition distributions of the emissions.

\subsubsection{Aerosol microphysics}

The main microphysical processes affecting the aerosol size distribution are nucleation, condensation/evaporation, coagulation and deposition (Seinfeld and Pandis, 1998). Nucleation, or the formation of new particles through a gas-toparticle phase change, has been observed to occur throughout the atmosphere (e.g. Kulmala et al., 2004) and is an important particle source, especially in the nucleation and Aitken mode size ranges. Clearly, particle growth by condensation does not change the number concentration, but alters particle size and the mass concentration. Atmospheric coagulation is typically a process between small nucleation or Aitken mode particles and larger accumulation-mode or coarse-mode particles. Coagulation does not change the mass concentration, but decreases the number concentration of particles.

In bulk schemes, deposition is considered without an accurate way to describe its dependence upon particle size. Condensation/evaporation is usually treated by assuming equilibrium between the gas and particle phases, by using a chemical equilibrium thermodynamics scheme, such as ISORROPIA (Nenes et al., 1998a) or the Equilibrium Simplified Aerosol Module (EQSAM; Metzger et al., 2002). In sectional and modal schemes, all the above-mentioned microphysical processes can be adequately described, which is important especially when detailed information is desired on the particle number concentration distribution or the chemical composition distribution as a function of size. A sizeresolved model is also crucial because different microphysical processes depend on different aerosol properties which cannot be taken into account using a bulk scheme representation.

\subsection{Deposition}

Dry and wet deposition are processes that remove pollutants from the atmosphere. Not only are accurate schemes required for producing realistic concentrations of pollutants in the atmosphere, but deposited pollutants can affect soil and vegetation (e.g. acidification) and water bodies (e.g. eutrophication). The spatial distributions of wet and dry deposition are therefore commonly assessed in the various longterm environmental assessment programmes (e.g. EMEP). Uncertainties in modelling deposition, however, can also limit short-term forecasts of ground-level pollutant concentrations. For example, sensitivity tests by Wesely and Hicks (2000) showed that daytime ozone concentration could increase by about $20 \%$ when dry deposition is not acting.

References and brief characterizations of the dry and wet parameterization schemes used in the CWF models considered are summarized in Table 7. 
Table 7. References or brief characterizations of the treatments for dry and wet deposition in the CWF models.

\begin{tabular}{|c|c|c|c|c|}
\hline $\begin{array}{l}\text { Model } \\
\text { name }\end{array}$ & $\begin{array}{l}\text { Canopy } \\
\text { Resistance }\end{array}$ & $\begin{array}{l}\text { Aerosol settling } \\
\text { velocity and } \\
\text { deposition }\end{array}$ & In-cloud scavenging & Below-cloud scavenging \\
\hline CAMx & Wesely (1989) & Slinn and Slinn (1980) & $\begin{array}{l}\text { Different scavenging coefficients for gases and } \\
\text { aerosols following Seinfeld and Pandis (1998); } \\
\text { precipitating water, snow and ice considered }\end{array}$ & $\begin{array}{l}\text { Different scavenging coefficients for gases } \\
\text { and aerosols following Seinfeld and Pandis } \\
\text { (1998); precipitating water, snow and ice } \\
\text { considered }\end{array}$ \\
\hline $\begin{array}{l}\text { Enviro- } \\
\text { HIRLAM }\end{array}$ & $\begin{array}{l}\text { Wesely (1989) and } \\
\text { Binkowski (1999) }\end{array}$ & $\begin{array}{l}\text { Näslund and Thaning } \\
\text { (1991) }\end{array}$ & $\begin{array}{l}\text { Scavenging coefficients for gases following } \\
\text { Seinfeld and Pandis (1998); in-cloud scavenging } \\
\text { of aerosols dependent on the aerosol radius and } \\
\text { rain rate (Baklanov and Sørensen, 2001) }\end{array}$ & $\begin{array}{l}\text { Scavenging coefficients for gases following } \\
\text { Seinfeld and Pandis (1998); below-cloud } \\
\text { scavenging of aerosols dependent on the } \\
\text { aerosol radius and rain rate (Baklanov } \\
\text { and Sørensen, 2001) }\end{array}$ \\
\hline $\begin{array}{l}\text { EURAD- } \\
\text { RIU }\end{array}$ & Walcek et al. (1986) & $\begin{array}{l}\text { Size dependent } \\
\text { resistance model and } \\
\text { gravitational settling } \\
\text { depending on the } \\
\text { three aerosol } \\
\text { lognormal modes }\end{array}$ & $\begin{array}{l}\text { Different scavenging coefficients based on } \\
\text { Henrys law equilibria for each specie; aerosol } \\
\text { mode dependent scavenging (Binkowski, 1999) }\end{array}$ & $\begin{array}{l}\text { Different scavenging coefficients based on } \\
\text { Henrys law equilibria for each specie; aerosol } \\
\text { mode dependent scavenging (Binkowski, 1999) }\end{array}$ \\
\hline FARM & Wesely (1989) & $\begin{array}{l}\text { Seinfeld and Pandis } \\
\text { (1998); Binkowski and } \\
\text { Shankar (1995) }\end{array}$ & $\begin{array}{l}\text { Gas scavenging as in EMEP Unified model } \\
\text { (Simpson et al., 2003) }\end{array}$ & $\begin{array}{l}\text { Gas scavenging as in EMEP Unified model } \\
\text { (Simpson et al., 2003); aerosols following Scott } \\
\text { (1978) }\end{array}$ \\
\hline $\begin{array}{l}\text { LOTOS- } \\
\text { EUROS }\end{array}$ & Erisman et al. (1994) & $\begin{array}{l}\text { Erisman and Draaijers } \\
(1995)\end{array}$ & $\begin{array}{l}\text { Neglected at start of paper writing, now via } \\
\text { scavenging coefficients }\end{array}$ & $\begin{array}{l}\text { Gases: scavenging rates depending on Henry's } \\
\text { law constant and precipitation intensity (Simpson } \\
\text { et al., 2003); aerosols following Scott (1978) }\end{array}$ \\
\hline MATCH & $\begin{array}{l}\text { Erisman et al. (1994) } \\
\text { Bartnicki et al. (2001) }\end{array}$ & $\begin{array}{l}\text { Seinfeld and Pandis } \\
\text { (1998) }\end{array}$ & $\begin{array}{l}\text { Ozone, } \mathrm{H}_{2} \mathrm{O}_{2} \text { and } \mathrm{SO}_{2} \text { in-cloud scavenging is } \\
\text { calculated by assuming Henry's law equilibrium } \\
\text { in the clouds; for sulfate particles, in-cloud } \\
\text { scavenging is assumed to be } 100 \% \text { effective }\end{array}$ & $\begin{array}{l}\text { For sulfate particles Berge (1993); neglected } \\
\text { for ozone, } \mathrm{H}_{2} \mathrm{O}_{2} \text { and } \mathrm{SO}_{2} \text {; for other species } \\
\text { proportional to the precipitation intensity and } \\
\text { a species-specific scavenging coefficient }\end{array}$ \\
\hline CHIMERE & Erisman et al. (1994) & $\begin{array}{l}\text { Seinfeld and Pandis } \\
\text { (1998); Zhang } \\
\text { et al. (2001); Giorgi } \\
\text { (1986); Peters and } \\
\text { Eiden (1992) }\end{array}$ & $\begin{array}{l}\text { Dissolution of gases in cloud droplets (Seinfeld } \\
\text { and Pandis, 1998); aerosol nucleation (Tsyro, } \\
\text { 2002; Guelle et al., 1998) }\end{array}$ & $\begin{array}{l}\text { Dissolution of gases in precipitating drops } \\
\text { (Mircea and Stefan, 1998); scavenging by } \\
\text { raining drops (Loosmore and Cederwall, 2004) }\end{array}$ \\
\hline CMAQ & $\begin{array}{l}\text { RADM (Wesely, } \\
\text { 1989); M3Dry (Pleim } \\
\text { et al., 2001) }\end{array}$ & $\begin{array}{l}\text { Binkowski and } \\
\text { Shankar (1995) }\end{array}$ & $\begin{array}{l}\text { Wet deposition algorithms taken from RADM } \\
\text { (Chang et al., 1987); wet deposition of } \\
\text { chemical species depending on precipitation } \\
\text { rate and cloud water concentration (Roselle } \\
\text { and Binkowski, 1999); accumulation and } \\
\text { coarse mode aerosols completely absorbed by } \\
\text { cloud and rain water, Aitken mode aerosols } \\
\text { slowly absorbed into cloud and rain water }\end{array}$ & $\begin{array}{l}\text { Wet deposition algorithms taken from RADM } \\
\text { (Chang et al., 1987); wet deposition of } \\
\text { chemical species depending on precipitation } \\
\text { rate and cloud water concentration (Roselle } \\
\text { and Binkowski, 1999); accumulation and } \\
\text { coarse mode aerosols completely absorbed by } \\
\text { cloud and rain water, Aitken mode aerosols } \\
\text { slowly absorbed into cloud and rain water }\end{array}$ \\
\hline MOCAGE & $\begin{array}{l}\text { ISBA (Interface } \\
\text { Soil Biosphere } \\
\text { Atmosphere) scheme } \\
\text { (Michou et al., 2004) }\end{array}$ & Nho-Kim et al. (2004) & $\begin{array}{l}\text { Convective (Mari et al., 2000) and stratiform } \\
\text { precipitation (Giorgi and Chameides, 1986) }\end{array}$ & Giorgi and Chameides (1986) \\
\hline NAME & $\begin{array}{l}\text { Resistance analogy } \\
\text { incorporating canopy } \\
\text { resistance }\end{array}$ & $\begin{array}{l}\text { Resistance analogy; } \\
\text { particles removed by } \\
\text { sedimentation and } \\
\text { impaction with the } \\
\text { surface }\end{array}$ & $\begin{array}{l}\text { Rain and snow scavenging coefficients for large- } \\
\text { scale and convective precipitation (Maryon et al., } \\
\text { 1996) }\end{array}$ & $\begin{array}{l}\text { Rain and snow scavenging coefficients for large- } \\
\text { scale and convective precipitation (Maryon et al., } \\
\text { 1996) }\end{array}$ \\
\hline OPANA & Wesely (1989) & $\begin{array}{l}\text { Binkowski and } \\
\text { Shankar (1995) }\end{array}$ & $\begin{array}{l}\text { Wet deposition algorithms taken from RADM } \\
\text { (Chang et al., 1987); wet deposition of } \\
\text { chemical species depending on precipitation } \\
\text { rate and cloud water concentration (Roselle } \\
\text { and Binkowski, 1999); accumulation and coarse } \\
\text { mode aerosols completely absorbed by cloud } \\
\text { and rain water, Aitken mode aerosols slowly } \\
\text { absorbed into cloud and rain water }\end{array}$ & $\begin{array}{l}\text { Wet deposition algorithms taken from RADM } \\
\text { (Chang et al., 1987); wet deposition of } \\
\text { chemical species depending on precipitation } \\
\text { rate and cloud water concentration (Roselle } \\
\text { and Binkowski, 1999); accumulation and coarse } \\
\text { mode aerosols completely absorbed by cloud } \\
\text { and rain water, Aitken mode aerosols slowly } \\
\text { absorbed into cloud and rain water }\end{array}$ \\
\hline RCG & Erisman et al. (1994) & $\begin{array}{l}\text { From Stoke's law } \\
\text { (Pleim et al., 1984) }\end{array}$ & Neglected & $\begin{array}{l}\text { Species dependent scavenging coefficients for } \\
\text { gases from Henry constant and precipitation rate } \\
\text { (Seinfeld and Pandis, 1998); scavenging } \\
\text { coefficient identical coefficients for all particles }\end{array}$ \\
\hline SILAM & $\begin{array}{l}\text { Hicks et al. (1987); } \\
\text { Lindfors et al. (1991) }\end{array}$ & From Stoke's law & $\begin{array}{l}\text { Water and snow scavenging from large-scale } \\
\text { and convective precipitation (Smith and Clark, } \\
\text { 1989; Jylhä, 1991) }\end{array}$ & $\begin{array}{l}\text { Water and snow scavenging from large-scale } \\
\text { and convective precipitation (Smith and Clark, } \\
\text { 1989; Jylhä, 1991) }\end{array}$ \\
\hline
\end{tabular}


Table 7. Continued.

\begin{tabular}{|c|c|c|c|c|}
\hline $\begin{array}{l}\text { Model } \\
\text { name }\end{array}$ & $\begin{array}{l}\text { Canopy } \\
\text { Resistance }\end{array}$ & $\begin{array}{l}\text { Aerosol settling } \\
\text { velocity and } \\
\text { deposition }\end{array}$ & In-cloud scavenging & Below-cloud scavenging \\
\hline $\begin{array}{l}\text { SKIRON/ } \\
\text { Dust }\end{array}$ & - & $\begin{array}{l}\text { Slinn and Slinn (1980), } \\
\text { Kumar et al. (1996) }\end{array}$ & $\begin{array}{l}\text { Constant scavenging coefficient (Seinfeld and } \\
\text { Pandis, 1998) }\end{array}$ & $\begin{array}{l}\text { Constant scavenging coefficient (Seinfeld and } \\
\text { Pandis, 1998) }\end{array}$ \\
\hline THOR & $\begin{array}{l}\text { Wesely and Hicks } \\
\text { (1977) }\end{array}$ & $\begin{array}{l}\text { Gravitational settling } \\
\text { velocity given by } \\
\text { Stokes equation } \\
\text { (Hanna et al., 1991) }\end{array}$ & $\begin{array}{l}\text { Rain and snow scavenging coefficients for large- } \\
\text { scale and convective precipitation (Maryon et al., } \\
\text { 1996) }\end{array}$ & $\begin{array}{l}\text { Rain and snow scavenging coefficients for large- } \\
\text { scale and convective precipitation (Maryon et al., } \\
\text { 1996) }\end{array}$ \\
\hline $\begin{array}{l}\text { WRF/ } \\
\text { CHEM }\end{array}$ & $\begin{array}{l}\text { Wesely (1989) and } \\
\text { Erisman et al. (1994) }\end{array}$ & $\begin{array}{l}\text { Slinn and Slinn (1980), } \\
\text { Pleim et al. (1984) }\end{array}$ & $\begin{array}{l}\text { In-cloud wet removal of aerosol particles involves } \\
\text { removal of the cloud-borne aerosol particles } \\
\text { collected by rain, graupel and snow, using the } \\
\text { same first-order rate that cloud water is } \\
\text { converted to precipitation. For trace gases, } \\
\text { the same removal rate is applied to the fraction } \\
\text { of each gas that is dissolved in cloud water }\end{array}$ & $\begin{array}{l}\text { Below-cloud wet removal of aerosol particles by } \\
\text { impaction scavenging via convective brownian } \\
\text { diffusion and gravitational or inertial capture. } \\
\text { Irreversible uptake of } \mathrm{H}_{2} \mathrm{SO}_{4}, \mathrm{HNO}_{3}, \mathrm{HCl}, \mathrm{NH}_{3} \\
\text { and simultaneous reactive uptake of } \mathrm{SO}_{2}, \mathrm{H}_{2} \mathrm{O}_{2} \text {. } \\
\text { (Easter, 2004) }\end{array}$ \\
\hline
\end{tabular}

\subsubsection{Dry deposition}

Dry deposition is governed by the turbulent and molecular diffusion of pollutants in the atmosphere, and the gravitational settling. The turbulent and molecular diffusion depends upon the characteristics of the surface, vegetation, and the physical and chemical properties of the depositing species (e.g. the solubility and chemical reactivity for gases and the size distribution and chemical composition for particles). Gravitational settling needs to be accounted for for coarse particles. For example, Seinfeld and Pandis (1998) and Sportisse (2007) provide more comprehensive descriptions of deposition.

Therefore, a successful dry deposition scheme should be capable of reproducing both the boundary-layer turbulent fluxes and the interaction between the pollutant and the surface. The choice of parameterization is conditioned by the meteorological model, which provides the surfacelayer turbulence, by the surface and soil characteristics and by input data availability. For example, in regional models, bulk schemes for vegetation canopies (often called bigleaf schemes) are generally preferred to so-called multi-layer canopy models. The latter could be considered more suitable to describe deposition processes within tall canopies, but their use may be hindered by the lack of input data to describe the vertical structure of vegetation.

Dry deposition is commonly formulated in Eulerian models as a boundary condition at the ground surface for the vertical diffusion term of the pollutant transport equation. In this term, a species-dependent vertical concentration flux is the product of a deposition velocity $V_{\mathrm{d}}$ and the surface concentration. In state-of-the-art CWF models, the mathematical treatments of the dry deposition for gases and aerosols are usually based on the resistance analogy, where the inverse deposition velocity is the sum of three different resistances in series $\left(V_{\mathrm{d}}^{-1}=R_{\mathrm{a}}+R_{\mathrm{b}}+R_{\mathrm{c}}\right)$ : the aerodynamic resistance $R_{\mathrm{a}}$, due to turbulent diffusion, the quasi-laminar layer resis- tance $R_{\mathrm{b}}$, due to molecular diffusion, and the canopy resistance $R_{\mathrm{c}}$, due to the capture of pollutants by the surface (e.g. Wesely, 1989; Seinfeld and Pandis, 1998). Differences in modelling dry deposition among various CWF models arise from different ways to estimate the resistance terms, but also from the way the CWF models are interfaced with the meteorological models. The aerodynamic and quasi-laminar resistances are a function of the atmospheric stability and friction velocity $\left(u_{*}\right)$, which depend on the coupling strategy chosen for each modelling system. On-line coupled models and some off-line coupled models use parameters (e.g. surface momentum flux) provided by the meteorological model, whereas other off-line models prefer to re-estimate them through diagnostic parameterizations usually based on similarity theory. These different approaches can cause differences in the predicted deposition, even if we consider models implementing the exact same parameterization.

The dry deposition schemes in the CWF models in this study are largely similar. The aerodynamic resistance $R_{\mathrm{a}}$ and the quasi-laminar sub-layer resistance $R_{\mathrm{b}}$ are parameterized in terms of the friction velocity, surface roughness and molecular diffusivity of species (Wesely and Hicks, 1977; Walcek et al., 1986; Hicks et al., 1987; Chang et al., 1987, 1990; Wesely, 1989). This approach is adopted by all the models considered in this paper. The only different approach is implemented by CMAQ in its second dry deposition scheme (M3Dry), where $R_{\mathrm{a}}$ is computed coherently with MM5 land-surface model (Byun and Ching, 1999; Pleim and Xiu, 1995) from the surface heat flux and the difference in virtual potential temperature between the air and the ground.

Greater differences among the CWF models occur for the parameterization implemented for the surface resistance $R_{\mathrm{c}}$ (Table 7). Usually, the surface resistance is expressed as a set of parallel resistances associated with leaf stomata, leaf cuticles, other canopy structures (e.g. bark, stems), and surface soil and water. Over land, $R_{\mathrm{c}}$ can be expressed 
as the sum of foliar $\left(R_{\mathrm{cf}}\right)$ and ground $\left(R_{\mathrm{cg}}\right)$ resistances $\left(1 / R_{\mathrm{c}}=1 / R_{\mathrm{cf}}+1 / R_{\mathrm{cg}}\right)$, and foliar resistance is subdivided in stomatal $\left(R_{\mathrm{st}}\right)$ and non-stomatal or cuticle $\left(R_{\text {cut }}\right)$ resistances $\left(1 / R_{\mathrm{cf}}=1 / R_{\mathrm{st}}+1 / R_{\mathrm{cut}}\right)$. Many different approaches have been developed for the calculation of stomatal resistance, varying from a simple function of solar radiation and temperature (Wesely, 1989), a big-leaf approach taking into account air temperature and humidity, together with leaf-area index and canopy wetness (Hicks et al., 1987), to a multilayer leaf-resistance model (Baldocchi et al., 1987). For nonstomatal resistance, a constant value is often chosen, depending on season and land type (e.g. Wesely, 1989 and Zhang et al., 2002). Other models use meteorological variables such as $u_{*}$ and canopy height as scaling parameters to characterize in-canopy aerodynamic resistance, and relative humidity to describe the cuticle resistance (Erisman et al., 1994). A more detailed parameterization for cuticles taking into account meteorological and season-dependent vegetation parameters has been proposed by Zhang et al. (2003). The influence of chemical-physical properties of depositing gaseous species has been analyzed by Zhang et al. (2002), who scaled cuticle and ground resistances of the species considered by their CTM to $\mathrm{O}_{3}$ and $\mathrm{SO}_{2}$ resistances on the basis of published dry deposition measurements and of the evaluation of their aqueous solubility and oxidizing capacity. The parameterizations implemented within each model for canopy resistance are summarized in Table 7.

The dry deposition velocity of particles $V_{\mathrm{d}}$ can be written as $V_{\mathrm{d}}=V_{\mathrm{s}}+\left(R_{\mathrm{a}}+R_{\mathrm{b}}+R_{\mathrm{a}} R_{\mathrm{b}} V_{\mathrm{s}}\right)^{-1}$, where $V_{\mathrm{s}}$ is the settling velocity. This formula is derived assuming that particle settling operates in parallel with the three resistances already introduced for gases operating in series. This approach is implemented in almost all the CWF models (Table 7).

Although the differences in these mathematical treatments may seem small, they can nevertheless result in substantial differences to the model predictions. For example, Sportisse (2007) showed that the implementation of a different mass-conserving formula, expressed as $V_{\mathrm{d}}=V_{\mathrm{s}}\left(1-\exp \left(-V_{\mathrm{s}}\left(R_{\mathrm{a}}+R_{\mathrm{b}}\right)\right)^{-1}(\right.$ Venkatram and Pleim, 1999), can reduce coarse-particle deposition velocities in low-wind conditions by up to $20 \%$. Published comparisons of deposition velocities obtained by different models applied on the same areas showed uncertainties of $\pm 30 \%$ (Wesely and Hicks, 2000). Timin et al. (2007) performed a sensitivity analysis of CMAQ surface concentrations to the dry deposition scheme, showing that the simpler scheme available in CMAQ (based on Wesely, 1989) produces lower deposition velocities for all the species and increases in ozone 8-h average concentrations up to $10-20 \mathrm{ppb}$ with respect to the more up-to-date M3Dry scheme (Pleim et al., 2001). Dry deposition parameterization has been identified as one of the main causes of differences between their CMAQ and CAMx simulations.

In their summary of dry deposition, Wesely and Hicks (2000) found that resistance schemes are quite reliable in daytime conditions over flat terrain, but are less reliable for mountainous areas and during nighttime stable conditions. The reasons are that the parameterizations of aerodynamic resistance, usually based on surface-layer similarity theory, do not provide an accurate evaluation of turbulent mixing during stable stratification and in complex terrain.

Additional uncertainties reside in the subgrid variation of surface and land-use features, where horizontal advection effects are not considered in summing the contributions from different patches with different surface effects. For homogeneous atmospheric and surface conditions, improper definition of surface features, e.g. vegetation and soil moisture, can result in large differences between modeled and measured deposition. Zhang et al. (2003) showed that a detailed description of cuticles and soil resistances can improve the description of daily variation and maximum value of deposition velocity for wet canopies. In such conditions, stomatal uptake is not important, due to stomata blocking by waterdrops and to the presence of very weak solar radiation. Zhang et al. (2002) analyzed the variation of $V_{\mathrm{d}}$ values for the 31 species modeled by their CTM AURAMS (A Unified (multiple-pollutant) size- and chemical compositionresolved, episodic, Regional Air-quality Modelling System) considering their dependence on land-cover, season and daytime. They computed values varying within an order of magnitude for vegetated surfaces, ranging between 0.3 and $5 \mathrm{~cm} \mathrm{~s}^{-1}$ over deciduous broadleaf forest during summer daytime conditions, and higher values for species with very high solubility and oxidizing capacity.

The evaluation of dry deposition models is quite difficult due to the lack of direct measurements of deposition fluxes. As a consequence, very few evaluation studies including extensive comparison with observations are available in the literature. Petroff et al. (2008) recently compared the performances of selected analytical and differential dry deposition models for aerosols versus measurements over grass and forest. Analytical models rely on parameterizations of different complexity, as those previously mentioned for the different resistances. Differential models solve the differential transport equations for the different chemical species within the canopy layer, and require as input vertical profiles of parameters describing vegetation features, as the leaf-area density.

Differences in the deposition velocity of up to one order of magnitude have been obtained for fine particles (Petroff et al., 2008). Analytical models (Slinn, 1982; Zhang et al., 2001) displayed small variations in the deposition velocity when applied to grass and forest. In contrast, differential models (Davidson et al., 1982; Wiman and Agren, 1985) exhibited large differences in deposition velocity, but showed a strong dependence on parameters describing canopy geometry and aerodynamics, such as the leaf-area index, obstacle size, roughness length and displacement height - properties that can be difficult to determine for regional-model applications. 


\subsubsection{Wet deposition}

Wet deposition refers to scavenging of contaminants and their transport to the earth's surface by atmospheric hydrometeors and is usually subdivided into in-cloud scavenging (rainout) and below-cloud scavenging (washout). Although dry deposition is introduced in Eulerian numerical models as a lower boundary condition in flux form, wet deposition is described as a depletion term within the transport-diffusion equation for pollutant concentration and can be parameterized by $\mathrm{d} C / \mathrm{d} t=-\Lambda C$, where $C$ is the substance concentration and $\Lambda$ is the scavenging coefficient $\left(\mathrm{s}^{-1}\right)$. The scavenging coefficient is different from zero where precipitation occurs and in the presence of condensation (clouds or fog). The existing computational schemes for the scavenging coefficient range from simple functions of rain rate and cloudwater content, to complex models describing the system of physical, microphysical and chemical processes that characterize the interaction of gases and aerosols with cloud condensate and precipitation (e.g. Seinfeld and Pandis, 1998; Sportisse, 2007).

Simple parameterizations could potentially be sufficient for CWF models, especially for off-line coupled models, which have no access to the full meteorological model microphysics. For a reliable short-term estimate of near-ground air-pollutant concentrations, below-cloud scavenging is expected to dominate, at least in areas characterized by relevant local and regional emissions - in other words, where shortrange transport dominates over long-range sources (e.g. in continental and Mediterranean Europe). Neglecting in-cloud scavenging should underestimate the mass of deposited pollutant, but have only a weak effect on surface concentrations. Moreover, cloud-aerosol interactions can modify precipitation rate and its spatial distribution, and therefore indirectly influence near-surface scavenging. However, these phenomena can be described only by on-line coupled CWFs that can implement cloud-pollutant interactions and can take into account feedback effects of air pollution on meteorology. Wet deposition schemes vary much more than the dry deposition schemes for the operational CWF models in this article. For example, LOTOS-EUROS, MATCH, FARM and RCG use simple parameterizations of scavenging rates that are similar to those implemented in the EMEP Unified model (Simpson et al., 2003). These depend on Henry's law constant, rain rate and cloud-water mixing ratio for gases, and, on particle size, precipitation intensity and raindrop fall speed for aerosols. The possible release of scavenged gases and aerosols due to cloud- or rain-water evaporation is not taken into account by the latter parameterization. In contrast, NAME, SILAM and THOR use scavenging coefficients depending upon cloud type (convective vs. stratiform) and precipitation type (rain vs. snow). Other models, such as CHIMERE and EnviroHIRLAM, use more complex in-cloud and below-cloud scavenging parametrizations, whereas LOTOS-EUROS and RCG neglect in-cloud scavenging.
Even though rain has a polydisperse distribution of drop size and pollutant scavenging is dependent upon the fall velocity of the droplets, expressing the scavenging coefficients as a simple function of rain rate, assuming a monodisperse raindrop distribution, appears to be justified as long as a representative droplet diameter is chosen (Wang et al., 2010), although this choice depends upon the properties of the pollutant (Mircea and Stefan, 1998; Andronache, 2003; Sportisse, 2007). The main uncertainty of this simplified approach, implemented in almost all the CWF models considered here, is how the rainfall intensity is determined and how it varies over the specified time interval from which it is output from the NWP model. Although wet deposition seems weakly related to drop size, it is much more strongly dependent upon aerosol size. For example, Baklanov and Sørensen (2001) and Andronache (2003) showed that below-cloud scavenging was dependent upon aerosol size distribution, being important for very small $(<0.01 \mu \mathrm{m})$ and coarse $(>2 \mu \mathrm{m})$ particles. Therefore, boundary-layer aerosol-size distribution can be modified by precipitation, with quick removal of coarse particles. A proper description of aerosol size distribution within precipitation scavenging parameterizations is therefore required to estimate size-resolved particulate matter (PM) concentrations.

Comparing the results from wet deposition schemes implemented inside different models is difficult because of the complexity of the CWF models (e.g. spatial and temporal differences between forecasted cloud and precipitation, aerosol size and composition). Textor et al. (2007) compared results from 16 global models participating in the AeroCom project (Schulz et al., 2009) and found a large variability in the ability of models to handle wet deposition. They had difficulty in identifying the reasons for the main differences (e.g. the models did not provide the same indication about the type of rain; convective or stratiform precipitation) that was most efficient in removing aerosols from the atmosphere.

Wang et al. (2010) recently performed a systematic examination of the uncertainties on below-cloud size-resolved scavenging coefficients for particles, considering both analytical and empirical parameterizations. The largest uncertainties were associated with specification of the raindropparticle collection efficiency. The use of different formulas can result in differences in $\Lambda$ values up to two orders of magnitude for particles in the range of $0.01-3 \mu \mathrm{m}$. The use of various raindrop number distributions can cause differences between a factor three and five for all particle sizes, whereas the uncertainty caused by different raindrop settling velocity formulations is smaller than a factor of two. Comparison with field measurements showed that most size-resolved $\Lambda$ parameterizations underestimate experimental values up to two orders of magnitude for particles smaller than $3 \mu \mathrm{m}$. This difference is not justified by the combined effect of the previously mentioned uncertainties, but is attributed to additional known physical processes (e.g. turbulent transport and mixing) that can influence field data, but are not taken into 
account by parameterizations.

The predicted size-resolved particle concentrations using different $\Lambda$ parameterizations can differ by up to a factor of two for particles smaller than $0.01 \mu \mathrm{m}$ and by a factor of more than ten for particles larger than $3 \mu \mathrm{m}$ after $2-5 \mathrm{~mm}$ of rain. The predicted bulk mass concentrations can differ by a factor of two between theoretical and empirical parameterizations after $2-5 \mathrm{~mm}$ of moderate intensity rainfall.

The major source of uncertainty for estimates of wet deposition is the rain rate, because biases in the precipitation predictions greatly affect the wet deposition estimates. Furthermore, the accurate estimation of precipitation amounts and location is still one the most difficult and challenging tasks for meteorological models, especially for convective systems.

\subsection{Natural emissions}

Emissions can be broadly classified into natural and anthropogenic ones. Natural emissions is a wide term that includes different compounds (e.g. $\mathrm{NO}_{\mathrm{x}}, \mathrm{SO}_{2}, \mathrm{NH}_{3}, \mathrm{PM}$, NonMethane Volatile Organic Compounds (NMVOCs), $\mathrm{CH}_{4}$ and $\mathrm{CO})$ emitted from sources such as vegetation, soils, animals, wetlands, sea salt, primary biological aerosol particles, windblown dust, volcanoes, lightning, forest fires, etc. Anthropogenic emission inventories are significant components in our growing effort to understand the impact of human activity on air quality, particularly in the large urban areas (Markakis et al., 2010). They represent important input data to CTMs (Russell and Dennis, 2000).

In the last years, CTMs have improved greatly and consequently more detailed and accurate anthropogenic emission data are needed. Modern anthropogenic emission inventories should have high temporal and spatial resolutions, include a large variety of anthropogenic emission sources and account for many different chemical compounds emitted. Probably the most commonly used anthropogenic emission inventory for Europe is that of the EMEP (http://www.ceip.at/). Anthropogenic emission inventories that can be used for operational air-quality forecasting over Europe have also been developed within the framework of EU projects, such as GEMS (Visschedijk et al., 2007) and MACC (Visschedijk et al., 2010). Anthropogenic emission inventories are not addressed in detail in this study, but some challenges in their development are discussed in Sect. 7.1.

Air pollutants from natural sources play a prominent role in the physics and chemistry of the atmosphere and also contribute to the ambient air concentrations of air pollutants (e.g. $\mathrm{O}_{3}$, PM, SOA; Seinfeld and Pandis, 1998). For example, the organic compounds released in the atmosphere by vegetation, collectively referred to as Biogenic Non-Methane Volatile Organic Compounds (BNMVOCs), contribute to the formation of $\mathrm{O}_{3}$ (Curci et al., 2009; Wang et al., 2008; Bell and Ellis, 2004) and SOA (Kleindienst et al., 2007; Kanakidou et al., 2005). Curci et al. (2009) simulated an average
$5 \%$ increase in summer daily ozone maxima over Europe due to BNMVOCs emissions with peaks over Portugal and the Mediterranean Region (+15\%). BNMVOCs suppress the concentrations of the hydroxyl radical $(\mathrm{OH})$, enhance the production of peroxy $\left(\mathrm{HO}_{2}\right.$ and $\left.\mathrm{RO}_{2}\right)$ radicals and generate organic nitrates that can sequester $\mathrm{NO}_{\mathrm{x}}$ and allow long-range transport of reactive nitrogen (Fehsenfeld et al., 1992).

The salt flux from the sea surface is an important factor in the formation of cloud condensation nuclei (CCN) in the marine boundary layer. The salt flux also affects sea surfaceatmosphere exchange and heterogeneous chemistry, including the oxidation of $\mathrm{SO}_{2}$ and $\mathrm{NO}_{2}$ in the marine boundary layer (Foltescu et al., 2005; Pryor et al., 2001). In Europe, the contribution of mineral dust to $\mathrm{PM}_{10}$ concentrations varies from 10 to more than $30 \%$ depending on location and season (Putaud et al., 2004) and, in the United States, the fraction of mineral dust found in $\mathrm{PM}_{2.5}$ exceeds $10 \%$ in most areas and reaches $50 \%$ in dry areas (Malm et al., 2004; Park et al., 2010).

Volcanoes release considerable fluxes of gases and particles to the atmosphere, both during eruptions and by longterm noneruptive degassing. Water, carbon dioxide, and sulphur species represent by far the predominant component of volcanic gases. In Europe, significant volcanic emissions have been to date limited to Italy and Iceland. An extensive compilation of available, measured volcanic sulphur fluxes has been carried out for the Global Emissions Inventory Activity (GEIA) (Andres and Kasgnoc, 1998). The dataset contains volcanic $\mathrm{SO}_{2}$ emissions averaged over $25 \mathrm{yr}$ from the early 1970s to 1997. It includes average $\mathrm{SO}_{2}$ emissions from 49 continuously emitting volcanoes (four located in Europe: Etna, Stromboli, Vulcano and Kverkfjoll) and maximum $\mathrm{SO}_{2}$ emissions from 25 sporadically emitting volcanoes (none located in Europe).

The gaseous and particulate natural emissions accounted for in the CWF systems, as well as their calculation methodologies, are presented in Table 8.

\subsubsection{Natural gaseous emissions}

In most cases, the methodologies for the quantification of natural emissions require input data such as emission potentials based on measurements, meteorological data and landuse data (e.g. land cover, leaf-area index) derived from satellite observations. The estimated natural emissions are gridded data and have to be speciated according to chemical mechanisms used by the photochemical grid models. On the European scale, there are some studies focusing on estimating natural emissions and their impact on air quality (Simpson et al., 1999; NATAIR, 2007; Curci et al., 2009). However, the uncertainties in natural emissions remain large (larger than those of anthropogenic emissions).

Almost all of the 18 CWF models use biogenic emissions (e.g. isoprene, monoterpenes, other volatile organic compounds) in the forecast runs. Biogenic emissions are 


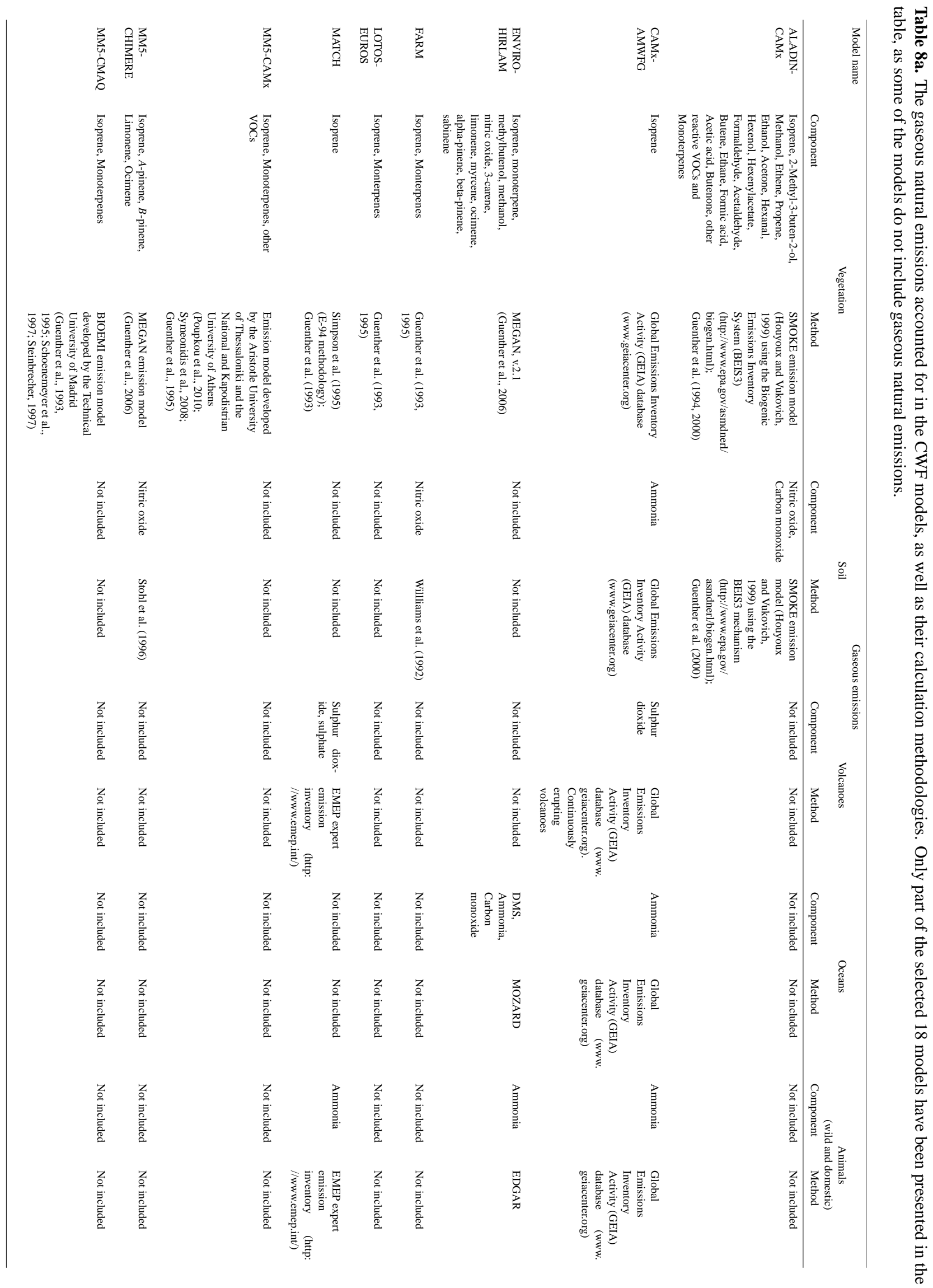




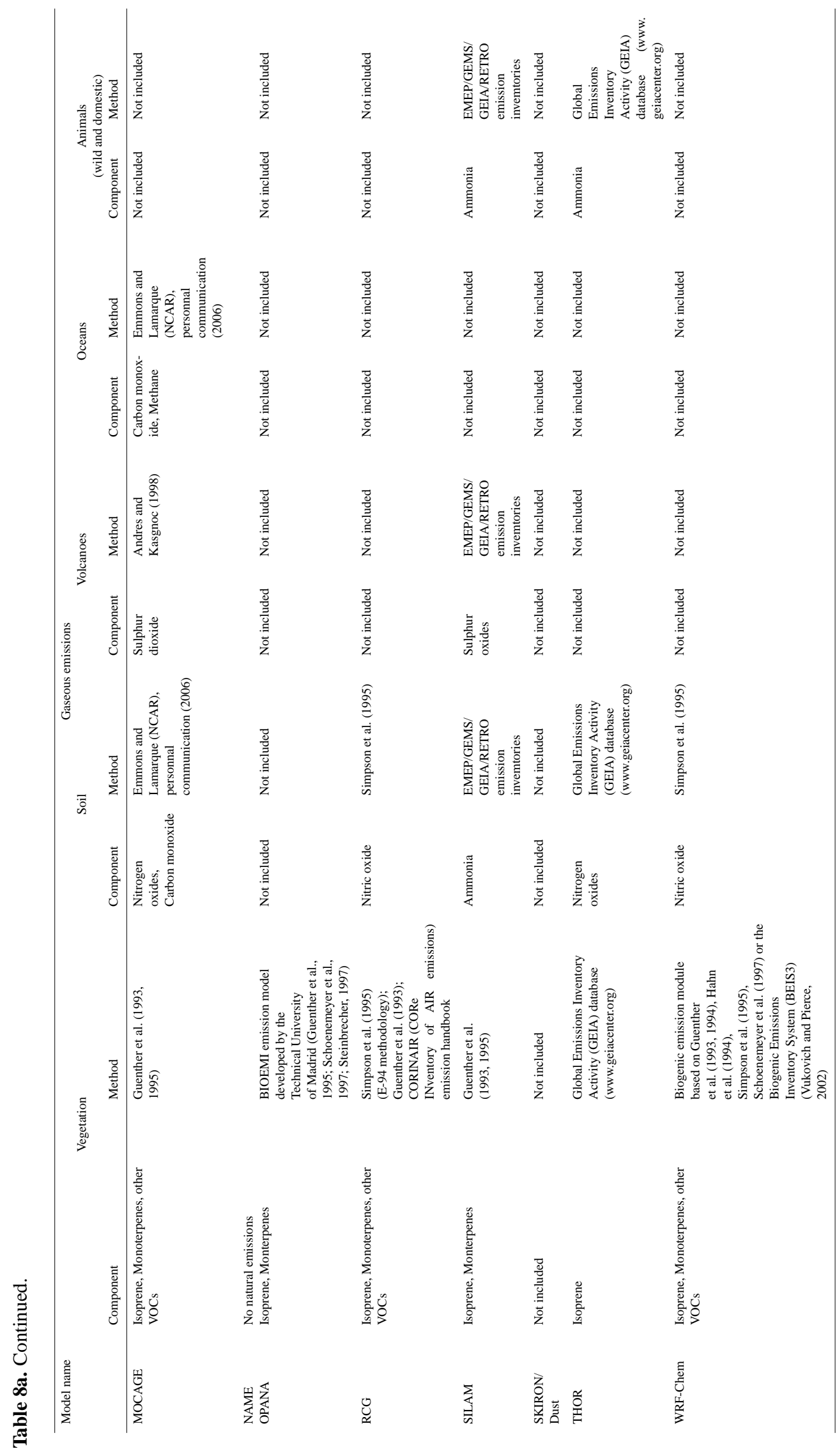


Table 8b. The particulate emissions accounted for in the CWF models, as well as their calculation methodologies.

\begin{tabular}{|c|c|c|c|}
\hline \multirow[t]{2}{*}{ Model name } & \multicolumn{3}{|c|}{ Particulate natural emissions } \\
\hline & $\begin{array}{l}\text { Dust } \\
\text { Methodology }\end{array}$ & $\begin{array}{l}\text { Sea salt } \\
\text { Methodology }\end{array}$ & $\begin{array}{l}\text { Pollen } \\
\text { Methodology }\end{array}$ \\
\hline ALADIN-CAMx & Not included & Not included & Not included \\
\hline CAMx-AMWFG & $\begin{array}{l}\text { Desert dust fluxes from } \\
\text { the SKIRON/Dust } \\
\text { modelling system }\end{array}$ & $\begin{array}{l}\text { Module developed by the } \\
\text { AM\&WF Group } \\
\text { at the National and } \\
\text { Kapodistrian } \\
\text { University of Athens } \\
\text { (de Leeuw et al., 2000; } \\
\text { Gong et al., 2002; Gong, 2003; } \\
\text { Zhang et al., 2005b; } \\
\text { Shankar et al., 2005; } \\
\text { Astitha and Kallos, 2009) }\end{array}$ & Not included \\
\hline $\begin{array}{l}\text { ENVIRO- } \\
\text { HIRLAM }\end{array}$ & Zakey et al. (2006) & Zakey et al. (2008) & $\begin{array}{l}\text { Birch pollen emission } \\
\text { module developed by the } \\
\text { Danish Meteorological } \\
\text { Institute and the Finish } \\
\text { Meteorological Institute } \\
\text { (Mahura et al., 2009) }\end{array}$ \\
\hline FARM & Vautard et al. (2005) & Zhang et al. (2005) & Not included \\
\hline LOTOS-EUROS & Not included & $\begin{array}{l}\text { Monahan et al. (1986); } \\
\text { TNO (2005) }\end{array}$ & Not included \\
\hline MATCH & $\begin{array}{l}\text { Only anthropogenic: } \\
\text { Andersson et al. (2009) }\end{array}$ & Foltescu et al. (2005) & Not included \\
\hline MM5-CAMx & Not included & Not included & Not included \\
\hline MM5-CHIMERE & $\begin{array}{l}\text { Vautard et al. (2005), } \\
\text { Marticorena and Bergametti (1995), } \\
\text { Menut et al. (2007) }\end{array}$ & Monahan et al. (1986) & Not included \\
\hline MM5-CMAQ & Not included & Not included & Not included \\
\hline MOCAGE & Martet et al. (2009) & Gong et al. (1997) & Not included \\
\hline NAME & No natural emissions & & \\
\hline OPANA & Not included & Not included & Not included \\
\hline $\mathrm{RCG}$ & $\begin{array}{l}\text { Loosmore and Hunt (2000), } \\
\text { Claiborn et al. (1998) }\end{array}$ & Gong et al. (1997) & Not included \\
\hline SILAM & Not included & $\begin{array}{l}\text { Module developed in the Finish } \\
\text { Meteorological Institute based } \\
\text { on Monahan et al. (1986) and } \\
\text { Martensson et al. (2003) }\end{array}$ & $\begin{array}{l}\text { Modules developed in the } \\
\text { Finish Meteorological } \\
\text { Institute for birch and } \\
\text { grass pollen (Sofiev et al., } \\
2006 \text { b) }\end{array}$ \\
\hline $\begin{array}{l}\text { SKIRON/ } \\
\text { Dust }\end{array}$ & $\begin{array}{l}\text { Dust module developed by the AM\&WF } \\
\text { Group at the National and Kapodistrian } \\
\text { University of Athens (Marticorena and } \\
\text { Bergametti, 1995; Nickovic et al., 2001; } \\
\text { Zender et al., 2003; Pérez et al., 2006) }\end{array}$ & Not included & Not included \\
\hline THOR & Not included & Not included & Not included \\
\hline WRF-Chem & Not included & Not included & Not included \\
\hline
\end{tabular}


mostly calculated from emission models (MEGAN - Model of Emissions of Gases and Aerosols from Nature), BEIS3, AUTH-NKUA - Aristotle University of ThessalonikiNational and Kapodistrian University of Athens model, BIOEMI - BIOgenic EMIssion model) and modules or, in a few cases, they are taken from existing databases. The algorithms that are usually applied are those introduced by Guenther et al. (1993, 1994, 1995), according to which isoprene emissions are temperature and light dependent whereas monoterpenes and other VOC emissions are temperature dependent. Additional processes relevant with the emissions of biogenic compounds are described by some of the emission models. For example, BEIS3 provides species-specific, seasonally-dependent biogenic emission factors and leafarea index for each land-use type, adjusting the isoprene emissions for the effects of the Photosynthetically Active Radiation penetrating through the leaf canopy. Another example is the AUTH-NKUA model, which accounts for the light dependency of monoterpenes emissions from some vegetation species.

MEGAN describes the variation of biogenic emissions as a function of numerous environmental variables and factors (e.g. temperature, light, humidity, wind within the canopy, leaf-area index, leaf age, soil moisture), whereas it also accounts for the losses and productions in the canopy. Emissions from soils (mainly nitric oxide as a function of soil temperature, land use and fertilizer input) are used as input data to only some of the CWF models (ALADIN-CAMx, CAMx-AMWFG, FARM, MM5-CHIMERE, MOCAGE, RCG, SILAM, THOR, WRF-Chem). Other gaseous natural emissions (e.g. volcanoes, oceans, animals) are hardly accounted for in chemical weather forecast models (only in CAMx-AMWFG, MOCAGE, SILAM and THOR). Lightning emissions of $\mathrm{NO}_{\mathrm{x}}$ from the GEIA database are used in the operational runs of THOR.

\subsubsection{Natural particulate matter emissions}

Some particulates occur naturally, originating from volcanoes, dust storms, forest and grassland fires, living vegetation, and sea spray. In this section, we focus on primary aerosol emissions, especially dust and sea-salt particles, which constitute the largest contribution to total aerosol mass. Other particulates are formed by way of the transformations of pollutants such as sulfur dioxide, nitrogen oxides and ammonia into sulfates, nitrates and ammonium, respectively (secondary aerosol). Many volatile organic compounds are converted to oxidized organic species with low volatility, thus becoming a component of ambient aerosol.

FARM and MM5-CHIMERE use a simplified bulk scheme for the calculation of mineral dust emissions as in Vautard et al. (2005) (cf. Table 8). Vautard et al. (2005) also propose a simplified scheme to calculate the emissions that depends upon turbulence near the ground, assuming that the resuspension of material that is available on the ground can explain the missing parts of the $\mathrm{PM}_{10}$ average load. The desert dust emission fluxes mainly depend on wind velocity and the surface features (Marticorena and Bergametti, 1995). The emission modules account for the effects of the soil size distribution, surface roughness and soil moisture. The dust module developed by the AM\&WF (Atmospheric Modelling and Weather Forecasting Group, School of Physics, University of Athens, Athens, Greece) Group is used by SKIRON/Dust and CAMx-AMWFG. The current model version incorporates state-of-the-art parameterizations of all the major phases of the atmospheric dust life cycle such as production, diffusion, advection, and removal, including the effects of the particle size distribution on aerosol dispersion and deposition. Different size bins can be considered with diameters ranging from $0.1-10 \mu \mathrm{m}$ following a log-normal distribution (Zender et al., 2003). During the model run, the prognostic atmospheric and hydrological conditions are used to calculate the effective rates of the injected dust concentration based on the viscous/turbulent mixing, shear-free convection diffusion and soil moisture. The RCG model uses the methods by Loosmore and Hunt (2000) and Claiborn (1998) to calculate the resuspension of dust. MOCAGE has been coupled with a module of dynamic source of dust emissions using a size-resolved (bin) approach (Martet et al., 2009).

Sea-spray droplets come in three varieties: film, jet, and spume. Film and jet droplets derive from one process: air bubbles bursting at the sea surface. When a bubble rises to the surface, its film-thin top eventually ruptures and ejects tens to hundreds of film droplets with radii ranging roughly from 0.5 to $5 \mu \mathrm{m}$. After the bubble bursts, it collapses and, in so doing, shoots up a jet of water from its bottom. Because of velocity differences along this jet, it soon breaks up into a few jet droplets with radii typically from 3 to $50 \mu \mathrm{m}$, depending on the size of the bubble. Spume droplets derive from another process: the wind tears them off the wave crests. Estimating the sea-salt emissions, and hence the amount of local marine aerosol, requires knowing the rate at which spray droplets of any given size are produced at the sea surface (i.e. the sea-spray generation function). LOTOSEUROS, SILAM and MM5-CHIMERE quantify the bubbleand spume-production mechanisms using the approach of Monahan et al. (1986).

In SILAM, the aerosol-size distribution is extended to submicrometer particles according to Martensson et al. (2003); a detailed description has been presented by Sofiev et al. (2011b). RCG and CAMx-AMWFG also simulate the processes of sea-salt aerosol generation, diffusive transport, transformation, and removal as a function of particle size (Gong et al., 1997). FARM and CAMx-AMWFG implemented the methods proposed by Zhang et al. (2005), which corrects sea-salt-emission particle-size distributions according to local relative humidity.

In comparison with the main anthropogenic emission sources, the pollen particles emitted depends on meteorological conditions. The emission modules for pollen therefore 
should include treatments for the effects of the accumulated heat, start and end dates of the pollinating season, mean climatological rate of release, correction functions related to wind, temperature, humidity, and precipitation, and diurnal cycle of the pollen production. Pollen emissions are used as input emission data only in SILAM and Enviro-HIRLAM forecast runs. For this reason, emission modules have been developed by FMI and DMI. The most difficult problems in pollen-dispersion are to evaluate the emission flux of grains and their time evolution. For example, trial forecasts during spring 2004 with SILAM used a "climatologic" emission term, which was based on the results of long-term mean observed birch flowering dates (Sofiev et al., 2006a). The system is based on the European flowering start and duration maps from the International Phenological Garden Project (IPG, 2004). The maps were compiled by Rötzer and Chmielewski (2001) using multilinear regression analysis of phenological observations in Europe over 35 yr (1961-1998).

Mahura et al. (2009) investigate the patterns of birch pollen counts over a diurnal cycle and propose a parameterization that is useful for inclusion into operational and research short- and long-term modelling with EnviroHIRLAM for birch pollen atmospheric transport and deposition at different spatial scales. The evaluation of patterns of diurnal cycles on monthly and interannual bases has been done based on analysis of a 26-yr time series of birch pollen counts from the Danish pollen measurement site in Copenhagen. The suggested parameterization, based on a simple trigonometric function, includes dependencies on the time of birch pollen maximum and minimum occurrence on a diurnal cycle, averaged concentration at the end of the previous day, and time shift.

Some models also account for biomass burning and wildland fires. For example, THOR uses the emission dataset of the EU project REanalysis of the TROpospheric chemical composition over the past $40 \mathrm{yr}$ (RETRO). In contrast, for SILAM, Sofiev et al. (2009) investigated the potential of two remotely-sensed wildland fire characteristics $(4 \mu \mathrm{m}$ brightness temperature anomaly - TA, and fire radiative power FRP) for the needs of operational chemical transport modelling and short-term forecasting of atmospheric composition and air quality. The core of the methodology is based on empirical emission factors that are used to convert the observed temperature anomalies and fire radiative powers into emission fluxes. A new generation fire assimilation system is presented, which evaluates the daily, global emission fluxes of primary particulate matter from wildland fires. The predicted emissions in Europe are subsequently scaled to other pollutants using emission factors from the literature and submitted to the chemical transport model SILAM for diagnostic assessment and forecasting of the atmospheric composition.

\subsection{Horizontal and vertical grid spacing}

In this article, we distinguish between grid spacing and resolution of the CWF models (Pielke, 1991, 2001; Laprise, 1992; Grasso, 2000a, b). Grid spacing for Eulerian models can be simply defined as the distance between numerical grid points; however, resolution can in many cases be an ambiguous or poorly defined concept. Resolution commonly refers to the smallest spatial or temporal scale, on which various phenomena can be resolved by the model or modelling system. However, for instance the minimum distance scale on which phenomena can be resolved, may vary from two to ten times the grid spacing. The resolution (or grid spacing) can also be different for the emission data, meteorological data, land-use data, other input data, the computational grid of the model, the receptor grid of the model, and other data. Thus, the meaning of the overall resolution of the modelling system, and how it has been evaluated for a specified phenomenon, may not always be clear. Therefore, whenever possible we prefer to use the more precise term grid spacing.

Lagrangian models also face a similar problem. For instance, the effective grid spacing for NAME is determined by the meteorological fields that the model uses and by the grid spacing of the emissions. In general, for both Lagrangian and Eulerian models, the effective resolution of the modelling system is no better than the coarsest of the grids that are employed by the NWP model, the emissions processing model, and the CTM.

A summary of the computational grid spacings and coordinate systems of the different models appear in Table 9. Clearly, CWF models can be implemented with various horizontal and vertical grid spacings, depending upon the atmospheric scales to be modeled. Computational time limitations of having forecasts appear in real-time during operational forecasts restrict the domain size and grid spacing. Modelling on the continental, regional, and background urban scales necessarily require different horizontal grid spacings. For example, a CWF model for forecasting regional or municipal air quality requires small horizontal grid spacing (e.g. of the order of from 1 to $20 \mathrm{~km}$ ), but does not necessarily require model levels in the stratosphere. In contrast, continental-scale models typically have $10-50$-km horizontal grid spacing and should include treatments for the entire troposphere and the lower stratosphere for many applications. Clearly, the selection of the appropriate grid spacing depends upon the details of the modelling system and the particular application.

Most of the models described in this paper use multiple grids that may have different horizontal grid spacings for the meteorological and air-quality components (for the offline models). In that way, the CWF models may cover the continental and regional scale across Europe and, with the finer grids (sometimes nested), they may focus on a more detailed forecast of a specific region. For instance, operational modelling on the European scale in 2010 featured horizontal 
Table 9. Details on the grid spacings and coordinate systems of the different CWF models.

\begin{tabular}{|c|c|c|c|}
\hline Model name & $\begin{array}{l}\text { Coordinate } \\
\text { system }\end{array}$ & Horizontal grid spacing & Vertical grid spacing \\
\hline ALADIN-CAMx & Arakawa $\mathrm{C}$ grid & $\begin{array}{l}28.9 \mathrm{~km} \text { for the mother grid (Central Europe) } \\
9.63 \mathrm{~km} \text { for the inner modelling domain (Aus- } \\
\text { tria and surroundings) }\end{array}$ & $\begin{array}{l}15 \text { vertical layers ( } 30 \mathrm{~m} \text { to } 2.5 \mathrm{~km} \text { ). The high- } \\
\text { est grid spacing (about } 30 \mathrm{~m} \text { ) is achieved in the } \\
\text { lowest } 5 \text { levels (up to about } 350 \mathrm{~m} \text { ) }\end{array}$ \\
\hline CAMx-AMWFG & Arakawa $\mathrm{C}$ grid & $\begin{array}{l}0.24^{\circ} \times 0.24^{\circ}(\sim 24 \mathrm{~km}) \\
\text { The area covered is the Mediterranean region, } \\
\left.\text { Europe (up to } 55^{\circ} \mathrm{N}\right) \text {, North and Central Africa, } \\
\text { Turkey and part of the Arabian Peninsula }\end{array}$ & $\begin{array}{l}22 \text { layers up to } 8 \mathrm{~km} \text { with variable spacing } \\
\text { First layer from the ground at } 50 \mathrm{~m}\end{array}$ \\
\hline $\begin{array}{l}\text { ENVIRO- } \\
\text { HIRLAM }\end{array}$ & Arakawa $\mathrm{C}$ grid & $5 \mathrm{~km}$ (pollen forecast) & $\begin{array}{l}\text { Hybrid terrain-following sigma and pressure } \\
\text { coordinate system } 40 \text { layers, grid spacing from } \\
30 \mathrm{~m} \text { to } 500 \mathrm{~m}\end{array}$ \\
\hline EURAD-RIU & & $\begin{array}{l}\text { Europe: } 125 \mathrm{~km} \text {; Central Europe: } 25 \mathrm{~km} \text {, } \\
\text { German States: } 5 \mathrm{~km}\end{array}$ & 23 layers from $40 \mathrm{~m}$ to $2000 \mathrm{~m}$ at top $(100 \mathrm{hPa})$ \\
\hline FARM & $\begin{array}{l}\text { UTM (Universal } \\
\text { Transverse Mercatore); } \\
\text { polar stereographic }\end{array}$ & 12 km (Italian Peninsula) & $\begin{array}{l}\text { Terrain following coordinates with variable ver- } \\
\text { tical spacing up to } 10 \mathrm{~km}\end{array}$ \\
\hline LOTOS-EUROS & & $\begin{array}{l}0.5^{\circ} \times 0.25^{\circ} \text { (Europe) }(\sim 25 \times 25 \mathrm{~km}) \\
\left.0.25^{\circ} \times 0.125^{\circ} \text { (Netherlands }\right)(\sim 12 \times 12 \mathrm{~km}) \\
\left.0.125^{\circ} \times 0.0625^{\circ} \text { (Netherlands }\right)(\sim 6 \times 6 \mathrm{~km})\end{array}$ & $\begin{array}{l}\text { Dynamic mixing layer approach } 4 \text { layers (sur- } \\
\text { face layer of } 25 \mathrm{~m} \text {, mixing height layer and } 2 \\
\text { reservoir layers up to } 3.5 \text { or optionally } 5 \mathrm{~km} \text { ) }\end{array}$ \\
\hline MATCH & & $\begin{array}{l}44 \mathrm{~km} \text { (MATCH-HIRLAM) (Europe) } \\
0.5^{\circ} \text { and } 0.2^{\circ}(\sim 50 \mathrm{~km} \text { and } 20 \mathrm{~km}, \\
\text { respectively) (MATCH-ECMWF) (Europe) }\end{array}$ & $\begin{array}{l}\text { Usually depending on met. model. At present } \\
\text { for HIRLAM: domain height } \sim 8 \mathrm{~km} \text {, lowest } \\
\text { level at } \sim 60 \mathrm{~m}\end{array}$ \\
\hline MM5-CAMx & & $\begin{array}{l}30 \mathrm{~km} \text { for Europe (mother grid) } \\
10 \mathrm{~km} \text { for the Balkan Peninsula and } \\
2 \mathrm{~km} \text { for Athens (nested grids) }\end{array}$ & $\begin{array}{l}\text { CAMx: } 15 \text { vertical layers, } 1 \text { st layer height } \\
20 \mathrm{~m} \text {, top at } 7 \mathrm{~km} \text {. MM5: } 29 \text { vertical sigma- } \\
\text { levels, top at } 100 \mathrm{mbar}\end{array}$ \\
\hline MM5-CHIMERE & & $\begin{array}{l}50 \mathrm{~km} \text { (Western Europe) } \\
10 \mathrm{~km} \text { (Portugal) }\end{array}$ & $\begin{array}{l}\text { In the vertical there are } 8 \text { layers up to } 500 \mathrm{hPa} \\
\text { with the surface layer located at } 50 \mathrm{~m}\end{array}$ \\
\hline MM5-CMAQ & & $\begin{array}{l}50 \mathrm{~km} \text { (Europe) } \\
27 \mathrm{~km} \text { (Iberian Peninsula) }\end{array}$ & 15 layers up to $100 \mathrm{hPa}$ \\
\hline MOCAGE & & $\begin{array}{l}\text { PREVAIR: } 2^{\circ}(\sim 200 \mathrm{~km})(\text { global}) ; 0.5^{\circ} \\
(\sim 50 \mathrm{~km}) \text { (Europe and Mediterraean area); } \\
0.1^{\circ}(\sim 10 \mathrm{~km}) \text { (France) GEMS, MACC: } 2^{\circ} \\
\text { (global); } 0.2^{\circ} \text { (Europe) } \\
\text { Currently testing: } 0.025^{\circ} \text { (France) }\end{array}$ & $\begin{array}{l}\text { Hybrid (sigma, P) coordinate system with } \\
\text { currently } 60 \text { levels from the surface up to } 1 \text { or } \\
0.1 \mathrm{hPa}(7-8 \text { levels in the PBL with a first layer } \\
\text { of } 20 \text { to } 40 \mathrm{~m})\end{array}$ \\
\hline NAME & & $\begin{array}{l}\text { No intrinsic grid. The Met Office Unified: glob- } \\
\text { ally at } 40 \mathrm{~km} \text { resolution and in a European lim- } \\
\text { ited area configuration at } 12 \mathrm{~km}\end{array}$ & Continuously variable \\
\hline OPANA & UTM & $\begin{array}{l}5 \mathrm{~km} \text { (coarse grid, Madrid) } 1 \mathrm{~km} \text { (nested grid, } \\
\text { Madrid) }\end{array}$ & $\begin{array}{l}\text { Terrain following coordinates with } 15 \text { layers up } \\
\text { to } 6 \mathrm{~km} \text {. Surface layer at } 20 \mathrm{~m}\end{array}$ \\
\hline RCG & & $25 \mathrm{~km}$ & $\begin{array}{l}5 \text { layers, surface layer of } 25 \mathrm{~m}, 2 \text { layers above } \\
\text { surface layer and mixing height and } 2 \text { reservoir } \\
\text { layers }\end{array}$ \\
\hline SILAM & & $\begin{array}{l}0.2^{\circ} \times 0.2^{\circ}(\sim 20 \mathrm{~km})(\text { Europe }) \\
5 \mathrm{~km}(\text { Northern Europe })\end{array}$ & $\begin{array}{l}\text { Multi-vertical approach with the meteorology- } \\
\text { resolving grid corresponding to the tropo- } \\
\text { spheric part of the IFS vertical: hybrid lev- } \\
\text { els. The chemical transformations and vertical } \\
\text { fluxes are computed on the basis of thick stag- } \\
\text { gered layers }\end{array}$ \\
\hline
\end{tabular}


Table 9. Continued.

\begin{tabular}{|c|c|c|c|}
\hline Model name & $\begin{array}{l}\text { Coordinate } \\
\text { system }\end{array}$ & Horizontal grid spacing & Vertical grid spacing \\
\hline SKIRON/Dust & $\begin{array}{l}\text { Polar stereoraphic } \\
\text { Arakawa E-grid }\end{array}$ & $\begin{array}{l}0.05 \times 0.05^{\circ}(\sim 5 \mathrm{~km}) \\
2 \text { grids: one for the Mediterranean Region and } \\
\text { Europe and one extended to the North Atlantic } \\
\text { Region }\end{array}$ & $\begin{array}{l}\text { Eta step-mountain vertical coordinate system } \\
\text { with } 38 \text { vertical levels from the surface up to } \\
22 \mathrm{~km}\end{array}$ \\
\hline THOR & & $\begin{array}{l}\text { DEHM mother domain: } 150 \times 150 \mathrm{~km} \\
\text { (hemispheric) DEHM first nest: } \\
50 \mathrm{~km} \times 50 \mathrm{~km} \text { (Europe) DEHM second nest: } \\
16.67 \times 16.67 \mathrm{~km} \\
\text { UBM: } 1 \mathrm{~km} \times 1 \mathrm{~km} \text { (urban) } \\
\text { OSPM: } 0.001 \mathrm{~km} \text { (street pollution) }\end{array}$ & $\begin{array}{l}\text { DEHM: } 20 \text { layers up to } \sim 15 \mathrm{~km} \text {, lowest model } \\
\text { layer } 50 \mathrm{~m}\end{array}$ \\
\hline WRF-Chem & & $50 \mathrm{~km}$ (Europe) & $\begin{array}{l}\text { The vertical structure has } 12 \text { layers in sigma co- } \\
\text { ordinates with the top pressure at } 100 \mathrm{hPa}\end{array}$ \\
\hline WRF/CMAQ & Arakawa C & $12 \mathrm{~km}$ & $\begin{array}{l}\text { Terrain-following hydrostatic pressure coordi- } \\
\text { nates. } 22 \text { layers extending from the surface to } \\
100 \mathrm{hPa} \text { are interpolated from the } 60 \mathrm{WRF} \\
\text { layers }\end{array}$ \\
\hline
\end{tabular}

grid spacings in the range of $20 \mathrm{~km}$ (SILAM), $25 \mathrm{~km}$ (CAMx-AMWFG, RCG, SKIRON/Dust, EURAD-RIU), $30 \mathrm{~km}$ (ALADIN-CAMx, MM5-CAMx), 44 km (MATCHHIRLAM) and $50 \mathrm{~km}$ (LOTOS-EUROS, MATCH-ECMWF, MM5-CHIMERE, MM5-CMAQ, MOCAGE, THOR, WRFCHEM).

For the finer-grid forecast simulations, the variety of horizontal grid spacing in 2010 ranged from $2 \mathrm{~km}$ (MM5CAMx for Athens area, MOCAGE over France at $2.5 \mathrm{~km}$ ) to $27 \mathrm{~km}$ (MM5-CMAQ for the Iberian Peninsula) for the three-dimensional Eulerian models. Many models use 1012-km horizontal grid spacing for their finer grids (MM5CAMx for the Balkan region, MM5-CHIMERE for Portugal, MOCAGE for France and WRF/CMAQ) and $5 \mathrm{~km}$ for Northern Europe (Enviro-HIRLAM, EURAD-RIU and SILAM). The other applied horizontal grid spacing is $9.6 \mathrm{~km}$ for ALADIN-CAMx covering Austria, $12 \mathrm{~km}$ for FARM (Italian Peninsula), $25 \times 12 \mathrm{~km}$ for LOTOS-EUROS (covering the Netherlands) and $17 \mathrm{~km}$ for THOR.

As well as the grid spacing, another parameter that differs among models and applications is the selection of the coordinate system. Horizontal spatial coordinates may be expressed in polar coordinates on a sphere, Cartesian coordinates on a plane, or one of several projections of a sphere onto a plane. Curvilinear coordinates may be used in both polar and planar instances, where the model refers to a pseudo-longitude and latitude, that is then mapped to geographic longitude and latitude (following the curved surface of the earth).

Following the Cartesian map projections (fixed physical distance coordinates on a flat plane), a number of models included in this paper use the Lambert Conic Conformal coordinate system (ALADIN-CAMx, MM5-CAMx,
MM5-CMAQ, WRF-Chem and WRF-CMAQ) for the forecasting applications. Another Cartesian map projection is the Universal Transverse Mercator (FARM). A rotated longitude-latitude grid is used by Enviro-HIRLAM model, and a curvilinear geodetic latitude-longitude projection is used by CAMx-AMWFG and LOTOS-EUROS. In all geographic projections, the surface of the Earth is distorted because the Earth's actual shape is irregular. Nevertheless, all projections produce similar results and most of the models allow the user to select the map projection among different options.

The models also have different vertical coordinate systems describing how the grid levels are separated in the vertical: height, terrain-following $\sigma$, pressure, and step-mountain coordinates. LOTOS-EURO uses a fifth system, a dynamic mixing-layer coordinate system with four layers (a surface layer of $25 \mathrm{~m}$, mixing-layer height, and two reservoir layers up to 3.5 or $5 \mathrm{~km}$ ). RCG also uses a dynamic mixing-layer coordinate system with a surface level, $25-\mathrm{m}$ surface layer, mixing layer and two reservoir layers up to $4 \mathrm{~km}$. Uniformity appears on the selection of the surface layer, where most of the models use $20-50 \mathrm{~m}$ above the surface as the first model level. Also, most of the models are focused on the troposphere with the top layers located at $2.5-15 \mathrm{~km}$, with two exceptions at $22 \mathrm{~km}$ (SKIRON/Dust) and $1 \mathrm{hPa}(\sim 50 \mathrm{~km}$, MOCAGE).

\section{Sensitivity analysis and evaluation of CWF models}

In this article, we use the term "model evaluation against data" or in abbreviated form "model evaluation" to refer to a systematic comparison of model predictions and observations. We avoid the term "validation", as, strictly speaking, 
Table 10. A summary description of the evaluation of each CWF model.

\begin{tabular}{|c|c|c|c|}
\hline Model name & How model was evaluated & References (up to 4) & Quantities evaluated \\
\hline ALADIN-CAMx & $\begin{array}{l}\text { Citydelta project: aimed to explore the changes in } \\
\text { urban air quality predicted by different chemistry- } \\
\text { transport dispersion models in response to changes } \\
\text { in urban emissions. Model provided good } \\
\text { performances for ozone (both on average and for } \\
\text { extreme values). Acceptable results have been } \\
\text { obtained for PM } 10 \text { yearly means. ESCOMPTE } \\
\text { project: the model has highlighted quite good } \\
\text { performance for both ozone and } \mathrm{NO}_{2}\end{array}$ & $\begin{array}{l}\text { - Hirtl et al. (2007) } \\
\text { - Baumann-Stanzer et al. (2005) } \\
\text { - Vautard et al. (2007) }\end{array}$ & $\mathrm{O}_{3}, \mathrm{O}_{\mathrm{x}}, \mathrm{PM}_{10}, \mathrm{NO}_{2}$ \\
\hline CAMx-AMWFG & $\begin{array}{l}\text { The evaluation of the model performance on the } \\
\text { known gas and aerosol species has been included } \\
\text { in several publications worldwide. The model } \\
\text { intercomparison has been done against in-situ } \\
\text { measurements for the species concentration and } \\
\text { against AERONET data for the dust optical depth } \\
\text { used for the calculation of the photolysis rates }\end{array}$ & $\begin{array}{l}\text { - Astitha et al. (2006) } \\
\text { - Astitha et al. (2007) } \\
\text { - Astitha and Kallos (2009) } \\
\text { - Astitha et al. (2010) }\end{array}$ & $\begin{array}{l}\text { The evaluation of the model performance } \\
\text { on the known gas and aerosol species such } \\
\text { as ozone, } \mathrm{NO}_{\mathrm{X}} \text {, sulfates, nitrates etc. }\end{array}$ \\
\hline Enviro-HIRLAM & $\begin{array}{l}\text { Evaluation against field experiments of ETEX and } \\
\text { MEGAPOLI, and Chernobyl measurements. } \\
\text { Meteorology and air-quality forecasts evaluated } \\
\text { against Paris surface observation network for } \\
\text { specific episodes. Model intercomparison: } \\
\text { participant in EU MEGAPOLI project. Needs } \\
\text { further evaluation over long-term periods }\end{array}$ & $\begin{array}{l}\text { - Chenevez et al. (2004) } \\
\text { - Korsholm et al. (2009) } \\
\text { - Korsholm (2009) } \\
\text { - Mahura et al. (2008) }\end{array}$ & $\begin{array}{l}\text { Transport and scavenging processes have } \\
\text { been evaluated using ETEX and } \\
\text { Chernobyl observations; meteorology } \\
\text { (with feedbacks), surface } \mathrm{O}_{3}, \mathrm{NO}_{\mathrm{x}}, \mathrm{SO}_{2} \text {, } \\
\text { PM using Paris monitoring and } \\
\text { MEGAPOLI campaign data }\end{array}$ \\
\hline EURAD-RIU & $\begin{array}{l}\text { GEMS: evaluation against measurements and other } \\
\text { air-quality forecast models. Participation of } \\
\text { the COST } 728 \text { model intercomparison for the } \\
\text { winter } 2003 \text { case }\end{array}$ & $\begin{array}{l}\text { - Hass et al. (1997) } \\
\text { - Jakobs et al. (2002) } \\
\text { - Schlünzen and Fock (2010) }\end{array}$ & $\mathrm{O}_{3}, \mathrm{PM}_{10}, \mathrm{NO}_{2}$ \\
\hline FARM & $\begin{array}{l}\text { On single model components and against } \\
\text { monitoring data in real applications. Long-term } \\
\text { model intercomparison exercise over Po Valley } \\
\text { (Northern Italy), carried out by Regional } \\
\text { Environmental Protection Agencies. Ongoing } \\
\text { long-term model intercomparison exercise over } \\
\text { Po Valley (Northern Italy), carried out by } \\
\text { Regional Environmental Protection Agencies }\end{array}$ & $\begin{array}{l}\text { - Silibello et al. (2008) } \\
\text { - Schlünzen and Fock (2010) } \\
\text { - Calori et al. (2010) } \\
\text { - Gariazzo et al. (2007) }\end{array}$ & $\mathrm{O}_{3}, \mathrm{NO}_{2}, \mathrm{NO}_{\mathrm{x}}, \mathrm{PM}_{10}$ \\
\hline LOTOS-EUROS & $\begin{array}{l}\text { Evaluation with groundbased measurements. } \\
\text { EURODELTA: a regional-scale model } \\
\text { intercomparison to analyse the responses of } \\
\text { different CTMs to emission changes/scenarios }\end{array}$ & - Schaap et al. (2008) & $\begin{array}{l}\mathrm{O}_{3}, \mathrm{NO}_{2}, \mathrm{NO}, \mathrm{NH}_{3}, \mathrm{SO}_{4}, \mathrm{SO}_{2} \text { and } \mathrm{NH}_{4} \text {. } \\
\text { Secondary organic aerosols, sea salt, and } \\
\text { heavy metal concentrations }\end{array}$ \\
\hline MATCH & $\begin{array}{l}\text { Eurodelta: evaluation of seven regional air-quality } \\
\text { models and their ensemble for Europe and Mics } \\
\text { Asia - Model intercomparison study for Southern } \\
\text { and Eastern Asia, Phase } 1 \text { and } 2\end{array}$ & $\begin{array}{l}\text { - Carmichael et al. (2002) } \\
\text { - Carmichael et al. (2008b) }\end{array}$ & $\begin{array}{l}\text { Evaluated reference dataset: chemistry } \\
\text { and transport including } \mathrm{SO}_{2}, \mathrm{NO}_{2}, \mathrm{NO}_{\mathrm{x}} \text {, } \\
\mathrm{NH}_{3}, \mathrm{HNO}_{3}, \mathrm{O}_{3}, \mathrm{CO}, \mathrm{CF}_{6},{ }^{137} \mathrm{Cs} \text {, seasalt, } \\
\left(\mathrm{CF}_{6} \text { during the ETEX-experiment and }\right. \\
{ }^{137} \mathrm{C} \text { s for the Chernobyl accident). Model } \\
\text { intercomparison: including } \mathrm{SO}_{2}, \mathrm{NO}, \mathrm{NO}_{2} \text {, } \\
\mathrm{NO}_{\mathrm{x}}, \mathrm{NH}_{3}, \mathrm{HNO}_{3}, \mathrm{O}_{3}, \mathrm{HCHO}\end{array}$ \\
\hline MM5-CAMx & $\begin{array}{l}\text { Within the European project GEMs, the air quality } \\
\text { forecast has been operationally evaluated against } \\
\text { surface measurements in Europe (rural stations } \\
\text { of EMEP, urban stations of AIRBASE in Athens, } \\
\text { Greece) and compared with the forecasts from other } \\
\text { models (e.g. CHIMERE, EMEP, EURAD etc.) and } \\
\text { the European ensemble forecast. Tropospheric } \\
\text { columns of } \mathrm{NO}_{2} \text { and } \mathrm{O}_{3} \text { have been compared with } \\
\text { satellite data. There has been also upper air } \\
\text { evaluation with WOUDC sites measurements }\end{array}$ & $\begin{array}{l}\text { - Huijnen et al. (2010) } \\
\text { - Kioutsioukis et al. (2009) } \\
\text { - Kioutsioukis et al. (2010) } \\
\text { - Poupkou et al. (2008) }\end{array}$ & $\begin{array}{l}\text { Ozone, nitrogen dioxide, sulphur dioxide, } \\
\text { carbon monoxide and particulate matter } \\
\left(\mathrm{PM}_{10}\right)\end{array}$ \\
\hline
\end{tabular}


Table 10. Continued.

\begin{tabular}{|c|c|c|c|}
\hline Model name & How model was evaluated & References (up to 4) & Quantities evaluated \\
\hline MM5-CHIMERE & $\begin{array}{l}\text { MM5: evaluated in many model intercomparison } \\
\text { studies, particularly compared to RAMS. } \\
\text { CHIMERE: analysis evaluation was performed } \\
\text { through studies published in more than } 30 \text { perr } \\
\text { reviewed papers. For the forecast, the evaluation of } \\
\text { the model is updated daily on the PREVAIR web } \\
\text { site with correlations scores compared to hourly } \\
\text { surface emasurements. Model intercomparison: } \\
\text { City-Delta, Euro-Delta, Esquif, escompte. Nu- } \\
\text { merous projects, described on the CHIMERE web } \\
\text { site }\end{array}$ & $\begin{array}{l}\text { - Hara et al. (2005) } \\
\text { - O'Neil et al. (2005) } \\
\text { - Menut et al. (2005) } \\
\text { - Vautard et al. (2007) }\end{array}$ & Dispersion simulations of $\mathrm{O}_{3}, \mathrm{O}_{\mathrm{x}}, \mathrm{PM}_{10}$ \\
\hline $\begin{array}{l}\text { MM5/WRF- } \\
\text { CMAQ }\end{array}$ & $\begin{array}{l}\text { The model is used for several experiments and } \\
\text { compared the results with the observational data. } \\
\text { Results show correlation coefficients between } \\
0.5 \text { to } 0.9 \text { for Ozone concentrations for one year } \\
\text { hourly concentrations ( } 8760 \text { data) }\end{array}$ & $\begin{array}{l}\text { - Meng et al. (2007) } \\
\text { - Vijayaraghavan et al. (2007) } \\
\text { - San José et al. (2007) } \\
\text { - Appel et al. (2009) }\end{array}$ & $\begin{array}{l}\text { Analysis of the amount of air pollutant } \\
\text { concentrations due to the industrial plant } \\
\text { emissions. Evaluation of the potential } \\
\text { impact of an incinerator. Modelling the } \\
\text { transport and transformation of mercury. } \\
\text { Performance of the model system is } \\
\text { compared with the existing measurements } \\
\text { of a total of } 22 \text { PCB congeners and the } 17 \\
\text { most toxic PCDD/F congeners }\end{array}$ \\
\hline MOCAGE & $\begin{array}{l}\text { Meteorological forcings from MOCAGE are pro- } \\
\text { vided by numerical weather prediction suites at } \\
\text { Météo-France (ARPEGE, ALADIN) and ECMWF } \\
\text { (IFS), with operational skill score evaluations. } \\
\text { MOCAGE has been evaluated against observations } \\
\text { in the context of a range of field campaigns and } \\
\text { international exercises (ESQUIF, ESCOMPTE, } \\
\text { City-Delta, ICARTT-ITOP,...), with over } 40 \\
\text { publications in the international refereed literature. } \\
\text { Evaluation range from the global scale (including } \\
\text { the stratosphere) to the regional/local scale for } \\
\text { gases and primary aerosol species. Continuous }\end{array}$ & $\begin{array}{l}\text { - Josse et al. (2004) } \\
\text { - Dufour et al. (2004) } \\
\text { - Bousserez et al. (2007) } \\
\text { - Ménégoz et al. (2009) }\end{array}$ & $\begin{array}{l}\text { Transport and scavenging processes have } \\
\text { been evaluated using ETEX and } \mathrm{Rn} / \mathrm{Pb} \\
\text { observations; surface } \mathrm{O}_{3}, \mathrm{NO}_{\mathrm{x}}, \mathrm{SO}_{2}, \\
\mathrm{HNO}_{3} \text {, PAN using routine surface } \\
\text { observation and campaign data; } \\
\text { deposition of ozone using ESCOMPTE } \\
\text { data; global tropospheric and stratospheric } \\
\text { distributions of Ozone, CO, } \mathrm{NO}_{2}, \mathrm{~N}_{2} \mathrm{O} \\
\text { using a range of satellite data products; } \\
\text { aerosol was evaluated using surface PM ob- } \\
\text { servations, Lidar and AERONET data, as } \\
\text { well as campaign data }\end{array}$ \\
\hline
\end{tabular}

- Webster and Thomson (2002) - Ryall and Maryon (1998)

- Simmonds et al. (1996) ETEX, and Kincaid. Air-quality forecasts evaluated against UK surface obs network. Model intercomparison: participant in EU ENSEMBLE project
OPANA
Evaluated at the end of EMMA project (CGXIII, 1996-98). The system has been tested again many data during the last 10 years. Model intercomparison: the model has been tested and compared with observational data in every air quality impact assessment (callibration phase) and in every realtime air-quality forecasting system developed for urban and/or industrial areas because the system is callibrated with one-year air-quality monitoring data in the subjected area and surroundings
- San José et al. (2005)
Plume rise scheme is evaluated against Kincaid dataset. NAME model predictions are compared against ETEX. Model has been evaluated against observations of a number of trace gases. Intercomparisons amongst European models used to simulate foot and mouth disease spread

$\mathrm{O}_{3}, \mathrm{NO}_{2}, \mathrm{CO}, \mathrm{SO}_{2}, \mathrm{PM}_{10}, \mathrm{PM}_{2.5}$, Cadmium, Arsenic, Nickel, Lead and Benzo(a)pyrene 
Table 10. Continued.

\begin{tabular}{|c|c|c|c|}
\hline Model name & How model was evaluated & References (up to 4) & Quantities evaluated \\
\hline $\mathrm{RCG}$ & $\begin{array}{l}\mathrm{PM}_{10} \text {-measurements done in and aroud the Greater } \\
\text { Berlin Area have been used to evaluate RCG on } \\
\text { different scales. EuroDelta model intercomparison } \\
\text { for Europe. EUROTRAC - GLOREAM: the focus } \\
\text { is primarily on model performance for aerosol } \\
\text { components in conjunction with the EMEP } \\
\text { observational data that has been extended using } \\
\text { Dutch and German special observation sites }\end{array}$ & $\begin{array}{l}\text { - Beekmann et al. (2007) } \\
\text { - van Loon et al. (2004) } \\
\text { - Hass et al. (2003) }\end{array}$ & $\begin{array}{l}\mathrm{PM}_{10} \text { (EC, OC, inorganic aerosols, } \\
\text { metals), sulphate, nitrate, ammonium, } \\
\text { elemental carbon, wind-blown-dust } \\
\text { events }\end{array}$ \\
\hline SILAM & $\begin{array}{l}\text { Regular emergency-type evaluations whenever } \\
\text { possible. Operational evaluation of the air-quality } \\
\text { forecasts using present-week observations over } \\
\text { Finland. European-scale re-analysis for 2000- } \\
\text { 2003. Emergency-type model intercomparisons } \\
\text { within EU-ENSEMBLE and follow-up projects, } \\
\text { NKS-MetNet network, etc. Air-quality inter- } \\
\text { comparison projects are on-going within the scope } \\
\text { of COST-728, EU-GEMS, and ESA-PROMOTE }\end{array}$ & $\begin{array}{l}\text { - Sofiev et al. (2006c) } \\
\text { - Galmarini et al. (2004a) } \\
\text { - Huijnen et al. (2010) }\end{array}$ & $\begin{array}{l}\text { Air-quality forecasts. Individual model } \\
\text { units were compared against analytical } \\
\text { solutions, chemical scheme tested as } \\
\text { a box model, etc. }\end{array}$ \\
\hline SKIRON/Dust & $\begin{array}{l}\text { evaluation of the model SKIRON/Dust have been } \\
\text { performed from AM\&WFG during several projects } \\
\text { (SKIRON, MEDUSE and ADIOS). Also, the mod- } \\
\text { elling system has been used by other Universities } \\
\text { and Institutes world-wide. Model intercomparison } \\
\text { has been performed against measurements and ob- } \\
\text { servations }\end{array}$ & $\begin{array}{l}\text { - Kallos et al. (2007) } \\
\text { - Kallos et al. (2009) } \\
\text { - Astitha and Kallos (2009) } \\
\text { - Spyrou et al. (2010) }\end{array}$ & $\begin{array}{l}\text { Intercomparison against in-situ } \\
\text { measurements of dust and PM } \\
\text { concentration, remote measurements } \\
\text { of aerosol optical depth from satellites } \\
\text { or radars }\end{array}$ \\
\hline
\end{tabular}

Table 10. Continued.

\begin{tabular}{|c|c|c|c|c|}
\hline Model name & How model was evaluated & $\begin{array}{l}\text { Evaluation } \\
\text { level }\end{array}$ & References (up to 4) & Quantities evaluated \\
\hline THOR & $\begin{array}{l}\text { EuroDelta experiment: long-term ozone simula- } \\
\text { tions from seven regional air-quality models were } \\
\text { intercompared and compared to ozone measure- } \\
\text { ments. Evaluation for two cities in Denmark with } \\
\text { Urban Backround Model, BUM, and Operational } \\
\text { Street Pollution Model, OSPM, included to THOR } \\
\text { system }\end{array}$ & Level 2 & - Brandt et al. (2001a) & $\begin{array}{l}\text { Performance of the air pollution models } \\
\text { BUM and OSP for } \mathrm{NO}_{\mathrm{x}}, \mathrm{O}_{3}, \mathrm{NO}, \mathrm{NO}_{2}\end{array}$ \\
\hline WRF-Chem & $\begin{array}{l}\text { WRF-Chem-MADRID has beeb evaluated with } \\
\text { Satellite and Surface Measurements }\end{array}$ & Level 2 & - Zhang et al. (2005a) & $\begin{array}{l}\text { The simulated concentrations of gas } \\
\text { and aerosol species (e.g., } \mathrm{O}_{3}, \mathrm{SO}_{2}, \\
\mathrm{NO}_{\mathrm{x}} \text {, and } \mathrm{PM}_{2.5} \text { ) and aerosol optical } \\
\text { properties (e.g., aerosol optical depth, } \\
\text { single scattering albedo, aerosol direct } \\
\text { radiative) are being compared against } \\
\text { available observational data }\end{array}$ \\
\hline
\end{tabular}

a complete validation of any atmospheric model is not possible. We use the term "verification" to refer to the testing of the fidelity of the computer code to the model equations and principles.

To develop and improve CWF models, different approaches can be employed to evaluate their skill and usefulness. In this section, we explore some of those approaches through sensitivity analysis (Sect. 5.1), individual model evaluation studies (Sect. 5.2), and multiple-model evaluation studies (Sect. 5.3). Also, the evaluation practices of each of the 18 models were reviewed and presented in Table 10.

\subsection{Sensitivity analysis}

The dynamical evolution of numerically simulated chemical weather is highly dependent upon uncertainties in the model structure (e.g. physical and computational parameterizations), as well as uncertainties in the input data (e.g. initial and boundary conditions, emissions). Such model behaviour can be investigated through sensitivity analysis, which seeks to determine the variation in model output as a function of variations in input variables and parameters (forward sensitivity analysis: applied to source-oriented modelling) or 
the variation in model inputs resulting from variations in the model output (adjoint sensitivity analysis: applied to receptor-oriented modelling). Sensitivity analysis could provide information on the input factors that are mainly responsible for the output uncertainties (forward) or the input factors that are mostly responsible for the discrepancy between the model output and the observations (adjoint). Observational data is therefore not used in forward sensitivity analysis - it is only required in adjoint sensitivity analysis.

Uncertainty and sensitivity analysis assist in understanding the relative importance of different processes in the atmosphere and in quantifying the impact (either singular or with interactions) of uncertain inputs (e.g. data, parameterizations) in the results. Sensitivity information from CWF models can be useful for various purposes, such as the design of optimal pollution control strategies, the estimation of model parameters, research for the improvement of forecast skill, the evaluation of the role of processes (e.g. emissions, chemical kinetics, boundary conditions, parameterizations of vertical diffusion, etc.), source apportionment, and data assimilation.

The quantitative apportionment of the variation in the modelled concentrations to different sources of variation is accomplished through either the statistical or the deterministic sensitivity analysis approach. In the statistical approach (e.g. Hanna et al., 2001; Tang et al., 2010), the model is executed several times, each time with slightly perturbed inputs and the sensitivity is estimated from the statistical properties of the multiple output variability. In the deterministic approach (e.g. Dunker et al., 2002; Hakami et al., 2003, 2006; Zhang et al., 2005b; Napelenok et al., 2006; Koo et al., 2007), the model output equations are differentiated with respect to its inputs, and the sensitivity is calculated simultaneously with the concentration fields through an auxiliary set of equations.

Deterministic sensitivity analysis techniques propagate the derivatives either forward or backward along the model trajectories. In the forward method (e.g. tangent linear model, direct decoupled method or DDM), the uncertain inputs are perturbed and these perturbations are propagated forward through the modelling domain at future times, providing sensitivity information at all receptors with respect to a few uncertain parameters (forward sensitivities). Technically, this can be accomplished using either additional differential equations (e.g. Dunker et al., 2002) or by inserting additional lines of code in the model that calculate the gradient of the output function at each point (e.g. Carmichael et al., 1997). In the backward method (adjoint model), the perturbation is made at the receptor end and is propagated backward in time and space, providing sensitivity information about specific receptors with respect to all sources and parameters (adjoint sensitivities) (e.g. Sandu et al., 2005). Implementation of adjoint sensitivities in CWF models is increasing, mainly because of their application in chemical data assimilation.
Of the 18 models reviewed in this article, the following sensitivity analysis modules are available. Forward sensitivity analysis modules (DDM) are included in CAMx and CMAQ. The adjoint of CMAQ is available, although the WRF-Chem adjoint is under development. The EURADIM (Inverse Model) is capable of both forward and backward sensitivity tests, and the MOCAGE-PALM system is a useful platform for sensitivity studies in chemical data assimilation. Published sensitivity analysis studies performed with these CWF models are listed in Table 13.

Statistical sensitivity analysis techniques do not require any model modification because they rely on multiple model simulations with different combinations of the uncertain inputs. The most common and representative methods are reviewed by Saltelli et al. (2000). The statistical approach has limited applications in three-dimensional CWF models, principally due to its high computational requirements and also its restrictions on the statistical distribution of uncertain inputs. Ensemble prediction appears to be a better framework to deal with those restrictions, as it can provide information both about the forecast uncertainty and the ensemble sensitivity, using a mixture of formal statistical treatments and an informal treatment on some parts of the modelling cascade.

\subsection{Evaluation of individual models against data}

Before a CWF model can be used as an operational tool, model users should ensure that all the stages of the evaluation have been critically performed. Although evaluating a CWF model under all circumstances and for all applications is not possible, evaluation for each specific application is more feasible. Therefore, proper assessment involves determining whether the model is properly simulating the spatial and temporal features on the scales resolved by the model and whether the physical and chemical processes are simulated correctly in the model, leading to proper model response to changes in meteorology and emissions.

The main goal of model evaluation is to demonstrate that the model is making reasonable predictions when compared with observations, taking into account the adequacy and accuracy of the science represented in the model for the purposes for which the model is applied (e.g. Britter et al., 1995). Such evaluation exercises are usually based on the analysis of the systematic biases and errors in model outcomes, together with correlation measures, but they should also indicate sensitivities and uncertainties in the atmospheric processes simulated within the model. The results of these exercises should lead to new directions in model development and improvement, as well as point to the need for additional measurements.

Several studies have discussed the evaluation of CWF models and the importance of improved characterization of model uncertainties (e.g. Chang and Hanna, 2004; Fox, 1984; Demerjian, 1985; Borrego et al., 2008, Dennis et al., 2010; Schlünzen and Fock, 2010), as well as 
suggestions for model evaluation methods (e.g. Venkatram, 1979, 1988; Weil et al., 1992; Dabberdt et al., 2004). Recently the Air-Quality Modelling Evaluation International Initiative (http://aqmeii.jrc.ec.europa.eu/) based its activities on a model evaluation framework that considers four main evaluation types: (i) operational (ii) diagnostic, (iii) dynamic and (iv) probabilistic.

In the first step, commonly referred to as operational evaluation, model predictions are compared to observed data, and some statistical measures are computed to gauge overall model performance. This evaluation against data determines how accurately the model predicts the real world from the perspective of the intended uses of the model. Schlünzen and Fock (2010) present an overview of the most common statistical parameters used to indicate the ability of the model to predict the tendency of observed values, errors on the simulation of average and peak observed values, and the type of errors (systematic or unsystematic). According to Weil et al. (1992) and Hanna et al. (1993), in the early 1990s, three performance measures were regularly applied to CWF model evaluation: mean bias, root mean square error, and correlation. Currently, a more extensive collection of statistical measures is commonly used. In particular, operational evaluation should include a calculation of the statistical confidence levels.

Clearly, there are several categories of measurements: ongoing routine network measurements and short-term, higherresource campaign measurements. These different types of measurements have different uses, advantages and limitations, and consequently, different degrees of uncertainty.

In the next steps (diagnostic and dynamic evaluation), the objective is to address whether the predicted concentrations stem from correctly modelled or incorrectly modelled processes, whether they be physical or chemical. This evaluation step determines whether the model implementation accurately represents the developer's conceptual description of the model and the solution to the simulation. These evaluation methods can cover a wide variety of evaluation studies that consider the physical, chemical, meteorological and emission processes.

Finally, model evaluation can include probabilistic evaluation that attempts to capture the uncertainty or confidence in model results for chemical weather forecasting applications. Many methods exist to estimate the uncertainty: ensemble runs (i.e. multiple runs with different configurations of the same model), direct calculation of variances in predicted concentrations, Monte Carlo runs, and analytical error-propagation methods for simple-model algorithms. This probabilistic model evaluation should allow quantification of the confidence in model-predicted values and determination of how observed concentrations compare within an range of uncertainty for model predictions. Sensitivity tests (Sect. 5.1) are one of the most common and traditional ways to ascertain whether inputs have a notable influence on model performance issues.
Because the majority of the model systems described in this article are based on a NWP model and on a chemistrytransport model, a two-stage evaluation procedure (in which the weather forecast is evaluated independently of the chemistry model) is often the common model evaluation strategy. As a large experience with NWP evaluation already exists, a few general principles can be summarized as follows.

- No single evaluation statistic (e.g. false alarm ratio, probability of detection, root-mean-square error) is capable of presenting a complete picture of the evaluation statistics, depending upon the density and adequacy of the observational networks (Chang and Hanna, 2004). Therefore, multiple statistics should be calculated to develop a better understanding of the model behavior.

- Terminology across the published literature can be used inconsistently (e.g. Barnes et al., 2009), so definitions of the statistics employed should generally be included in any model evaluation study.

- Evaluating higher-resolution forecasts will necessarily result in a relatively worse evaluation relative to lowerresolution forecasts using most of the common statistical parameters (e.g. Roebber et al., 2004). Thus, different approaches need to be considered, especially at convection-permitting resolutions. For more discussion of these particular issues, see the March 2008 special issue on forecast verification in Meteorological Applications. In addition, new ways of visualizing forecast quality have been developed (e.g. Roebber 2009).

- Statistical significance of errors should be evaluated and spatial fields should be tested for field significance (e.g. Livezey and Chen, 1983; Elmore et al., 2006a).

Table 10 lists and summarizes some CWF models evaluation activities. A substantial fraction of the evaluation activities included in Table 10 can be classified as diagnostic and dynamic evaluation exercises.

\subsection{Multi-model evaluation studies}

Model intercomparison studies also offer the chance to see the weaknesses in the models, and thereby lead to efficient improvement. Although all $18 \mathrm{CWF}$ models considered in this article have been evaluated individually by comparison to observations (Table 10), multi-model evaluation projects can tackle some of the problems more costeffectively. A structured intercomparison among models can also indicate whether a general consensus exists among the models or whether there are outliers.

Multi-model evaluation against field experiments includes the passive-tracer field experiment ETEX (European Tracer EXperiment, http://rem.jrc.ec.europa.eu/etex/), EuroDelta (http://eurodelta.pangaea.de/), CityDelta (Cuvelier et al., 2007, http://aqm.jrc.ec.europa.eu/citydelta/), ESCOMPTE 
(Expérience sur Site pour COntraindre les Modèles de Pollution atmosphérique et de Transport d'Emissions; http:// escompte.mediasfrance.org), and ESQUIF (Etude et Simulation de la QUalité de l'air en Ile de France, a synthesis of the Air Pollution Over the Paris Region, Vautard et al., 2003). The ETEX experiment is useful for testing meteorological and diffusion processes, but of course not suitable for the evaluation of chemical transformation or deposition of various pollutant species. Multi-model evaluation results are expected to be available from the AQMEII study in near future (Rao et al., 2011).

Three of these projects are described below: EuroDelta, CityDelta and ESCOMPTE. These three model intercomparison projects were selected because they compare several CWF models, including some of those described in this article.

\subsubsection{EuroDelta}

The EuroDelta experiment was designed to evaluate airquality improvement over Europe in response to regional emission reduction scenarios for 2020. Within the framework of EuroDelta, van Loon et al. (2007) studied the longterm ozone simulations from seven chemical weather models: CHIMERE, DEHM, Unified EMEP model, LOTOSEUROS, MATCH, RCG and TM5 (Tracer Model 5); the latter is a global chemistry transport model. The remaining models are regional-scale models using European domain. van Loon et al. (2007) compared the models forecasts to observed ozone concentrations. All modelling groups adopted the same annual emission inventory of ozone, $\mathrm{O}_{\mathrm{x}}$ and $\mathrm{NO}_{2}$ to their model grid and model species.

Most of the models in EuroDelta realistically reproduced the observed ozone diurnal cycle, the daily averages, and the variability in the daily maxima. van Loon et al. (2007) found that "the daily maxima in ozone concentrations were better simulated than the daily averages, and summertime concentrations were better simulated than wintertime concentrations". Daytime ozone concentrations were overestimated by all models except for TM5 and DEHM. These two models also had small diurnal cycle. LOTOS-EUROS and RCG, which use the same meteorology and mixing layer concept, had a more-pronounced diurnal cycle than observed. CHIMERE produced a large all-day-long positive bias in ozone concentration, which according to van Loon et al. (2007) may be due to a bias in the boundary conditions. MATCH, DEHM, EMEP and the average of the concentrations from all seven models accurately represented the diurnal cycle of ozone (van Loon et al., 2007).

\subsubsection{CityDelta}

The aim of the CityDelta project was to evaluate the airquality response of several emission reduction scenarios in the European continent for 2010, with a focus specifically in the cities (Cuvelier et al., 2007). CityDelta proceeded in two stages. In the first stage, 15 modelling groups participated in the project, with a total of 22 model configurations (e.g. CAMx, CHIMERE, EMEP, LOTOS; Cuvelier et al., 2007). Participants performed a one-year (1999) control scenario simulation for PM and a 6-month simulation for ozone for at leat one of the six European cities selected (Berlin, Katowice, London, Milan, Paris and Prague; Cuvelier et al., 2007).

Within the second stage of CityDelta, Vautard et al. (2007) used the predictions of six models (CAMx, CHIMERE, EMEP, LOTOS, OFIS (Ozone Fine Structure model), and REM-CALGRID) to simulate ozone and $\mathrm{PM}_{10}$ concenrations for 1999 around four cities: Berlin, Milan, Paris and Prague. All the models used small-scale grid spacing $(5 \mathrm{~km})$, but three of the models (CHIMERE, LOTOS, REMCALGRID) were used also at large-scale $(50 \mathrm{~km})$ grid spacing. A model simulation domain of $300 \times 300 \mathrm{~km}$ around the cities were used in the both stages.

The models captured reasonably well the mean, daily maxima and variability of ozone concentrations, as well as the time variability of the ozone response to emission scenarios for each city and the spatial variability between cities. However, the large-scale models overestimated the ozone concentration in the city centres. All models had difficulties in capturing the $\mathrm{PM}_{10}$ concentrations and the spatial variability between cities is not reproduced. Especially the large-scale models underestimated the mass of $\mathrm{PM}_{10}$ due to the lack of horozontal grid spacing. Vautard et al. (2007) found that the small-scale models show better performance for $\mathrm{PM}_{10}$ and ozone concentrations in urban areas than the larger-scale models.

\subsubsection{ESCOMPTE}

The European campaign ESCOMPTE (Cros et al., 2004) documented four photochemical episodes, lasting 3-4 days each, near Marseilles in the coast of South-East France during June and July of 2001. These days corresponded to about $30 \%$ of the ozone pollution days ( $120 \mathrm{ppbv}$ or greater) in this region in 2001. The main objectives of the field campaign were to analyze and document several photochemical episodes in this area, as well as to create a detailed chemical and meteorological database for testing and evaluation of regional-scale CTMs. Aerosol measurements were also carried out during ESCOMPTE. The cooperative experimental project was open to all research groups. The objective of ESCOMPTE was not to rank modelling systems according to specific statistical performance, but rather to provide a convenient and comprehensive benchmark to evaluate models or different versions of the models (http://escompte. mediasfrance.org/exercice/HTML/overview.html).

The data from the ESCOMPTE campaign has been used in many studies (e.g. Menut et al., 2005; Coll et al., 2007; Pirovano et al., 2007). Coll et al. (2007) focused on the 
simulation of two intense ozone episodes on 21-23 June 2001 and 24-26 June 2001 using two models, CAMx and CHIMERE, with several configurations. The results of all the model configurations were examined to determine how much the changes in dynamical and chemical input data affected the models outputs, in an attempt to discriminate between the influence of internal and external configuration choices. One conclusion of Coll et al. (2007) was that ozone plumes are strongly influenced by the modelled representation of the wind circulation, because the structure of the ozone plume over the domain was driven by wind fields.

\section{User operations}

This section provides an overview of how the user interacts with the different models that produce the operational forecasts. Section 6.1 discusses the availability, documentation and user interfaces of the different models. This section also discusses the computer requirements and lists the levels of documentation. Section 6.2 discusses how the output is disseminated. Section 6.3 describes internet portals where CWF model output is disseminated and presented. A summary of the availability, user communities, and documentation of the various CWF systems is presented in Table 11.

\subsection{Model availability and documentation}

The availability of CWF models, and more specifically their source code and documentation, may be described in terms of software availability, and their use may be categorized in a similar way. On this basis, many of the models are provided as free and open-source environmental software (Karatzas and Masouras, 2004), such as CAMx, CHIMERE, CMAQ, MM5, SILAM and WRF-Chem. In contrast, other models are not publicly available or are otherwise restricted in some way, such as Eta, MEMO, Unified Model, GME, ALADIN, EURAD, FARM, MATCH, MOCAGE, NAME, OPANA, SKIRON/Dust and THOR. There are also models that combine public and restricted source codes, such as CAMx-AMWFG, Enviro-HIRLAM and MM5-CHIMERE.

The terms of use for those models that are not freely available are not identical for all categories of users; research institutes are usually not charged for their use, although this may not be the case for commercial applications. In addition, model availability options may also exist, as in the case of free access being limited to institutes participating in a specific consortium, or in the case of a distinction between the operational version and the research version. Some models may have well-organized and regularly updated web sites, including documentation on model applications, evaluation and user communities. In contrast, others suffer from poor or incomplete documentation.

The level of documentation of each model included in Table 11 is ranked according to a five-level scale based on the relevant information provided by the Model Documentation System (MDS) of the European Environment Agency (http://pandora.meng.auth.gr/mds/help/lh documentation.html). The MDS is an on-line database for CWF models that provides various search facilities and a structured, homogenized display of model information. This system has been available for the last ten years (http: //pandora.meng.auth.gr/mds/mds.php, Moussiopoulos et al., 2000). Another internet-based system of model properties is in the joint COST 728 and COST 732 Model Inventory, accessible at http://www.cost728.org (Schluenzen and Sokhi, 2008).

Because CWF models are computationally intensive, they are not usually prepared as a software product ready to be installed and executed. Sometimes various software tools may be used that commonly accompany the source code and are usually described in the model documentation. Few model packages have dedicated user interfaces that allow for the automatic installation, set-up and use of the model. Commonly, command-line scripts (usually shell scripts) and compilers are required to produce an operational executable. In addition, using CWF models requires software tools for the preprocessing (e.g. input data preparation, formatting, autofeeding), as well as post-processing (e.g. model visualization) of model output data.

\subsection{Users of CWF model results and information dissemination}

CWF models require a high degree of expertise to be used, applied and configured, and interpretation of their output also requires some experience. Due to the complexity of CWF models, the need for the training and support of CW users is absolutely essential. Examples of training courses and programs can be found in the past for models such as CMAQ, and general courses for training personnel in different institutes and commercial companies have been developed in the past from American and European universities and research laboratories.

CWF model users are usually scientists who set up and execute the model for operational or research uses and produce model results. However, CWF model results are of interest for many other categories of users. Specifically, the importance of this output may be traced to the environmental regulatory and legal framework, the resulting mandate for improved air-quality management, and the interest of citizens in environmental issues.

In Europe, CWF has been guided by a number of directives - which have been implemented by different agencies or government bodies in different European countries that define the quantitative thresholds to be applied to address air-pollution problems. The latest update of this legal framework is related to the adoption of the Clean Air for Europe Directive 2008/50/EC, which states that "Member States shall ensure that timely information about actual 


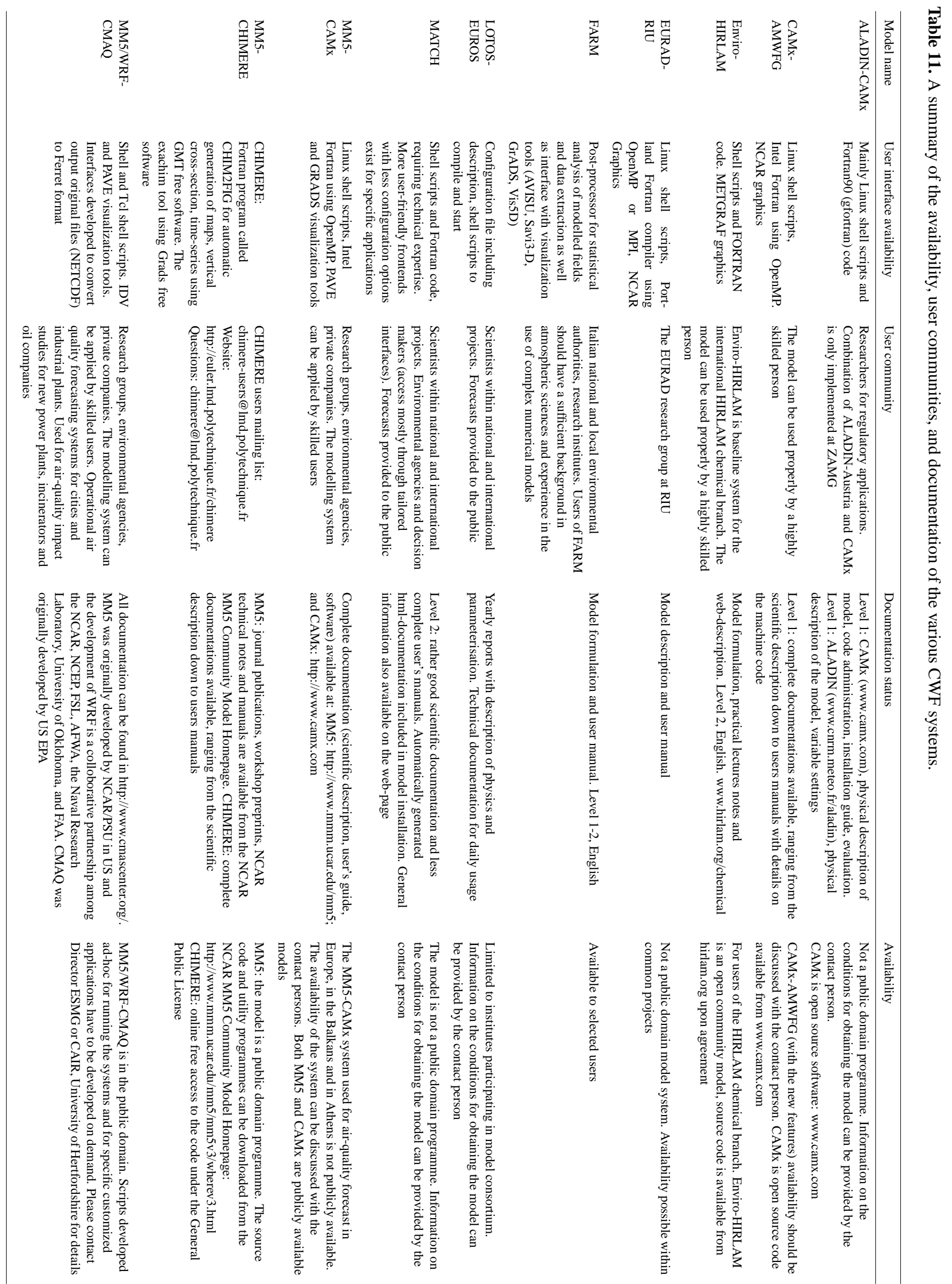




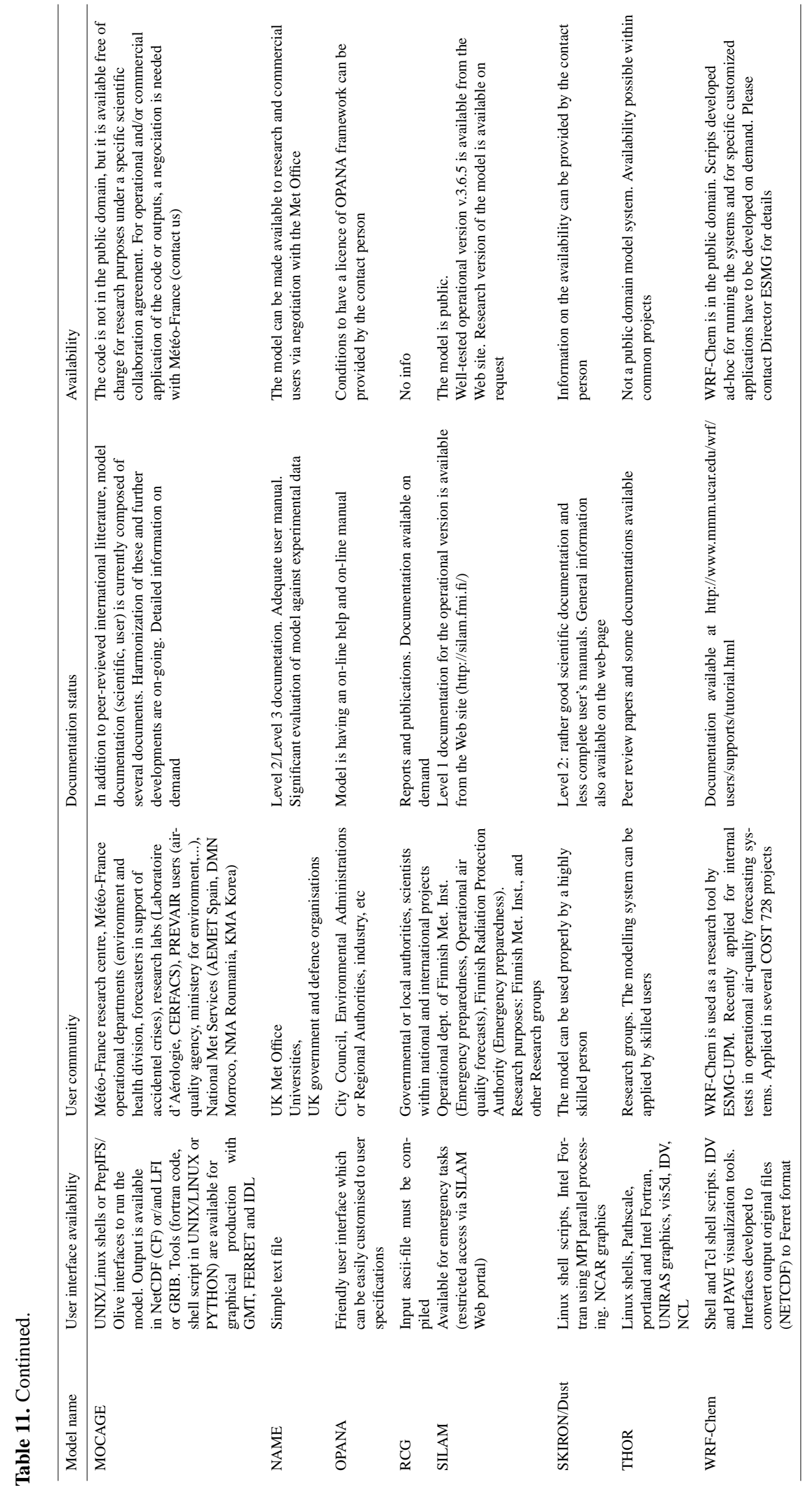


or predicted exceedance of alert thresholds, and any information threshold is provided to the public". On this basis, a set of CWF goals is defined that include the reporting of the geographical area of expected excedence of an air-quality threshold, the expected changes in pollution (such as improvement, stabilization or deterioration), and the reasons for those changes.

Moreover, the same directive states that "it is necessary to adapt procedures for data provision, assessment and reporting of air quality to enable electronic means and the Internet to be used as the main tools to make information available". This means that it is necessary to develop operational airquality management and citizen notification systems that will make use of modern information and communication technologies and will allow for the early forecasting of air pollution levels (Karatzas, 2010). This means that environmental authorities are required to operate systems that will include operational CWF models, and would allow them to estimate the spatial and temporal occurrence of air pollution, in advance of any actual incidents, and thus notify citizens and other interested parties.

Directive 2008/50/EC establishes the need to measure the uncertainty for a CWF model applied to a specific area, as well as the uncertainty of monitoring stations. It is important to take into account that scientific community, policy makers and citizens have relative different approaches to categorize and interpret model skill and the use of different categorical statistics such as hits, misses and false alarms (e.g. Barnes et al., 2007, 2009).

The users of CWF model output may be defined with the aid of the air-quality information provision requirements of the 2008/50 EC Directive, as well as from common practice (e.g. Fedra and Witner, 2009; Slørdal et al., 2008; Karatzas and Nikolaou, 2009). Specifically, we provide some examples of how CWF models are currently being applied by end users.

\subsubsection{Industry and business end-users}

The main interest of these users is to forecast the impact of industrial emissions from installations such as power plants and petroleum refineries. As these users are interested primarily in the output of CWF models, it is easier for them to commission these forecasts as a service rather than having to install and maintain the modelling system themselves.

One important category of the use of CWF model results is the assessment of air quality in industrial areas and their surroundings. The spatial scale in such applications may be of the order of from tens to hundreds of kilometers, and the temporal scale of the order of days, or years in case of forecasts for future scenarios. For example, in the case of a multi-source industrial complex, the MM5-CMAQ airquality management system may be applied (San José et al., 2006, 2008a, b). Due to the computational demand of such problems, a computer cluster or a multi-processor machine are among the most appropriate hardware set-ups, where the models are run in parallel, handling different emission scenarios. For these applications, the service provider usually prepares the software for managing the simulations, as well as the software required for the pre-processing of the input data and the post-processing of the results and the necessary web-based interfaces for the client. Such systems provide decision-making support for clients, who need to decide whether to switch off some emission sources, usually within the next $24 \mathrm{~h}$, to avoid an air-quality episode.

\subsubsection{The environmental decision and policy makers}

These users are responsible for making decisions about airquality abatement measures, as well as managing air-quality status and dealing with problems on a local to regional scale. An important category of users is city authorities. Clearly, city authorities are interested in the capability of the modelling system to forecast all the parameters that are required by the relevant regulatory framework, as well as the accuracy and accountability of the information that is being produced. In both cases, information dissemination is usually based on the automatic (or semi-automatic) preparation of tables and graphs, providing estimates of concentrations, their spatial and temporal evolution, and scenario-based estimates of the emissions and meteorology.

Designing and predicting forecast-based scenarios is important for decision making, as it allows authorities to take preventive measures to avoid an air-quality episode or reduce the duration or spatial scale of a forecasted episode, in accordance to the mandates of the 2008/50/EC Directive. Originally, many city authorities had maintained and operated their own operational CWF modelling systems. However, due to the increased complexity of the latest versions of such systems and the capacity required in terms of experienced personnel and hardware, the tendency now is to hire such services from partners such as institutes, universities or private companies that are active in this area, or to install the system locally and contract with consultants for services, upgrades, and maintenance.

\subsubsection{The CWF scientific community}

The CWF scientific community has a strong interest in the science and the understanding of CWF phenomena and problems. This community requires detailed information, which is usually of little or no interest to the other user communities. This information includes model performance indicators, model improvements, and environmental decisionmaking analysis data. Nevertheless, the detailed results of the operational CWF model calculations are generally not made available to those outside the group that has developed and is maintaining the CWF modelling system. 


\subsubsection{The general public and susceptible populations}

These include inhabitants of the area covered by the operational CWF models, as well as people living outside this area, who nevertheless are interested in the air-pollution levels near the area where they live or work. The susceptible populations comprise of children, the elderly, and adults with respiratory, cardiovascular or other relevant impairments. For these users, CWF models are combined with air-quality information systems, that make use of complementary pushpull communication channels (Zhu et al., 2002; Karatzas et al., 2005; Karatzas, 2007; Karatzas and Nikolaou, 2009).

The dissemination of the air-quality information to the general public is usually in the form of air-quality indexes, graphical representations of air-pollution levels, text descriptions, and multimedia. The means of dissemination are quite variable, including mass media, Internet, personalized SMS (short message system) messages, voice servers, and dynamic street-level displays. These characteristics have also resulted from the analysis of a set of air-quality information dissemination systems that was conducted under COST Action ES0602 (www.chemicalweather.eu; Kukkonen et al., 2009a). This COST Action inventoried the way that airquality information was disseminated to the public by analyzing data from 93 air-quality information systems, originating from seven European countries (Karatzas and Kukkonen, 2009). The air-quality information systems that were screened were divided into two types:

1. Those that disseminate air-quality information based on observational data. In many of the systems analyzed, air-quality observations are provided to the public on the basis of hourly data. In some cases, this information is made available in near real time (with a time lag of $1-2 \mathrm{~h}$ ), whereas, in other cases, this information is provided for the previous day, or up to the last period, for which data have been evaluated.

2. Those that disseminate air-quality information based on operational CWF model forecasts. However, in many of the air-quality information systems investigated, no CWF models were applied. This suggests that the CWF modelling community needs to apply models, not only for regulatory purposes, but also for producing information for all three categories of users. In the cases where CWF models were applied, these were mostly threedimensional models, although statistical models and computational-intelligence models were also employed in some cases instead of three-dimensional models. In some cases, human judgment is applied to estimate the quality of the atmospheric environment for those systems that have no CWF model support, whereas in some cases both human expertise and models are used.

\subsection{Dissemination of forecasts on the Internet}

To investigate the basic characteristics of operational CWF modelling systems, an analysis was made based on the systems that are currently included in the European Open Access Chemical Weather Forecasting Portal, which has been implemented within the framework of COST Action ES0602 (Balk et al., 2011; available at http://www.chemicalweather. eu/Domains, and registered as a GEOSS service in 2010). This portal provides access to available CWF systems in Europe in a user-friendly graphical format. The portal currently includes about 20 operational CWF modelling systems (12 included in this article) from across Europe, covering local to regional and continental scales of air quality. The basic characteristics of these systems are summarized in Table 12.

In all these studied systems, users only had to make one or two selections to obtain the information (in terms of graphs or maps). Many systems do not archive forecasts, whereas others archived information for the last two days or two months, and others archived years of data.

The Internet is the most popular way to disseminate output from operational CWF models. For the models in the European Open Access CWF Portal, many provide output in the form of concentration fields, usually superimposed on maps of the area of interest. The use of coverages (i.e. twodimensional pollution images) for the presentation of CWF results is the most popular method of relevant information dissemination. Such information usually includes various pollutants and refers to the surface (ground) layer, as well as in some higher vertical levels. Such output graphics are always geo-referenced (covers a specific geographic area) and time-stamped (usually of to $72 \mathrm{~h}$ ahead, in hourly intervals). Commonly, multiple CWF models produce information for the same geographical area and time. Yet, as every model uses its own color-scale for mapping pollution levels, geographic projection and other parameters of information presentation, it is not easy for the end user to compare information coming from different CWF systems. Importantly, model output is usually not accompanied by any quality and reliability indicators related to the forecasting performance of the model and the robustness and trustworthy of the forecasting service.

The seamless and comparable access to CWF results, quality of information, and reliability of service are considered to be the most important factors for the use of forecasts by every user community. In addition, different user communities have different interests in forecasting products. Citizens and the general population are usually interested in exceedances, their intensity, duration and location, as they would like to safeguard as much as possible their quality of life. For the same reason, users also prefer simple, intuitive methods of information presentation (e.g. graphs, color scales), and they do not like to receive graphs, tables and any type of information that requires additional expertise to be interpreted. They also prefer CWF products that are tailored to everyday 
Table 12. Dissemination of CWF system predictions in the Internet. The results correspond to characteristic properties for European regional-scale CWF systems (Balk et al., 2011).

\begin{tabular}{ll}
\hline $\begin{array}{l}\text { Operational CWF } \\
\text { modelling system } \\
\text { characteristic }\end{array}$ & Parameters and explanation \\
\hline $\begin{array}{l}\text { Forecasting } \\
\text { period }\end{array}$ & The time frame of the forecasting, ranging from $24 \mathrm{~h}$ to 3 days in advance \\
$\begin{array}{l}\text { Pollutants } \\
\text { forecasted }\end{array}$ & $\begin{array}{l}\text { Two to seven pollutants were addressed, and include } \mathrm{PM}_{2.5}, \mathrm{PM}_{10}, \mathrm{NO}, \mathrm{NO}_{2}, \mathrm{NH}_{3}, \\
\mathrm{O}_{3}, \mathrm{SO}_{2}, \mathrm{CO}, \text { benzene, and radon }\end{array}$ \\
$\begin{array}{l}\text { Information type } \\
\text { provided }\end{array}$ & $\begin{array}{l}\text { Varies on a case-by-case basis, and includes daily mean, daily maxima, hourly val- } \\
\text { ues, hourly averages, hourly maxima, } 8 \mathrm{~h} \text { running average (for Ozone), and }\end{array}$ \\
$\begin{array}{l}\text { Anformation } \\
\text { presentation }\end{array}$ & $\begin{array}{l}\text { In the majority of cases, the information is presented with the aid of two- } \\
\text { dimensional pseudo-color concentration contours. Some times are available as an- } \\
\text { imations or spot maps. Images are GIF formatted, and in a few cases are available } \\
\text { also as PNG files, or via a Java Applet }\end{array}$ \\
$\begin{array}{l}\text { Additional } \\
\text { information }\end{array}$ & $\begin{array}{l}\text { Some systems also provided information on the road and railroad network, wind } \\
\text { speed, cloud coverage, temperature, mixing layer, animated trajectories, wet depo- } \\
\text { sition, and time series graphs for selected locations. Animations of various days } \\
\text { were also available for some parameters ion some systems }\end{array}$ \\
$\begin{array}{l}\text { In the majority of cases, this was covered with HTML and AJAX. Although in many } \\
\text { cases, the solution adopted was HTML and PHP, or the applications used HTML } \\
\text { and Java, HTML, AJAX and Java, HTML, or PHP and AJAX }\end{array}$ \\
usechnology and
\end{tabular}

human activities, such as commuting and recreation, as was found for mesoscale weather information in the Helsinki Testbed (Koskinen et al., 2010). Policy makers prefer products that may help them in environmental management and decision-making tasks such as the number of exceedences and the most affected areas. Another useful product is a scenario-based analysis of alternatives that may help identify the potential of preventive or abatement measures (socalled it what-if scenarios). Scientists and CW experts prefer products that help them in developing a better understanding of the underlying phenomena, in analyzing the mechanisms (physical, chemical, etc.) employed in CWF, and in evaluating the accuracy of models and model ensembles.

A common demand by each category of users is that model results are made available seamlessly and in advance and that they be accompanied by near-real-time data coming from actual measurements. Overall, there is a growing demand for a service-oriented approach in CWF that can tailor related products to user categories in a more effective and reliable way.

\section{Emerging areas and future challenges}

The aim of this section is to highlight selected emerging scientific areas, as well as future challenges that would be expected to lead to improving the reliability of chemical weather forecasts. These topics include emission and chem- istry uncertainties (Sect. 7.1), integration of NWP and atmospheric chemistry transport models (Sect. 7.2), boundary conditions (Sect. 7.3), assimilating chemical data into the models (Sect. 7.4), improved understanding and parameterization of physical processes (Sect. 7.5), evaluation of CWF models against data (Sect. 7.6) and generation of model ensembles (Sect. 7.7).

\subsection{Emission inventories and modelling}

The evaluation of emissions is one of the main sources of the uncertainties in the predictions of the CWF models. In this section, we address the research challenges in terms of the pollutants and source categories, and in terms of how various emission inventories should be refined and harmonised.

\subsubsection{Research challenges of emission inventories of species and source categories}

Improvement is required for the emission inventories, particularly of PM and organic species. Most of the regional emission inventories currently consider $\mathrm{PM}_{10}$ and $\mathrm{PM}_{2.5}$; however, primary aerosol emissions need to be further specified in terms of the aerosol size distributions, chemical composition and source origins. Clearly, all the chemical constituents of PM are needed for particle mass closure, for determining the physical and chemical properties of PM, and for comparison with speciated PM concentration and precipitation-chemistry measurements. In 
Table 13. Brief demonstration of some sensitivity analysis applications with the examined CWF models.

\begin{tabular}{|c|c|c|c|c|}
\hline Model & Uncertain inputs & Method & Main findings & References \\
\hline CAMx & $\begin{array}{l}\text { Initial and boundary } \\
\text { conditions, emissions }\end{array}$ & $\begin{array}{l}\text { Direct Decoupled Method, } \\
\text { Tangent Linear Model }\end{array}$ & $\begin{array}{l}\text { Ozone changes predicted with the DDM sensitivities were compared } \\
\text { to actual changes obtained from simulations with perturbed by } \\
40 \% \text { inputs. The DDM sensitivities converged toward the brute- } \\
\text { force sensitivities for the perturbations in initial or boundary } \\
\text { concentrations while for the perturbations in VOC and/or } \mathrm{NO}_{\mathrm{x}} \\
\text { emissions, the magnitude of the predicted changes is } 10-20 \% \\
\text { smaller than the actual changes on average }\end{array}$ & $\begin{array}{l}\text { Dunker } \\
\text { et al. (2002) }\end{array}$ \\
\hline CAMx & $\begin{array}{l}\text { Boundary conditions, } \\
\text { area and point emissions }\end{array}$ & Tangent Linear Model & $\begin{array}{l}\text { The importance of the studied uncertain inputs varied among the } \\
\text { examined metropolitan areas (Athens, Milan, London) during the } \\
\text { selected episode days corresponding to the 98th annual ozone } \\
\text { percentile. However, the variation in only two inputs, namely } \\
\text { the boundary conditions of } \mathrm{O}_{3} \text { and the area emissions of } \mathrm{NO}_{\mathrm{x}} \text { was } \\
\text { found to produce the highest change in ozone concentrations in } \\
\text { the examined urban areas. In terms of validation, the linear } \\
\text { perturbation fields tangent linear model represented very well } \\
\text { in both location and magnitude the expected values for at least } \\
25 \% \text { reduction in } \mathrm{NO}_{\mathrm{x}} \text { and VOC emissions and for at least } 50 \% \\
\text { variation in the boundary conditions of ozone. }\end{array}$ & $\begin{array}{l}\text { Kioutsioukis } \\
\text { et al. (2005) }\end{array}$ \\
\hline CHIMERE & $\begin{array}{l}\text { Boundary conditions, emis- } \\
\text { sions, reaction rates, mete- } \\
\text { orological fields, dry depo- } \\
\text { sition }\end{array}$ & Adjoint Model & $\begin{array}{l}\text { The results point out three types of model parameters to which the } \\
\text { concentrations are very sensitive: (i) the boundary conditions } \\
\text { (mainly ozone, PAN and HCHO seem to have a relevant effect on the } \\
\text { simulated concentrations), (ii) the meteorological fields (such as } \\
\text { temperature, wind speed and vertical diffusivity) and (iii) the } \\
\text { surface emissions ( } \mathrm{NO}_{\mathrm{x}} \text { in the urban areas and VOC in the rural areas). } \\
\text { On the other hand, dry deposition was found to be not so sensitive. }\end{array}$ & Menut (2003) \\
\hline CHIMERE & $\begin{array}{l}\text { Boundary conditions, urban } \\
\text { emissions and chemical re- } \\
\text { action rates }\end{array}$ & Adjoint Model & $\begin{array}{l}\text { The ozone peak, for this particular day, is essentially sensitive } \\
\text { to traffic and solvent emissions (and about in the same ratio). } \\
\text { The sensitivity to reaction rates is fairly nhomogeneous: only } \\
\text { a few reactions are sensitive, among which the photochemical } \\
\text { equilibrium between } \mathrm{NO}_{\mathrm{x}} \text { and ozone, the reaction of } \mathrm{NO}_{2} \text { with } \mathrm{OH} \text {, } \\
\text { the photolysis of ozone and aldehydes and the oxidation of } \\
\text { reactive primary hydrocarbons. In terms of ozone boundary } \\
\text { conditions, it was found that a correct estimation of these } \\
\text { fluxes is of crucial importance for a correct simulation of the } \\
\text { ozone concentration in the urban area (Paris). }\end{array}$ & $\begin{array}{l}\text { Vautard } \\
\text { et al. }(2000)\end{array}$ \\
\hline CMAQ & Emissions, temperature & Adjoint Model & $\begin{array}{l}\text { The efficiency of the CMAQ adjoint was demonstrated in this study } \\
\text { through several examples. In particular, adjoint analysis can for } \\
\text { example: (i) identify the most influential emission sources that } \\
\text { contribute to the overall population exposure, (ii) quantify the } \\
\text { impact of increased ozone on crops and vegetation and in addition } \\
\text { indicate the sources where emission control can result in largest } \\
\text { reductions in the environmental exposure metric, (iii) measure the } \\
\text { effect of temperature variation on air pollution levels to e.g. } \\
\text { formally quantify the impact of future climate conditions on } \\
\text { regional air quality. }\end{array}$ & $\begin{array}{l}\text { Hakami } \\
\text { et al. (2007) }\end{array}$ \\
\hline $\begin{array}{l}\text { EURAD- } \\
\text { RIU }\end{array}$ & Emission rates & Adjoint model (4D-var) & $\begin{array}{l}\text { The objective of the present study was to test the potential of } \\
\text { the } 4 \mathrm{D} \text {-var method for emission rate optimization. It is } \\
\text { demonstrated that in the case of NO the emission rates can be } \\
\text { estimated, provided the first guess is not too far from the } \\
\text { locally governing chemical regime. Emission rates of VOCs could } \\
\text { not be analyzed individually. However, by adopting regularization } \\
\text { techniques, well established a priori knowledge of exhaust VOC } \\
\text { composition is introduced and a skillful analysis could be obtained. } \\
\text { In addition, temporal variations of the emitting sources could be } \\
\text { retrieved. In general, it can be concluded that four-dimensional } \\
\text { variational parameter estimation appears to be a promising tool to } \\
\text { analyze emission rates of various emitted, but not observed, } \\
\text { species, if some reasonable regularization assumptions can be made. }\end{array}$ & Elbern et al. (2000) \\
\hline
\end{tabular}


Table 13. Continued.

\begin{tabular}{|c|c|c|c|c|}
\hline Model & Uncertain inputs & Method & Main findings & References \\
\hline MOCAGE & Deposition velocities & Brute force & $\begin{array}{l}\text { The highest maximum relative differences are found for } \mathrm{HNO}_{3}(17 \% \\
\text { mean), with the largest differences to appear in the troposphere. } \\
\text { The next species in terms of large relative differences is } \mathrm{NO}_{2} \\
\text { (10\% mean). Then comes } \mathrm{OH} \text { and } \mathrm{O}_{3} \text { with means of } 5 \text { and } 2 \% \\
\text { respectively. For } \mathrm{O}_{3} \text {, the relative differences decrease rapidly } \\
\text { from the surface up to about } 800 \mathrm{hPa} \text {; the highest differences appear } \\
\text { in May. Finally, all maximum relative differences are below } 6 \% \text { for } \\
\mathrm{CO} \text { throughout the whole atmosphere. As for } \mathrm{ClO} \text { and } \mathrm{HCl} \text { they have } \\
\text { non significant relative differences in the troposphere due to their very } \\
\text { small mixing ratios, and relative differences lower than } 10 \% \text { in the } \\
\text { stratosphere. For } \mathrm{NO}_{2} \text {, relative differences are almost nil throughout } \\
\text { the atmosphere. The variability of the } \mathrm{HNO}_{3} \text { deposition velocity is } \\
\text { high as it is driven by the aerodynamic resistance and thus the } \\
\text { stability of the atmosphere. }\end{array}$ & $\begin{array}{l}\text { Teyssèdre } \\
\text { et al. (2007) }\end{array}$ \\
\hline
\end{tabular}

particular, particulate black carbon, organic carbon, and organic mass should be specified. Clearly, all aerosol chemical components, originated from various source categories, should be included in order to obtain an aerosol mass closure. Reff et al. (2009) have provided a review of the speciated PM emissions. Natural emissions of PM - for example, duststorms in arid or semi-arid areas, wild-land fires (e.g. Saarikoski et al., 2007; Sofiev et al., 2009; Saarnio et al., 2010) and sea-spray - are emerging areas of further research. In particular, information is scarce on the size distribution of particulate matter formed from natural dust sources and the temporal variability of dust emissions.

Substantial progress has recently been achieved in the representation of processes controlling biogenic VOC emissions (Monks et al., 2009). However, biogenic VOC emission models still need improved quantification by species type (e.g. isoprene) and increased number of species in inventories. Also numerous semi-volatile and low-reactivity organic compounds that contribute to secondary organic aerosol formation are not commonly included in the inventories. Information on the emissions of residential and other small-scale combustion is scarce, although its influence on the exposure of the population may be substantial in some countries and regions (e.g. Karvosenoja et al., 2008, 2010; Denby et al., 2010).

Major uncertainties remain for emissions from transport, including emissions from shipping and aviation, and on the vehicular non-exhaust emissions. For example, not all emis- sion inventories consider ship emissions, which can be important to air pollution in coastal areas (e.g. Jalkanen et al., 2009 and 2011). Also, uncertainties remain in the modelling of emissions that are dependent upon meteorology, such as allergenic pollen (e.g. Sofiev et al., 2006b, 2011a; Veriankaitë et al., 2010) and dust.

The man-made or natural activities that give rise to discharges of various substances into the atmosphere are identified in a reference list known as SNAP (Selected Nomenclature for Air Pollution). SNAP is structured on three levels: source sector, sub-sector and activity. Currently, the existing gridded anthropogenic emission inventories over Europe identify SNAP level 1 emitting sources. Improvement is required in the availability of European spatially resolved anthropogenic emission data for SNAP level 2 (and 3) emitting sources. Also, detailed libraries of temporal profiles and speciation profiles associated with these emitting sources could allow better temporal allocation and chemical speciation of pollutant emissions to be used in CTMs applications.

\subsubsection{Research challenges on harmonisation of emission inventories}

The lack of harmonisation of emission inventories at European and national levels is one of the main obstacles to the quantitative comparison of the predictions of operational CWF systems. Currently, the horizontal grid spacing of the emission inventories can be reasonably accurate for regional CWF systems (e.g. the grid spacing for the pan-European 
domain is $7 \times 7 \mathrm{~km}$ in the emission inventory within the MEGAPOLI project). However, the temporal variability of emissions and the vertical distribution of the heights of the emission sources are not considered accurate in all cases, and these aspects of the emission inventories need to be improved.

Further work is also needed to improve the relationships between global, regional and local inventories, especially for developing countries and urban areas. Global emission inventories (e.g. EDGAR, Emission Database for Global Atmospheric Research; IPCC/IIASA and Intergovernmental Panel on Climate Change/International Institute of Applied System Analysis) result in major uncertainties for the total emissions of individual major cities. For example, nonmethane hydrocarbon emissions for London as specified by the various available inventories differ by about $65 \%$; for Moscow and Paris, they differ by almost a factor of three (Gurjar et al., 2008). Even for $\mathrm{NO}_{\mathrm{x}}$ emissions, the emissions for Paris differ about by a factor of 2.5 and for Moscow more than $60 \%$ (Gurjar et al., 2008).

The global emission inventories commonly underestimate the urban emissions relative to national and municipality databases, as is the case, e.g. for the London Atmospheric Emission Inventory database (LAEI, 2009). A quantitative analysis of such differences is therefore needed, and more accurate emission inventories are required on regional and city levels. The first step in this direction was taken within the European CityDelta project (Sect. 5.3.2; Cuvelier et al., 2007). Within the MEGAPOLI project, a new emission inventory has been developed for Europe and the world, with downscaling to urban areas at a horizontal grid spacing of down to $1 \mathrm{~km}$ (van der Gon et al., 2009).

When CWF models are used with European gridded emission inventories on a smaller domain, numerical errors are caused due to grid interpolation (as there may be different grid spacings and orientation, and map projections). Clearly, such errors can result, even if the CWF model applies a grid spacing that is similar in magnitude, compared with the larger domain grid spacing.

\subsubsection{Research challenges on the temporal variation and satellite observations in emission modelling}

Because CWF models typically use emission inputs with data every hour, emission models are used for characterization of daily, weekly, monthly and yearly cycles of sources or their categories. For anthropogenic sources, these models are usually static and simple. Typically, multiplicative coefficients are used to calculate proportions of the total annual emissions appropriate for a given month, weekday and hour. The next generation of dynamic anthropogenic emission models could take inspiration from energy consumption models, which take into account meteorological variables, especially ambient temperature, cloudiness and wind speed. For example, combustion, which is one of the key emission sectors, could be represented in this manner. For operational air quality forecasting, the available inventories are always retrospective and never current. Similarly, in non-operational research projects, the availability of sufficiently up-to-date emission inventories is commonly a challenge, for instance, in the simulations of project field experiments.

Satellite instruments (e.g. OMI, GOME-2 - the Global Ozone Monitoring Experiment, MODIS - Moderate Resolution Imaging Spectroradiometer, MOPITT - Measurements Of Pollution In The Troposphere) provide new opportunities for evaluation and data-driven estimates of emissions. Burrows and Borrell (2009) provide an overview of different instruments. Standard approaches to analyzing satellite data often involve comparing long-term averages of satelliteretrieved columns with simulated columns based on a CWF model. This approach can also be used to evaluate emission inventories. Another approach to estimate the longterm trends in emissions is the so-called analog approach where trends in observed columns are compared to trends based on inventories (e.g. Konovalov et al., 2008). Adjoint (i.e. inverse) dispersion modelling can also be used to evaluate the emissions or the sensitivities of concentrations with respect to changes in emissions (e.g. Tanimoto et al., 2008; Kurokawa et al., 2009), or even to reveal inaccuracies or mistakes included in emission datasets (Prank et al., 2010).

\subsection{Improved integration of NWP and atmospheric chemistry transport models}

Historically, air-pollution forecasting and NWP were developed separately and the corresponding communities had limited contact and cooperation. Although this situation could be tolerated in previous decades when NWP data were rarely available operationally for chemical weather forecast models and the resolution of NWP models was too coarse for mesoscale air-pollution forecasting, this situation has changed during this century as modern NWP models approach or include mesoscale and city-scale resolution. This progress has been possible due to advances in computing power, high-speed computing networks and the availability of land-use databases and remote-sensing data on a finer resolution.

As a result, the conventional concepts of air-pollution forecasting may need revision, as greater integration is required between NWP models and atmospheric chemical transport models. Several national meteorological services (e.g. Environment Canada, DMI, FMI) have suggested extending meteorological weather forecasting to environmental forecasting that includes both NWP and CWF. Clearly, this concept would ideally also include biological forecasting, such as allergenic pollen species (Kukkonen et al., 2009a, b, c; Baklanov et al., 2010b).

The on-line integration of NWP or other meteorological models with atmospheric chemical transport and aerosol models has several advantages. Such an integration provides 
the opportunity to use all three-dimensional meteorological fields in CTMs at each time step and to include feedbacks of air pollution (especially those due to aerosol particles) onto meteorological processes. Extensions into climate modelling include the feedbacks between air pollution and climate forcing, as well as the atmospheric chemical composition. Such a future research direction could be viewed as part of a step towards Earth Modelling Systems and could potentially lead to a new generation of models for NWP and CWF (Baklanov, 2010b).

However, the on-line approach is not the best way for model integration in all cases. For some tasks, such as for emergency preparedness, when NWP data are available, offline coupling can provide results more quickly. Both off-line and on-line coupling of NWP models and CTMs are therefore useful. A future research area will therefore be to assess the interfaces of these two categories and to establish a basis for their harmonization and benchmarking.

The communication between off-line coupled meteorological and chemical weather models is a problem of oftenunderestimated importance. The multitude of modelling systems previously introduced gives rise to different approaches and methods implemented within interface modules. Tasks covered by interfaces are minimized in coupled systems. Other systems use interface modules that implement surface and boundary-layer parameterisations to estimate dispersion parameters. Sometimes these latter choices are due to the need to rely on conventionally used meteorological products and to guarantee the robustness of chemical weather modelling for practical applications.

In other cases, interfaces are used to enhance the resolution of local physiographic data and possibly to introduce advanced parameterisations (e.g. those for the urbanisation of models). Atmospheric physics parameterisations - and even default and upper- or lower-limit values assumed for some key parameters - can have effects on pollutant concentration fields in critical conditions (e.g. low wind-speed conditions, stable conditions). Moreover, interface modules may involve the evaluation of emissions of species that can be substantially influenced by meteorology, such as biogenic VOC, windblown dust and sea-salt spray.

Improvements in CWF will also come from assimilating physical parameters that will lead to better estimates of clouds and mixing-layer heights. For example, the assimilation of satellite-derived skin temperatures can be used to better determine heat capacity and moisture fraction of grids. Such data can fill gaps in diurnal energy budgets, resulting in improved short-term forecasts of temperatures, mixing heights, clouds, and photolysis rates (McNider et al., 2005; Arastoo et al., 2007). The recently established new COST Action ES1004: European Framework for On-Line Integrated Air-Quality and Meteorology Modelling (EuMetChem) will focus on further development of integrated CWF systems and on the new generation of online integrated chemistry and meteorology models with two- way interactions between atmospheric chemistry (including gases and aerosols), clouds, radiation, boundary layer and other meteorological and climate processes.

\subsection{Boundary conditions and nesting of CWF models}

An important aspect in the regional applications of CWF models is the type of initial and chemical boundary conditions used by CWF models. The use of climatological averages is one of the common practices, but implementing boundary conditions obtained from global chemical weather models is currently a significant challenge (Tang et al., 2007). This challenge consists of obtaining the required parameters (especially regarding the properties of particulate matter) from the global model within enough time and at sufficient resolution to produce a real-time forecast. Another emerging research area is the development of optimal nesting techniques of CWF models from the global to city scale, using one- or two-way nesting techniques, with boundary conditions on the inner domains provided from larger-scale model domains. For instance, in the PASODOBLE project, most participating models are first used to compute Europeanscale air quality using global chemical boundary conditions from the global MOZART model from the MACC project, and then applied using nesting inside the same participating model.

Chemical boundary conditions from global CWF systems are already provided operationally to some regional CWFSs around the world. For example, within the MEGAPOLI project, the global forecasts are provided by the MATCH-MPIC (Max Planck Institute for Chemistry version) model. These provide boundary conditions for several operational European regional CWFSs. The ECMWF global CWF model provided chemical boundary conditions for the regional-scale European CWF models in the GEMS project. The global CWF ensemble to be constructed in the MACC project will update the regional model ensemble provided within the GEMS project.

Although using boundary conditions from global models should in principle improve predictive skill in regional models by providing more realistic temporal and spatial variability, they also can transfer biases and errors. Further improvements are therefore needed in the observing systems that provide information on the three-dimensional pollutant concentrations. For example, such improvements are needed to better quantify the long-range pollutant transport of Saharan dust to Southern Europe and Asian brown dust cloud to the US West Coast (Huang et al., 2010).

\subsection{Data assimilation of chemical species}

As near-real-time measurements of chemical concentrations are limited, one of the challenges in CWF is how to insert that data into the models to obtain the best initial conditions (e.g. the initial spatial concentrations of the relevant chemical 
species) and to improve the quality of CWF. The way this data is inserted is called data assimilation. Powerful assimilation techniques may actually be more critical for achieving accurate forecasts than improvements in the model formulations, at least regarding the short-range forecasts (1-2 days) (e.g. Carmichael et al., 2008a). The implementation of the various chemical data assimilation methods in CWF models is therefore one of the crucial tasks in the improvement of regional CWF models.

The assimilation of meteorological data has traditionally been an essential part of weather forecasting. Different methods of data assimilation are used in NWP models: Newtonian nudging, optimum interpolation, regional fourdimensional data assimilation (FDDA), ensemble Kalman filter (EnKF), the three-dimensional variational (3DVAR) and four-dimensional variational (4DVAR) data assimilation. In CWF, EnKFs and 4DVAR are most commonly used. Although beyond the scope of this paper to provide a description of these methods, we provide a few remarks relevant for data assimilation into $\mathrm{CW}$ models.

In both the 4DVAR and EnKF approaches, the difference between observed and model values is measured by a weighted sum of squares, where the weights are constructed from several covariance matrices. These matrices reflect uncertainties in both data and model, and at least some of them have very large dimensions. Ensemble methods circumvent the intractability of large covariance matrices by approximating them by an ensemble of model states (in the CWF case, these are usually states of the CWF model).

The EnKF advances each member of an ensemble one time step ahead. Then, an EnKF updating formula is applied, using observed data and covariance matrices approximated by low-rank sample covariance matrices defined by the ensemble. The classical EnKF update formula is based on assumptions of an unbiased model and the error distribution being Gaussian. In real-life applications, nonlinearity of chemical reactions causes departures from the Gaussian, whereas deficiencies in the model and errors in the inputs contribute to the bias (one typical example is nightly values of ozone in some models). The departures from the EnKF assumptions are much larger in CWF models than in NWP models. These issues and other types of filters are studied in Hanea et al. (2007).

A substantial difference between data assimilation in NWP models and CWF models is due to different types of model equations. In CWF models, stiff differential equations with forcing terms from meteorological and emission inputs make the model quickly converge from any reasonable initial conditions to a stable solution. Thus, in off-line CWF models, improvement of initial conditions by means of data assimilation brings only a limited improvement in the forecast. The same issue causes loss of spread in ensembles generated by perturbations of initial conditions. The sample covariance matrices generated by the ensemble become ill-conditioned, and covariance inflation or similar methods have to be used to avoid divergence of ensemble filters (Eben et al., 2005; Constantinescu et al., 2007).

Another challenge for the use of data assimilation in CWF models is that the number of chemical species in the models varies from tens to hundreds). A key issue is choosing which chemical species to optimize in order to provide the best results of the target forecast species. In variational methods, one may select a receptor location and investigate which variables or parameters are responsible for changes and errors of the model at the receptor. These methods (called adjoint sensitivity analysis or receptor-oriented approach; Carmichael et al., 2008a) may be used to select state variables for data assimilation. Also, short-lived species and radicals are usually not subject to optimization.

The difficulties mentioned above are the main reasons why data assimilation in CWF models has grown slowly relative to NWP modelling. Operational forecasting with incorporated data assimilation is occurring for the EURAD model and for RCG (only ozone maxima), and research-based studies have also been performed for LOTOS-EUROS, MATCH, RCG and SILAM. Most of the operational CWF models are routinely initialized using concentrations of species obtained from the forecasts of the previous day, with no regard to the observations. In order to make data assimilation more beneficial for the forecast, other parameters than initial conditions should be optimized, too, and the assimilation could be continued after the initialisation phase. Emission rates are the first candidate for optimization, but photolysis rates and deposition rates also may come into consideration (Hanea et al., 2004). However, stability and validity (from the point of view of chemistry or emission modelling) of such corrected parameters has to be checked in order to avoid artifacts.

Instead of optimizing initial conditions and other parameters for the operational forecasts, more sophisticated data assimilation methods can be applied. A fast-growing research area is inverse modelling of emissions using adjoint methods and 4DVAR. Although it is being used mainly in global modelling for monitoring atmospheric constituents (e.g. Kopacz et al., 2010), its benefit to forecasting has also been demonstrated (e.g. Elbern et al., 2000, 2007 for the EURAD model). In the US, the adjoints of the global model GEOS-Chem (Henze et al., 2007) and mesoscale models STEM (Sandu et al., 2005) and CMAQ (Hakami et al., 2007) have been developed. Adjoint modelling methods have been briefly reviewed in Table 13.

Research on both inverse modelling and data assimilation has been boosted by the availability of satellite-retrieved measurements (e.g. Chai et al., 2009). Global spatial coverage, better representativeness of the measured area and gradually improving resolution are the main virtues of these data, whereas censoring by clouds, relatively poor time resolution (e.g. two times daily over one spot) and inaccuracies of the retrieval process are the main drawbacks. Satellite instruments can also provide information that is largely complementary to that obtained from in-situ measurements. An 
overview of European research on remote-sensing of tropospheric constituents is given by the ACCENT-TROPOSAT-2 (Atmospheric Composition Change the European Network - Use and Usability of Satellite Data for Tropospheric Research) report (Burrows and Borrel, 2009). We confine ourselves here to some general remarks related to CWF.

The satellite-based abundance data, which enter a data assimilation system, are most commonly integrated over the whole atmospheric column, although vertical profiles are also provided in some cases (e.g. the IASI instrument - Infrared Atmospheric Sounding Interferometer). Tropospheric columns are derived from total columns; one then has to address the generally poorer sensitivity of satellite observations to concentrations in the lower troposphere. Cloud cover has to be estimated, as well as other meteorological variables. For example, air-mass factor (the ratio between the retrieved slant column and the atmospheric vertical column) is needed for knowing the absorption of the light path through the atmosphere. As a result, satellite columns are a result of a complicated retrieval process leading from the observed spectra to a vertical column density. The uncertainty of the retrieval process therefore needs to be quantified for successful data assimilation.

In the future, real-time regional-scale CWF models may use data assimilation of the vertical distribution of chemical species using the vertical profile from a global $\mathrm{CW}$ model as a first guess. For example, a global CWF model TM (http://www.knmi.nl/ velthove/tm.html) is used in retrieving $\mathrm{NO}_{2}$ column from the OMI instrument in the near-real-time service TEMIS (Tropospheric Emission Monitoring Internet Service, www.temis.nl) of the European Space Agency.

\subsection{Improved understanding and parameterization of physical processes}

The improvements required for the understanding and parameterization of subgrid-scale physical processes for CWF include at least two emerging areas. The first area is the accuracy of meteorological parameters (e.g. atmospheric boundary-layer structure, velocity, temperature, turbulence, humidity, cloud water, precipitation) within NWP models or in meteorological pre-processors (e.g. Fisher et al., 2006). The second area is the description of the interactions of chemical species in the atmosphere (e.g. clouds, radiation, removal processes, chemical reactions, aerosol formation and dynamics) within CWF models themselves.

Areas of necessary NWP model improvement include the overall treatment of complex terrain and rough surfaces (e.g. for urban areas), turbulence closure and mesoscale convection. The description of complex terrain and mesoscale circulations can be of crucial importance in CWF models (e.g. Millan et al., 1996; Gangoiti et al., 2001; Dayan and Levy, 2002; Dayan and Lamb, 2005). Among the most challenging cases for CWFSs to predict are episodes of high pollutant concentrations, which commonly occur with low winds and stable stratification, sometimes in complex terrain (e.g. Kukkonen et al., 2005a, b). These situations create problems for current methods and models to realistically reproduce meteorological input fields. In particular, the currently used NWP models may have severe problems in forecasting the occurrence and strength of strong ground-based temperature inversions (Pohjola et al., 2004; Rantamäki et al., 2005; Kukkonen et al., 2005a, b). A gap has thus emerged between modern understanding of boundarylayer physics and the limited applicability of boundary-layer schemes in operational CWF models.

As most of the pollutants are dispersed within the boundary layer, the mechanisms controlling concentrations substantially depend on the turbulence and the boundary-layer height. The temporal and spatial variations of the boundarylayer height and the entrainment processes at the top of the boundary layer lead to the infiltration of pollutants from the boundary layer to the free troposphere and, vice versa, to the intrusion of some chemical compounds (e.g. ozone) from the upper-atmospheric layers down to the surface. Physical processes controlling the boundary-layer height and the turbulent entrainment are therefore of crucial importance for CWFSs. Some of the important physical processes at the top of the boundary layer (e.g. Zilitinkevich et al., 2007) are still insufficiently understood, such as turbulent entrainment in rapidly deepening convective boundary layers and nonsteady interactions between the stable boundary layers and the free flow. In the presence of cloud-topped boundary layers, the mixing and dispersion of gases is not always reflected well in traditional parameterization models, in which clouds usually suppress dispersion by diminishing solar irradiance. Due to the reduced vertical diffusion caused by clouds, precursors tend to remain near the ground level. As a consequence of the non-linearity of many chemical reactions, these concentration gradients can lead to different chemical reactions.

Most of the operational CWF models use simplified wet deposition schemes based on two-dimensional surface precipitation intensity data; however, on-line integrated models (e.g. Enviro-HIRLAM) are allowed to realise more comprehensive schemes using fully three-dimensional real-time cloud characteristics. One of the challenges in this emerging area is to improve the quality of the simulation of cloud processes and precipitation forecasts within NWP models. Increasing computational power makes it possible to decrease the horizontal and vertical grid spacings of the models. As the physical parameterization is dependent on the resolution of a prediction model, some adjustments of parameterizations have to be made when the resolution is increased.

Piriou et al. (2007) presented an approach in which the grid-scale budget equations of parameterization used separate microphysics and transport terms. This separation is used both as a way to introduce into the parameterization a more explicit causal link between all involved processes and as a vehicle for an easier representation of the memory of 
convective cells. Piriou et al. (2007) argued that future results could be improved by using more complex microphysics (e.g. prognostic liquid, ice, rain, snow), getting closer to that of a cloud-permitting model, and relaxing the small-area assumption. As discussed by Roebber et al. (2004), however, the interpretation of forecasts at cloud-permitting resolutions becomes different than at larger grid spacings, complicating - if not offsetting - advantages of going to smaller scales.

In the future, a possible perspective will be to unify the convection parameterization, using a single equation set at grid-scale and a single microphysical package. As an example, Gerard (2007) has introduced microphysics and transport advective scheme equations into a scheme using more complex prognostic microphysics, area fraction, and vertical velocity with encouraging results. Gerard (2007) developed a package that aims at efficiently combining resolved and subgrid condensation at all resolutions, in particular in the range between 10 and $2 \mathrm{~km}$, where deep convection is partly resolved and partly subgrid.

Knowledge of the emissions of relevant organic species and their atmospheric chemistry limits the understanding of secondary organic aerosols, which are of importance for both air quality and climate change (e.g. Monks et al., 2009). Correspondingly, the models for aerosol formation and dynamics need to be implemented into CWF models, and the chemical mechanisms used in CWF models should be substantially improved to be able to simulate sufficiently accurately such processes.

Combined models have already been developed for chemistry transport modelling and aerosol processes, including the size distributions and chemical speciation (e.g. Vignati et al., 2004; Gross and Baklanov, 2004; Dusek et al., 2006; Pohjola et al., 2007; Hussein et al., 2007; Medina et al., 2007; Langmann et al., 2008). The aerosol processes include the growth and nucleation processes, and the transport and deposition pathways of the aerosols. Furthermore, as aerosol dynamics models (this term is used here as a synonym to aerosol process models) are important tools to investigate both the direct and the indirect effects on climate, aerosol-radiation-cloud interactions are important processes that need to be treated in the models (Ramanathan et al., 2001; Rosenfeld et al., 2008; Levin and Cotton, 2009). Several of these processes require direct coupling of the meteorological and chemical weather models.

These processes need to be included to achieve a comprehensive representation of the atmosphere. State-of-theart aerosol modules include a sectional representation of the size and chemical composition distribution functions, as well as aerosol microphysical processes. However, the available emission databases do not currently provide sufficient detail for executing such combined dispersion and aerosol process models over extensive regions. This means that estimates of the sectional emissions that are needed as input for the detailed models have to be mostly based on indirect information.
Improvements in three-dimensional wet-deposition mechanisms within and below clouds for interacting different chemical gas and aerosol species are needed. Improvements in the parameterization of pollutant emissions removal processes in the subgrid-scale are also required. Any removal that may occur near the emission source (on a scale of tens to hundreds of meters) is usually beyond our present capability. Pace (2005) discuss the need to treat the subgrid-scale, near-source fugitive dust emissions removal by settling and impaction on surface cover.

\subsection{Better evaluation of CWF models with data}

Model evaluation is fundamental to build confidence in the models and their specific applications. Nevertheless, the evaluation of models by comparison with measured data also has to advance the model performance, rather than solely characterize whether a simulation is successful or not (e.g. Gilliland et al., 2008). The comparisons should use as broad and diverse set of measured data as possible. Currently the evaluation of chemical weather models is mainly based on the comparison of measured and simulated concentration levels at ground level, although satellite data is also commonly used. Clearly, a data comparison only based on one vertical level does not assure a proper simulation of the state of the atmosphere. Whenever possible, vertical profiles of air pollutants, such as MOZAIC data (Kalabokas et al., 2007), should be included in the evaluation procedure.

Moreover, the performance of models is usually evaluated only for a limited number of pollutants, such as $\mathrm{NO}_{\mathrm{x}}, \mathrm{O}_{3}$ and $\mathrm{PM}_{10}$, which are the ones measured routinely at most monitoring networks. An ideal comparison would be based on the analysis of a sufficiently large number of pollutants, for the selected period of time (or periods) and location (or locations). Clearly, monitoring supersites (or their networks), such as the EPA's particulate matter supersites (e.g. Sioutas et al., 2004; Stanier and Solomon, 2006) or the Mace Head Research Station supersite in Ireland (e.g. Cape et al., 2000; Heard et al., 2006), are useful for this kind of evaluation and could potentially allow for an evaluation of the model capabilities to simulate various physical-chemical processes.

A special concern for the evaluation of operational CWF models is the availability of near-real-time meteorological and air quality data. Efforts to deliver near-real-time data (centralised in a common and accessible database) have been made within the GEMS project, which fits into the current WMO (World Meteorological Organization) activities. However, there is still a substantial amount of work to be done in this area; fast mechanisms need to be developed, implemented and tested to access the data and to evaluate the CWF models.

Currently, the evaluation of particulate matter in models commonly uses mostly the measurements of $\mathrm{PM}_{10}$ and, only to a smaller extent, $\mathrm{PM}_{2.5}$, and size- and chemicallyresolved PM data. However, the evaluation of models in 
Europe should in the future focus on $\mathrm{PM}_{2.5}$ (or $\mathrm{PM}_{1}$ ) instead of $\mathrm{PM}_{10}$, as it is more relevant from a health perspective. Clearly, more focus should also be on transferred to other PM measures instead of particulate mass, such as particle number concentrations, ultrafine particles, and chemically resolved size distributions. Due to the new European legislation, $\mathrm{PM}_{2.5}$ monitoring data will be extensively measured in the European Union, and the new monitoring network needs to be evaluated.

Furthermore, the understanding and evaluation of the chemical components of particulate matter is needed to ensure that the model predictions are right for the right reasons and to close the gap between modeled and measured concentrations of PM. For instance, the evaluation of only the total $\mathrm{PM}_{10}$ concentration may not reveal serious shortcomings in the treatments of the PM components in the model. Moreover, size-resolved PM data are crucial to reduce uncertainties in our understanding of the modelling of the emissions, dispersion and transformation of PM. Aerosol chemistry and process modules are needed to evaluate the aerosol components. In that case, the model evaluation does not need to be restricted to only $\mathrm{PM}_{10}$ and $\mathrm{PM}_{2.5}$.

Clearly, measurements routinely carried out at air pollution networks can only be used for model evaluation in case of a limited set of chemical components and measures. Species of interest for model comparison are not necessarily measured (e.g. peroxyacetyl nitrate (PAN), aldehydes, actinic flux, turbulent flux, other particulate matter measures except for PM masses), and the measurement locations are not always representative of the regional background air (e.g. the station could be located downwind of an urban area). In addition, the vertical profiles of concentrations are typically not measured.

More emphasis should also be given to the systematic evaluation of the spatial representativeness of the monitored and simulated data. Clearly, when comparing model predictions to measured data we compare one spatially and temporally averaged value (a predicted one) to another one (the measured one). However, in general, the averaging or representative space and time scales are not the same (Kang et. al., 2007).

The model evaluation against observed data requires statistical analysis that should provide information about the ability of the model to predict the observed values and type of errors (systematic or unsystematic). Generally, the statistical analysis contains a computation of a set of parameters and measures. It is possible to define various subsets of such statistical parameters that can fairly well represent the various aspects of the performance of the model (e.g. correlation coefficient, fractional bias, root and normalized mean square errors). However, these statistical quality indicators should be accompanied by other methods - time series and scatterplots could be an important complement to the above statistical indicators. Clearly, parameters that reflect the ca- pability to simulate concentration peaks should also be taken into consideration in CWF.

Besides the comparison of model results to data, several other steps should be considered to ensure model quality. These include model sensitivity tests, model intercomparisons and uncertainty analysis (e.g. Borrego et al., 2008). Several international model intercomparison exercises have been and are currently ongoing within the MEGAPOLI and MACC projects, CityDelta and EURODELTA (Sect. 5.3), various COST Actions, AQMEII and FAIRMODE (Forum for AIR quality MODElling). Such intercomparison exercises are useful to identify the strengths and weaknesses of models, and to show the strategies to improve their performance. Their important role in collecting intensive data during special field campaigns to assist diagnostic evaluation of model processes should also be acknowledged.

\subsection{Model ensembles}

Ensemble forecasting has been a key area of traditional meteorology during the last few decades (Lewis, 2005). From the experience of operational meteorology, two major sources of forecast errors can be distinguished. In operational meteorology, the first source resides in the uncertainties of the initial meteorological conditions, as a result of the limited number and inaccuracies of available observations. The second source is the imperfection of the NWP models, resulting from limitations in the descriptions of physical processes, the finite spatio-temporal resolution of numerical models and the inability to explicitly resolve and simulate processes beyond the selected grid scale. As a consequence of these two sources of forecast errors, and due to instabilities of the flow itself, weather forecasts deteriorate as the forecasting period increases.

In addition to the accuracy of the initial conditions and the limitations of the numerical model, the forecast skill also depends on instabilities of the flow itself, as was already identified in the early works of Lorenz (1963, 1965). Simmons et al. (1995) note the difficulty in assessing a priori whether a forecast would be skillfull or unskillfull, using only a deterministic approach to weather prediction.

Two important benchmarks occurred in the implementation of operational ensemble prediction systems, at both ECMWF and NCEP (e.g. Palmer et al., 1993; Molteni et al., 1996; Tracton and Kalnay, 1993). These systems were focused on the perturbation of the initial conditions, following indications on the relative importance of the uncertainties in initial conditions compared to deficiencies in the model (e.g. Downton and Bell, 1988; Richardson, 1998). Ensemble forecasting continues to be an area of active research in NWP, specifically the design and composition of the ensembles (e.g. Kalnay, 2002).

Ensemble CWF is still an emerging area (e.g. Potempski et al., 2008). There are currently numerous well-evaluated CWFISs in Europe that are used both for research and 
operational applications in direct support of decision making. However, any of these single modelling approaches bears inherent uncertainties, both originated from its formulation, the parameterization used, and from the input data used (e.g. meteorology, emissions, chemical rate constants). It is therefore desirable to enrich the information provided by the individual deterministic models with probabilistic information (e.g. Kukkonen et al., 2009c). The three key objectives of ensemble forecasting (e.g. Kalnay, 2002) are to (i) improve the forecast by ensemble averaging, (ii) to provide an indication of the reliability of the forecast, and (iii) to provide a quantitative basis for probabilistic forecasting. The spread of predictions in a collection of models can also be used as a measure of the model uncertainty (Vautard et al., 2006). The comparison of the predictions of model ensemble and those of the individual models can also give valuable insight on model performance, e.g. regarding model outliers for specific pollutants or conditions.

Compared to traditional weather forecasting using model ensembles, chemical weather ensemble prediction has a much shorter historical record. Early studies comprise works in the field of chemical weather forecasting (Delle Monache and Stull, 2003) and chemical transport modelling (Galmarini et al., 2004b, c). As in NWP, these studies have investigated both techniques based on the perturbation of single modelling systems (Mallet and Sportisse, 2006) and on a collection of results from different modelling systems (van Loon et al., 2007; Vautard et al., 2008). Unlike in meteorology, however, air quality is not primarily determined by initial conditions but rather is the result of a range of processes such as emissions, transport, deposition and chemistry that all provide tendencies with similar orders of magnitude. This state of affairs requires one to develop approaches that are more complex than the well-established techniques used in numerical weather prediction (e.g. Pinder et al., 2009).

The forecasts obtained by processing the ensemble of models (for instance, taking the median of all values in each grid-point) can, in many cases, perform better than any single model. Riccio et al. (2007) have proposed a theoretical basis in the case of dispersion, providing some justification to the relatively better performance of the median of models. Recently, Galmarini et al. (2010) evaluated various ensemble atmospheric dispersion simulations for the ETEX1 tracer experiment case. They analyzed on one hand the so-called multi-model prediction systems that rely on model simulations produced by different CTM's using meteorological data from potentially different weather prediction systems, on the other hand prediction systems running a single atmospheric dispersion model with the ensemble weather prediction members.

The current operations in the GEMS and MACC projects have used a more elaborate ensemble technique, based upon the differential weighting of the individual models according to their skill over the last few days. However, a long-term improvement in CWF performances will be based on the improvement of individual models and their representation of dynamical, physical and chemical processes.

\section{Conclusions}

What do we see in the future for CWF models? To summarize this paper, we focus on two challenge areas: the large number of chemical species and processes, and communicating uncertainty.

First, although a relatively new field, CWF is developing quickly, touching upon research, development, and operational forecasting. An analogy with weather forecasting can be useful to demonstrate the challenges ahead. Although CTMs can be coupled to NWP models either off-line or online at present, a scientific perspective of CWF would argue for an eventual migration from off-line modelling (where the CTM is run after the NWP model run is completed) to on-line modelling, allowing coupling and integration of the physical and the chemical components of CWFISs. Such a future is not hard to imagine, given similar trends of Earth system modelling, for example. Specifically, better and more complete representations of physical and chemical processes and interactions in the models are needed. When compared to weather forecasting, CWF still has a long way to go. Despite the nearly 50-yr lead that NWP has over CWF (e.g. Harper et al., 2007), CWF models have other challenges that inhibit as rapid a progress.

A key challenge appears to rather be the dimensionality and complexity of the problem itself. For example, the traditional set of prognostic state variables in weather forecasting (e.g. temperature, wind, precipitation) expands to hundreds of prognostic variables because of the extensive number of chemical species involved. In particular, resolving, simulating, and parameterizing processes is no longer limited to relatively well-known physical processes, but is compounded by a huge amount of both chemical and physical processes (e.g. interactions between species, emission, deposition, radiation). This simple fact has important ramifications for predictability, data assimilation, and ensemble prediction, where scientific and technological progress in CWF is slower than in traditional meteorology. Importantly, progress is also inhibited by the lack of or insufficient monitoring of many relevant species, the lack of sufficient chemical and aerosol measurements, and the lack of well-established monitoring dataexchange mechanisms, although several projects and initiatives are working to address these issues.

Second, as is evident from this review article, numerous well-evaluated operational CWFISs operate in Europe, addressing the needs of a large spectrum of users from governmental organizations to the individual citizen (e.g. Schluenzen and Sokhi, 2008; Karatzas and Kukkonen, 2009; Baklanov et al., 2010b; Balk et al., 2011). Despite these numerous activities, it is challenging to transfer the output from 
CWF models for the end users in a form that is properly assessed and interpreted. Moreover, how do we interact with those users to provide the needed services? Through initiatives such as the GMES Atmospheric Service and its implementation projects GEMS, PROMOTE, MACC and PASODOBLE and the various relevant COST actions, such as COST 728, ES0602 and ES1004 scattered modelling initiatives and efforts - which are often national or regional in scale - can be integrated. Such integration also offers the possibility to move from deterministic forecasts of chemical weather to ensemble chemical weather prediction systems.

With the ability to assess and explore ensemble prediction systems comes the challenge in communicating probabilistic chemical weather forecasts. Again, many lessons can be learned from the weather forecasting community, who are actively facing such concerns with weather forecasts, in general (e.g. Board on Atmospheric Sciences and Climate, 2006; Novak et al., 2008; Morss et al., 2008; Rauhala and Schultz, 2009), and the communication of hurricane tracks, in particular (e.g. Broad et al., 2007). Although some user communities of weather information (e.g. industrial, agricultural, hydrological) are comfortable dealing with probabilistic forecasts, many chemical weather users are relatively new to this concept. Thus, much can be gained through a closer dialogue with relevant user communities (e.g. the so-called "end-toend-to-end" approach described by Morss et al., 2005), and this communication can spawn future research opportunities.

Successful CWFIS services will also need to aggregate and integrate information and deliver it in a way that is comprehensible, user-friendly, timely, and reliable. International activities such as the WMO Global Atmospheric Watch Urban Research Meteorology and Environment (GURME) project can assist in these efforts. As a first step, the European CWF portal created by the COST ES0602 action (Balk et al., 2011) attempts to integrate existing chemical weather forecast and information solutions offered by numerous institutions within Europe. This portal provides a direct gateway to the individual resources and is intended to complement and support other European initiatives such as the GMES Atmospheric Services.

\section{Appendix A}

\section{Abbreviations and acronyms used in this article}

\begin{tabular}{|c|c|}
\hline $\begin{array}{l}\text { ACCENT- } \\
\text { TROPOSAT-2 }\end{array}$ & $\begin{array}{l}\text { Atmospheric Composition Change the Eu- } \\
\text { ropean Network - Use and Usability of } \\
\text { Satellite Data for Tropospheric Research }\end{array}$ \\
\hline $\mathrm{ACM}$ & Asymmetric Convective Model \\
\hline aero? & 3rd generation CMAQ aerosol module \\
\hline ALADIN & $\begin{array}{l}\text { Aire Limite Adaptation Dynamique INi- } \\
\text { lalisation }\end{array}$ \\
\hline ALADIN-CAMx & $\begin{array}{l}\text { Comprehensive Air-quality Model with } \\
\text { extensions based on ALADIN-Austria } \\
\text { forecast data }\end{array}$ \\
\hline
\end{tabular}

AM\&WFG

ANA

AOD

AROME

ARPA

ARW

AURAMS

AUTH-NKUA

AQA

AQMEII

BEIS3

BIOEMI

BNMVOC

BOKU

CAC

CALGRID

CAM3

CAMx

CAMx-AMWFG

CBM-IV

$\mathrm{CCN}$

CECILIA

CITYZEN

CMAQ

COSMO

COST

CTM

CWF

CWFIS

CWFS

DDM

DEHM

DERMA

DMAT

DMI

DMS

DREAM

DWD
Atmospheric Modeling and Weather Forecasting Group

Atmospheric mesoscale Numerical pollution model for urban and regional Areas

Aerosol Optical Depth

Applications of Research to Operations at Mesoscale

Italian Regional Environmental Protection Agency

Advanced Research WRF

A Unified (multiple-pollutant) size- and chemical composition-resolved, episodic, Regional Air-quality Modelling System

Aristotle University of Thessaloniki National and Kapodistrian University of Athens

Air-Quality model for Austria

Air-Quality Modeling Evaluation International Initiatives

Biogenic Emission Inventory System

BIOgenic EMIssion model

Biogenic Non-Methane Volatile Organic Compound

the University of Natural Resources and Applied Life Sciences in Vienna

tropospheric Chemistry Aerosol Cloud transport model

California Grid Model

Community Atmosphere Model v.3

Comprehensive Air-quality Model with extensions

Comprehensive Air-Quality Model with Extensions - The Atmospheric Modeling and Weather Forecasting Group

Carbon Bond Mechanism IV

Cloud Condensation Nuclei

Central and Eastern Europe Climate Change Impact and Vulnerability Assessment

megaCITY - Zoom for the Environment

United States Environmental Prediction Agency, Community Multiscale Air-Quality Model

Consortium for Small Scale Modeling

European Cooperation in Science and Technology

Chemistry-Transport Models

Chemical Weather Forecasting

Chemical Weather Forecasting and Information System

Chemical Weather Forecasting System

direct decoupled method

Danish Eulerian Hemispheric Model

Danish Emergency Response Model of the Atmosphere

Dispersion Model for Atmospheric Transport

Danish Meteorological Institute

DiMethyl Sulfide

Danish Rimpuff and Eulerian Accidental release Model

German Weather Service 


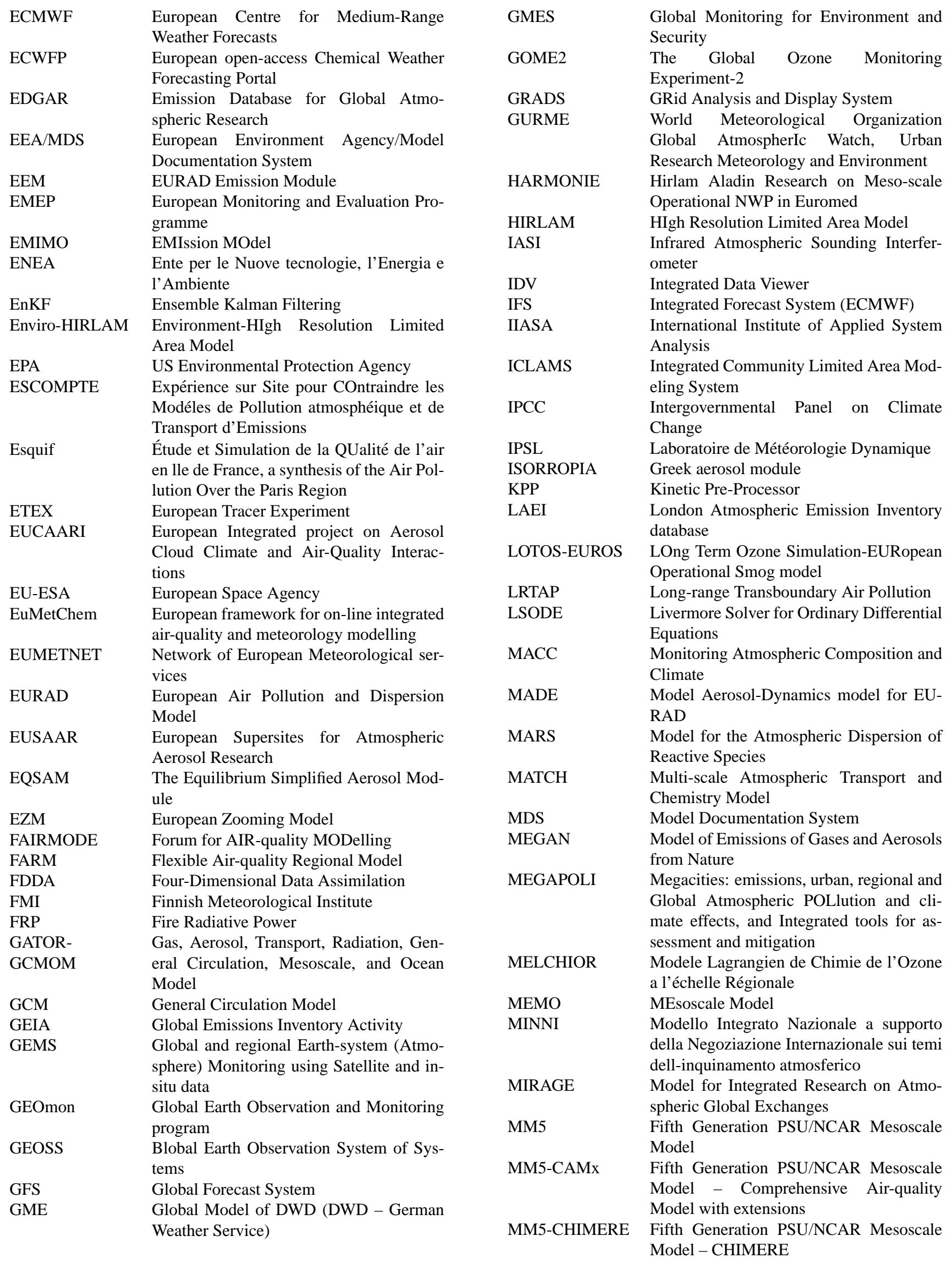


MM5-CMAQ Fifth Generation PSU/NCAR Mesoscale Model - Community Multiscale AirQuality Model

MOCAGE Modéle de Chimie Atmosphérique à Grande Echelle, Model of Atmospheric Composition at Large Scales

MODIS Moderate Resolution Imaging Spectroradiometer

MOPITT Measurements Of Pollution In The Troposphere

MPIC

MRF

M3Dry

NAME

NASA

NCAR

NCEP

NETCDF

NMM

NMVOC

NOAA

NWP

NWP-Chem-

liquid

OFIS

OMI

OML

OPANA

OSPM

PALM

PASODOBLE

PAVE

PBL

PM

PNNL

POP

PPM

PREVAIR

PROMOTE

PSU/NCAR

RACM

RADM

RAMS
Max Planck Institute for Chemistry

Medium Range Forecast model

dry deposition velocity scheme

Numerical Atmospheric-dispersion Modelling Environment

National Aeronautics and Space Administration

National Center for Atmospheric Research National Centers for Environmental Prediction

NETwork Common Data Form

Nonhydrostatic Mesoscale Model

Non-Methane Volatile Organic Compounds

National Oceanic and Atmospheric Administration

Numerical Weather Prediction

thermodynamic equilibrium model

Ozone Fine Structure model

Ozone Monitoring Instrument

point source model

Operational version of Atmospheric mesoscale Numerical pollution model for urban and regional Areas

Operational Street Pollution Model

computational fluid dynamics software

Promote Air-Quality Services integrating

Observations - Development Of Basic Localised Information for Europe

Package for Analysis and Visualization of

Environmental data

Planetary Boundary Layer

Particulate Matter

Pacific Northwest National Laboratory

Persistent Organic Pollutant

Piecewise Parabolic Method

Air-Quality forecasts and observations in

France and Europe

PROtocol MOniToring for the GMES Service Element

Pennsylvania State University/National

Center for Atmospheric Research

Regional Atmospheric Chemistry Mechanism

Regional Acid Deposition Model

Regional Atmospheric Model System
RCG (REM3-

CALGRID)

REMEST

RETRO

RIU

RIVM

SAPRC99

SILAM

SMHI

SMOKE

SNAP

SOA

STEM

STOCHEM

STRACO

SURFPRO

TA

TEMIS

TESSEL

THOR

TM5

TNO

TRAMPER

TRANSPHORM

TSP

TUV

UBM

UM

USGS

VOC

WMO

WRF-Chem

YSU

3DVAR

4DVAR
Regional Eulerian Model - California Grid Model

a nonhydrostatic mesoscale meteorological model

Reanalysis of the TROpospheric chemical composition

Rhenish Institute for Environmental Research

National Institute for Public Health and the Environment

chemical mechanism developed at the Statewide Air Pollution Research Center in Riverside, California

Air-Quality and Emergency Modelling System

Swedish Meteorological and Hydrological Institute

Sparse Matrix Operator Kernel Emissions model

Selected Nomenclature for Air Pollution

Secondary Organic Aerosols

Sulfur Transport and dEposition Model

UK Meteorological Office Chemistrytransport Model

Soft TRAnsition Convection

SURrface atmosphere interFace PROcessor

Temperature Anomaly

Tropospheric Emission Monitoring Internet Service

Tiled ECMWF Scheme for Surface Exchanges over Land

an integrated air pollution forecast and scenario management system

Tracer Model 5

the Netherlands Organisation for Applied Scientific Research, Utrecht, Netherlands

Tropospheric Realtime Applied Meteorological Procedures for Environmental Research

Transport related Air Pollution and Health Impacts - Integrated Methodologies for Assessing Particulate Matter

Total mass of Suspended Particles

Tropospheric Ultraviolet-Visible model

Urban Background Model

Unified Model

United States Geological Survey

Volatile Organic Compounds

World Meteorological Organization

Weather Research and Forecast model coupled with Chemistry

Yonsei University

three-dimensional variational assimilation approach

3DVAR with assimilating data in time 
Acknowledgements. We acknowledge the funding of COST ES0602, ES1004, 728, and EU TRANSPHORM. The research leading to these results has received funding from the European Union's Seventh Framework Programme FP/2007-2011 within the project MEGAPOLI, grant agreement no. 212520. David Schultz is partially funded by Vaisala Oyj. We thank the following people for their contributions to this manuscript: Paul Agnew, Gregory Carmichael, Lucy Davis, Oriol Jorba, Mark Lawrence, Dimitros Melas, Arjo Segers, William Skamarock, and Christos Zerefos. Kenneth Schere and an anonymous reviewer provided detailed comments that improved this article. Kenneth Schere (US Environmental Protection Agency) is thanked for a thorough review of this article, and for his many valuable comments.

Edited by: R. Vautard

\section{References}

Ackermann, I. J., Hass, H., Memmesheimer, M., Ebel, A., Binkowski, F. S., and Shankar, U.: MADE: modal aerosol dynamics model for Europe; development and first applications, Atmos. Environ., 32, 2981-2999, 1998.

Andersson, C., Langner, J., and Bergström, R.: Inter-annual variation and trends in air pollution over Europe due to climate variability during 1958-2001 simulated with a regional CTM coupled to the ERA40 reanalysis, Tellus B, 59, 77-98, doi:10.1111/j.1600-0889.2006.00196.x, 2007.

Andersson, C., Bergström, R., and Johansson, C.: Population exposure and mortality due to regional background PM in Europe - long-term simulations of source region and shipping contributions, Atmos. Environ., 43, 3614-3620, doi:10.1016/j.atmosenv.2009.03.040, 2009.

Andersson-Sköld, Y. and Simpson, D.: Comparison of the chemical schemes of the EMEP MSC-W and IVL photochemical trajectory models, Atmos. Environ., 33, 1111-1129, 1999.

Andres, R. J. and Kasgnoc, A. D.: A time-averaged inventory of sub-aerial volcanic sulfur emissions, J. Geophys. Res., 103, 25251-25261, 1998.

Andronache, C.: Estimated variability of below-cloud aerosol removal by rainfall for observed aerosol size distributions, Atmos. Chem. Phys., 3, 131-143, doi:10.5194/acp-3-131-2003, 2003.

Ansari, A. S. and Pandis, S. N.: Prediction of multicomponent inorganic atmospheric aerosol behavior, Atmos. Environ., 33, 745757, 1999a.

Ansari, A. S. and Pandis, S. N.: An analysis of four models predicting the partitioning of semivolatile inorganic aerosol components, Aerosol. Sci. Tech., 31, 129-153, 1999b.

Arakawa, A. and Schubert, W. H.: Interaction of a cumulus cloud ensemble with the large-scale environment, Part 1, J. Atmos. Sci., 31, 674-701, 1974.

Astitha, M. and Kallos, G.: Gas-phase and aerosol chemistry interactions in South Europe and the Mediterranean region, Environ. Fluid Mech., 9, 3-22, doi:10.1007/s10652-008-9110-7, 2008.

Astitha, M., Kallos, G., Katsafados, P., Pytharoulis, I., and Mihalopoulosx, N.: Radiative effects of natural PMs on photochemical processes in the Mediterranean region, in: Oral PresentationProceedings, 28th NATO/CCMS International Technical Meeting on Air Pollution Modelling and its Applications, Leipzig, Germany, May 2006, edited by: Borrego, C. and Renner, E., El- sevier Pub., ISBN 978-0-444-52987-9, 548-559, London, UK, 2006.

Astitha, M., Kallos, G., Katsafados, P., and Mavromatidis, E.: Heterogeneous chemical processes and their role on particulate matter formation in the Mediterranean region, in: Air Pollution Modeling and Its Application XIX, NATO Science for Peace and Security Series C: Environmental Security, 5, 505513, doi:10.1007/978-1-4020-8453-9_55, 2007.

Astitha, M., Kallos, G., and Katsafados, P.: Air pollution modeling in the Mediterranean region: from analysis of episodes to forecasting, Atmos. Res., 89, 358-364, 2008.

Astitha, M., Kallos, G., Katsafados, P., and Mavromatidis, E.: Heterogeneous chemical processes and their role on particulate matter formation in the Mediterranean region, in: Air Pollution Modeling and Its Application XIX, NATO Science for Peace and Security Series C: Environmental Security, 5, 505-513, doi:10.1007/978-1-4020-8453-9_55, 2008.

Astitha, M., Kallos, G., Spyrou, C., O'Hirok, W., Lelieveld, J., and Denier van der Gon, H. A. C.: Modelling the chemically aged and mixed aerosols over the eastern central Atlantic Ocean - potential impacts, Atmos. Chem. Phys., 10, 5797-5822, doi:10.5194/acp-10-5797-2010, 2010.

Atanassov, D.: Validation of the Eulerian pollution transport model PolTran on the Kincaid dataset, Int. J. Environ. Pollut., 20, 105113, 2003.

Aumont, B., Jaecker-Voirol, A., Martin, B., and Toupance, G.: Tests of some reduction hypotheses made in photochemical mechanisms, Atmos. Environ., 30, 2061-2077, 1996.

Baklanov, A.: Chemical Weather Forecasting: A New Concept of Integrated Modelling, Adv. Sci. Res., 4, 23-27, 2010.

Baklanov, A. and Grisogono, B. (Eds.): Atmospheric Boundary Layers: Nature, Theory and Application to Environmental Modelling and Security, Springer, 248 pp., ISBN 978-0-387-74318-9, New York, USA, 2007.

Baklanov, A. and Sørensen, J. H.: Parameterisation of radionuclide deposition in atmospheric long-range transport modelling, Phys. Chem. Earth. Pt. B, 26, 787-799, 2001.

Baklanov, A., Fay, B., Kaminski, J., Sokhi, R., Pechinger, U., De Ridder, K., Delcloo, A., Smith Korsholm, U., Gross, A., Männik, A., Kaasik, M., Sofiev, M., Reimer, E., Schlünzen, H., Tombrou, M., Bossioli, E., Finardi, S., Maurizi, A., Castelli, S. T., Finzi, G., Carnevale, C., Pisoni, E., Volta, M., Struzewska, J., Kaszowski, W., Godlowska, J., Rozwoda, W., Miranda, A. I., San José, R., Persson, C., Foltescu, V., Clappier, A., Athanassiadou, M., Hort, M. C., Jones, A., Vogel, H., Suppan, P., Knoth, O., Yu, Y., Chemel, C., Hu, R.-M., Grell, G., Schere, K., Manins, P., and Flemming, J.: Overview of existing integrated (off-line and on-line) mesoscale meteorological and chemical transport modelling systems in Europe, WMO TD No. 1427, WMO, Geneva, Switzerland, 2008a.

Baklanov, A., Korsholm, U., Mahura, A., Petersen, C., and Gross, A.: ENVIRO-HIRLAM: on-line coupled modelling of urban meteorology and air pollution, Adv. Sci. Res., 2, 41-46, doi:10.5194/asr-2-41-2008, 2008b.

Baklanov A., Lawrence, M., Pandis, S., Mahura, A., Finardi, S., Moussiopoulos, N., Beekmann, M., Laj, P., Gomes, L., Jaffrezo, J.-L., Borbon, A., Coll, I., Gros, V., Sciare, J., Kukkonen, J., Galmarini, S., Giorgi, F., Grimmond, S., Esau, I., Stohl, A., Denby, B., Wagner, T., Butler, T., Baltensperger, U., 
Builtjes, P., van den Hout, D., van der Gon, H. D., Collins, B., Schluenzen, H., Kulmala, M., Zilitinkevich, S., Sokhi, R., Friedrich, R., Theloke, J., Kummer, U., Jalkinen, L., Halenka, T., Wiedensholer, A., Pyle, J., and Rossow, W. B.: MEGAPOLI: concept of multi-scale modeling of megacity impact on air quality and climate, Adv. Sci. Res., 4, 115-120, doi:10.5194/asr-4115-2010, 2010a.

Baklanov, A., Mahura, A., and Sokhi, R. (Eds.): Integrated Systems of Meso-Meteorological and Chemical Transport Models, Springer, Berlin, Heidelberg, Germany, ISBN 978-3-642-139796, 186 pp., 2010 b.

Baldasano, J. M., Jiménez-Guerrero, P., Jorba, O., Pérez, C., López, E., Güereca, P., Martin, F., García-Vivanco, M., Palomino, I., Querol, X., Pandolfi, M., Sanz, M. J., and Diéguez, J. J.: CALIOPE: An operational air quality forecasting system for the Iberian Peninsula, Balearic Islands and Canary Islands - First annual evaluation and ongoing developments, Adv. Sci. Res., 2, 89-98, 2008.

Baldwin, M. E., Kain, J. S., and Kay, M. P.: Properties of the convection scheme in NCEP's Eta model that affect forecast sounding interpretation, Weather Forecast., 17, 1063-1079, 2002.

Balk, T., Kukkonen, J., Karatzas, K., Bassoukos, T., and Epitropou, V.: A European open access chemical weather forecasting portal, Atmos. Environ., 45, 6917-6922, 2011.

Barnes, L. R., Gruntfest, E. C., Hayden, M. H., Schultz, D. M., and Benight, C.: False alarms and close calls: A conceptual model of warning accuracy, Weather Forecast., 22, 1140-1147, 2007.

Barnes, L. R., Gruntfest, E. C., Hayden, M. H., Schultz, D. M., and Benight, C.: Corrigendum: False alarm rate or false alarm ratio?, Weather Forecast., 24, 1452-1454, 2009.

Bartnicki, J., Salbu, B., Saltbones, J., Foss, A., and Lind, O. C.: Gravitational settling of particles in dispersion model simulation using the Chernobyl accident as a test case, Research Report, 131, Norwegian Met. Inst., Oslo, 43 pp., 2001.

Baumann-Stanzer, K., Hirtl, M., and Krueger, B. C.: Regionalscale air quality forecasts for Austria, in: Abstracts of the 5th EMS Annual Meeting/ECAM, Vol. 2, 12-16 September 2005, Utrecht, The Netherlands, EMS05-A-00036, ISSN 1812-7053 (CD-ROM), 2005.

Bechtold, P., Bazile, E., Guichard, F., Mascart, P., and Richard, E.: A mass flux convection scheme for regional and global models, Q. J. Roy. Meteor. Soc., 127, 869-886, doi:10.1256/smsqj.57308, 2001.

Beekmann, M. and Vautard, R.: A modelling study of photochemical regimes over Europe: robustness and variability, Atmos. Chem. Phys., 10, 10067-10084, doi:10.5194/acp-1010067-2010, 2010.

Beekmann, M., Kerschbaumer, A., Reimer, E., Stern, R., and Möller, D.: PM measurement campaign HOVERT in the Greater Berlin area: model evaluation with chemically specified particulate matter observations for a one year period, Atmos. Chem. Phys., 7, 55-68, doi:10.5194/acp-7-55-2007, 2007.

Bell, M. and Ellis, H.: Sensitivity analysis of tropospheric ozone to modified biogenic emissions for the Mid-Atlantic region, Atmos. Environ., 38, 1879-1889, 2004.

Beljaars, A. C. M. and Viterbo, P.: Soil moisture-precipitation interaction: experience with two land surface schemes in the ECMWF model, in: Global Energy and Water Cycles, edited by: Browning, K. and Gurney, R., Cambridge University Press, Cambridge,
223-233, 1999.

Berge, E.: Coupling of wet scavenging of sulphur to clouds in a numerical weather prediction model, Tellus, 45B, 1-22, 1993.

Betts, A. K. and Miller, M. J.: A new convective adjustment scheme, Part II: Single column tests using GATE wave, BOMEX, ATEX and Arctic Air mass datasets, Q. J. Roy. Meteor. Soc., 112, 693-709, 1986.

Binkowski, F. S.: The aerosol portion of Models-3 CMAQ, in: Science Algorithms of the EPA Models-3 Community Multiscale Air Quality (CMAQ) Modeling System, Part II: Chapters 9-18, edited by: Byun, D. W. and Ching, J. K. S., EPA-600/R-99/030, National Exposure Research Laboratory, US Environmental Protection Agency, Research Triangle Park, NC, 10-1-10-16, 1999.

Binkowski, F. S. and Shankar, U.: The regional particulate matter model, 1. Model description and preliminary results, J. Geophys. Res., 100, 26191-26209, 1995.

Board on Atmospheric Sciences and Climate: Completing the Forecast: Characterizing and Communicating Uncertainty for Better Decisions Using Weather and Climate Forecasts, National Academies Press, Washington DC, USA, 112 pp., 2006.

Borrego, C., Monteiro, A., Ferreira, J., Miranda, A. I., Costa, A. M., Carvalho, A. C., and Lopez, M.: Procedures for estimation of modelling uncertainty in air quality assessment, Environ. Int., 34, 613-620, ISSN 0160-4120, 2008.

Bott, A.: A positive definite advection scheme obtained by nonlinear renormalization of the advective fluxes, Mon. Weather Rev. 117, 1006-1015, 1989.

Bott, A.: Monotone flux limitation in the area-preserving flux form advection algorithm, Mon. Weather Rev., 120, 2592-2602, 1992.

Bott, A.: The monotone area-preserving flux-form advection algorithm: reducing the time-splitting error in two-dimensional flow fields, Mon. Weather Rev., 121, 2637-2641, 1993.

Bougeault, P.: A simple parameterization of the large-scale effects of deep cumulus convection, Mon. Weather Rev., 113, 21082121, 1985.

Bousserez, N., Attié, J.-L., Peuch, V.-H., Michou, M., Pfister, G., Edwards, D., Avery, M., Sachse, G., Browell, E., and Ferrare, E.: Evaluation of MOCAGE chemistry and transport model during the ICARTT/ITOP experiment, J. Geophys. Res., 112, D120S42, doi:10.1029/2006JD007595, 2007.

Boussinesq, J.: Essai sur la theorie des eaux courantes, Mem Savants Etrange, Paris, 23, 46 pp., 1877.

Brandt, J., Christensen, J. H., Frohn, L. M., and Berkowicz. R.: Operational air pollution forecasts from regional scale to urban street scale, Part 2: Performance evaluation, Phys. Chem. Earth. Pt. B, 26, 825-830, doi:10.1016/S1464-1909(01)00092-2, 2001a.

Brandt, J., Christensen, J. H., Frohn, L. M., Palmgren, F., Berkowicz, R., and Zlatev, Z.: Operational air pollution forecasts from European to local scale, Atmos. Environ., 35, Sup. No. 1, S91S98, 2001b.

Britter, R. E., Collier, C., Griffiths, R., Mason, P., Thomson, D., Timmis, R., and Underwood, B.: Atmospheric dispersion modeling - guidelines on the justification of choice and use of models, and the communication and reporting of results, Royal Meteorol. Soc. Policy Statement, RMS, Reading, UK, 8 pp., 1995.

Broad, K., Leiserowitz, A., Weinkle, J., and Steketee, M.: Misinterpretations of the "cone of uncertainty" in Florida during the 2004 hurricane season, B. Am. Meteorol. Soc., 88, 651-667, 2007. 
Brown, A. R., Beare, R. J., Edwards, J. M., Lock, A. P., Keogh, S. J., Milton, S. F., and Walters, D. N.: Upgrades to the boundary-layer scheme in the Met Office numerical weather prediction model, Bound.-Lay. Meteorol., 128, 117-132, 2008.

Builtjes, P. J. H.: The LOTOS-Long Term Ozone Simulationproject Summary Report, TNO Report TNO-MW-R92/240, Netherlands Organization for Applied Scientific Research, Utrecht, The Netherlands, 1992.

Bukovsky, M. S., Kain, J. S., and Baldwin, M. E.: Bowing convective systems in a popular operational model: are they for real?, Weather Forecast., 21, 307-324, 2006.

Burrows, J. and Borrell, P. (Eds.): The Remote Sensing of Tropospheric Constituents form Space, ACCENTTROPOSAT-2: Activities 2007-8 and Final Report, ACCENT Secretariat, Urbino, available at: http: //troposat.iup.uni-heidelberg.de/AT2/AT2/Reports_and_papers/ 2008_Ann_Rep/AT2_Fin_Rep_2008_A_overview.pdf, 2009.

Byun, D. W.: Dynamically consistent formulations in meteorological and air quality models for multi-scale atmospheric applications: Part I. Governing equations in generalized coordinate system, J. Atmos. Sci., 56, 3789-3807, 1999a.

Byun, D. W.: Dynamically consistent formulations in meteorological and air quality models for multi-scale atmospheric applications: Part II. Mass conservation issues, J. Atmos. Sci., 56, 38083820, 1999b.

Byun, D. W. and Ching, J. K. S. (Eds.): Science Algorithms of the EPA Models-3 Community Multiscale Air Quality (CMAQ) modeling system, EPA/600/R-99/030, US Environmental Protection Agency, Atmospheric Modeling Division, Research Triangle Park, NC, available at: http://www.epa.gov/AMD/CMAQ/ CMAQscienceDoc.html, 1999.

Byun, D. W. and Schere, K. L.: Review of the governing equations, computational algorithms, and other components of the models3 community multiscale air quality (CMAQ) modeling system, Appl. Mech. Rev., 59, 51-77, 2006.

Calori, G., Finardi, S., Nanni, A., Radice, P., Riccardo, S., Bertello, A., and Pavone, F.: Long-term air quality assessment: modeling sources contribution and scenarios in Ivrea and Torino areas, Environ. Model. Assess., 13, 329-335, doi:10.1007/s10666-007-9105-7, 2008.

Cape, J. N., Methven, J., and Hudson, L. E.: The use of trajectory cluster analysis to interpret trace gas measurements at Mace Head, Ireland, Atmos. Environ., 34, 3651-3663, 2000.

Carmichael, G. R., Sandu, A., and Potra, F. A.: Sensitivity analysis for atmospheric chemistry models via automatic differentiation, Atmos. Environ., 31, 475-489, 1997.

Carmichael, G. R., Uno, I., Phadnis, M. J., Zhang, Y., and Sunwoo, Y.: Tropospheric ozone production and transport in the springtime in East Asia, J. Geophys. Res., 103, 10649-10671, 1998.

Carmichael, G. R., Calori, G., Hayami, H., Uno, I., Cho, S. Y., Engardt, M., Kim, S.-B., Ichikawa, Y., Ikeda, Y., Woo, J.-H., Ueda, H., and Amann, M.: The MICS-Asia study: model intercomparison of long-range transport and sulfur deposition in East Asia, Atmos. Environ., 36, 175-199, 2002.

Carmichael, G. R., Sandu, A., Chai, T., Daescu, D. N., Constantinescu, E. M., and Tang, Y.: Predicting air quality: improvements through advanced methods to integrate models and measurements, J. Comput. Phys., 227, 3540-3571, 2008a.
Carmichael, G. R., Sakuraib, T., Streetsc, D., Hozumib, Y., Uedab, H., Parkd, S. U., Funge, C., Hanb, Z., Kajinof, M., Engardtg, M., Bennetg, C., Hayamih, H., Sarteleti, K., Hollowayj, T., Wangk, Z., Kannaril, A., Fum, J., Matsudan, K., Thongboonchooa, N., and Amanno, M.: MICS-ASIA II: the model intercomaprison study for Asia phase II methodology and overview of findings, Atmos. Environ., 42, 3468-3490, $2008 \mathrm{~b}$.

Carter, W. P. L.: A detailed mechanism for the gas-phase atmospheric reactions of organic compounds, Atmos. Environ., 24A, 481-518, 1990.

Carter, W. P. L.: Development of ozone reactivity scales for volatile organic compounds, J. Air Waste Manage., 44, 881-899, 1994.

Carter, W. P. L.: Condensed atmospheric photo-oxidation mechanisms for isoprene, Atmos. Environ., 30, 4275-4290, 1996.

Carter, W. P. L.: Documentation of the SAPRC-99 chemical mechanism for VOC reactivity assessment, Final report to California Air Resources Board Contract 92-329 and Contract 95-308, Air Pollution Research Center and College of Engineering Center for Environmental Research and Technology, University of California, Riverside, CA, 230 pp., available at: http://www.engr.ucr. edu/ carter/absts.htm\#saprc99, 2000.

Carter, W. P. L., Luo, D., Malkina, I. L., and Fitz, D.: The University of California, Riverside Environmental Chamber Data Base for Evaluating Oxidant Mechanisms, Indoor Chamber Experiments Through 1993, Report submitted to the US Environmental Protection Agency, 20 March 1995, EPA/AREAL, Research Triangle Park, NC, University of California, Riverside, available at: http://www.cert.ucr.edu/ carter/absts.htm\#databas, 1995.

Chai, T., Carmichael, G., Tang, Y., and Sandu, A.: Regional $\mathrm{NO}_{2}$ emission inversion through four-dimensional variational approach using Sciamachy tropospheric column observations, Atmos. Environ., 43, 5046-5055, 2009.

Chang, J. C. and Hanna, S. R.: Air quality model performance evaluation, Meteorol. Atmos. Phys., 87, 167-196, 2004.

Chang, J. S., Brost, R. A., Isaksen, I. S. A., Madronich, S., Middleton, P., Stockwell, W. R., and Walcek, C. J.: A three-dimensional Eulerian acid deposition model: physical concepts and formulation, J. Geophys. Res., 92, 14681-14700, 1987.

Chang, J. S., Binkowski, F. S., Seaman, N. L., Byun, D. W., McHenry, J. N., Samson, P. J., Stockwell, W. R., Walcek, C. J., Madronich, S., Middleton, P. B., Pleim, J. E., and Landsford, H. L.: The regional acid deposition model and engineering model, NAPAP SOS/T Report 4, in: National Acid Precipitation Assessment Program, Acidic Deposition: State of Science and Technology, Vol. I, Washington, DC, 1990.

Chenevez, J., Baklanov, A., and Sørensen, J. H.: Pollutant transport schemes integrated in a numerical weather prediction model: model description and verification results, Meteorol. Appl., 11, 265-275, 2004.

Claiborn, C., Lamb, B., Miller, A., Beseda, J., Clode, B., Vaughan, J., Kang, L., and Nevine, C.: Regional measurements and modelling of windblown agricultural dust: the Columbia Plateau PM $_{10}$ program, J. Geophys. Res., 103, 19753-19767, 1998.

Coll, I., Pirovano, G., Lasry, F., Alessandrini, S., Bedogni, M., Costa, M., Gabusi, V., Menut, L., and Vautard, R.: Application and sensitivity analysis of CAMx and CHIMERE air quality models in coastal area, in: Air Pollution Modeling and its Application XVIII, Dev. Environm. Sci., vol. 6., edited by: Borrego, C. 
and Renner, E., Elsevier Science Ltd, Oxford, UK, 362-373, ISSN 1474-8177, doi:10.1016/S1474-8177(07)06042-1, 2007.

Collins, W. J., Stevenson, D. S., Johnson, C. E., and Derwent, R. G.: Tropospheric ozone in a global-scale three-dimensional model and its response to $\mathrm{NO}_{\mathrm{x}}$ emission controls, J. Atmos. Chem., 26, 223-274, 1997.

Constantinescu, E. M., Sandu, A., Chai, T., and Carmichael, G. R.: Ensemble-based chemical data assimilation, I: General approach, Q. J. Roy. Meteor. Soc., 133, 1229-1243, 2007.

Cotton, W. R., Pielke, R. A., Walko, R. L., Liston, G. E., Tremback, C. J., Jiang, H., McAnelly, R. L., Harrington, J. Y., Nicholls, M. E., Carrio, G. G., and McFadden, J. P.: RAMS 2001: current status and future directions, Meteorol. Atmos. Phys., 82, 5-29, 2003.

Cros, B., Durand, P., Cachier, H., Drobinski, Ph., Fréjafon, E., Kottmeier, C., Perros, P. E., Peuch, V.-H., Ponche, J.-L., Robin, D., Saïd, F., Toupance, G., and Wortham, H.: The ESCOMPTE program: an overview, Atmos. Res., 69, 241-279, 2004.

Crowley, W. P.: Second order numerical advection, J. Comput. Phys., 1, 471-484, 1967.

Cullen, M. J. P.: The unified forecast/climate model, Meteorol. Mag., 1449, 81-94, 1993.

Cullen, M. J. P., Davies, T., Mawson, M. H., James, J. A., Coulter, S. C., and Malcolm, A.: An overview of numerical methods for the next generation of NWP and climate models, in: Numerical Methods in Atmospheric and Ocean Modelling, The Andre Robert Memorial Volume, edited by: Lin, C., Laprise, R., and Ritchie, H., Canadian Meteorological and Oceanographic Society, Ottawa, Canada, 425-444, 1997.

Curci, G., Beekmann, M., Vautard, R., Smiatek, G., Steinbrecher, R., Theloke, J., and Friedrich, R.: Modelling study of the impact of isoprene and terpene biogenic emissions on European ozone levels, Atmos. Environ., 43, 1444-1455, 2009.

Cuvelier, C., Thunis, P., Vautard, R., Amann, M., Bessagnet, B., Bedogni, M., Berkowicz, R., Brandt, J., Brocheton, J., Builtjes, P., Carnavale, C., Coppalle, A., Denby, B., Douros, J., Graf, A., Hellmuth, O., Hodzic, A., Honore, C., Jonson, J., Kerschbaumer, A., de Leeuw, F., Minguzzi, E., Moussiopoulos, M., Pertot, C., Peuch, V.-H., Pirovano, G., Rouil, L., Sauter, F., Schaap, M., Stern, R., Tarrasón, L., Vignati, E., Volta, M., White, L., Wind, P., and Zuber, A.: CityDelta: a model intercomparison study to explore the impact of emission reductions in European cities in 2010, Atmos. Environ., 41, 189-201, 2007.

Cuxart, J., Bougeaults, P., and Redelsberger, J. L.: A turbulence scheme allowing for mesoscale and large-eddy simulations, Q. J. Roy. Meteor. Soc., 126, 1-30, 2000.

Dabberdt, W. F., Carroll, M. A., Baumgardner, D., Carmichael, G., Cohen, R., Dye, T., Ellis, J., Grell, G., Grimmond, S., Hanna, S., Irwin, J., Lamb, B., Madronich, S., McQueen, J., Meagher, J., Odman, T., Pleim, J., Schmid, H. P., and Westphal, D. L.: Meteorological research needs for improved air quality forecasting, B. Am. Meteorol. Soc., 85, 563-586, 2004.

Davidson, C. I., Miller, J. M., and Pleskow, M. A.: The influence of surface structure on predicted particle dry deposition to natural grass canopies, Water Air Soil Poll., 18, 25-43, 1982.

Davies. T., Cullen, M. J. P., Malcolm, A. J., Mawson, M. H., Staniforth, A., White, A. A., and Wood, N.: A new dynamical core for the Met Office's global and regional modelling of the atmo- sphere, Q. J. Roy. Meteor. Soc., 131, 1759-1782, 2005.

Daescu, D., Sandu, A., and Carmichael, G. R.: Direct and adjoint sensitivity analysis of chemical kinetic systems with KPP: II - Validation and numerical experiments, Atmos. Environ., 37, 5097-5114, 2003.

Damian, V., Sandu, A., Damian, M., Potra, F., and Carmichael, G. R.: The kinetic preprocessor KPP - a software environment for solving chemical kinetics, Comput. Chem. Eng., 26, 1567-1579, 2002.

Dayan, U. and Lamb, D.: Global and synoptic-scale weather patterns controlling wet atmospheric deposition over Central Europe, Atmos. Environ., 39, 521-533, 2005.

Dayan, U. and Levy, I.: Relationship between synoptic-scale atmospheric circulation and ozone concentrations over Israel, J. Geophys. Res., 107, 4813, doi:10.1029/2002JD002147, 2002.

de Leeuw, F. A. A. M., van Rheineck Leyssius, H. J.: Modeling study of $\mathrm{SO}_{\mathrm{x}}$ and $\mathrm{NO}_{\mathrm{x}}$ during the January 1985 smog episode, Water Air Soil Poll., 51, 357-371, 1990.

de Leeuw, G., Neele, F. P., Hill, M., Smith, M. H., and Vignati, E.: Production of sea spray aerosol in the surf zone, J. Geophys. Res., 105, 29397-29409, doi:10.1029/2000JD900549, 2000.

Delle Monache, L. and Stull, R. B.: An ensemble air-quality forecast over Western Europe during an ozone episode, Atmos. Environ., 37, 3469-3474, 2003.

Demerjian, K. L.: Quantifying uncertainty in long range transport models: a summary of the AMS Workshop on Sources and Evaluation of Uncertainty in Long Range Transport Models, B. Am. Meteorol. Soc., 66, 1533-1540, 1985.

Denby, B., Karl, M., Laupsa, H., Johansson, C. H., Pohjola, M., Karppinen, A., Kukkonen, J., Ketzel, M., and Wåhlin, P.: Estimating domestic wood burning emissions of particulate matter in two nordic cities by combining ambient air observations with receptor and dispersion models, Chem. Ind. Chem. Eng. Q., 16, 237-241, doi:10.2298/CICEQ091214019D, 2010.

Dennis, R., Fox, T., Fuentes, M., Gilliland, A., Hanna, S., Hogrefe, C., Irwin, J., Rao, S. T., Scheffe, R., Schere, K., Steyn, D., and Venkatram, A.: A framework for evaluating regional-scale photochemical modeling systems, Environ. Fluid. Mech., 10, 471-489, 2010.

Derognat, C., Beekmann, M., Baeumle, M., Martin, D., and Schmidt, H.: Effect of biogenic volatile organic compound emissions on tropospheric chemistry during the atmospheric pollution over the paris area (ESQUIF) campaign in the Ile-de-France region, J. Geophys. Res., 108, 8560, doi:10.1029/2001JD001421, 2003.

Dodge, M.: Chemical oxidant mechanisms for air quality modeling: critical review, Atmos. Environ., 34, 2103-2130, 2000.

Doms, G. and Schättler, U.: The nonhydrostatic limited-are a model LM (Lokal-Modell) of DWD, Part I: Scientific documentation, Deutscher Wetterdienst, available at: Deutscher Wetterdienst Postfach 100465, 63004 Offenbach, Germany, 155 pp., 1997.

Downton, R. A. and Bell, R. S.: The impact of analysis differences on a medium-range forecast, Meteorol. Mag., 117, 279285,1988

Dudhia, J.: A nonhydrostatic version of the Penn State-NCAR mesoscale model: validation tests and simulation of an Atlantic cyclone and cold front, Mon. Weather Rev., 121, 1493-1513, 1993.

Dufour, A., Amodei, M., Ancellet, G., and Peuch, V.-H.: Observed 
and modelled "chemical weather" during ESCOMPTE, Atmos. Res., 74, 161-189, 2004.

Dunker, A. M., Yarwood, G., Ortmann, J. P., and Wilson, G. M.: The decoupled direct method for sensitivity analysis in a threedimensional air quality model - implementation, accuracy and efficiency, Environ. Sci. Technol., 36, 2965-2976, 2002.

Dusek, U., Frank, G. P., Hildebrandt, L., Curtius, J., Schneider, J., Walter, S., Chand, D., Drewnick, F., Hings, S., Jung, D., Borrmann, S., and Andreae, M. O.: Size matters more than chemistry for cloud-nucleating ability of aerosol particles, Science, 312, 1375-1378, doi:10.1126/science.1125261, 2006.

Egan, B. A. and Mahoney, J. R.: Numerical modeling of advection and diffusion of urban area source pollutants, J. Appl. Meteorol., 11, 312-322, 1972.

Eben, K., Jurus, P., Resler, J., Belda, M., Pelikan, E., Krueger, B. C., and Keder, J.: An ensemble Kalman filter for short term forecasting of tropospheric ozone concentrations, Q. J. Roy. Meteor. Soc., 131, 3313-3322, 2005.

Eder, B., Kang, D., Mathur, R., Yu, S., and Schere, K.: An operational evaluation of the Eta-CMAQ air quality forecast model, Atmos. Environ., 40, 4894-4905, 2006.

Eder, B., Kang, D., Mathur, R., Pleim, J., Yu, S., Otte, T., and Pouliot, G.: A performance evaluation of the national air quality forecast capability for the summer of 2007, Atmos. Environ., 43, 2312-2320, 2009.

EEA: Air pollution in Europe 1990-2004, EEA report No 2/2007, European Environment Agency, Copenhagen, Denmark, 79 pp., 2007.

Eerola, K.: Experimentation with a three-dimensional trajectory model, in: Meteorological Publications No. 15, Finnish Meteorological Institute, Helsinki, Finland, 33 pp., 1990.

El Amraoui, L., Attiè, J.-L., Semane, N., Claeyman, M., Peuch, V.H., Warner, J., Ricaud, P., Cammas, J.-P., Piacentini, A., Josse, B., Cariolle, D., Massart, S., and Bencherif, H.: Midlatitude stratosphere - troposphere exchange as diagnosed by MLS $\mathrm{O}_{3}$ and MOPITT CO assimilated fields, Atmos. Chem. Phys., 10, 2175-2194, doi:10.5194/acp-10-2175-2010, 2010.

Elbern, H., Schmidt, H., Talagrand, O., and Ebel, A.: 4-Dvariational data assimilation with an adjoint air quality model for emission analysis, Environ. Modell. Softw., 15, 539-548, 2000.

Elbern, H., Strunk, A., Schmidt, H., and Talagrand, O.: Emission rate and chemical state estimation by 4-dimensional variational inversion, Atmos. Chem. Phys., 7, 3749-3769, doi:10.5194/acp7-3749-2007, 2007.

Eliassen, A.: The OECD study of long range transport of air pollutants: long range transport modeling, Atmos. Environ., 12, 479487, 1978.

Elmore, K. L., Baldwin, M. E., and Schultz, D. M.: Field significance revisited: spatial bias errors in forecasts as applied to the Eta model, Mon. Weather Rev., 134, 519-531, 2006a.

Elmore, K. L., Schultz, D. M., and Baldwin, M. E.,: The behavior of synoptic-scale errors in the Eta model, Mon. Weather Rev., 134, 3355-3366, $2006 b$.

Emanuel, K. A.: Atmospheric Convection, Oxford University Press, Oxford, 580 pp., 1994.

Engardt, M., Siniarovina, U., Khairul, N. I., and Leong, C. P.: Country to country transport of anthropogenic sulphur in Southeast Asia, Atmos. Environ., 39, 5137-5148, 2005.

ENVIRON: User's Guide to the Comprehensive Air Quality Model with Extensions (CAMx), Version 1.10, ENVIRON International Corporation, Novato, California, USA, 1997.

ENVIRON: CAMx (Comprehensive Air Quality Model with extensions) - User's Guide, Version 4.00, Internal Report, ENVIRON International Corporation, Novato, California, USA, 2003.

ENVIRON: User's Guide; Comprehensive Air Quality model with Extensions, Version 4.40, ENVIRON International Corporation, Novato, California, USA, available at: www.camx.com, last access: 11 February 2011, 2006.

Erisman, J. W. and Draaijers, G. P. J.: Atmospheric deposition in relation to acidication and eutrophication, in: Studies in Environmental Science 63, edited by: Erisman, J. W. and Draaijers, G. P. J., Elsevier, Amsterdam, The Netherlands, 91 pp., 1995.

Erisman, J. W., van Pul, A., and Wyers, P.: Parametrization of surface resistance for the quantification of atmospheric deposition of acidifying pollutants and ozone, Atmos. Environ., 28, 25952607, 1994.

Eskes, H. J. and Boersma, K. F.: Averaging kernels for DOAS totalcolumn satellite retrievals, Atmos. Chem. Phys., 3, 1285-1291, doi:10.5194/acp-3-1285-2003, 2003.

Faraji., M., Kimura, Y., McDonald-Buller, E., and Allen, D.: Comparison of the carbon bond and SAPRC photochemical mechanisms under conditions relevant to Southeast Texas, Atmos. Environ., 42, 5821-5836, 2008.

Fedra, K. and Witwer, C.: Operational web-based air quality forecasts: cascading models for assessment, management and public information, presented at the AOGS 2009, Singapore, 11-15 August, avialable at: http://www.ess.co.at/PDF/FandW_manuscript. pdf, last access: 11 February 2011, 2009.

Fehsenfeld, F., Calvert, J., Fall, R., Goldan, P., Guenther, A., Hewitt, C. N., Lamb, B., Liu, S., Trainer, M., Westberg, H., and Zimmerman, P.: Emissions of volatile organic compounds from vegetation and the implications for atmospheric chemistry, Global Biogeochem. Cy., 6, 389-430, 1992.

Ferrier, B. S., Jin, Y., Lin, Y., Black, T., Rogers, E., and DiMego, G.: Implementation of a new grid-scale cloud and precipitation scheme in the NCEP Eta model, in: Proceedings of the 15th Conf. on Numerical Weather Prediction, Amer. Meteor. Soc., San Antonio, TX, 280-283, 2002.

Finardi, S., De Maria, R., D’ Allura, A., Cascone, C., Calori, G., and Lollobrigida, F.: A deterministic air quality forecasting system for Torino urban area, Italy, Environ. Modell. Softw., 23, 344 355, 2008.

Finardi, S., D’Allura, A., Maddalena, M., Silibello, C., Radice, P., Morelli, M., Bolignano, A., and Sozzi, R.: An air quality forecast system for Rome metropolitan area: first evaluation and identification of critical issues, in: Proceedings of the 7th International Conference on Air Quality - Science and Application (Air Quality 2009), Istanbul, 24-27 March 2009, 2009.

Finlayson-Pitts, B. J. and Pitts, J. N.: Atmospheric Chemistry Fundamentals and Experimental Techniques, Wiley, New York, 1998.

Fisher, B., Kukkonen, J., Piringer, M., Rotach, M. W., and Schatzmann, M.: Meteorology applied to urban air pollution problems: concepts from COST 715, Atmos. Chem. Phys., 6, 555-564, doi:10.5194/acp-6-555-2006, 2006.

Flemming, J. and Reimer, E.: The impact of special features of numerically predicted and analysed meteorological data on the results of ozone forecast by a PBL-chemical transport model, in: 
ITM Air Pollution Modelling and its Applications XXIII, edited by: Gryning, S. and Batchvarova, E., NATO CMS, Kluwer Academic/Plenum Publishers, New York, 2000.

Foltescu, V. L., Pryor, S. C., and Bennet, C.: Sea salt generation, dispersion and removal on the regional scale, Atmos. Environ., 39, 2123-2133, 2005.

Fountoukis, C. and Nenes, A.: ISORROPIA II: a computationally efficient thermodynamic equilibrium model for $\mathrm{K}^{+}-\mathrm{Ca}^{2+}$ $\mathrm{Mg}^{2+}-\mathrm{NH}^{4+}-\mathrm{Na}^{+}-\mathrm{SO}_{4}^{2-}-\mathrm{NO}_{3}^{-}-\mathrm{Cl}^{-}-\mathrm{H}_{2} \mathrm{O}$ aerosols, Atmos. Chem. Phys., 7, 4639-4659, doi:10.5194/acp-7-4639-2007, 2007.

Fox, D. G.: Uncertainty in air quality modeling, B. Am. Meteorol. Soc., 65, 27-35, 1984.

Gallus, W. A.: The impact of step orography on flow in the Eta model: two contrasting examples, Weather Forecast., 15, 630 $639,2000$.

Gallus, W. A. and Klemp, J. B.: Behavior of flow over step orography, Mon. Weather Rev., 128, 1153-1164, 2000.

Galmarini, S., Bianconi, R., Klug, W., Mikkelsen, T., Addis, R., Andronopoulos, S., Astrup, P., Baklanov, A., Bartniki, J., Bartzis, J. C., Bellasio, R., Bompay, F., Buckley, R., Bouzom, M., Champion, H., D’Amours, R., Davakis, E., Eleveld, H., Geertsema, G. T., Glaab, H., Kollax, M., Ilvonen, M., Manning, A., Pechinger, U., Persson, C., Polreich, E., Potemski, S., Prodanova, M., Saltbones, J., Slaper, H., Sofev, M. A., Syrakov, D., Sùrensen, J. H., Van der Auwera, L., Valkama, I., and Zelazny, R.: Can the confidence in long-raqnge atmospheric transport models be increased? The pan-European experience of ENSEMBLE, Radiat. Prot. Dosim., 109, 19-24, doi:10.1093/rpd/nch261, 2004a.

Galmarini, S., Bianconi, R., Klug, W., Mikkelsen, T., Addis, R., Andronopoulos, S., Astrup, P., Baklanov, A., Bartniki, J., Bartzis, J. C., Bellasio, R., Bompay, F., Buckley, R., Bouzom, M., Champion, H., D'Amours, R., Davakis, E., Eleveld, H., Geertsema, G. T., Glaab, H., Kollax, M., Ilvonen, M., Manning, A., Pechinger, U., Persson, C., Polreich, E., Potempski, S., Prodanova, M., Saltbones, J., Slaper, H., Sofiev, M. A., Syrakov, D., Sorensen, J. H., Van der Auwera, L., Valkama, I., and Zelazny, R.: Ensemble dispersion forecasting Part I: Concept, approach and indicators, Atmos. Environ., 38, 4607-4617, 2004b.

Galmarini, S., Bianconi, R., Klug, W., Mikkelsen, T., Addis, R., Andronopoulos, S., Astrup, P., Baklanov, A., Bartniki, J., Bartzis, J. C., Bellasio, R., Bompay, F., Buckley, R., Bouzom, M., Champion, H., D'Amours, R., Davakis, E., Eleveld, H., Geertsema, G. T., Glaab, H., Kollax, M., Ilvonen, M., Manning, A., Pechinger, U., Persson, C., Polreich, E., Potemski, S., Prodanova, M., Saltbones, J., Slaper, H., Sofiev, M. A., Syrakov, D., Sørensen, J. H., Van der Auwera, L., Valkama, I., and Zelazny, R.: Ensemble dispersion forecasting Part II: Application and evaluation, Atmos. Environ., 38, 46194632, 2004c.

Galmarini, S., Bonnardot, F., Jones, A., Potempski, S., Robertson, L., and Martet, M.: Multi-model vs. EPS-based ensemble atmospheric dispersion simulations: A quantitative assessment on the ETEX-1 tracer experiment case, Atmos. Environ., 44, 3558$3567,2010$.

Galperin, M. V.: Approaches for improving the numerical solution of the advection equation, in: Large Scale Computations in Air Pollution Modelling, edited by: Zlatev, Z., Dongarra, J., Dimov, I., Brandt, J., and Builtjes, P. J., Kluwer Academic Publishers, Dordrecht, The Netherlands, 161-172, 1999.

Galperin, M. V.: The approaches to correct computation of airborne pollution advection, in: Problems of Ecological Monitoring and Ecosystem Modelling, Vol. XVII, Gidrometeoizdat, St. Petersburg, 54-68, 2000 (in Russian).

Galperin, M. V. and Sofiev, M.: The long-range transport of ammonia and ammonium in the Northern Hemisphere, Atmos. Environ., 32, 373-380, 1998.

Gangoiti, G., Millan, M. M., Salvador, R., and Mantilla, E.: Longrange transport and re-circulation of pollutants in the Western Mediterranean during the project regional cycles of air pollution in the West-Central Mediterranean area, Atmos. Environ., 135 6267-6276, 2001.

Gariazzo, C., Silibello, C., Finardi, S., Radice, P., Piersanti, A., Calori, G., Cecinato, A., Perrino, C., Nussio, F., Pelliccioni, A., Gobbi, G. P., and Di Filippo, P.: A gas/aerosol air pollutants study over the urban area of Rome using a comprehensive chemical transport model, Atmos. Environ., 41, 7286-7303, 2007.

Genikhovich, E., Sofiev, M., and Gracheva, I.: Interactions of meteorological and dispersion models at different scales, in: Air Polution Modelling and its Applications XVII, edited by: Borrego, C and Norman, A.-L., Springer (2007), 158-166, ISBN-10:0-38728255-6, 2004.

Gerard, L.: An integrated package for subgrid convection, clouds and precipitation compatible with the meso-gamma scales, Q. J. Roy. Meteor. Soc., 133, 711-730, 2007.

Gery, M. W., Whitten, G. Z., Killus, J. P., and Dodge, M. C.: A photochemical kinetics mechanism for urban and regional scale computer modeling, J. Geophys. Res., 94, 12925-12956, 1989.

Gidhagen, L., Johansson, C., Langner, J., and Foltescu, V. L.: Urban scale modeling of particle number concentration in Stockholm, Atmos. Environ., 39, 1711-1725, 2005.

Gilliland, A. B., Hogrefe, C., Pinder, R. W., Godowitch, J. M., Foley, K. L., and Rao, S. T.: Dynamic evaluation of regional air quality models: assessing changes in $\mathrm{O}_{3}$ stemming from changes in emissions and meteorology, Atmos. Environ., 42, 5110-5123, 2008.

Giorgi, F.: A particle dry deposition parameterisation scheme for use in tracer transport models, J. Geophys. Res., 91, 9794-9806, 1986.

Giorgi, F. and Chameides, W. L.: Rainout lifetimes of highly soluble aerosols and gases as inferred from simulations with a general circulation model, J. Geophys. Res., 91, 14367-14376, 1986.

Gong, S. L.: A parameterization of sea-salt aerosol source function for sub- and super-micron particles, Global Biogeochem. Cy., 17, 1097, doi:1029/2003GB002079, 2003.

Gong, S. L., Barrie, L. A., and Blanchet, J.-P.: Modeling seasalt aerosols in the atmosphere: 1. Model development, J. Geophys. Res., 102, 3805-3818, 1997.

Gong, S. L., Barrie, L. A., and Lazare, M.: Canadian aerosol module (CAM): a size-segregated simulation of atmospheric aerosol processes for climate and air quality models: 2 . Global sea-salt aerosol and its budgets, J. Geophys. Res., 107, 4779, doi:10.1029/2001JD002004, 2002.

Grasso, L. D.: The differentiation between grid spacing and resolution and their application to numerical modeling, B. Am. 
Meteorol. Soc., 81, 579-580, 2000a.

Grasso, L. D.: Reply: "The differentiation between grid spacing and resolution and their application to numerical modeling", B. Am. Meteorol. Soc., 81, p. 2479, 2000b.

Gregory, D. and Rowntree, P. R.: A mass flux convection scheme with representation of cloud ensemble characteristics and stability dependent closure, Mon. Weather Rev., 118, 1483-1506, 1990.

Grell, G. A., Dudhia, J., and Stauffer, D. R.: A description of the fifth-generation Penn State/NCAR Mesoscale Model (MM5), NCAR Tech. Note NCAR/TN-398+STR, 138 pp., available from: NCAR, P. O. Box 3000, Boulder, CO 80307-3000, National Center for Atmospheric Research, Boulder, Colorado, USA, 1994.

Grell, G. A., Dudhia, J., and Stauffer, D. R.: A description of the fifth-generation Penn State/NCAR mesoscale model (MM5), NCAR Tech. Rep. NCAR/TN-398, 122 pp., National Center for Atmospheric Research, Boulder, Colorado, USA, 1995.

Grell, G. A., Peckham, S. E., Schmitz, R., McKeen, S. A., Frost, G., Skamarock, W. C., and Eder, B.: Fully coupled on-line chemistry within the WRF model, Atmos. Environ., 39, 6957-6975, 2005.

Gross, A. and Baklanov, A.: Modelling the influence of dimethyl sulphide on the aerosol production in the marine boundary layer, Int. J. Environ. Pollut., 22, 51-71, 2004.

Gross, A. and Stockwell, W. R.: Comparison of the EMEP, RADM2 and RACM mechanisms, J. Atmos. Chem., 44, 151-170, 2003.

Guelle, W., Balkanski, Y. J., Dibb, J. E., Schulz, M., and Dulac, F.: Wet deposition in a global size-dependent aerosol transport model, 2. Influence of the scavenging scheme on $\mathrm{Pb}$ vertical profiles, and deposition, J. Geophys. Res., 103, 28875-28891, 1998.

Guenther, A. B., Zimmerman, P. R., Harley, P. C., Monson, R., and Fall, R.: Isoprene and monoterpene emission rate variability: model evaluations and sensitivity analyses, J. Geophys. Res., 98, 12609-12617, 1993.

Guenther, A., Zimmerman, P., and Wildermuth, M.: Natural volatile organic compound emission rate estimates for US woodland landscapes, Atmos. Environ., 28, 1197-1210, 1994.

Guenther, A., Hewitt, N., Erickson, D., Fall, R., Geron, C., Graedel, T., Harley, P., Klinger, L., Lerdau, M., McKay, W., Pierce, T., Scholes, B., Steinbrecher, R., Tallamraju, R., Taylor, J., and Zimmerman, P.: A global model of natural volatile organic compounds emissions, J. Geophys. Res., 100, 8873-8892, 1995.

Guenther, A., Geron, C., Pierce, T., Lamb, B., Harley, P., and Fall, R.: Natural emissions of non-methane volatile organic compounds, carbon monoxide, and oxides of nitrogen from North America, Atmos. Environ., 34, 2205-2230, 2000.

Guenther, A., Karl, T., Harley, P., Wiedinmyer, C., Palmer, P. I., and Geron, C.: Estimates of global terrestrial isoprene emissions using MEGAN (Model of Emissions of Gases and Aerosols from Nature), Atmos. Chem. Phys., 6, 3181-3210, doi:10.5194/acp-63181-2006, 2006.

Gurjar, B. R., Butler, T. M., Lawrence, M. G., and Lelieveld, J.: Evaluation of emissions and air quality in megacities, Atmos. Environ., 42, 1693-1606, 2008.

Hahn, J., Steinbrecher, J., and Steinbrecher, R.: Studie F: Emission von Nicht-Methan-Kohlenwasserstoffen aus der Landwirtschaft, in: Enquete-Kommission "Schutz der Erdatmosphaere" des
Deutschen Bundestages (Ed.), Studienprogramm Band 1 "Landwirtschaft", Teilband 1, Economica Verlag, Bonn, 1994.

Hakami, A., Odman, M., Talat, R., and Armistead, G.: High-order, direct sensitivity analysis of multidimensional air quality models, Environ. Sci. Technol., 37, 2442-2452, 2003.

Hakami, A., Seinfeld, J. H., Chai, T. F., Tang, Y. H., Carmichael, G. R., and Sandu, A.: Adjoint sensitivity analysis of ozone nonattainment over the continental United States, Environ. Sci. Technol., 40, 3855-3864, 2006.

Hakami, A., Henze, D. K., Seinfeld, J. H., Singh, K., Sandu, A., Kim, S., Byun, D., and Li, Q.: The Adjoint of CMAQ, Environ. Sci. Technol., 41, 7807-7817, 2007.

Hanea, R. G., Velders, G. J. M., and Heemink, A.: Data assimilation of ground-level ozone in Europe with a Kalman filter and chemistry transport model, J. Geophys. Res., 109, D10302, doi:10.1029/2003JD004283, 2004.

Hanea, R. G., Velders, G. J. M., Segers, A. J., Verlaan, M., and Heemink, A. W.: A hybrid Kalman filter algorithm for largescale atmospheric chemistry data assimilation, Mon. Weather Rev., 135, 140-151, 2007.

Hanna, S. R., Gifford, F. A., and Yamartino, R. J.: Long range radioactive plume transport simulation model/code - phase I, Technical report, USNRC Division of Contracts and Property Management, Contract Administration Branch, P-902, Washington, DC 20555, 121 pp., 1991.

Hanna, S. R., Chang, J. C., and Strimaitis, D. G.: Hazardous gas model evaluation with field observations, Atmos. Environ., 27A, 2265-2285, 1993.

Hanna, S. R., Lu, Z., Frey, H. C., Wheeler, N., Vukovich, J., Arunachalam, S., Fernau, M., and Hansen, D. A.: Uncertainties in predicted ozone concentrations due to input uncertainties for the UAM-V photochemical grid model applied to the July 1995 OTAG domain, Atmos. Environ., 35, 891-903, 2001.

Hara, T., Hozumi, Y., Wang, Z., Ohba, R., and Ueda, H.: An intercomparison study of MM5 and RAMS simulations in a coastal desert area of Saudi Arabia, 6th WRF/15th MM5 Users' Workshop, National Center for Atmospheric Research, 27-30 June, abstract no. 3.28, 2005.

Harper, K., Uccellini, L. W., Kalnay, E., Carey, K., and Morone, L.: 50th anniversary of operational numerical weather prediction, B. Am. Meteorol. Soc., 88, 639-650, 2007.

Hass, H., Builtjes, P. J. H., Simpson, D., and Stern, R.: Comparison of model results obtained with several European regional air quality models, Atmos. Environ., 31, 3259-3279, 1997.

Hass, H., van Loon, M., Kessler, C., Matthijsen, J., Sauter, F., Stern, R., Zlatev, R., Langner, J., Fortescu, V., and Schaap, M.: Aerosol modeling: results and intercomparison from European regional-scale modeling systems, A contribution to the EUROTRAC-2 subproject GLOREAM, EUROTRAC report, 2003.

Heard, D. E., Read, K. A., Methven, J., Al-Haider, S., Bloss, W. J., Johnson, G. P., Pilling, M. J., Seakins, P. W., Smith, S. C., Sommariva, R., Stanton, J. C., Still, T. J., Ingham, T., Brooks, B., De Leeuw, G., Jackson, A. V., McQuaid, J. B., Morgan, R., Smith, M. H., Carpenter, L. J., Carslaw, N., Hamilton, J., Hopkins, J. R., Lee, J. D., Lewis, A. C., Purvis, R. M., Wevill, D. J., Brough, N., Green, T., Mills, G., Penkett, S. A., Plane, J. M. C., Saiz-Lopez, A., Worton, D., Monks, P. S., Fleming, Z., Rickard, A. R., Alfarra, M. R., Allan, J. D., Bower, K., Coe, H., Cubison, 
M., Flynn, M., McFiggans, G., Gallagher, M., Norton, E. G., O’Dowd, C. D., Shillito, J., Topping, D., Vaughan, G., Williams, P., Bitter, M., Ball, S. M., Jones, R. L., Povey, I. M., O’Doherty, S., Simmonds, P. G., Allen, A., Kinnersley, R. P., Beddows, D. C. S., Dall'Osto, M., Harrison, R. M., Donovan, R. J., Heal, M. R., Jennings, S. G., Noone, C., and Spain, G.: The North Atlantic Marine Boundary Layer Experiment(NAMBLEX). Overview of the campaign held at Mace Head, Ireland, in summer 2002, Atmos. Chem. Phys., 6, 2241-2272, doi:10.5194/acp-6-2241-2006, 2006.

Henze, D. K., Hakami, A., and Seinfeld, J. H.: Development of the adjoint of GEOS-Chem, Atmos. Chem. Phys., 7, 2413-2433, doi:10.5194/acp-7-2413-2007, 2007.

Hesstvedt, E., Öystein, H., and Isaksen, I. S. A.: Quasi-steady-state approximations in air pollution modeling: comparison of two numerical schemes for oxidant prediction, Int. J. Chem. Kinet., 10, 971-994, 1978.

Hicks, B. B., Baldocchi, D. D., Meyers, T. P., Hosker Jr., R. P., and Matt, D. R.: A preliminary multiple resistance routine for deriving dry deposition velocities from measured quantities, Water Air Soil Poll., 36, 311-330, 1987.

Hirtl, M., Baumann-Stanzer, K., and Krüger, B. C.: Operational ozone forecasts for Austria, COST728/NetFAM workshop on "Integrated systems of meso-meteorological and chemical transport models", Copenhagen, Denmark, 21-23 May 2007.

Holtslag, A. A. M., de Bruijn, E. I. F., and Pan, H.-L.: A high resolution air mass transformation model for short-range weather forecasting, Mon. Weather Rev., 118, 1561-1575, 1990.

Honoré, C., Rouill, L., Vautard, R., Beekmann, M., Bessagnet, B., Dufour, A., Elichegaray, C., Flaud, J.-M., Malherbe, L., Meleux, F., Menut, L., Martin, D., Peuch, A., Peuch, V.H., and Poisson, N.: Predictability of European air quality: assessment of 3 years of operational forecasts and analyses by the PREV'AIR system, J. Geophys. Res., 113, D04301, doi:10.1029/2007JD008761, 2008.

Houyoux, M. R. and Vukovich, J. M.: Updates to the sparse matrix operator kernel emission (SMOKE) modeling system and integration with Models-3, The emission inventory: regional strategies for the future, 26-28 October, Raleigh, NC, Air and Waste Management Association, 1999.

Hov, Ø., Hjøllo, B. A. and Eliassen, A.: Transport distance of ammonia and ammonium in Northern Europe, 1. Model description, J. Geophys. Res., 99, 18735-18748, 1994.

Huang, M., Carmichael, G. R., Adhikary, B., Spak, S. N., Kulkarni, S., Cheng, Y. F., Wei, C., Tang, Y., Parrish, D. D., Oltmans, S. J., D'Allura, A., Kaduwela, A., Cai, C., Weinheimer, A. J., Wong, M., Pierce, R. B., Al-Saadi, J. A., Streets, D. G., and Zhang, Q.: Impacts of transported background ozone on California air quality during the ARCTAS-CARB period - a multi-scale modeling study, Atmos. Chem. Phys., 10, 6947-6968, doi:10.5194/acp-10-6947-2010, 2010.

Huijnen, V., Eskes, H. J., Poupkou, A., Elbern, H., Boersma, K. F., Foret, G., Sofiev, M., Valdebenito, A., Flemming, J., Stein, O., Gross, A., Robertson, L., D’Isidoro, M., Kioutsioukis, I., Friese, E., Amstrup, B., Bergstrom, R., Strunk, A., Vira, J., Zyryanov, D., Maurizi, A., Melas, D., Peuch, V.-H., and Zerefos, C.: Comparison of OMI $\mathrm{NO}_{2}$ tropospheric columns with an ensemble of global and European regional air quality models, Atmos. Chem. Phys., 10, 3273-3296, doi:10.5194/acp-10-3273-
2010, 2010.

Hussein, T., Kukkonen, J., Korhonen, H., Pohjola, M., Pirjola, L., Wraith, D., Härkönen, J., Teinilä, K., Koponen, I. K., Karppinen, A., Hillamo, R., and Kulmala, M.: Evaluation and modeling of the size fractionated aerosol particle number concentration measurements nearby a major road in Helsinki - Part II: Aerosol measurements within the SAPPHIRE project, Atmos. Chem. Phys., 7, 4081-4094, doi:10.5194/acp-7-4081-2007, 2007.

IPG: International Phenological Gardens, http://www.agrar. hu-berlin.de/struktur/institute/nptw/agrarmet/phaenologie/ipg, last access: 11 February 2011, 2004.

Jablonowski, C.: Adaptive grids in weather and climate modeling, Ph. D. dissertation, University of Michigan, Ann Arbor, MI, 2004.

Jablonowski, C., Herzog, M., Penner, J. E., Oehmke, R. C., Stout, Q. F., van Leer, B., and Powell, K. G.: Block-structured adaptive grids on the sphere: advection experiments, Mon. Weather Rev., 134, 3691-3713, 2006.

Jacobson, M. Z.: Fundamentals of Atmospheric Modeling, Second Edn., Cambridge University Press, New York, 813 pp., 2005.

Jakobs, H. J., Tilmes, S., Heidegger, A., Nester, K., and Smiatek, G.: Short-term ozone forecasting with a network model system during Summer 1999, J. Atmos. Chem., 42, 23-40, 2002.

Jalkanen, J.-P., Brink, A., Kalli, J., Pettersson, H., Kukkonen, J., and Stipa, T.: A modelling system for the exhaust emissions of marine traffic and its application in the Baltic Sea area, Atmos. Chem. Phys., 9, 9209-9223, doi:10.5194/acp-9-9209-2009, 2009.

Jalkanen, J.-P., Johansson, L., Kukkonen, J., Brink, A., Kalli, J., and Stipa, T.: Extension of an assessment model of ship traffic exhaust emissions for particulate matter and carbon monoxide, Atmos. Chem. Phys. Discuss., 11, 22129-22172, doi:10.5194/acpd-11-22129-2011, 2011.

Janjić, Z. I.: The step-mountain coordinate: physical package, Mon. Weather Rev., 118, 1429-1443, 1990.

Janjić, Z. I.: The step-mountain Eta coordinate model: further developments of the convection, viscous sublayer and turbulence closure schemes, Mon. Weather Rev., 122, 927-945, 1994.

Janjić, Z. I.: Advection scheme for passive substance in the NCEP Eta model, in: Research Activities in Atmospheric and Oceanic Modeling, edited by: Ritchie, H., World Meteorol. Organ., Geneva, Switzerland, 1997.

Janjić, Z. I.: A nonhydrostatic model based on a new approach, Meteorol. Atmos. Phys., 82, 271-285, 2003.

Janjić, Z. I., Gerrity, J. P. Jr., and Nickovic, S.: An alternative approach to nonhydrostatic modeling, Mon. Weather Rev., 129, 1164-1178, 2001.

Jimenez, P., Baldasano, J. M., and Dabdub, D.: Comparison of photochemical mechanisms for air quality modeling, Atmos. Environ., 37, 4179-4194, 2003.

Jones, A. R., Thomson, D. J., Hort, M., and Devenish, B.: The UK Met Office's next-generation atmospheric dispersion model, NAME III, in: Air Pollution Modeling and its Application XVII, Proceedings of the 27th NATO/CCMS International Technical Meeting on Air Pollution Modelling and its Application, 24-29 October 2004, New York, USA, edited by: Borrego, C. and Norman, A.-L., Springer, 580-589, 2007.

Josse, B., Simon, P., and Peuch, V.-H.: Rn-222 global simulations with the multiscale CTM MOCAGE, Tellus, 56B, 339-356, 
2004.

Jylhä, K.: Empirical scavenging coefficients of radioactive substances released from Chernobyl, Atmos. Environ., 25A, 263$270,1991$.

Kaas, E.: A simple and efficient locally mass conserving semiLagrangian transport scheme, Tellus, 60A, 305-320, 2008.

Kain, J. S.: The Kain-Fritsch convective parameterization: an update, J. Appl. Meteorol., 43, 170-181, 2004.

Kain, J. S. and Fritsch, J. M.: A one-dimensional entraining/detraining plume model and its application in convective parameterization, J. Atmos. Sci., 47, 2784-2802, 1990.

Kain, J. S. and Fritsch, J. M.: Convective parameterization for mesoscale models: the Kain-Fritsch scheme, The representation of cumulus convection in numerical models, Meteor. Monogr., No. 24, Amer. Meteor. Soc., 165-170, Boston, USA, 1993.

Kain, J. S., Baldwin, M. E., and Weiss, S. J.: Parameterized updraft mass flux as a predictor of convective intensity, Weather Forecast., 18, 106-116, 2003.

Kalabokas, P. D., Volz-Thomas, A., Brioude, J., Thouret, V., Cammas, J.-P., and Repapis, C. C.: Vertical ozone measurements in the troposphere over the Eastern Mediterranean and comparison with Central Europe, Atmos. Chem. Phys., 7, 3783-3790, doi:10.5194/acp-7-3783-2007, 2007.

Kallos, G., Papadopoulos, A., Katsafados, P., and Nickovic, S.: Trans-Atlantic Saharan dust transport: model simulation and results, J. Geophys. Res., 111, D09204, doi:10.1029/2005JD006207, 2006.

Kallos, G., Spyrou, C., Papantoniou, N., Mitsakou, C., Astitha, M., Solomos, S., and Katsafados, P.: Analysis of the particulate matter exceedances in Greece, period 2001-2004, Final Report Prepared for the Ministry of Environment City Planning and Public Work, University of Athens, Athens, Greece, June 2007.

Kallos, G., Spyrou, C., Astitha, M., Mitsakou, C., Solomos, S., Kushta, J., Pytharoulis, I., Katsafados, P., Mavromatidis, E., and Papantoniou, N.: Ten-year operational dust forecasting - recent model development and future plans, WMO/GEO Expert Meeting on a International Sand and Dust Storm Warning System, Barcelona, Spain, 7-9 November 2007, IOP C. Ser. Earth Env., 7, 012012, doi:10.1088/1755-1307/7/1/012012, 2009.

Kalnay, E.: Atmospheric Modeling, Data Assimilation and Predictability, Cambridge University Press, Cambridge, 341 pp., 2002.

Kanakidou, M., Seinfeld, J. H., Pandis, S. N., Barnes, I., Dentener, F. J., Facchini, M. C., Van Dingenen, R., Ervens, B., Nenes, A., Nielsen, C. J., Swietlicki, E., Putaud, J. P., Balkanski, Y., Fuzzi, S., Horth, J., Moortgat, G. K., Winterhalter, R., Myhre, C. E. L., Tsigaridis, K., Vignati, E., Stephanou, E. G., and Wilson, J.: Organic aerosol and global climate modelling: a review, Atmos. Chem. Phys., 5, 1053-1123, doi:10.5194/acp5-1053-2005, 2005.

Kang, D., Mathur, R., Schere, K., Yu, S., and Eder, B.: New Categorical Metrics for Air Quality Model Evaluation, J. Appl. Meteorol. Clim., 46, 549-555, 2007.

Karatzas, K.: State-of-the-art in the dissemination of AQ information to the general public, in: Proceedings of the 21st International Conference on Informatics for Environmental Protection - EnviroInfo2007, Warsaw, Poland, 12-14 September 2007, Vol. 2., edited by: Hryniewicz, O., Studziñski, J., and Romaniuk, M., Shaker Verlag, Aachen, ISBN 978-3-8322-6397-3, 41-
47, 2007.

Karatzas, K.: Artificial intelligence applications in the atmospheric environment: status and future trends, Environ. Eng. Manag. J., 9, 171-180, 2010.

Karatzas, K. and Kukkonen, J. (Eds.): Quality of life information services towards a sustainable society for the atmospheric environment, COST Action ES0602, Workshop Proceedings, Chemical weather information services for quality of life, 8-9 May 2008, Sofia Publications S. A., Thessaloniki, Greece, ISBN 978960-6706-20-2, 118 pp., 2009.

Karatzas, K. and Masouras, A.: Using FLOSS towards building environmental information systems, in: Complexity and Integrated Resources Management, Transactions of the 2nd Biennial Meeting of the International Environmental Modelling and Software Society, Vol. 2, edited by: Pahl-Wostl, C., Schmidt, S., Rizzoli, A. E., and Jakeman, A. J., iEMSs, Manno, Switzerland, ISBN 88-900787-1-5, 525-530, 2004.

Karatzas, K. and Nikolaou, K.: Early warning for environmental information: the AIRTHESS system, in: Proceedings of the 2nd International CEMEPE and SECOTOX Conference, Mykonos, 21-26 June 2009, edited by: Kungolos, A., Aravossis, K., Karagiannidis, A., and Samaras, P., ISBN 978-960-6865-09-1, 20852090, 2009.

Karatzas, K., Endregard, G., and Fløisand, I.: Citizen-oriented environmental information services: usage and impact modelling, in: Proceedings of the "Informatics for Environmental ProtectionNetworking Environmental Information" - 19th International EnviroInfo Conference, edited by: Hrebicek, J. and Racek, J., Brno, Czech Rebublic, 872-878, 2005.

Karvosenoja, N., Tainio, M., Kupiainen, K., Tuomisto, J. T., Kukkonen, J., and Johansson, M.: Evaluation of the emissions and uncertainties of $\mathrm{PM}_{2.5}$ originated from vehicular traffic and domestic wood combustion in Finland, Boreal Environ. Res., 13, 465474, 2008.

Karvosenoja, N., Kangas, L., Kupiainen, K., Kukkonen, J., Karppinen, A., Sofiev, M., Tainio, M., Paunu, V.-V., Ahtoniemi, P., Tuomisto, J. T., and Porvari, P.: Integrated modeling assessments of the population exposure in Finland to primary $\mathrm{PM}_{2.5}$ from traffic and domestic wood combustion on the resolutions of 1 and $10 \mathrm{~km}$, Air Qual. Atmos. Health, 4, 179-188, doi:10.1007/s11869-010-0100-9, 2010.

Kessler, E.: On the distribution and continuity of water substance in atmospheric circulations, Meteorol. Monogr., No. 32, American Meteorological Society, 84 pp., Boston, USA, 1969.

Kioutsioukis, I., Melas, D., Zerefos, C., and Ziomas, I.: Efficient sensitivity computations in 3-D air quality models, Comput Phys. Commun., 167, 23-33, 2005.

Kioutsioukis, I., Poupkou, A., Katragkou, E., Giannaros, T., Markakis, K., Balis, D., Melas, D., and Zerefos, C.: An evaluation of the MM5/CAMx system for Europe, in: Proceedings of the ESA Atmospheric Science Conference, 7-11 September 2009, Barcelona, Spain, abstract no. 1084, 2009.

Kioutsioukis, I., Poupkou, A., Katragkou, E., Giannaros, T., Markakis, K., Balis, D., Melas, D., and Zerefos, C.: Performance evaluation of the MM5/CAMx system for Europe (2003), in: Proceedings of the 10th International Conference on Meteorology, Climatology and Atmospheric Physics, 25-28 May 2010, Patra, Greece, 6 p., 2010.

Kleindienst, T. E., Jaoui, M., Lewandowski, M., Offenberg, J. H., 
Lewis, C. W., Bhave, P. V., and Edney, E. O.: Estimates of the contributions of biogenic and anthropogenic hydrocarbons to secondary organic aerosol at a Southeastern US location, Atmos. Environ., 41, 8288-8300, 2007.

Kokkola, H., Vesterinen, M., Anttila, T., Laaksonen, A., and Lehtinen, K. E. J.: Technical note: Analytical formulae for the critical supersaturations and droplet diameters of CCN containing insoluble material, Atmos. Chem. Phys., 8, 1985-1988, doi:10.5194/acp-8-1985-2008, 2008.

Konovalov, I. B., Beekmann, M., Burrows, J. P., and Richter, A.: Satellite measurement based estimates of decadal changes in European nitrogen oxides emissions, Atmos. Chem. Phys., 8, 26232641, doi:10.5194/acp-8-2623-2008, 2008.

Koo, B., Dunker, A. M., and Yarwood, G.: Implementing the decoupled direct method for sensitivity analysis in a particulate matter air quality model, Environ. Sci. Technol., 41, 2847-2854, 2007.

Kopacz, M., Jacob, D. J., Fisher, J. A., Logan, J. A., Zhang, L., Megretskaia, I. A., Yantosca, R. M., Singh, K., Henze, D. K., Burrows, J. P., Buchwitz, M., Khlystova, I., McMillan, W. W., Gille, J. C., Edwards, D. P., Eldering, A., Thouret, V., and Nedelec, P.: Global estimates of $\mathrm{CO}$ sources with high resolution by adjoint inversion of multiple satellite datasets (MOPITT, AIRS, SCIAMACHY, TES), Atmos. Chem. Phys., 10, 855-876, doi:10.5194/acp-10-855-2010, 2010.

Korsholm, U. S.: Integrated modeling of aerosol indirect effects develoment and application of a chemical weather model, $\mathrm{Ph}$. D. thesis, University of Copenhagen, Niels Bohr Institute and DMI, Research department, 2009.

Korsholm, U. S., Baklanov, A., Gross, A., Mahura, A., Sass, B. H., and Kaas, E.: Online coupled chemical weather forecasting based on HIRLAM - overview and prospective of Enviro-HIRLAM, HIRLAM Newsl., 54, 151-168, available at: http://hirlam.org/index.php?option=com_docman\&task $=$ doc download\&gid=148\&Itemid=70, last access: 11 February 2011, 2008.

Korsholm, U. S., Baklanov, A., Gross, A., and Sørensen, J. H.: On the importance of the meteorological coupling interval in dispersion modeling during ETEX-1, Atmos. Environ., 43, 4805-4810, 2009.

Koskinen, J. T., Poutiainen, J., Schultz, D. M., Joffre, S., Koistinen, J., Saltikoff, E., Gregow, E., Turtiainen, H., Dabberdt, W. F., Damski, J., Eresmaa, N., Göke, S., Hyvärinen, O., Jrvi, L., Karppinen, A., Kotro, J., Kuitunen, T., Kukkonen, J., Kulmala, M., Moisseev, D., Nurmi, P., Pohjola, H., Pylkkö, P., Vesala, T., and Viisanen, Y.: The Helsinki Testbed: A mesoscale measurement, research, and service platform, B. Am. Meteor. Soc., 92, 325-342, 2011.

Kreiss, H. O. and Oliger, J.: Comparison of accurate methods for integration of hyperbolic equation, Tellus, XXIV, 199-215, 1972.

Krüger, B. C., Katragkou, E., Tegoulias, I., Zanis, P., Melas, D., Coppola, E., Rauscher, S., Huszar, P., and Halenka, T.: Regional photochemical model calculations for Europe concerning ozone levels in a changing climate, Idöjaras, 112, 285-300, 2008.

Kuhn, M., Builtjes, P. J. H., Poppe, D., Simpson, D., Stockwell, W. R., Andersson-Sköld, Y., Baart, A., Das, M., Fiedler, F., Hov, Ø., Kirchner, F., Makar, P. A., Milford, J. B., Roemer, M. G. M., Ruhnke, R., Strand, A., Vogel, B., and Vogel, H.: Intercomparison of the gas-phase chemistry in several chemistry and transport models, Atmos. Environ., 32, 693-709, 1998.
Kukkonen, J., Sokhi, R., Slørdal, L. H., Sandro, F., Barbara, F., Millan, M., Salvador, R., Palau, J. L., Rasmussen, A., Schayes, G., and Berge, E.: Analysis and evaluation of European air pollution episodes, in: Meteorology Applied to Urban Air Pollution Problems, Final Report COST Action 715, edited by: Fisher, B., Joffre, S., Kukkonen, J., Piringer, M., Rotach, M., and Schatzmann, M., Demetra Ltd Publishers, Sofia, Bulgaria, ISBN 9549526-30-5, 99-114, 2005a.

Kukkonen, J., Pohjola, M., Sokhi, R. S., Luhana, L., Kitwiroon, N., Rantamäki, M., Berge, E., Odegaard, V., Slørdal, L. H., Denby, B., and Finardi, S.: Analysis and evaluation of selected local-scale $\mathrm{PM}_{10}$ air pollution episodes in four European cities: Helsinki, London, Milan and Oslo, Atmos. Environ., 39, 27592773, 2005b.

Kukkonen, J., Sokhi, R., Luhana, L., Härkönen, J., Salmi, T., Sofiev, M., and Karppinen, A.: Evaluation and application of a statistical model for assessment of long-range transported proportion of $\mathrm{PM}_{2.5}$ in the United Kingdom and in Finland, Atmos. Environ., 42, 3980-3991, doi:10.1016/j.atmosenv.2007.02.036, 2008.

Kukkonen, J., Karatzas, K., Tørseth, K., Fahre Vik, A., Klein, T., San José, R., Balk, T., and Sofiev, M.: An overview of the COST action "Towards a European network on chemical weather forecasting and information systems", in: Quality of life information services towards a sustainable society for the atmospheric environment, COST Action ES0602, Workshop Proceedings, edited by: Karatzas, K. and Kukkonen, J., Sofia Publishers, Thessaloniki, Greece, ISBN 978-960-6706-20-2, 21-37, 2009a.

Kukkonen, J., Karatzas, K., Tørseth, K., Fahre Vik, A., Klein, T., San José, R., Balk, T., and Sofiev, M.: An overview of the cost action "Towards a European network on chemical weather forecasting and information systems", in: Proceedings of Short Papers, 7th International Conference on Air Quality - Science and Application, Istanbul, 24-27 March 2009, edited by: Francis, X. V. and Ask, J., University of Hertfordshire, 37-40, $2009 \mathrm{~b}$.

Kukkonen, J., Klein, T., Karatzas, K., Torseth, K., Fahre Vik, A., San José, R., Balk, T., and Sofiev, M.: COST ES0602: towards a European network on chemical weather forecasting and information systems, Adv. Sci. Res., 3, 27-33, doi:10.5194/asr-3-272009, 2009c.

Kulmala, M., Vehkamäki, H., Petäjä, T., Dal Maso, M., Lauri, A., Kerminen, V.-M., Birmili, W., and McMurry, P. H.: Formation and growth rates of ultrafine atmospheric particles: a review of observations, J. Aerosol Sci., 35, 143-176, 2004.

Kumar, N., Lurmann, F. W., and Carter, W. P. L.: Development of the flexible chemical mechanism version of the urban airshed model, Final Report STI-94470-1508-FR, California Air Resources Board, Sacramento, California, USA, 1995.

Kumar, N., Lurmann, F. W., Wexler, A. S., Pandis, S., and Seinfeld, J. H.: Development and application of a three dimensional aerosol model, A\&WMA Specialty Conference on Computing in Environmental Resource Management, Research Triangle Park, North Carolina, USA, 2-4 December 1996, STI-1609, 1996.

Kunz, R. and Moussiopoulos, N.: Simulation of the wind field in Athens using refined boundary conditions, Atmos. Environ., 29, 3575-3591, 1995.

Kuo, H. L.: On formation and intensification of tropical cyclones through latent heat release by cumulus convection, J. Atmos. Sci., 22, 40-63, 1965. 
Kuo, H. L.: Further studies of the parameterization of the influence of cumulus convection on large-scale flow, J. Atmos. Sci., 31, 1232-1240, 1974.

Kurokawa, J., Yumimoto, K., Uno, I., and Ohara, T.: Adjoint inverse modeling of $\mathrm{NO}_{\mathrm{x}}$ emissions over Eastern China using satellite observations of $\mathrm{NO}_{2}$ vertical column densities, Atmos. Environ., 43, 1827-1944, 2009.

LAEI: London atmospheric emissions inventory 2006 report (2006, 2010 and 2015), June 2009, Greater London Authority, available at: www.london.gov.uk, last access: 11 February 2011, 2009.

Lagzi, I., Kármán, D., Turányi, T., Tomlin, A. S., and Haszpra, L.: Simulation of the dispersion of nuclear contamination using an adaptive Eulerian grid model, J. Environ. Radioactiv., 75, 59-82, 2004.

Langmann, B., Varghese, S., Marmer, E., Vignati, E., Wilson, J., Stier, P., and O'Dowd, C.: Aerosol distribution over Europe: a model evaluation study with detailed aerosol microphysics, Atmos. Chem. Phys., 8, 1591-1607, doi:10.5194/acp-8-1591-2008, 2008.

Langner, J., Robertson, L., Persson, C., and Ullerstig, A.: Validation of the operational emergency response model at the Swedish meteorological and hydrological institute using data from ETEX and the Chernobyl accident, Atmos. Environ., 32, 4325-4333, 1998.

Langner, J., Bergström, R., and Foltescu, V. L.: Impact of climate change on surface ozone and deposition of sulphur and nitrogen in Europe, Atmos. Environ., 39, 1129-1141, 2005.

Laprise, R.: The resolution of global spectral models, B. Am. Meteorol. Soc., 73, 1453-1454, 1992.

Lattuati, M.: Contribution à l'étude du bilan de l'ozone troposphérique à l'interface de l'Europe et de l'Atlantique Nord: modélisation lagrangienne et mesures en altitude, Thèse de sciences, Université Paris 6, France, 1997.

Lawrence, M. G., Hov, Ø., Beekmann, M., Brandt, J., Elbern, H., Eskes, H., Feichter, H., and Takigawa, M.: The chemical weather, Environ. Chem., 2, 6-8, doi:10.1071/EN05014, 2005.

Lefèvre, F., Brasseur, G. P., Folkins, I., Smith, A. K., and Simon, P.: Chemistry of the 1991-1992 stratospheric winter: threedimensional model simulations, J. Geophys. Res., 99, 81838195, 1994.

Leith, C. E.: Numerical simulation of the Earth's atmosphere, in: Methods in Computational Physics, Vol. 4, edited by: Alder, B., Fernbach, S., and Rotenberg, M., Academic Press, New York, $1-28,1965$.

Lewis, J. M.: Roots of ensemble forecasting, Mon. Weather Rev., 133, 1865-1885, 2005.

Levin, Z. and Cotton, W. R (Eds.): Aerosol Pollution Impact on Precipitation - a Scientific Review, Springer, Dordrecht, ISBN 978-1-4020-8689-2, 45-89, 386 pp., 2009.

Lin, J.-T., McElroy, M. B., and Boersma, K. F.: Constraint of anthropogenic $\mathrm{NO}_{\mathrm{x}}$ emissions in China from different sectors: a new methodology using multiple satellite retrievals, Atmos. Chem. Phys., 10, 63-78, doi:10.5194/acp-10-63-2010, 2010.

Lindfors, V., Joffre, S. M., and Damski, J.: Determination of the Wet and Dry Deposition of Sulphur and Nitrogen Compounds Over the Baltic Sea Using Actual Meteorological Data, Finnish Meteorological Institute contributions No. 4, Finnish Meteorological Institute, Helsinki, Finland, 1991.

Livezey, R. E. and Chen, W. Y.: Statistical field significance and its determination by Monte Carlo techniques, Mon. Weather Rev., 111, 46-59, 1983.

Lock, A. P., Brown, A. R., Bush, M. R., Martin, G. M., and Smith, R. N. B.: A new boundary layer mixing scheme, Part I: Scheme description and single-column model tests, Mon. Weather Rev., 128, 3187-3199, 2000.

Loosmore, G. A. and Cederwall, R. T.: Precipitation scavenging of atmospheric aerosols for emergency response applications: testing an updated model with new real-time data, Atmos. Environ., 38, 993-1003, 2004.

Loosmore, G. A. and Hunt, J. R.: Dust resuspension without saltation, J. Geophys. Res., 105, 20663-20671, 2000.

Lorenz, E. N.: Deterministic non-periodic flow, J. Atmos. Sci., 20, 130-141, 1963.

Lorenz, E. N.: A study of the predictability of a 28-variable atmospheric model, Tellus, 17, 321-333, 1965.

Louis, J.-F.: A parametric model of vertical eddy fluxes in the atmosphere, Bound.-Lay. Meteorol., 17, 187-202, 1979.

Louis, J. F., Tiedtke, M., and Geleyn, J. F.: A short history of the operational PBL-parameterization at ECMWF, Workshop on boundary layer parameterization, November 1981, ECMWF, Reading, England, 25-27 November 1981, 59-79, 1982.

Luecken, D. J., Phillips, S., Sarwar, G., and Jang, C.: Effects of using the CB05 vs. SAPRC99 vs. CB4 chemical mechanism on model predictions: ozone and gas-phase photochemical precursor concentrations, Atmos. Environ., 42, 5805-5820, 2008.

Madronich, S.: Photodissociations in the atmosphere, 1, Actinic flux and the effects of ground reflections and clouds, J. Geophys. Res., 92, 9740-9752, 1987.

Majewski, D., Liermann, D., Prohl, P., Ritter, B., Buchhold, M., Hanisch, T., Paul, G., and Wergen, W.: The operational global icosahedral-hexagonal gridpoint model GME: description and high-resolution tests, Mon. Weather Rev., 130, 319-338, 2002.

Mahura, A., Petersen, C., Baklanov, A., Amstrup, B., Korsholm, U. S., and Sattler, K.: Verification of long-term DMIHIRLAM NWP model runs using urbanization and building effect parameterization modules, HIRLAM Newsl., 53, 50-60, 2008.

Mahura, A., Baklanov, A., and Korsholm, U.: Parameterization of the birch pollen diurnal cycle, Aerobiologia, 25, 203-208, doi:10.1007/s10453-009-9125-7, 2009.

Mallet, V. and Sportisse, B.: Uncertainty in a chemistry-transport model due to physical parameterizations and numerical approximations: an ensemble approach applied to ozone modelling, J. Geophys. Res., 111, D01302, doi:10.1029/2005JD006149, 2006.

Malm, W., Schichtel, B. A., Pitchford, M., Ashbaugh, L., and Eldred, R. A.: Spatial and monthly trends in speciated fine particle concentration in the United States, J. Geophys. Res., 109, 1-22, D03306, 2004.

Manders, A. M. M., Schaap, M., and Hoogerbrugge, R.: Testing the capability of the chemistry transport model LOTOS-EUROS to forecast $\mathrm{PM}_{10}$ levels in The Netherlands, Atmos. Environ., 43, 4050-4059, doi:10.1016/j.atmosenv.2009.05.006, 2009.

Mapes, B. E.: Equilibrium versus activation control of large-scale variations of tropical deep convection, in: The Physics and Parameterization of Moist Atmospheric Convection, NATO ASI Series, Vol. 505, edited by: Smith, R. K., Kluwer Academic Publishers, Amsterdam, The Netherlands, 321-358, 1997. 
Marchuk, G. I.: Mathematical models in environmental problems, in: Studies in mathematics and its applications, 16, Elseview Sci. Pub, Co. ISBN 044487965X, 217 pp., 1986.

Mari, C., Jacob, D. J., and Betchold, P.: Transport and scavenging of soluble gases in a deep convective cloud, J. Geophys. Res., 105, 22255-22267, 2000.

Markakis, K., Poupkou, A., Melas, D., Tzoumaka, P., and Petrakakis, M.: A computational approach based on GIS technology for the development of an anthropogenic emission inventory of gaseous pollutants in Greece, Water Air Soil Poll., 207, 157180,2010

Martensson, E. M., Nilsson, E. D., de Leeuw, G., Cohen, L. H., and Hansson, H.-C.: Laboratory simulations and parameterization of the primary marine aerosol production, J. Geophys. Res., 108, 4297, doi:10.1029/2002JD002263, 2003.

Martet, M., Peuch, V.-H., Laurent, B., Marticorena, B., and Bergametti, G.: Evaluation of long-range transport and deposition of desert dust with the CTM Mocage, Tellus, 61B, 449-463, 2009.

Marticorena, B. and Bergametti, G.: Modeling the atmospheric dust cycle: 1. Design of a soil-derived dust emission scheme, J. Geophys. Res., 100, 16415-16430, 1995.

Maryon, R. H., Saltbones, J., Ryall, D. B., Bartnicki, J., Jakobsen, H. A., and Berge, E.: An intercomparison of three long range dispersion models developed for the UK meteorological office, DNMI and EMEP, UK Met Office Turbulence and Diffusion, Note 234, ISBN 82-7144-026-08, 44 pp., 1996.

Matthijsen, J., Sauter, F. J., and de Waal, E. S.: Modelling of particulate matter on a European scale, in: Proceedings of GLOREAM Symposium, 2001, edited by: Keller, J. and AndreaniAksojoglu, S., Wengen, Switzerland, 2002.

McNider, R. T., Lapenta, W. M., Biazar, A. P., Jedlovec, G. J., Suggs, R. J., and Pleim, J.: Retrieval of model grid-scale heat capacity using geostationary satellite products, Part I: First casestudy application, J. Appl. Meteorol., 44, 1346-1360, 2005.

Medina, J., Nenes, A., Sotiropoulou, R.-E. P., Cottrell, L. D., Ziemba, L. D., Beckman, P. J., and Griffin, R. J.: Cloud condensation nuclei closure during the International Consortium for Atmospheric Research on Transport and Transformation 2004 campaign: effects of size-resolved composition, J. Geophys. Res., 112, D10S31, doi:10.1029/2006JD007588, 2007.

Mellor, G. L. and Yamada, T.: A hierarchy of turbulence closure models for planetary boundary layers, J. Atmos. Sci., 31, 17911806, 1974.

Ménégoz, M., Salas y Melia, D., Legrand, M., Teyssèdre, H., Michou, M., Peuch, V.-H., Martet, M., Josse, B., and Dombrowski-Etchevers, I.: Equilibrium of sinks and sources of sulphate over Europe: comparison between a six-year simulation and EMEP observations, Atmos. Chem. Phys., 9, 4505-4519, doi:10.5194/acp-9-4505-2009, 2009.

Meng, F., Zhang, B., Gbor, P., Wen, D., Yang, F., Shi, C., Aronson, J., and Sloan, J.: Models for gas/particle partitioning, transformation and air/water surface exchange of PCBs and PCDD/Fs in CMAQ, Atmos. Environ., 41, 9111-9127, 2007.

Menut, L.: Adjoint modeling for atmospheric pollution process sensitivity at regional scale, J. Geophys. Res.-Atmos., 108, 8562, doi:10.1029/2002JD002549, 2003.

Menut, L., Coll, I., and Cautenet, S.: Impact of meteorological data resolution on the forecasted ozone concentrations during the ESCOMPTE IOP2a and b, Atmos. Res., 74, 139-159, 2005.
Menut, L., Forêt, G., and Bergametti, G.: Sensitivity of mineral dust concentrations to the model size distribution accuracy, J. Geophys. Res., 112, D10210, doi:10.1029/2006JD007766, 2007.

Mesinger, F., Janjić, Z. I., Nickovic, S., and Gavrilov, D.: The stepmountain co-ordinate: model description and performance for cases of Alpine lee cyclogenesis and for a case of an Appalachian redevelopment, Mon. Weather Rev., 116, 1497-1518, 1988.

Metzger, S.: Gas/Aerosol partitioning: a simplified method for global modeling. Ph.D. thesis, University Utrecht, available at: http://igitur-archive.library.uu.nl/dissertations/1930853/ inhoud.htm, 2000.

Metzger, S., Dentener, F., Pandis, S., and Lelieveld, J.: Gas/aerosol partitioning: 1. A computationally efficient model, J. Geophys. Res., 107, 4312, doi:10.1029/2001JD001102, 2002

Michou, M., Laville, P., Serça, D., Fotiadi, A., Bouchou, P., and Peuch, V.-H.: Measured and modeled dry deposition velocities over the ESCOMPTE area, Atmos. Res., 74, 89-116, 2004.

Middleton, P., Stockwell, W. R., and Carter, W. P. L.: Aggregation and analysis of volatile organic compound emissions for regional modeling, Atmos. Environ., 24, 1107-1133, 1990.

Millán, M., Salvador, R., Mantilla, E., and Artnano, B.: Meteorology and photochemical air pollution in Southern Europe: experimental results from EC research projects, Atmos. Environ., 30, 1909-1924, 1996.

Mircea, M. and Stefan, S.: A theoretical study of the microphysical parameterization of the scavenging coeffcient as a function of precipitation type and rate, Atmos. Environ., 32, 2931-2938, 1998.

Molteni, F., Buizza, R., Palmer, T. N., and Petroliagis, T.: The new ECMWF ensemble prediction system: methodology and validation, Q. J. Roy. Meteor. Soc., 122, 73-119, 1996.

Monahan, E. C., Spiel, D. E., and Davidson, K. L.: A model of marine aerosol generation via whitecaps and wave disruption, in: Oceanic Whitecaps and Their Role in Air/Sea Exchange, edited by: Monahan, E. C., Mac Niocaill, G., and Reidel, D., Norwell, Mass., USA, 167-174, 1986.

Monks, P. S., Granier, C., Fuzzi, S., Stohl, A., Williams, M., Akimoto, H., Amman, M., Baklanov, A., Baltensperger, U., Bey, I., Blakem, N., Blake, R. S., Carslaw, K., Cooper, O. R., Dentener, F., Fowler, D., Fragkou, E., Frost, G., Generoso, S., Ginoux, P., Grewet, V., Guenther, A., Hansson, H. C., Hennew, S., Hjorth, J., Hofzumahaus, A., Huntrieser, H., Isaksen, I. S. A., Jenkin, M. E., Kaiser, J., Kanakidou, M., Klimont, Z., Kulmala, M., Laj, P., Lawrence, M. G., Lee, J. D., Liousse, C., Maione, M., McFiggans, G., Metzger, A., Mieville, A., Moussiopoulos, N., Orlando, J. J., O’Dowd, C., Palmer, P. I., Parrish, D. D., Petzold, A., Platt, U., Poeschl, U., Prevot, A. S. H., Reeves, C. E., Reimann, S., Rudich, Y., Sellegri, K., Steinbrecher, R., Simpson, D., ten Brink, H., Theloke, J., van der Werf, G. R., Vautard, R., Vestreng, V., Vlachokostas, C., and von Glasow, R.: Atmospheric composition change - global and regional air quality, Atmos. Environ., 43, 5268-5350, doi:10.1016/j.atmosenv.2009.08.021, 2009.

Morss, R. E., Wilhelmi, O. V., Downton, M. W., and Gruntfest, E.: Flood risk, uncertainty, and scientific information for decision making: lessons from an interdisciplinary project, B. Am. Meteorol. Soc., 86, 1593-1601, 2005.

Morss, R. E., Demuth, J. L., and Lazo, J. K.: Communicating uncertainty in weather forecasts: a survey of the U. S. public, Weather 
Forecast., 23, 974-991, 2008.

Moussiopoulos, N.: An efficient scheme to calculate radiative transfer in mesoscale models, Environ. Softw., 2, 172-191, 1987.

Moussiopoulos, N.: The EUMAC zooming model, a tool for localto-regional air quality studies, Meteorol. Atmos. Phys., 57, 115133, 1995.

Moussiopoulos, N., Sahm, P., Kunz, R., Voegele, T., Schneider, C., and Kessler, C.: High resolution simulations of the wind flow and the ozone formation during the Heilbronn ozone experiment, Atmos. Environ., 31, 3177-3186, 1997.

Moussiopoulos, N., de Leeuw, F., Karatzas, K., and Bassoukos, A.: The air quality model documentation system of the European Environment Agency, Int. J. Environ. Pollut., 14, 10-17, 2000.

Napelenok, S. L., Cohan, D. S., Hu, Y. T., and Russell, A. G.: Decoupled direct 3D sensitivity analysis for particulate matter (DDM-3D/PM), Atmos. Environ., 40, 6112-6121, 2006.

NATAIR: Improving and applying methods for the calculation of natural and biogenic emissions and assessment of impacts to the air quality, European Commission - Sixth Framework Programme, Specific Targeted Research or Innovation Project, Final activity report, Chapter 4.2, 15 August 2007, Proposal No. 513699, available at: http://natair.ier.uni-stuttgart.de/, last access: 10 February 2011, 2007.

Nenes, A., Pandis, S. N., and Pilinis, C.: ISORROPIA: a new thermodynamic equilibrium model for multiphase multicomponent inorganic aerosols, Aquat. Geochem., 4, 123-152, 1998a.

Nenes, A., Pilinis, C., and Pandis, S. N.: Continued development and testing of a new thermodynamic aerosol module for urban and regional air quality models, Atmos. Environ., 33, 15531560, 1998b.

Nho-Kim, E.-Y., Michou, M., and Peuch, V.-H.: Parameterization of size dependent particle dry deposition velocities for global modeling, Atmos. Environ., 38, 1933-1942, 2004.

Nho-Kim, E.-Y., Peuch, V.-H., and Oh, S. N.: Estimation of the global distribution of black carbon aerosols with MOCAGE, the CTM of Météo-France, J. Korean Meteor. Soc., 41, 587-598, 2005.

Nickovic, S., Kallos, G., Papadopoulos, A., and Kakaliagou, O.: A model for prediction of desert dust cycle in the atmosphere, J. Geophys. Res., 106, 18113-18129, 2001.

Nordeng, T. E.: Extended versions of the convection parametrization scheme at ECMWF and their impacts upon the mean climate and transient activity of the model in the tropics, Research Department Technical Memorandum No. 206, ECMWF, Shinfield Park, Reading, RG2 9AX, UK, 1994.

Novak, D. R., Bright, D. R., and Brennan, M. J.: Operational forecaster uncertainty needs and future roles, Weather Forecast., 23, 1069-1084, 2008.

Nowak, J. B., Huey, L. G., Russell, A. G., Neuman, J. A., Orsini, D., Sjostedt, S. J., Sullivan, A. P., Tanner, D. J., Weber, R. J., Nenes, A., Edgerton, E., and Fehsenfeld, F. C.: Analysis of urban gas-phase ammonia measurements from the 2002 Atlanta aerosol nucleation and real-time characterization experiment (ANARChE), J. Geophys. Res., 111, D17308, doi:10.1029/2006JD007113, 2006.

Nutter, P., Stensrud, D., and Xue, M.: Effects of coarsely resolved and temporally interpolated lateral boundary conditions on the dispersion of limited-area ensemble forecasts, Mon. Weather Rev., 132, 2358-2377, 2004.
Näslund, E. and Thaning, L.: On the settling velocity in a nonstationary atmosphere, Aerosol Sci. Tech., 14, 247-256, 1991.

Odman, M. T.: Research on Numerical Transport Algorithms for Air Quality Simulation Models, EPA Report, EPA/660/R97/142, National Exposure Research Laboratory, US EPA, Research Triangle Park, NC, 1998.

O'Neill, S. M. and Lamb, B. K.: Intercomparison of the community multiscale air quality model and CALGRID using process analysis, Environ. Sci. Technol., 39, 5742-5753, 2005.

Orthofer, R., Humer, H., Winiwarter, W., Kutschera, P., Loibl, W., Strasser, T., und Peters-Anders, J.: emikat.at - Emissionsdatenmanagement für die Stadt Wien, ARC system research, Bericht ARC-sys-0049, ARC systems research GmbH, Seibersdorf, Austria, April 2005.

Pace, T. G.: Methodology to Estimate the Transportable Fraction (TF) of Fugitive Dust Emissions for Regional and Urban Scale Air Quality Analyses, US EPA, Research Triangle Park NC, August 2005, http://www.epa.gov/ttnchie1/emch/dustfractions/ transportable_fraction_080305_rev.pdf, 2005

Palmer, T. N., Molteni, F., Mureau, R., Buizza, R., Chapelet, P., and Tribbia, J.: Ensemble prediction, in: Proceedings of the ECMWF seminar on validation of models over Europe: Vol. I, ECMWF, Shinfield Park, Reading, RG2 9AX, UK, 21-66 (285 pp.), 1993.

Park, S. H., Gong, S. L., Gong, W., Makar, P. A., Moran, M. D., Zhang, J., and Stroud, C. A.: Relative impact of windblown dust versus anthropogenic fugitive dust in $\mathrm{PM}_{2.5}$ on air quality in North America, J. Geophys. Res., 115, D16210, doi:10.1029/2009JD013144, 2010

Pedersen, L. B. and Prahm, L. P.: A method for numerical solution of the advection equation, Tellus, XXVI, 594-602, 1974.

Péréz, C., Nickovic, S., Baldasano, J. M., Sicard, M., Rocadenbosch, F., and Cachorro, V. E.: A long Saharan dust event over the Western Mediterranean: Lidar, Sun photometer observations, and regional dust modelling, J. Geophys. Res., 111, D15214, doi:10.1029/2005JD006579, 2006.

Peters, K. and Eiden, R.: Modelling the dry deposition velocity of aerosol particles to a spruce forest, Atmos. Environ., 26A, 25552564, 1992.

Petroff, A., Mailliat, A., Amielh, M., and Anselmet, F.: Aerosol dry deposition on vegetative canopies, Part I: Review of present knowledge, Atmos. Environ., 42, 3625-3653, 2008.

Pielke Sr., R. A.: A recommended specific definition of "resolution", B. Am. Meteor. Soc., 72, 1914, 1991.

Pielke Sr., R. A.: Further comments on "The differentiation between grid spacing and resolution and their application to numerical modeling", B. Am. Meteor. Soc., 82, 699-700, 2001.

Pielke, R. A., Cotton, W. R., Walko, R. L. Tremback, C. J., Lyons, W. A., Grasso, L. D., Nicholls, M. E., Moran, M. D., Wesley, D. A., Lee, T. J., and Copeland, J. H.: A comprehensive meteorological modeling system RAMS. Meteorol. Atmos. Phys., 49, 69-91, 1992.

Pinder, R. W., Gilliam, R. C., Appel, K. W., Napelenok, S. L., Foley, K. M., and Gilliland, A. B.: Efficient probabilistic estimates of surface ozone concentration using an ensemble of model configurations and direct sensitivity calculations, Environ. Sci. Technol., 43, 2388-2393, 2009.

Piriou, J.-M., Redelsperger, J.-L., Geleyn, J.-F., Lafore, J.-P., and Guichard, F.: An approach for convective parameterization with memory: separating microphysics and transport in grid-scale 
equations, J. Atmos. Sci., 64, 4127-4139, 2007.

Pirovano, G., Coll, I., Bedogni, M., Alessandrini, A., Costa, M. P., Gabusi, V., Lasry, F., Menut, L., and Vautard, R.: On the influence of meteorological input on photochemical modelling of a severe episode over a coastal area, Atmos. Environ., 41, 64456464, 2007.

Pittini, T., Morselli, M. G., Finardi, S., D’Allura, A., Guerrini, E., Manazza, S., Muraro, M., Bande, S., Clemente, M., and De Maria, R.: An air quality forecasting modelling system for Novara Province, Northern Italy, in: Proceedings of the 11th International Conference on Harmonisation within Atmospheric Dispersion Modelling for Regulatory Purposes, 2-5 July 2007, Cambridge UK, 2007.

Pleim, J. E.: A combined local and nonlocal closure model for the atmospheric boundary layer. Part I: Model description and testing, J. Appl. Meteorol. Clim., 46, 1383-1395, 2007 a.

Pleim, J. E.: A combined local and nonlocal closure model for the atmospheric boundary layer. Part II: Application and evaluation in a mesoscale meteorological model, J. Appl. Meteorol. Clim., 46, 1396-1409, $2007 \mathrm{~b}$.

Pleim, J. E. and Chang, J. S.: A non-local closure model for vertical mixing in the convective boundary layer, Atmos. Environ., 26A, 965-981, 1992.

Pleim, J. E. and Xiu, A.: Development and testing of a surface flux and planetary boundary layer model for application in mesoscale models, J. Appl. Meteorol., 34, 16-32, 1995

Pleim, J. E., Venkatram, A., and Yamartino, R.: ADOM/TADAP Model Development Program, The Dry Deposition Module, Vol. 4, Ontario Ministry of the Environment, Rexdale, Canada, 1984.

Pleim, J. E., Clarke, J. F., Finkelstein, P. L., Cooter, E. J., Ellestad, T. G., Xiu, A., and Angevine, W. M.: Comparison of measured and modeled surface fluxes of heat, moisture and EPA/600/R-99/030 12-77 chemical dry deposition, in: Air Pollution Modeling and its Application XI, edited by: Gryning, S.-E. and Schiermeier, F. A., Plenum Press, New York, 1996.

Pleim, J. E., Xiu, A., Finkelstein, P. L., and Clarke, J. F.: Evaluation of a coupled landsurface and dry deposition model through comparison to field measurements of surface heat, moisture, and ozone fluxes, in: Proceedings of the 12th Symposium on Boundary Layers and Turbulence, July 28-August 1997, Vancouver, BC, 1997.

Pleim, J. E., Xiu, A., Finkelstein, P. L., and Otte, T. L.: A coupled land-surface and dry deposition model and comparison to field measurements of surface heat, moisture, and ozone fluxes, Water Air Soil Poll. Focus, 1, 243-252, 2001.

Pohjola, M. A., Rantamäki, M., Kukkonen, J., Karppinen, A., and Berge, E.: Meteorological evaluation of a severe air pollution episode in Helsinki on 27-29 December 1995. Boreal Environ. Res., 9, 75-87, 2004.

Pohjola, M. A., Pirjola, L., Karppinen, A., Härkönen, J., Korhonen, H., Hussein, T., Ketzel, M., and Kukkonen, J.: Evaluation and modelling of the size fractionated aerosol particle number concentration measurements nearby a major road in Helsinki - Part I: Modelling results within the LIPIKA project, Atmos. Chem. Phys., 7, 4065-4080, doi:10.5194/acp-7-4065-2007, 2007.

Poupkou, A., Melas, D., Kioutsioukis, I., Lisaridis, I., Symeonidis, P., Balis, D., Karathanasis, S., and Kazadzis, S.: Regional air quality forecasting over Greece within PROMOTE, Atmospheric Science Conference, 8-12 May 2006, ESA ESRIN, Frascati, ESA SP-628, published on CD-ROM, p. 85.1, 2006.

Poupkou, A., Kioutsioukis, I., Lisaridis, I., Markakis, K., Giannaros, T., Katragkou, E., Melas, D., Zerefos, C., and Viras, L.: Evaluation in the greater Athens area of an air quality forecast system, in: Proceedings of the IX EMTE NationalInternational Conference of Meteorology-Climatology and Atmospheric Physics, Thessaloniki, Greece, 28-31 May 2008, 759-766, 2008.

Poupkou, A., Giannaros, T., Markakis, K., Kioutsioukis, I., Curci, G., Melas, D., and Zerefos, C.: A model for European biogenic volatile organic compound emissions: software development and first validation, Environ. Modell. Softw., 25, 18451856, 2010.

Potempski, S., Galmarini, S., Addis, R., Astrup, P., Bader, S., Bellasio, R., Bianconi, R., Bonnardot, F., Buckley, R., D’Amours, R., van Dijk, A., Geertsema, G., Jones, A., Kaufmann, P., Pechinger, U., Persson, C., Polreich, E., Prodanova, M., Robertson, L., Sorensen, J., and Syrakov, D.: Multi-model ensemble analysis of the ETEX-2 experiment, Atmos. Environ., 42, 7250 7265, 2008.

Pour-Biazar, A., McNider, R. T., Roselle, S. J., Suggs, R., Jedlovec, G., Kim, S., Byun, D. W., Lin, J. C., Ho, T. C., Haines, S., Dornblaser, B., and Cameron, R.: Correcting photolysis rates on the basis of satellite observed clouds, J. Geophys. Res., 112, D10302, doi:10.1029/2006JD007422, 2007.

Prahm, L. P. and Christensen, O.: Long range transmission of pollutants simulated by a two-dimensional pseudospectral dispersion model, J. Appl. Meteorol., 16, 896-910, 1977.

Prank, M., Sofiev, M., Denier van der Gon, H. A. C., Kaasik, M., Ruuskanen, T. M., and Kukkonen, J.: A refinement of the emission data for Kola Peninsula based on inverse dispersion modelling, Atmos. Chem. Phys., 10, 10849-10865, doi:10.5194/acp10-10849-2010, 2010.

Prather, M. J.: Numerical advection by conservation of secondorder moment, J. Geophys. Res., 91, 6671-6681, 1986.

Pressman, A. Y., Galperin, M. V., Popov, V. A., Afinogenova, O. G., Subbotin, S. R., Grigoryan, S. A., and Dedkova, I. S.: A routine model of chemical transformation and transport of nitrogen compounds, ozone, and PAN within a regional scale, Atmos. Environ., 25, 1851-1862, 1991.

Pryor, S. C., Barthelmie, R. J., Schoof, J. T., Sorensen, L. L., and Erickson, D. J.: Implications of heterogeneous chemistry of nitric acid for nitrogen deposition to marine ecosystems: observations and modeling, Water Air Soil Poll. Focus, 1, 99-107, 2001.

Putaud, J.-P., Raes, F., Van Dingenen, R., Bruggemann, E., Facchini, M.-C., Decesari, S., Fuzzi, S., Gehrig, R., Huglin, C., Laj, P., Lorbeer, G., Maenhaut, W., Mihalopoulos, N., Muller, K., Querol, X., Rodriguez, S., Schneider, J., Spindler, G., ten Brink, H., Torseth, K., and Wiedensohler, A.: A European aerosol phenomenology-2: chemical characteristics of particulate matter at kerbside, urban, rural and background sites in Europe, Atmos. Environ., 38, 2579-2595, 2004.

Radhakrishnan, K. and Hindmarsh, A.: Description and Use of LSODE, the Livermore Solver for Differential Equations, NASA reference publication 1327, CA, US, 1993.

Ramanathan, V., Crutzen, P. J., Kiehl, J. T., and Rosenfeld, D.: Aerosols, climate and the hydrological cycle, Science, 294, 
2119-2124, doi:10.1126/science.1064034, 2001.

Rantamäki, M., Pohjola, M. A., Tisler, P., Bremer, P., Kukkonen, J., and Karppinen, A.: Evaluation of two versions of the HIRLAM numerical weather prediction model during an air pollution episode in southern Finland, Atmos. Environ., 39, 27752786, 2005.

Rao, S. T., Galmarini, S., and Puckett, K.: Air Quality Model Evaluation International Initiative (AQMEII) - Advancing the state of the science in regional photochemical modeling and its applications, B. Am. Meteor. Soc., 92, 23-30, 2011.

Rasch, P. J. and Kristjánsson, J. E.: A comparison of the CCM3 model climate using diagnosed and predicted condensate parameterizations, J. Climate, 11, 1587-1614, 1998.

Rauhala, J. and Schultz, D. M.: Severe thunderstorm and tornado warnings in Europe, Atmos. Res., 93, 369-380, 2009.

Reff, A., Bhave, P., Simon, H., Pace, T., Pouliot, G, Mobley, D., and Houyoux, M.: Emissions Inventory of $\mathrm{PM}_{2.5}$ Trace Elements across the United States, Environ. Sci. Technol., 43, 5790-5796, 2009.

Reimer, E. and Dlabka, M.: Local forecast of low level ozone by use of cluster methods and fuzzy-models, in: Air Pollution Modeling and its Application XIII, edited by: Gryning, S. and Batchvarova, E., Kluwer Academic/Plenum Publisher, New York, 2000.

Reimer, E. and Scherer, B.: An operational meteorological diagnostic system for regional air pollution analysis and long-term modelling. Air Poll. Modelling and its Applications IX, Plenum Press, 1992.

Reimer, E., Wiegand, G., Flemming, J., Dlabka, M., Enke, W., Berendorf, K., Weiß, W., and Stern, R.: Development of an Ozone Short Range Forecast for the Smog Warning system, Final Report, UBA F\&E project 29543817, Berlin, Germany, 2000 (in German).

Resler, J., Eben, K., Jurus, P., and Liczki, J.: Inverse modelling of emissions and their time profiles, Atmos. Poll. Res., 1, 288-295, doi:10.5094/APR.2010.036, 2010.

Riccio, A., Giunta, G., and Galmarini, S.: Seeking for the rational basis of the Median Model: the optimal combination of multimodel ensemble results, Atmos. Chem. Phys., 7, 6085-6098, doi:10.5194/acp-7-6085-2007, 2007.

Richardson, D. S.: The relative effect of model and analysis differences on ECMWF and UKMO operational forecasts, in: Proceedings of the ECMWF Workshop on Predictability, 20-22 October 1997, ECMWF, Shinfield Park, Reading RG2 9AX, UK, 1998.

Richtmyer, R. D.: A Survey of Difference Methods for Non-Steady Fluid Dynamics, NCAR Technical Note 63-2, National Center for Atmospheric Research, Boulder, CO, 1962, 325 pp., 1962.

Roach, P.: Computational Hydrodynamics, Hermosa Publishers, Albuquerque, New Mexico, 453 pp., ISBN 0-913478-05-9, 1976.

Robertson, L., Langner, J., and Engardt, M.: An Eulerian limitedarea atmospheric transport model, J. Appl. Meteorol., 38, 190210, 1999

Roebber, P. J.: Visualizing multiple measures of forecast quality, Weather Forecast., 24, 601-608, 2009.

Roebber, P. J., Schultz, D. M., Colle, B. A., and Stensrud, D. J.: Toward improved prediction: high-resolution and ensemble modeling systems in operations, Weather Forecast., 19, 936-949, 2004.

Roselle, S. J. and Binkowski, F. S.: Chapt. 11: Cloud dynamics and chemistry, in: Science Algorithms of the EPA Models-3, Technical Report 600/R-99/030, EPA, Research Triangle Park, NC, 1999.

Rosenfeld, D., Lohmann, U., Raga, G. B., O’Dowd, C. D., Kulmala, M., Fuzzi, S., Reissell, A., and Andreae, M. O.: Flood or drought: how do aerosols affect precipitation?, Science, 321, 1309-1313, doi:10.1126/science.1160606, 2008.

Rouil, L., Honoré, C., Vautard, R., Beekmann, M., Bessagnet, B., Malherbe, L., Méleux, F., Dufour, A., Elichegaray, C., Flaud, J.M., Menut, L., Martin, D., Peuch, A., Peuch, V.-H., and Poisson, N.: PREV'AIR: an operational forecasting and mapping system for air quality in Europe, B. Am. Meteorol. Soc., 90, 7383, doi:10.1175/2008BAMS2390.1, 2009.

Russell, A. and Dennis, R.: NARSTO critical review of photochemical models and modeling, Atmos. Environ., 34, 22612282, 2000.

Russell, G. L. and Lerner, J. A.: A new finite-differencing scheme for the tracer transport equation, J. Appl. Meteorol., 20, 1483 1498, 1981.

Ryall, D. B. and Maryon, R. H.: Validation of the UK Met Office's NAME model against the ETEX dataset, Atmos. Environ., 32, 4265-4276, 1998.

Rötzer, T. and Chmielewski, F.-M.: Phenological maps of Europe, Clim. Res., 18, 249-257, 2001.

Saarnio, K., Aurela, M., Timonen, H., Saarikoski, S., Teinilä, K., Mäkelä, T., Sofiev, M., Koskinen, J., Aalto, P. P., Kulmala, M., Kukkonen, J., and Hillamo, R.: Chemical composition of fine particles in fresh smoke plumes from boreal wild-land fires in Europe, Sci. Total Environ., 408, 2527-2542, 2010.

Saarikoski, S., Sillanpää, M., Sofiev, M., Timonen, H., Saarnio, K., Teinilä, K., Karppinen, A., Kukkonen, J., and Hillamo, R.: Chemical composition of aerosols during a major biomass burning episode over Northern Europe in spring 2006: experimental and modelling assessments, Atmos. Environ., 41, 3577-3589, 2007.

Saltelli, A., Chan, K., and Scott, E. (Eds.): Sensitivity Analysis, John Wiley \& Sons, 475 pp., 2000.

Siljamo, P., Sofiev, M., Severova, E., Ranta, H., Kukkonen, J., Polevova, S., Kubin, E., and Minin, A.: Sources, impact and exchange of early-spring birch pollen in the Moscow region and Finland, Aerobiologia, 24, 211-230, doi:10.1007/s10453-0089100-8, 2008.

Sandu, A., Daescu, D., and Carmichael, G. R.: Direct and adjoint sensitivity analysis of chemical kinetic systems with KPP: I Theory and software tools, Atmos. Environ., 37, 5083-5096, 2003.

Sandu, A., Daescu, D. N., Carmichael, G. R., and Chai, T. F.: Adjoint sensitivity analysis of regional air quality models, J. Comput. Phys., 204, 222-252, 2005.

San José, R., Salas, I., Martín, A., Pérez, J. L., Carpintero, A. B., Ramos, M. C., Peña, J. I., and González, R. M.: Development of a global-through-urban scale nested air quality forecast model (RSM-ANA): Application over the Madrid domain, SAMS, 42, 1551-1560, 2002.

San José, R., Pérez, J. L., and Gonzzález, R. M.: The evaluation of the air quality impact of an incinerator by using MM5-CMAQEMIMO modeling system: north of Spain case study, Thrid International Symposium on Air Quality Management at Urban, Regional and Global Scales, Istanbul, Turkey, 26-30 September 
2005, 461-470, 2005.

San José, R., Baklanov, A., Sokhi, R. S., Karatzas, K., and Pérez, J. L.: Air quality modeling-state of the art, in: Proceedings of the iEMSs Third Biennial Meeting: "Summit on Environmental Modelling and Software", edited by: Voinov, A., Jakeman, A., and Rizzoli, A., International Environmental Modelling and Software Society, Burlington, USA, July 2006, CD-ROM, available at: http://www.iemss.org/iemss2006/sessions/all.html, last access: 10 February 2011, ISBN:1-4243-0852-6 978-14243-0852-1, 2006.

San José, R., Pérez, J. L., and González, R. M.: An operational real time air quality modelling system for industrial plants, Environ. Modell. Softw., 22, 297-307, 2007.

San José, R., Pérez, J. L., Morant, J. L., and Gonzalez, R. M.: European operational air quality forecasting systemby using MM5CMAQ-EMIMO tool, Simul. Model. Pract. Th., 16, 1534-1540, 2008a.

San José, R., Perez, J. L., and Gonzalez, R. M.: The evaluation of the air quality impact of an incinerator by using MM5-CMAQEMIMO modeling system: north of Spain case study, Environ. Int., 34, 714-719, 2008b.

Sarwar, G., Luecken, D., Yarwood, G., Whitten, G., and Carter, W. P. L.: Impact of an updated carbon bond mechanism on predictions from the CMAQ modeling system: preliminary assessment, J. Appl. Meteorol. Clim., 47, 3-14, 2008.

Schaap, M., van Loon, M., ten Brink, H. M., Dentener, F. J., and Builtjes, P. J. H.: Secondary inorganic aerosol simulations for Europe with special attention to nitrate, Atmos. Chem. Phys., 4, 857-874, doi:10.5194/acp-4-857-2004, 2004.

Schaap, M., Timmermans, R. M. A., Roemer, M., Boersen, G. A. C., Builtjes, P. J. H., Sauter, F. J., Velders, G. J. M., and Beck, J. P.: The LOTOS-EUROS model: description, validation and latest developments, Int. J. Environ. Pollut., 32, 270-290, 2008.

Schell, B., Ackermann, I. J., Hass, H., Binkowski, F. S., and Ebel, A.: Modeling the formation of secondary organic aerosol within a comprehensive air quality model system, J. Geophys. Res., 106, 28275-28293, 2001.

Schmidt, H., Derognat, C., Vautard, R., and Beekmann, M.: A comparison of simulated and observed ozone mixing ratios for the summer of 1998 in Western Europe, Atmos. Environ., 35, 62776297, 2001.

Schlünzen, K. H. and Fock, B. H. (Eds.): Model applications and model evaluation, Results of COST 728 Workshop at ZMAW, University of Hamburg, Germany - 15 and 16 May 2008, 2010.

Schlüenzen, K. H. and Sokhi, R. S.: Overview of tools and methods for meteorological and air pollution mesoscale model evaluation and user training, Joint report by WMO and COST 728, WMO/TD-No. 1457, Geneva, Switzerland, Electronic version: November 2008, 2008.

Schoenemeyer, T., Richter, K., and Smiatek, G.: Vorstudie uber ein raumlich und zeitlich aufgelostes Kataster anthropogener und biogener Emissionen fuer Bayern mit Entwicklung eines Prototyps und Anwendung fur Immissionsprognosen, Abschluss bericht an das Bayerische Landesamt fur Umweltschutz, Fraunhofer-Institut fuer Atmosphaerische Umweltforschung, Garmisch-Partenkirchen, 1997.

Schulz, M., Chin, M., and Kinne, S.: The aerosol model comparison project, AeroCom, Phase II: Clearing up diversity, IGAC Newsl.,
No 41, May 2009.

Scott, B. C.: Parameterization of sulphate removal by precipitation, J. Appl. Meteorol., 17, 1375-1389, 1978.

Seinfeld, J. H. and Pandis, S. N.: Atmospheric Chemistry and Physics: From Air Pollution to Climate Change, John Wiley and Sons, Inc., NY, 1998.

Seinfeld, J. H. and Pandis, S. N.: Atmospheric Chemistry and Physics: From Air Pollution to Climate Change, 2nd edn., John Wiley \& Sons, New Jersey, 2006.

Seity, Y., Brousseau, P., Malardel, S., Hello, G., Bénard, P., Bouttier, F., Lac, C., and Masson, V.: The AROME-France convective-scale operational model, Mon. Weather Rev., 139, 976-991, 2010.

Shankar, U., Bhave, P. V., Vukovich, J. M., and Roselle, S. J.: Implementation and initial applications of sea salt aerosol emissions and chemistry algorithms in the CMAQ v4.5-AERO4 module, in: 4th annual CMAS Models-3 Users' Conference, Chapel Hill, NC, 26-28 September 2005, available at: http://www cmascenter.org/conference/2005/abstracts/p7.pdf, p. 6, 2005.

Silibello, C., Calori, G., Brusasca, G., Giudici, A., Angelino, E., Fossati, G., Peroni, E., and Buganza, E.: Modelling of $\mathrm{PM}_{10}$ concentrations over Milano urban area using two aerosol modules, Environ. Modell. Softw., 23, 333-343, 2008.

Simmons, A. J., Mureau, R., and Petroliagis, T.: Error growth and predictability estimates for the ECMWF forecasting system, Q. J. Roy. Meteor. Soc., 121, 1739-1771, 1995.

Simmonds, P. G., Derwent, R. G., McHulloch, A., O'Doherty, S., and Gaudry, A.: Long term trends in concentrations of halocarbons and radiatively active gases in Atlantic and European air masses monitored at Mace Head, Ireland from 1987-1994, Atmos. Environ., 30, 4041-4063, 1996.

Simpson, D.: Long period modeling of photochemical oxidants in Europe, Calculations for July 1985, Atmos. Environ., 26, 16091634, 1992.

Simpson, D., Andersson-Sköld, Y., and Jenkin, M. E.: Updating the Chemical Scheme for the EMEP MSC-W Oxidant Model: Current Status, Norwegian Meteorological Institute, EMEP MSC-W Note 2/93, Oslo, Norway, 1993.

Simpson, D., Guenther, A., Hewitt, C. N., and Steinbrecher, R.: Biogenic emissions in Europe 1, Estimates and uncertainties, J. Geophys. Res., 100, 22875-22890, 1995.

Simpson, D., Winiwarter, W., Börjesson, G., Cinderby, S., Ferreiro, A., Guenther, A., Hewitt, C. N., Janson, R., Khalil, M. A. K., Owen, S., Pierce, T. E., Puxbaum, H., Shearer, M., Skiba, U., Steinbrecher, R., Tarrasón, L., and Öquist, M. G.: Inventorying emissions from nature in Europe, J. Geophys. Res., 104, 8113-8152, 1999.

Simpson, D., Fagerli, H., Jonson, J. E., Tsyro, S., Wind, P., and Tuovinen, J.-P.: Transboundary Acidification and Eutrophication and Ground Level Ozone in Europe: Unified EMEP Model Description, EMEP Status Report 1/2003 Part I, EMEP/MSC-W Report, The Norwegian Meteorological Institute, Oslo, Norway, 2003.

Sioutas, C., Pandis, S. N., Allen, D. T., and Solomon, P. A.: Preface: Special Issue of Atmospheric Environment on Findings from EPAs Particulate Matter Supersites Program, Atmos. Environ., 38, 3101-3106, 2004.

Skamarock, W. C.: Positive-definite and montonic limiters for unrestricted-timestep transport schemes, Mon. Weather Rev., 
134, 2241-2250, 2006.

Skamarock, W. C. and Klemp, J. B.: A time-split nonhydrostatic atmospheric model for research and NWP applications, J. Comput. Phys., 227, 3465-3485, 2008.

Skamarock, W. C. and Weisman, M. L.: The impact of positivedefinite moisture transport on NWP precipitation forecasts, Mon. Weather Rev., 137, 488-494, 2009.

Skamarock, W. C., Klemp, J. B., Dudhia, J., Gill, D. O., Barker, D. M., Wang, W., and Powers, J. G.: A Description of the Advanced Research WRF Version 2, available at: http:// www.wrf-model.org/wrfadmin/publications.php, last access: 10 February 2011, 2005.

Slinn, W. G. N.: Predictions for particle deposition to vegetative canopies, Atmos. Environ., 16, 1785-1794, 1982.

Slinn, S. A. and Slinn, W. G. N.: Predictions for particle deposition on natural waters, Atmos. Environ., 14, 1013-1026, 1980.

Slørdal, L. H., McInnes, H., and Krognes, T.: The air quality information system AirQUIS, Environ. Sci. Eng., 1, 40-47, 2008.

Smagorinsky, J.: General circulation experiments with the primitive equations: I. The basic experiment, Mon. Weather Rev., 91, 99164, 1963.

Smith, F. B. and Clark, M. J.: The transport and deposition of radioactive debris from the Chernobyl nuclear power plant accident with special emphasis on consequences to the UK, Meterorological Office Scientific Paper, N42, HMSO, London, 1989.

Smolarkiewicz, P. K.: The multidimensional Crowley advection scheme, Mon. Weather Rev., 113, 1109-1130, 1982.

Sofiev, M.: A model for the evaluation of long-term airborne pollution transport at regional and continental scales, Atmos. Environ., 34, 2481-2493, 2000.

Sofiev, M. and Atlaskin, E.: An example of application of data assimilation technique and adjoint dispersion modelling to an inverse dispersion problem based on the ETEX experiment, in: Air Pollution Modelling and its Applications XVII, edited by: Borrego, C. and Norman, A.-L., Springer (2007), New York, USA, ISBN-10:0-387-28255-6, 438-449, 2004.

Sofiev, M., Gusev, L., and Strijkina, I.: Results of MSC-East current model calibration with measurement of $\mathrm{SO}_{\mathrm{x}}, \mathrm{NO}_{\mathrm{x}}, \mathrm{NH}_{\mathrm{x}}$ 1987-93, EMEP/MSC-E Report 4/94, Co-operative programme for monitoring and evalutation of the long-range transmission of air pollutants in Europe, March 1994, Meteorological Synthesizing Center East, Moscow, Russia, 125 pp., 1994

Sofiev, M., Siljamo, P., Valkama, I., Ilvonen, M., and Kukkonen, J.: A dispersion modelling system SILAM and its evaluation against ETEX data, Atmos. Environ., 40, 674-685, 2006a.

Sofiev, M., Siljamo, P., Ranta, H., and Rantio-Lehtimäki, A.: Towards numerical forecasting of long-range air transport of birch pollen: theoretical considerations and a feasibility study, Int. J. Biometeorol., 50, 392-402, 2006b.

Sofiev, M., Vankevich, R., Lotjonen, M., Prank, M., Petukhov, V., Ermakova, T., Koskinen, J., and Kukkonen, J.: An operational system for the assimilation of the satellite information on wildland fires for the needs of air quality modelling and forecasting, Atmos. Chem. Phys., 9, 6833-6847, doi:10.5194/acp-9-68332009, 2009.

Sofiev, M., Genikhovich, E., Keronen, P., and Vesala, T.: Diagnosing the Surface Layer Parameters for Dispersion Models within the Meteorological-to-Dispersion Modeling Interface, J. Appl. Meteorol. Clim., 49, 221-233, doi:10.1175/2009JAMC2210.1,
2010.

Sofiev, M., Siljamo, P., Ranta, H., Linkosalo, T., Jaeger, S., Jaeger, C., Rassmussen, A., Severova, E., Oksanen, Karppinen, A., and Kukkonen, J.: From Russia to Iceland: an evaluation of a largescale pollen and chemical air pollution episode during April and May, 2006, in: Aerobiological Monographs, edited by: Clot, B., Comtois, P., and Escamilla-Garcia, B., v.1. MeteoSwiss and Univ. of Montreal, Montreal, Canada, 95-114, 2011 a.

Sofiev, M., Soares, J., Prank, M., de Leeuw, G., and Kukkonen, J.: A regional-to-global model of emission and transport of sea salt particles in the atmosphere, J. Geophys. Res., 116, D21302, doi:10.1029/2010JD014713, 2011 b.

Sokhi, R., Baklanov, A., and Schluenzen, H. (Eds.): Mesoscale Meteorological Modelling for air Pollution and Dispersion Applications, COST728 Final Book, Anthem Press, in press, 260 pp., 2010.

Solomon, S., Qin, D., Manning, M., Chen, Z., Marquis, M., Averyt, K. B., Tignor, M., and Miller, H. L. (Eds.): Climate Change: the Physical Basis, IPCC Report 2007, Cambridge University Press, Cambridge, UK, 2007.

Solomos, S., Kallos, G., Kushta, J., Astitha, M., Tremback, C., Nenes, A., and Levin, Z.: An integrated modeling study on the effects of mineral dust and sea salt particles on clouds and precipitation. Atmos. Chem. Phys., 11, 873-892, doi:10.5194/acp11-873-2011, 2011.

Sportisse, B.: A review of parameterizations for modelling dry deposition and scavenging of radionuclides, Atmos. Environ., 41, 2683-2698, 2007.

Spyrou, C., Mitsakou, C., Kallos, G., Louka, P., and Vlastou, G.: An improved limited-area model for describing the dust cycle in the atmosphere, J. Geophys. Res., 115, D17211, doi:10.1029/2009JD013682, 2010.

Stanier, C. O. and Solomon, P. A.: Preface to Special Section on Particulate Matter Supersites Program and Related Studies, J. Geophys. Res., 111, D10S01, doi:10.1029/2006JD007381, 2006.

Staniforth, A.: Regional modeling: A theoretical discussion, Meteorol. Atmos. Phys., 63, 15-29, 1997.

Staniforth, A. and Côté, J.: Semi-Lagrangian integration schemes for atmospheric models - a review, Mon. Weather Rev., 119, 2206-2223, 1991.

Steinbrecher, R.: Isoprene: production by plants and ecosystemlevel estimates, in: Biogenic Volatile Hydrocarbon Compounds in the Atmosphere, edited by: Helas, G., Slanina, J., and Steinbrecher, R., SPF Academic Publishing, Amsterdam, 101-104, 1997.

Stensrud, D. J.: Parameterization Schemes: Keys to Understanding Numerical Weather Prediction Models, Cambridge University Press, New York, 459 pp., 2007.

Stern, R.: Entwicklung und Anwendung des chemischen Transportmodells REM/CALGRID, Abschlussbericht zum Forschungsund Entwicklungsvorhaben 29841252 des Umweltbundesamts, Modellierung und Prüfung von Strategien zur Verminderung der Belastung durch Ozon, Freie Universität Berlin, Institut für Meteorologie, 2003 (in German).

Stern, R., Builtjes, P., Schaap, M., Timmermans, R., Vautard, R., Hodzic, A., Memmesheimer, M., Feldmann, H., Renner, E., Wolke, R., and Kerschbaumer, A.: A model inter-comparison study focussing on episodes with elevated $\mathrm{PM}_{10}$ concentrations, 
Atmos. Environ., 42, 4567-4588, 2008

Stockwell, W. R.: A homogeneous gas phase mechanism for use in a regional acid deposition model, Atmos. Environ., 20, 1615$1632,1986$.

Stockwell, W. R. and Kley, D.: The Euro-RADMechanism, A GasPhase Chemical Mechanism for European Air Quality Studies, Berichte des Forschungszentrums Jülich 2686, Research Centre Juelich, Germany, 114 pp., 1994.

Stockwell, W. R., Middleton, P., Chang, J. S., and Tang, X.: The second generation regional acid deposition model chemical mechanism for regional air quality modeling, J. Geophys. Res., 95, 16343-16367, 1990.

Stockwell, W. R., Kirchner, F., Khun, M., and Seefeld, S.: A new mechanism for regional atmospheric chemistry modelling, J. Geophys. Res., 102, 25847-25879, 1997.

Stohl, A., Williams, E., Wotawa, G., and Kromp-Kolb, H.: A European inventory of soil nitric oxide emissions and the effect of these emissions on the photochemical formation of ozone in Europe, Atmos. Environ., 30, 3741-3755, 1996.

Stohl, A., Forster, C., Frank, A., Seibert, P., and Wotawa, G.: Technical note: The Lagrangian particle dispersion model FLEXPART version 6.2, Atmos. Chem. Phys., 5, 2461-2474, doi:10.5194/acp-5-2461-2005, 2005.

Straka, J.: Cloud and Precipitation Microphysics: Principles and Parameterizations, Cambridge University Press, Cambridge, England, 384 pp., 2009.

Symeonidis, P., Poupkou, A., Gkantou, A., Melas, D., Yay, O. D., Pouspourika, E., and Balis, D.: Development of a computational system for estimating biogenic NMVOCs emissions based on GIS technology, Atmos. Environ., 42, 1777-1789, 2008.

Syrakov, D.: On the TRAP advection scheme - description, tests and applications, in: Regional Modelling of Air Pollution in Europe, edited by: Geernaert, G., Walloe-Hansen, A., and Zlatev, Z., National Environmental Research Institute, Denmark, 141-152, 1996.

Syrakov, D. and Galperin, M.: On a new BOTT-type advection scheme and its further improvement, in: Proceedings of the first GLOREAM Workshop, September 1997, edited by: Hass, H. and Ackermann, I. J., Ford Forschungszentrum Aachen, Aachen, Germany, 103-109, 1997.

Syrakov, D. and Galperin, M.: On some explicit advection schemes for dispersion modelling applications, Int. J. Environ. Pollut., 14, 267-277, 2000.

Sørensen, J. H., Baklanov, A., and Hoe, S.: The Danish emergency response model of the atmosphere, J. Environ. Radioactiv., 96, 122-129, 2007

Tainio, M., Sofiev, M., Hujo, M., Tuomisto, J. T., Loh, M., Jantunen, M. J., Karppinen, A., Kangas, L., Karvosenoja, N., Kupiainen, K., Porvari, P., and Kukkonen, J.: Evaluation of the European population intake fractions for European and Finnish anthropogenic primary fine particulate matter emissions, Atmos. Environ., 43, 3052-3059, doi:10.1016/j.atmosenv.2009.03.030, 2009.

Tainio, M., Tuomisto, J. T., Pekkanen, J., Karvosenoja, N., Kupiainen, K., Porvari, P., Sofiev, M., Karppinen, A., Kangas, L., and Kukkonen, J.: Uncertainty in health risks due to anthropogenic primary fine particulate matter from different source types in Finland, Atmos. Environ., 44, 2125-2132, doi:10.1016/j.atmosenv.2010.02.036, 2010.
Tang, Y., Carmichael, G. R., Thongboonchoo, N., Chai, T., Horowitz, L. W., Pierce, R. B., Al-Saadi, J. A., Pfister, G., Vukovich, J. M., Avery, M. A., Sachse, G. W., Ryerson, T. B., Holloway, J. S., Atlas, E. L., Flocke, F. M., Weber, R. J., Huey, L. G., Dibb, J. E., Streets, D. G., and Brune, W. H.: The influence of lateral and top boundary conditions on regional air quality prediction: a multi-scale study coupling regional and global chemical transport models, J. Geophys. Res., 112, D10S18, doi:10.1029/2006JD007515, 2007.

Tang, X., Wang, Z., Zhu, J., Gbaguidi, A. E., Wu, Q., Li, J., and Zhu, T.: Sensitivity of ozone to precursor emissions in urban Beijing with a Monte Carlo scheme, Atmos. Environ., 44, 3833 3842, 2010.

Tanimoto, H., Sawa, Y., Yonemura, S., Yumimoto, K., Matsueda, H., Uno, I., Hayasaka, T., Mukai, H., Tohjima, Y., Tsuboi, K., and Zhang, L.: Diagnosing recent $\mathrm{CO}$ emissions and ozone evolution in East Asia using coordinated surface observations, adjoint inverse modeling, and MOPITT satellite data, Atmos. Chem. Phys., 8, 3867-3880, doi:10.5194/acp-8-3867-2008, 2008.

Tarrasón, L., Fagerli, H., Jonson, J. E., Klein, H., van Loon, M., Simpson, D., Tsyro, S., Vestreng, V., Wind, P., Posch, M., Solberg, S., Spranger, T., Cuvelier, K., Thunis, P., and White, L.: Transboundary Acidification, Eutrophication and Ground Level Ozonein Europe, EMEP Report 1/2004, ISSN 0806-4520, 2004.

Textor, C., Schulz, M., Guibert, S., Kinne, S., Balkanski, Y., Bauer, S., Berntsen, T., Berglen, T., Boucher, O., Chin, M., Dentener, F., Diehl, T., Feichter, J., Fillmore, D., Ginoux, P., Gong, S., Grini, A., Hendricks, J., Horowitz, L., Huang, P., Isaksen, I. S. A., Iversen, T., Kloster, S., Koch, D., Kirkevåg, A., Kristjansson, J. E., Krol, M., Lauer, A., Lamarque, J. F., Liu, X., Montanaro, V., Myhre, G., Penner, J. E., Pitari, G., Reddy, M. S., Seland, Ø., Stier, P., Takemura, T., and Tie, X.: The effect of harmonized emissions on aerosol properties in global models an AeroCom experiment, Atmos. Chem. Phys., 7, 4489-4501, doi:10.5194/acp-7-4489-2007, 2007.

Teyssèdre, H., Michou, M., Clark, H. L., Josse, B., Karcher, F., Olivié, D., Peuch, V.-H., Saint-Martin, D., Cariolle, D., Attié, J.-L., Nédélec, P., Ricaud, P., Thouret, V., van der A, R. J., VolzThomas, A., and Chéroux, F.: A new tropospheric and stratospheric Chemistry and Transport Model MOCAGE-Climat for multi-year studies: evaluation of the present-day climatology and sensitivity to surface processes, Atmos. Chem. Phys., 7, 58155860, doi:10.5194/acp-7-5815-2007, 2007.

Tiedtke, M.: A comprehensive mass flux convection scheme for cumulus parametrization in large-scale model, Mon. Weather Rev., 117, 1779-1800, 1989.

Tiedtke, M.: Representation of clouds in large-scale models, Mon. Weather Rev., 121, 3040-3061, 1993.

Tilmes, S., Brandt, J., Flatoy, F., Bergström, R., Flemming, J., Langner, J., Christensen, J. H., Frohn, L. M., Hov, O., Jacobson, I., Reimer, E., Stern, R., and Zimmermann, J.: Comparison of five eulerian air pollution forcasting systems for the Summer of 1999 using the german Ozone monitoring data, J. Atmos. Chem., 42, 91-121, 2002.

Timin, B., Wesson, K., Dolwick, P., Possiel, N., and Phillips, S.: An exploration of model concentration differences between CMAQ and CAMx, in: Proceedings of the 6th Annual CMAS Conference, Chapel Hill, NC, available online at: http:// 
www.cmascenter.org/conference/2007/agenda.cfm, last access: 9 February 2011, 1-3 October 2007.

TNO Report: LOTOS-EUROS: Documentation, B\&O-A R 2005/297, Order No: 36584, TNO Built Environment and Geosciences, The Netherlands, 2005.

Tracton, M. S. and Kalnay, E.: Operational ensemble prediction at the National Meteorological Center: practical aspects, Weather Forecast., 8, 379-398, 1993.

Tribbia, J. J. and Anthes, R. A.: Scientific basis of modern weather prediction, Science, 31, 493-499, 1987.

Tsyro, S.: First Estimates of the Effect of Aerosol Dynamics in the Calculation of $\mathrm{PM}_{10}$ and $\mathrm{PM}_{2.5}$, EMEP/MSC-W Note 4/2002, Norwegian Meteorological Institute, Oslo, Norway, Research Note no. 76, http://emep.int/publ/reports/2002/ mscw_note_4_2002.pdf, last access: 11 February 2011, 2002.

Tunved, P., Hansson, H.-C., Kerminen, V.-M., Ström, J., Dal Maso, M., Lihavainen, H., Viisanen, Y., Aalto, P. P., Komppula, M., and Kulmala, M.: High natural aerosol loading over boreal forests, Science, 312, 261-263, 2006.

Tørseth, K. and Fahre Vik, A.: An overview of WG1: "Exhange of AQ Forecasts and input data", in: Quality of life information services towards a sustainable society for the atmospheric environment, COST Action ES0602, Workshop Proceedings, edited by: Karatzas, K. and Kukkonen, J., Sofia Publications S. A., Thessaloniki, Greece, ISBN 978-960-6706-20-2, 39-42, 2009.

Undén, P., Rontu, L., Järvinen, H., Lynch, P., Calvo, J., Cats, G., Cuxart, J., Eerola, K., Fortelius, C., Garcia-Moya, J. A., Jones, C., Lenderlink, G., McDonald, A., McGrath, R., Navascues, B., Nielsen, N. W., Ødegaard, V., Rodriguez, E., Rummukainen, M., Rõõm, R., Sattler, K., Hansen, B. S., Savijärvi, H., Schreur, B. W., Sigg, R., The, H., and Tijm, A.: HIRLAM-5 Scientific Documentation, HIRLAM-5 Project, c/o Per Undén SMHI, SE-601 76 Norrköping, Sweden, available at: http://hirlam.org/index.php?option=com_docman\&amp; task=doc_download\&amp;gid=270\&amp;Itemid=70, last access: 9 February 2011, 2002.

van der Gon Denier, H. A. C., Visschedijk, A. J. H., van der Brugh, H., Dröge, R., and Kuenen, J.: A Base Year (2005) MEGAPOLI European Gridded Emission Inventory, 1st version, Deliverable 1.2, MEGAPOLI Scientific Report 09-02, 17 pp., MEGAPOLI-02-REP-2009-10, ISBN 978-87-992924-2-4, TNO Built Environment and Geosciences, Utrecht, The Netherlands, 2009.

van Leer, B.: Towards the ultimate conservative difference scheme, II. Monotonicity and conservation combined in a second-order scheme, J. Comput. Phys., 14, 361-370, 1974.

van Leer, B.: Towards the ultimate conservative difference scheme, IV. A new approach to numerical convection, J. Comput. Phys., 23, 276-299, 1977.

van Loon, M., Roemer, M. G. M., and Builtjes, P. J. H.: Model Intercomparison in the framework of the review of the Unified EMEP model, TNO-Report R 2004/282, 53 pp., 2004.

van Loon, M., Vautard, R., Schaap, M., Bergström, R., Bessagnet, B., Brandt, J., Builtjes, P. J. H., Christensen, J. H., Cuvelier, C., Graff, A., Jonson, J. E., Krol, M., Langner, J., Roberts, P., Rouil, L., Stern, R., Tarrasón, L., Thunis, P., Vignati, E., White, L., and Wind, P.: Evaluation of long-term ozone simulations from seven regional air quality models and their ensemble, Atmos. Environ., 41, 2083-2097, 2007.
Vautard, R., Beekmann, M., and Menut, L.: Applications of adjoint modelling in atmospheric chemistry: sensitivity and inverse modelling, Environ. Modell. Softw., 15, 703-709, 2000

Vautard, R., Beekmann, M., Roux, J., and Gombert, D.: Validation of a hybrid forecasting system for the ozone concentrations over the Paris area, Atmos. Environ., 35, 2449-2461, 2001.

Vautard, R., Menut, L., Beekmann, M., Chazette, P., Flamant, P. H., Gombert, D., Guédalia, D., Kley, D., Lefebvre, M.-P., Martin, D., Mégie, G., Perros, P., and Toupance, G.: A synthesis of the air pollution over the Paris region (ESQUIF) field campaign, J. Geophys. Res., 108, 8558, doi:10.1029/2003JD003380, 2003.

Vautard, R., Bessagnet, B., Chin, M., and Menut, L.: On the contribution of natural Aeolian sources to particulate matter concentrations in Europe: testing hypotheses with a modeling approach, Atmos. Environ., 39, 3291-3303, 2005.

Vautard, R., Van Loon, M., Schaap, M., Bergstrom, R., Bessagnet, B., Brandt, J., Builtjes, P. H. J., Christensen, J. H., Cuvelier, C., Graff, A., Jonson, J. E., Krol, M., Langner, J., Roberts, P., Rouil, L., Stern, R., Tarrasón, L., Thunis, P., Vignati, E., White, L., and Wind, P.: Is regional air quality model diversity representative of uncertainty for ozone simulation?, Geophys. Res. Lett., 33, L24818, doi:10.1029/2006GL027610, 2006.

Vautard, R., Builtjes, P. H. J., Thunis, P., Cuvelier, C., Bedogni, M., Bessagnet, B., Honoré, C., Moussiopoulos, N., Pirovano, G., Schaap, M., Stern, R., Tarrasón, L., and Wind, P.: Evaluation and intercomparison of ozone and $\mathrm{PM}_{10}$ simulations by several chemistry transport models over four European cities within the CityDelta project, Atmos. Environ., 41, 173-188, 2007.

Vautard, R., Schaap, M., Bergstrom, R., Bessagnet, B., Brandt, J., Builtjes, P. H. J., Christensen, J. H., Cuvelier, C., Foltescu, V., Graff, A., Kerschbaumer, A., Krol, M., Roberts, P., Rouil, L., Stern, R., Tarrasón, L., Thunis, P., Vignati, E., and Wind, P.: Skill and uncertainty of a regional air quality model ensemble, Atmos. Environ., 43, 4822-4832, doi:10.1016/j.atmosenv.2008.09.083, 2008.

Venkatram, A.: The expected deviation of observed concentrations from predicted ensemble means, Atmos. Environ., 13, 15471549, 1979.

Venkatram, A.: Inherent uncertainty in air quality modeling, Atmos. Environ., 22, 1221-1227, 1988.

Venkatram, A. and Pleim, J.: The electrical analogy does not apply to modelling dry deposition of particles, Atmos. Environ., 33, 3075-3076, 1999.

Veriankaitë, L., Siljamo, P., Sofiev, M., Šaulienë, I., and Kukkonen, J.: Modelling analysis of source regions of long-range transported birch pollen that influences allergenic seasons in Lithuania, Aerobiologia, 26, 47-62, 2010.

Vestreng, V., Rigler, E., Adams, M., Kindbom, K., Pacyna, J. M., Denier van der Gon, H., Reis, S., and Travnikov, O.: Inventory Review 2006, Emission Data Reported to LRTAP and NEC Directive, Stage 1, 2 and 3 Review and Evaluation of Inventories of HM and POPs, EMEP/MSC-W Technical Report 1/2006, ISSN 1504-6179, Oslo, Norwegian Meteorological Institute, http://www.emep.int/publ/reports/2006/emep_technical_ 1_2006.pdf, 2006.

Vignati, E., Wilson, J., and Stier, P.: M7: an efficient size-resolved aerosol microphysics module for large-scale aerosol transport models, J. Geophys. Res., 109, D22202, doi:10.1029/2003JD004485, 2004. 
Vijayaraghavan, K., Seigneur, C., Karamchandani, P., and Chen, S.Y.: Development and application of a multi-pollutant model for atmospheric mercury deposition, J. Appl. Meteorol. Clim., 46, 1341-1353, 2007.

Visschedijk, A. J. H., Zandveld, P. Y. J., and Denier van der Gon, H.: High Resolution Gridded European Emission Database for the EU Integrate Project GEMS, TNO-report 2007-A-R0233/B, 2007.

Visschedijk, A. J. H., Denier van der Gon, H., van der Brugh, H., and Droge. R.: A high resolution European emission data base for the year 2005, TNO Report TNO-034-UT-2010-01895_RPTML, 2010.

Vukovich, J. and Pierce, T.: The Implementation of BEIS3 within the SMOKE Modeling Framework, GA, in: Proceedings of the 11th International Emissions Inventory Conference, Atlanta, Georgia, 15-18 April available online: www.epa.gov/ttn/chief/ conference/ei11/modeling/vukovich.pdf, 2002.

Walcek, C. J.: Minor flux adjustment near mixing ratio extremes for simplified yet highly accurate monotonic calculation of tracer advection, J. Geophys. Res., 105, 9335-9348, 2000.

Walcek, C. J., Brost, R. A., Chang, J. S., and Wesely, M. L.: $\mathrm{SO}_{2}$, sulfate and $\mathrm{HNO}_{3}$, deposition velocities computed using regional landuse and meteorological data, Atmos. Environ., 20, 949-964, 1986.

Wang, H., Skamarock, W. C., and Feingold, G.: Evaluation of scalar advection schemes in the advanced research WRF model using large-Eddy simulations of aerosol-cloud interaction, Mon. Weather Rev., 137, 2547-2558, doi:10.1175/2009MWR2820.1, 2009.

Wang, Q., Han, Z., Wang, T., and Zhang, R.: Impacts of biogenic emissions of VOC and $\mathrm{NO}_{\mathrm{x}}$ on tropospheric ozone during summertime in Eastern China, Sci. Total Environ., 395, 41-49, 2008.

Wang, X., Zhang, L., and Moran, M. D.: Uncertainty assessment of current size-resolved parameterizations for below-cloud particle scavenging by rain, Atmos. Chem. Phys., 10, 5685-5705, doi:10.5194/acp-10-5685-2010, 2010.

Webster, H. N. and Thomson, D. J.: Validation of a Lagrangian model plume rise scheme using the Kincaid dataset, Atmos. Environ., 36, 5031-5042, 2002.

Webster, H. N., Carroll, E. B., Jones, A. R., Manning, A. J., and Thomson, D. J.: The Buncefield oil depot incident: a discussion of the meteorology, Weather, 62, 325-330, 2007.

Weil, J. C., Sykes, R. I., and Venkatram, A.: Evaluating air quality models: review and outlook, J. Appl. Meteorol., 31, 1121-1145, 1992.

Wesely, M. L.: Parametrization of surface resistances to gaseous deposition in regional-scale numerical models, Atmos. Environ., 23, 1293-1304, 1989.

Wesely, M. L. and Hicks, B. B.: Some factors that affect the deposition rates of sulfur dioxide and similar gases on vegetation, JAPCA J. Air Waste Manage., 27, 1110-1117, 1977.

Wesely, M. L. and Hicks, B. B.: A review of the current status of knowledge on dry deposition, Atmos. Environ., 34, 2261-2282, 2000.

Whitby, E. R. and McMurry, P. H.: Modal aerosol dynamics modelling, Aerosol Sci. Technol., 27, 673-688, 1997.

Wicker, L. J. and Skamarock, W. C.: Time splitting methods for elastic models using forward time schemes, Mon. Weather Rev., 130, 2088-2097, 2002.
Williams, E. J., Parrish, D. D., and Fehsenfeld, F. C.: Determination of $\mathrm{NO}_{\mathrm{x}}$ emissions from soils, J. Geophys. Res., 92, 2173-2179, 1987.

Williams, E. J., Guenther, A., and Fehsenfeld, F. C.: An inventory of nitric oxide emissions from soils in the United States, J. Geophys. Res., 97, 7511-7519, 1992.

Williamson, D. L. and Rasch, P. J.: Two-dimensional semilagrangian transport with shape-preserving interpolation, Mon Weather Rev., 117, 102-129, 1989.

Wiman, B. L. B. and Agren, G. I.: Aerosol depletion and deposition in forests - a model analysis, Atmos. Environ., 19, 335-347, 1985.

Woods, A.: Medium-Range Weather Prediction: The European Approach, The Story of the European Centre for Medium-Range Weather Forecasts, Springer, 270 pp., New York, USA, 2006.

Yamartino, R. J.: Nonnegative, conserved scalar transport using grid-cell-centered, spectrally constrained Blackman cubics for applications on a variable-thickness mesh, Mon. Weather Rev., 121, 753-763, 1993.

Yamartino, R. J., Scire, J. S., Carmichael, G. R., and Chang, Y. S.: The CALGRID mesoscale photochemical grid model - Part I. Model formulation, Atmos. Environ., 26A, 1493-1512, 1992.

Yarwood, G., Rao, S., Yocke, M., and Whitten, G. Z.: Updates to the Carbon Bond Chemical Mechanism: CB05. Final Report to the US EPA, RT-0400675, 2005.

Yu, S., Dennis, R., Roselle, S., Nenes, A., Walker, J. T., Eder, B., Schere, K., Swall, J., and Robarge, W.: An assessment of the ability of 3-D air quality models with current thermodynamic equilibrium models to predict aerosol $\mathrm{NO}_{3}^{-}$, J. Geophys. Res., 110, D07S13, doi:10.1029/2004JD004718, 2005.

Yu, X. and Lee, T.-Y.: Role of convective parameterization in simulations of a convection band at grey-zone resolutions, Tellus, 62A, 617-632, 2010.

Yu, Y., Sokhi, R. S., Kitwiroon, N., Middleton, D. R., and Fisher, B.: Performance characteristics of MM5-SMOKECMAQ for a summer photochemical episode in Southeast England, UK, Atmos. Environ., 42, 4870-4883, 2008.

Zakey, A. S., Solmon, F., and Giorgi, F.: Implementation and testing of a desert dust module in a regional climate model, Atmos. Chem. Phys., 6, 4687-4704, doi:10.5194/acp-6-4687-2006, 2006.

Zakey, A. S., Giorgi, F., and Bi, X.: Modeling of Sea Salt in a Regional Climate Model: Fluxes and Radiative Forcing, J. Geophys. Res.-Atmos., 113, D14221, doi:10.1029/2007JD009209, 2008.

Zaveri, R. Z. and Peters, L. K.: A new lumped structure photochemical mechanism for long-scale applications, J. Geophys. Res. 104, 30387-30415, 1999.

Zender, C. S., Bian, H., and Newman, D.: Mineral dust entrainment and deposition (DEAD) model: description and 1990s dust climatology, J. Geophys. Res.-Atmos., 108, D14, doi:10.1029/2002JD002775, 2003.

Zhang, K. M., Knipping, E. M., Wexler, A. S., Bhave, P. V., and Tonnesen, G. S.: Size distribution of sea-salt emissions as a function of relative humidity, Atmos. Environ., 39, 3373-3379, 2005 b.

Zhang, L., Brook, J. R. S., Padro, J., and Barrie, L.: A sizesegregated particle dry deposition scheme for an atmospheric aerosol module, Atmos. Environ., 35, 549-560, 2001. 
Zhang, L., Moran, M. D., Makar, P. A., Brook, J. R., and Gong, S.: Modelling gaseous dry deposition in AURAMS: a unified regional air-quality modelling system, Atmos. Environ., 36, 537$560,2002$.

Zhang, L., Brook, J. R., and Vet, R.: A revised parameterization for gaseous dry deposition in air-quality models, Atmos. Chem. Phys., 3, 2067-2082, doi:10.5194/acp-3-2067-2003, 2003.

Zhang, Y.: Online-coupled meteorology and chemistry models: history, current status, and outlook, Atmos. Chem. Phys., 8, 28952932, doi:10.5194/acp-8-2895-2008, 2008.

Zhang, Y., Seigneur, C., Seinfeld, J. H., Jacobson, M. Z., and Binkowski, F. S.: Simulation of aerosol dynamics: a comparative review of algorithms used in air quality models, Aerosol Sci. Technol., 31, 487-514, 1999.

Zhang, Y., Hu, X., Wang, K., Huang, J., Fast, J. D., Gustafson, W. I., Chu, D. A., and Jang, C. J.: Evaluation of WRF-Chem-MADRID with satellite and surface measurements: chemical and optical properties of aerosols, American Geophysical Union, Fall Meeting 2005, abstract A34A-02, Fall Meeting, 5-9 December, San Francisco, GA, 2005a.
Zhang, Y., Vijayaraghavan, K., and Seigneur, C.: Evaluation of Three Probing Techniques in a Three-Dimensional Air Quality Model, J. Geophys. Res., 110, D02305, doi:10.1029/2004JD005248, 2005b.

Zhou, Y., Brunner, D., Boersma, K. F., Dirksen, R., and Wang, P.: An improved tropospheric $\mathrm{NO}_{2}$ retrieval for OMI observations in the vicinity of mountainous terrain, Atmos. Meas. Tech., 2, 401-416, doi:10.5194/amt-2-401-2009, 2009.

Zhu, Y, Hinds, W. C, Kim, S. K, Shen, S, and Sioutas, C.: Study of ultrafine particles near a major highway with heavy-duty diesel traffic, Atmos. Environ., 36, 4323-4335, doi:10.1016/S13522310(02)00354-0, 2002.

Zilitinkevich, S., Esau, I., and Baklanov, A.: Further comments on the equilibrium height of neutral and stable planetary boundary layers, Q. J. Roy. Meteorol. Soc., 133, 265-271, 2007.

Zlatev, Z.: Coupling advection with chemistry in large air pollution models, Proceedings of the NMR Workshop on Eulerian Air Pollution Models, Helsinki, Finland, 1-2 November, 1995.

Zlatev, Z. and Berkowicz, R.: Numerical treatment of large-scale air pollution model, J. Comput. Appl. Math., 16, 93-109, 1988. 